Discussion Paper No. 06-047

How Do Employment Effects of Job Creation Schemes Differ with Respect to the Foregoing Unemployment Duration?

Reinhard Hujer and Stephan L. Thomsen

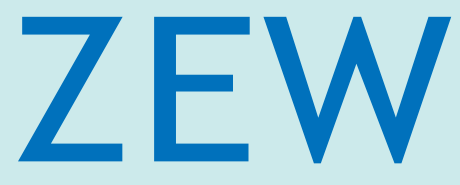

Zentrum für Europäische Wirtschaftsforschung $\mathrm{GmbH}$

Centre for European

Economic Research 
Discussion Paper No. 06-047

\title{
How Do Employment Effects of Job Creation Schemes Differ with Respect to the Foregoing Unemployment Duration?
}

\author{
Reinhard Hujer and Stephan L. Thomsen
}

Download this ZEW Discussion Paper from our ftp server:

ftp://ftp.zew.de/pub/zew-docs/dp/dp06047.pdf

Die Discussion Papers dienen einer möglichst schnellen Verbreitung von neueren Forschungsarbeiten des ZEW. Die Beiträge liegen in alleiniger Verantwortung der Autoren und stellen nicht notwendigerweise die Meinung des ZEW dar.

Discussion Papers are intended to make results of ZEW research promptly available to other economists in order to encourage discussion and suggestions for revisions. The authors are solely responsible for the contents which do not necessarily represent the opinion of the ZEW. 


\section{Non-Technical Summary}

Job Creation Schemes (Arbeitsbeschaffungsmaßnahmen, JCS) are designed as a kind of subsidised jobs for unemployed persons facing barriers to employment. In particular during the 1990s and early 2000s, the Federal Employment Agency (FEA) invested immense efforts in these programmes. Nevertheless, doubts increased about the effectiveness of programmes in terms of improved employment chances. In a number of previous studies, effects of job creation schemes for the participants have been analysed, and the overall picture from these studies is heterogeneous, but still disappointing.

However, differences due to the timing of the schemes have not yet been analysed. These differences are of particular interest to policymakers and caseworkers at the employment agencies as they provide useful information for developing strategies to avoid and reduce long-term unemployment. Based on unique data derived form several administrative sources of the FEA, we analyse the effects of job creation schemes for participants starting the programmes between July 2000 and May 2001 with respect to the timing of treatment, gender and region as well. To do so, we apply a stratified propensity score matching approach conditional on the discretised duration of unemployment until the programme starts (in quarters). Programme effects are estimated up to 30 months after the job creation scheme has started.

The results present a mixed picture. Whereas in West Germany persons who started in the fifth or ninth quarter of receiving unemployment benefit, the groups in the other quarters show at best the same results as comparable non-participants. In East Germany, most of the groups participating in JCS experience negative employment effects even 30 months after programmes started compared to non-participants. Furthermore, the results for both parts of Germany indicate that JCS are more harmful for persons when starting them early in the unemployment spell, and tend to help long-term unemployed people to find jobs in West Germany. Since such programmes are designed for long-term unemployed persons, a tighter allocation of this group is recommended. In summary, JCS perform poorly in improving the employment chances of the participants. In the 30 months following the start of the programme participants fail to be re-integrated more efficiently into regular (unsubsidised) employment than non-participants. 


\title{
How Do Employment Effects of Job Creation Schemes Differ with Respect to the Foregoing Unemployment Duration?*
}

\author{
Reinhard Hujer ${ }^{\dagger}$ and Stephan L. Thomsen ${ }^{\ddagger}$ \\ $\dagger$ J.W.Goethe-University Frankfurt/Main, IZA and ZEW \\ $\ddagger$ ZEW, Mannheim
}

This version: June 14, 2006

\begin{abstract}
Based on new administrative data for Germany covering entrances into job creation schemes between July 2000 and May 2001, we evaluate the effects of this active labour market policy programme on the employability of the participating individuals. The programme effects are estimated considering the timing of treatment in the individual unemployment spell. Applying propensity score matching in a dynamic setting where the time until treatment in the unemployment spell is stratified into quarters, regional (East and West Germany) as well as gender differences are considered in the estimation. As matching is concerned with selection on observables only, we test the robustness of the estimates against possible unobserved influences. The results in terms of employment present a mixed picture. For West Germany, most of the estimates are insignificant at the end of the observation period, but positive exceptions are found for persons starting in the fifth or ninth quarter of the unemployment spell. For East Germany, none of the groups experiences an improvement of the labour market situation. Instead, the majority of the estimates establish negative employment effects until the end of the observation period (30 months after start of programmes). Hence, job creation schemes decrease the employment chances of the participating individuals.
\end{abstract}

Keywords: Evaluation, Active Labour Market Policy, Job Creation Schemes, Administrative Data, Propensity Score Matching, Hidden Bias

JEL Classification: J68, C14, H43

\footnotetext{
${ }^{*}$ We thank Bernd Fitzenberger, Michael Lechner, Marie Waller, Henrik Winterhager, Christopher Zeiss and the participants of seminars at IZA, Bonn, ZEW, Mannheim, and University of Frankfurt, and of the Pentecost meeting of German Statistical Society, Hamburg, for valuable comments, and Steffen Kaimer and Melanie Stamm for help in the preparation of the data. Financial support of the Institute for Employment Research (IAB) within the project 'Effects of Job Creation and Structural Adjustment Schemes' is gratefully acknowledged. All remaining errors are our own.

${ }^{\dagger}$ Reinhard Hujer is Professor of Statistics and Econometrics at the J.W.Goethe-University of Frankfurt/Main and Research Fellow of IZA and ZEW. E-mail: hujer@wiwi.uni-frankfurt.de.

${ }^{\ddagger}$ Stephan L. Thomsen (corresponding author) is Research Assistant at the Centre for European Economic Research (ZEW), L7,1 D-68161 Mannheim. E-mail: thomsen@zew.de.
} 


\section{Introduction}

Germany's active labour market policies (ALMP) are in crucial need of renewal, as evidenced by the country's perpetually weak labour market, high unemployment (9.3 percent in the West and 20.1 percent in the East in 2003), along with increasingly tight government budgets and high spending on labour market policy (73.7 billion euros in 2003). Specific programmes, such as Job Creation Schemes (Arbeitsbeschaffungsmaßnahmen, JCS) were important during the 1990s and early 2000s. Designed as a kind of subsidised work for unemployed people facing barriers to employment, JCS aim at stabilising and qualifying people for later reintegration into regular jobs. Although the Federal Employment Agency (FEA) invested immense efforts in these programmes, which have been the second most important in terms of fiscal spending and persons promoted (about 1.6 million persons between 1997 and 2003, with expenditures of over 23 billion euros), there have been increasing doubts as to the effectiveness of the programmes in terms of improved employment chances. The main criticism concerns the lack of components that improve human capital, and the presence of negative incentives for job search due to too-high wages as well as the long duration of the programmes (about twelve months).

The effects of JCS in Germany have been analysed in a number of previous studies. ${ }^{1}$ These studies concentrate on East Germany and are based on survey data sets covering only a few observations, which do not allow effect heterogeneity to be considered explicitly. In addition, due to inexact information on programmes and programme duration, it is difficult to derive concrete policy recommendations. In a series of more recent studies based on administrative data of the FEA covering entries in JCS in February 2000, employment effects of programmes for West and East Germany have been analysed taking account of several sources of effect heterogeneity. The overall picture from the studies is disappointing and JCS seem to perform poorly in improving the employability or the participants' chances of leaving unemployment. However, although the recent studies present a heterogeneous picture of the effects for different subgroups and economic sectors covered by the programme, possible differences due to the timing of the programme in the unemployment spell have not yet been analysed.

Differences due to the timing of JCS are of particular interest to policymakers and caseworkers at employment agencies: this information can be used to develop intervention strategies to avoid long-term unemployment. One might speculate that programmes designed to stabilise and qualify people facing barriers to employment are more useful if applied later in the unemployment spell (when long-term unemployment has already occurred), but are useless for those in short-term unemployment and would only artificially prolong the individual unemployment duration. Measuring the programme effects with respect to the timing of treatment is not an easy task. Abbring and van den Berg (2003) suggest the use of a multivariate mixed proportional hazards model to estimate the programme effect. Unfortunately, reliable data on programmes

\footnotetext{
${ }^{1}$ See e.g., Huebler (1997), Kraus, Puhani, and Steiner (2000), Eichler and Lechner (2002), Caliendo, Hujer, and Thomsen (2005b) and Caliendo, Hujer, and Thomsen (2006).
} 
and labour market outcomes for Germany are only available from 2000 onwards with a time lag of up twoyears. Thus, analysing JCS that are designed for the long-term unemployed and have a regular duration of twelve months would lead to a very small sample of inflows. A more feasible approach has been proposed by Sianesi (2004) and will be used here. She suggests discretising the unemployment duration and estimating the treatment effects by a series of matching estimators. For different durations of unemployment prior to the start of the programmes, treatment effects are estimated separately. Thus, the estimated effects provide a picture of the effects with respect to the timing of treatment. However, it has to be mentioned that this approach does not look at any interdependencies between the individual groups under analysis, and effects with respect to the timing of treatment can only be compared descriptively.

The analysis is based on unique data derived from the final version of the Programme Participants Master Data Set (Maßnahme-Teilnehmer-Grunddatei, MTG) and the Employment Statistics Register (Beschäftigtenstatistik, BSt) covering participants in JCS between July 2000 and May 2001. Since the main goal of the programmes is to prepare participants for their integration into regular employment and to increase their employment chances, we analyse the programme effects in terms of integration into regular employment up to 30 months after having started the programme. Other goals of the programme are not explicitly considered in the study. The data contain rich information characterising the individuals' labour market situations. Therefore, this study is the first one covering participants in programmes in a one-year period and taking account of possible seasonal differences. In addition, the large number of observations in the sample allows explicit consideration of possible effect heterogeneity due to regional differences (East and West Germany) and gender. Programme effects are estimated using propensity score matching. Due to the rich data at hand and the large number of observations, assuming conditional independence seems justified in our context. We consider the timing of treatment by estimating the effects of JCS separately for different unemployment durations preceding treatment, i.e., for up to twelve quarters of unemployment. Since matching deals with selection on observables only, additional unobserved influences are excluded by assumption. Thus, a major issue when using matching methods is to justify the conditional independence assumption with respect to the process of programme and job assignments and the data at hand. In addition, Rosenbaum (2002) suggests that the robustness of the estimates be tested for a possible hidden bias. Although the test does not provide evidence of further unobserved variables, it indicates the sensitivity of the estimates and may be helpful for interpretation.

The results present a mixed picture. In West Germany, on the one hand, participants seem to suffer more from the programme when joining early in the unemployment spell. However, for most of the groups, the estimated treatment effects are insignificant at the end of the observation period, i.e., the employment rates of the participants do not differ from those of the matched non-participants. On the other hand, there are two exceptions. Persons starting the programmes in the fifth or ninth quarter of the unemployment spell show an increase in the employment rate 30 months after the programme started. The findings for East Germany 
are more discouraging. Here, the majority of the groups show negative employment effects by the end of the observation period. On the other hand, six of the male and four of the female groups under analysis have insignificant employment effects at the end.

The paper is structured as follows. In the next section, we briefly describe the set-up and implementation of JCS in Germany. Section three presents the data used. We introduce the evaluation approach applied in this study in the fourth section and its empirical implementation in section five. The estimated employment effects of JCS are discussed in section six. The final section concludes this paper.

\section{Job Creation Schemes in Germany}

JCS were introduced in 1969. For many years, they were the second-most important measure of German ALMP after vocational training programmes. The legal basis is defined in $\S \S 260$ to 271 and 416 of the Social Code III (Sozialgesetzbuch III, SGB III) enacted in 1998, replacing the Work Support Act of 1969. As our analysis is based on programmes that started in 2000 and 2001, we concentrate our description of the institutional set-up on this time span. JCS provide jobs for unemployed persons facing barriers to employment and aim at providing participants with a stable foundation and relevant qualifications for later (re-)integration into regular (non-subsidised) work. The jobs are in different economic sectors, e.g., agriculture, construction and social services. Financial support is provided by wage subsidies (in general, 30 to 75 percent of the worker's salary) or loans to the implementing institutions, i.e., service providers or employers. ${ }^{2}$ The ordinary duration of support for JCS is twelve months, but exceptions can be made to lengthen the duration (up to 24 months if programmes are of enforced priority or even 36 months if followed by permanent employment). To avoid distortions of the market and to prevent substitution effects and windfall gains, activities should be granted only if they are additional in nature, of value to society and carried out by persons in need of assistance. Additional in nature means that without the subsidies, the activities would not be accomplished now or in the near future. They are of value to society if their outcome is for the collective good. Due to these requirements, the majority of JCS are low-qualification jobs.

Assignment of eligible individuals to programmes results from decisions by caseworkers. Eligibility is in general approved if persons are unemployed long-term (more than one year) or unemployed for at least six out of the last twelve months prior to programme start. Moreover, they have to fulfil the eligibility criteria to receive unemployment benefits or assistance, for vocational training programmes, or for vocational integration of the disabled. ${ }^{3}$ Independently of these requirements, the local employment agencies (LEAs) are

\footnotetext{
${ }^{2}$ From 2002 to 2004, the implementing institutions could alternatively be granted lump sum support. Since 2004, grants for JCS consist of lump sum payments only.

${ }^{3}$ Unemployment benefits (Arbeitslosengeld, UB) are paid for individuals who have contributed for at least twelve months to unemployment insurance (UI) during the last three years before unemployment (seasonally employed workers have a reduced contribution period of six months). UB amount to 60 (67) percent of the last average net earnings from insured employment (with at least one dependent child) and are paid from UI funds. The entitlement lasts for at least six months. The maximum duration is up to 32 months and depends on the contribution period and the individual's age. Payment to the UI is compulsory for all employees and amounts to 6.5 percent of employee's gross salary. However, persons with only a minor employment, civil servants, judges,
} 
allowed to place younger unemployed people (aged 25 or younger) without completed professional training, severely disabled people, tutors and up to five percent of the participants who do not meet the general eligibility criteria. When the unemployed person has registered at the LEA, the case is assigned to a caseworker who meets the unemployed person at regular intervals to evaluate the individual's efforts to find a job and to develop a plan together with the unemployed person for the integration into employment. Through this procedure, the responsible caseworker possesses a large degree of discretion for placing unemployed persons in programmes. The caseworker decides to offer a specific occupation in a JCS solely if his assessment of the individual's need for assistance implies that the unemployed person cannot be integrated into regular employment and does not meet the conditions for other ALMP programmes. The caseworker chooses the job in consultation with the unemployed person and according to the individual's qualifications and interests. Priority is to be given to projects that explicitly aim at improving the foundations for permanent employment, provide jobs to unemployed people facing special barriers to employment, or improve the social and environmental infrastructure. ${ }^{4}$ Once assigned by a caseworker, the programme is compulsory for the individual and rejection is sanctioned by revocation of benefits for up to twelve weeks. In repeated cases, the unemployed individual may lose his/her UI entitlement permanently. ${ }^{5}$ Since space in programmes is limited, it may occur that unemployed persons are not assigned to a programme, e.g., when no space is available.

JCS in Germany have been analysed in a number of studies, see e.g., Huebler (1997), Kraus, Puhani, and Steiner (2000), Eichler and Lechner (2002) and Caliendo, Hujer, and Thomsen (2004; 2005b; 2005a; 2006). Whereas the earlier studies are based on survey data and concentrate on East Germany, the more recent studies (since 2003) are based on administrative data of the FEA similar to that used here. Most studies could not establish positive effects in terms of the different outcome variables analysed (e.g., employment, unemployment) with some exceptions (see Eichler and Lechner (2002) and a number of subgroups in Caliendo, Hujer, and Thomsen $(2004 ; 2005 b ; 2005 a ; 2006))$. Due to this, the overall picture is rather disappointing. There are a number of possible effects that may be reasonably expected based on the empirical findings in the literature on JCS in Germany. A widely assumed effect of offering jobs to unemployed individuals is that this avoids human capital depreciation and promotes development of human capital. However, as Spitznagel and Magvas (1997) point out about 40 percent of the participants are allocated to jobs that are below the individual qualification level. Therefore, it may also be likely that JCS have a negative effect on human capital. Further positive effects of the programme relate to the provision of 'soft' human capital (Gerfin,

clergymen, professional soldiers, and some other groups of persons are exempted from contributions. Minor employment are jobs with a salary of less than Euro 325 (Euro 400 since 04/2003) as well as short-term and occasional jobs. The set-up of unemployment assistance (Arbeitslosenhilfe, UA) was changed within the Fourth Law 'Modern Services on the Labour Market' on January 1st, 2005. Until that time, UA was paid for persons who had exhausted their UB entitlement. UA amounted to 53 (57) percent of the last average net earnings from insured employment (with at least one dependent child). UA could have been paid potentially unlimited (until retirement age) if the individual satisfied the benefit conditions. UA was administered by the FEA, but funding was by tax. Since 2005, UA is pooled with social assistance (Sozialhilfe) in the so-called unemployment benefits II (Arbeitslosengeld II).

${ }^{4}$ Unemployed persons with special barriers to employment are defined as long-term unemployed, severely disabled persons, older unemployed persons with placement restrictions, as well as applicants for vocational rehabilitation programmes.

${ }^{5}$ See $\$ 144$ SGB III for the definitions regarding the exposure of income support. 
Lechner, and Steiger, 2005) and in accustoming these individuals to regular employment (Spitznagel, 1992). The programme also intends to increase individual motivation and self-respect and signal the participants' willingness to work and productivity. Nevertheless, these programmes may signal low productivity given that they are targeted to those persons with the a-priori worst labour market perspectives (negative selection of people with low productivity). In addition, participants may be seen as passive in terms of job search activities as they simply accept a place in the programme that is offered to them. Further negative effects for the individual include a reduced initiative to look for a job due to unrealistic expectations concerning permanent contracts following the programmes, excessively high wages during participation, or just the time and effort involved in participation (locking-in effects).

\section{Data}

Our empirical analysis is based on data that stem from different administrative sources of the FEA that have been merged for this purpose. The interested reader is referred to the Data Appendix (Appendix B) for more details on the extraction and merging of the data as well as their contents. We use information on participants who joined JCS in the six months July, September, November 2000, January, March and May 2001. In addition, we have drawn six random samples from the job-seekers' population in the months preceding the programmes to construct the comparison group. Whereas the original participants' samples contain all individuals joining the programmes in the respective months, the proportions for the non-participants' samples were 20:1, i.e., for each participant starting a JCS in July 2000, we have drawn 20 job-seekers from June 2000 as potential comparisons, and so on.

The data cover a large number of characteristics to describe the individual's labour market situation. There is information on the socio-demographic background of the unemployed individuals (e.g., age, gender), some detailed information on qualifications (e.g., schooling, occupational group) as well as the labour market history (e.g., duration of last job, number of job offers). All characteristics are surveyed by the caseworkers and are used as the basis for their decisions. Besides these 'objective' characteristics, the data contain some 'subjective' measures, including, for example, the appraisal of the individual's qualifications by the caseworker and an assessment of the placement restrictions. To consider demand-side aspects, the data are supplemented by a set of indicators describing the regional labour markets according to Blien et al. (2004). With these extensive and informative data at hand, we are able to consider all relevant variables in the model for the participation decision and the labour market outcome. The outcome variable is regular employment. We define only regular employment as a success, all other kinds of subsidised work or participation in ALMP programmes are defined as a failure.

Since the labour markets in East and West Germany are different even 11 years ${ }^{6}$ after German unification,

\footnotetext{
${ }^{6}$ With respect to the time the programmes started.
} 
we analyse the effects separately for both parts. To achieve better homogeneity of the groups under analysis, we exclude persons below 25 and over 55 years. To consider possible heterogeneity due to gender, we estimate the effects for men and women. We observe 5,360 $(2,834)$ participating men (women) in West and $10,956(13,491)$ in East Germany. In addition, we are able to use information on 1,104,664 job seekers to construct the comparison groups.

\section{Evaluation Approach}

\subsection{Model of Potential Outcomes}

A widely used method to evaluate the efficiency of ALMP programmes is the matching estimator embedded in the so-called model of potential outcomes. ${ }^{7}$ The model considers two possible states, i.e., individual $i$ is considered to either participate in a programme (1) or not (0), with $Y_{i}^{1}$ and $Y_{i}^{0}$ denoting the potential outcomes corresponding to the states. The individual causal effect of treatment is then defined as the difference between the two potential outcomes, i.e., $\Delta_{i}=Y_{i}^{1}-Y_{i}^{0}$. However, since the individual cannot be in both states of the world at the same time, the observable outcome for $i$ is given by $Y_{i}=Y_{i}^{1} \cdot D_{i}+\left(1-D_{i}\right) \cdot Y_{i}^{0}$, where $D_{i} \in\{0,1\}$ is a binary treatment indicator. Thus, one of the outcomes is unobservable for each individual and there is no opportunity to calculate the individual treatment effect directly from the data.

To render the model useful for causal analysis, we must take the stable unit treatment value assumption (SUTVA, see e.g., Rubin (1986)). SUTVA rules out any cross-effects, or general equilibrium effects, that may occur among potential programme participants because of their participation decision (Lechner, 2001). In other words, the potential outcomes of an individual depend on the his or her participation decision only and are not affected by the treatment status of other individuals. Furthermore, whether an individual participates or not does not depend on the participation decision of other individuals. This additional feature excludes peer-effects (Sianesi, 2004). If we are willing to estimate the effect of the programme for a person drawn randomly from the participants sample, those effects are negligible and SUTVA could be assumed to be fulfilled. ${ }^{8}$

Due to the unobservability of one of the outcomes, direct estimation of the treatment effects is impossible and evaluation has to focus on population averages of gains from treatment. The most common parameter of interest in the empirical literature is the average effect of treatment on the treated (ATT), defined as

$$
\Delta^{A T T}=E(\Delta \mid D=1)=E\left(Y^{1}-Y^{0} \mid D=1\right)=E\left(Y^{1} \mid D=1\right)-E\left(Y^{0} \mid D=1\right),
$$

which is the difference between the expected outcomes with and without treatment for participants. As it

\footnotetext{
${ }^{7}$ This approach has been variously attributed to e.g., Neyman (1923), Roy (1951) and Rubin (1974).

${ }^{8}$ It should be noted, that since JCS have been used to a large extent especially in East Germany, assuming no spill-over effects on non-participants may be questionable. Thus, microeconometric evaluation can only analyse partial equilibrium effects of the programmes. Further macroeconometric analyses of programme effects are necessary for a full evaluation, see e.g., Hujer and Zeiss (2005).
} 
focusses directly on the actually treated participants, it determines the realised gross gain for this group (Heckman, LaLonde, and Smith, 1999). Thus, its importance for policymakers becomes obvious, as programmes are in general targeted at certain groups, and by comparing the programme effect with its costs, the ATT appears to be a reasonable approach to measure the performance of the programme, i.e., determining the programme's success (see Heckman, Ichimura, and Todd (1997)).

The second term on the right-hand side of eq. 1 is not identified. Simply using the observable nonparticipants' outcomes to approximate the unobservable participants' outcomes without treatment may lead to biased estimates, since participants and non-participants may be selective groups even in the absence of the programme, and thus $E\left(Y^{0} \mid D=1\right) \neq E\left(Y^{1} \mid D=1\right)$. The basic idea of the matching approach is to find, in a large group of non-participants, those individuals who are similar to the participants in all relevant pre-treatment characteristics $X$ ('statistical twins'). For this reason, the method appeals to the intuitive principle that it is possible to 'adjust away' differences between participants and non-participants using the available regressors (Heckman, LaLonde, and Smith, 1999). Having originated in the statistical literature, matching thus generates a comparison group that resembles an experimental control group in one key respect: conditional on $X$, the distribution of the counterfactual outcome for the participants is the same as the observed distribution of the outcome of the comparison group (Heckman, LaLonde, and Smith, 1999). That is, the construction of the correct sample counterpart for the missing information on the treated outcomes had they not participated consists in pairing each programme participant with one or more members of a comparison group (Blundell and Costa Dias, 2002). Therefore, the matching approach makes it possible to compare the treated and the non-treated outcomes directly, without having to impose structure on the problem. This is the analogy to random assignment in a (social) experiment. Since the method of matching is a non-parametric approach, an advantage is its generality. However, since matching methods concern themselves solely with selection on observables, they require very rich data in order to make the estimates of the treatment effects credible (Smith, 2000).

For the ATT to be identified, the so-called conditional independence assumption (CIA) has to be invoked (Lechner, 2001), $Y^{0} \amalg D \mid X$. This states that, conditional on the set of relevant (observable) covariates $X$, the non-participation outcome $Y^{0}$ is independent of the participation decision. In addition, the availability of non-participating analogues for the participants must be guaranteed (common support), i.e., $\operatorname{Pr}(D=1 \mid X)<1$ (Smith and Todd, 2005a). Since the CIA is in general untestable, one has to be careful in choosing the set of relevant variables. It is well known that matching on $X$ can become hazardous when $X$ is of high dimension ('curse of dimensionality', Pagan and Ullah (1999)). To deal with this dimensionality problem, Rosenbaum and Rubin (1983) suggest the use of balancing scores. One possible balancing score is the probability of participation in a programme, i.e., the propensity score $p(X)=E(D=1 \mid X)$, which summarises the information of the relevant covariates $X$ into a single index function. All biases due to observable covariates can thus be removed by conditioning solely on the propensity score. 


\subsection{Some Methodological Issues}

Up to now, we have discussed the evaluation approach for the static binary treatment case, i.e., treatment is exposed once and at one specific point in time only. In that case, those individuals who take the treatment are defined as the participants; all others are the non-participants. Simplifying the evaluation problem in this way may be reasonable for social experiments. In contrast, for most regular ALMP programmes this approach may be rather inappropriate (Fredriksson and Johansson (2004)). This becomes obvious when looking at the ALMP system in Germany. This comprehensive system is characterised by a wide array of different ongoing programmes which take place continuously over time and are open to job-seekers who meet the differing eligibility criteria. For this reason, job-seekers can participate in a programme at different points of time in an unemployment spell. Furthermore, for some programmes, like for example JCS, unemployment is a general pre-condition for participation. Therefore, the starting point of the programme within the individual unemployment spell may be an important determinant for the type of programme an individual is assigned to, as well as for the selection of participating individuals. Moreover, the calendar time of the treatment also affects the assignment process, because of changing budget constraints within the calendar year or changes in the focus of the policy interventions from one year to another (Speckesser (2004)). An important issue in this context is raised by Sianesi (2004), who analyses the efficiency of Swedish ALMP programmes, which are similar to the German programmes. She argues that within the Swedish system an unemployed person will join a programme at some point, provided the individual remains unemployed long enough. Consequently, the reason why an unemployed individual is not observed as participating in a programme is that the person has found a job before this point, or the time horizon of the analysis is too short. Obviously, although participation in a programme is not mandatory in Germany like in Sweden, it tends to be true that unemployed persons become more likely to participate in any programme the longer they are unemployed. Thus, the use of Sianesi's argumentation is reasonable for the evaluation of German ALMP as well.

This has serious implications for the choice of the comparison group and the econometric evaluation estimator. If we chose as the comparison group those individuals who have been observed to never participate in the data, this may invalidate the CIA, as we have to condition on future outcomes. The conditioning on future outcomes may furthermore bias the estimates. To give an example, if we select all individuals as the comparison group who have never been in a programme within the observation window and for whom we observe a transition into employment, we may underestimate the true treatment effects because one can assume that this group contains a large number of individuals who were intended to be treated because they have a per se higher probability of finding a regular job.

For this reason, participation and non-participation have to be defined dynamically, i.e., with respect to the point in time the comparison should be made. According to Sianesi (2004), we define persons who have neither entered a programme nor left unemployment up to a specific point in time as non-participants of interest or 'waiters' (in the sense that they are waiting to be allocated to a programme). Thus, non- 
participation can be interpreted as the default state for each individual, and everybody is a non-participant until entering a programme or leaving to take a job. In this context, it should be noted that individuals who are defined as non-participants at the moment we start our comparison may enter a programme at a later point in time. This approach has been used by Steiger (2004) evaluating the effects of different ALMP programmes in Switzerland as well. Speckesser (2004) and Fitzenberger and Speckesser (2005) use it to analyse the effects of a programme called provision of specific professional skills and techniques in Germany. A similar definition of non-participation is used by Brodaty, Crépon, and Fougere (2001), who focus on the effects of youth employment programmes in France. Fredriksson and Johansson (2004) try to formalise this idea and to connect the matching approach with the concept of duration models.

In contrast, several studies use only individuals who have never participated during the observation window as the comparison group, for example Gerfin and Lechner (2002) and Lechner, Miquel, and Wunsch (2005a; 2005b). To overcome the problem of comparing participating individuals to non-participants who were never intended to be treated, they apply an approach suggested by Lechner (1999). In this approach, each comparison individual is assigned a random starting date by drawing from the discrete distribution of the estimated starting dates of the participants. All non-participants who are already employed at the time of the hypothetical starting date are excluded from the analysis. However, this approach adds additional noise to the data and does not take the timing of events seriously (Fitzenberger and Speckesser (2005)). Moreover, since the observation window is in general limited, the observable distribution of the starting dates will be truncated. Thus, imposing the starting date distribution on the non-participants by random drawing may be biased (Fredriksson and Johansson (2004)).

Before starting to formalise the evaluation approach in the dynamic setting, some words should be spent on the effect we estimate. In general, two aspects of a programme determine the programme effect: the content of the programme and the reduced search intensity for regular work while in it. On the one hand, the content of the JCS should be the occupational stabilisation (and qualification) of an unemployed individual through placement in a subsidised job. On the other hand, programme participation is associated with full-time employment and consequently a reduced search intensity for regular jobs during the programme (locking-in effect). Whereas the first aspect is assumed to affect the employability of the individual positively, the second aspect reduces the employment chances (for at least the time of the programme). Both effects could not be disentangled and are assumed to be the main components of the programme effect. However, the relevance of both aspects for the programme effect is a priori unclear due to a third component that drives the effect: the time of the treatment start. The composition of the impacts of both aspects has to be assumed to differ with time. To give an example: the content of the programme (occupational stabilisation) may be more useful for the individual the longer he/she is unemployed. In contrast, being locked into the programme after a longer duration of unemployment may have less severe effects on employment chances, as job offers must be expected to arrive less often than earlier in the unemployment spell. Hence, the utility of the programme is 
expected to be increased with longer unemployment duration due to the higher relevance of the programme content and the decreased importance of the locking-in effect. From this discussion, it becomes obvious that the programme effect depends on the time the treatment is offered. In other words, the effect of a JCS offered at time $u$ of the unemployment spell is different from the effect of a JCS offered at $u+1$ since the composition of the determinants of the programme effects differs. This is particularly important for the policy maker, since offering the programme at different times in the unemployment spell implies differing impacts of the programme on the employment chances. For this reason, assessing 'the' programme effect independently of the timing is difficult since the timing is a major aspect of the programme's effectiveness.

\subsection{Evaluation Approach in the Dynamic Setting}

To formalise the evaluation approach in the dynamic setting, i.e., when the timing of treatment in the unemployment spell is considered explicitly, we will introduce some additional notation. Let $U=\left\{0, \ldots, U_{\max }\right\}$ define the discrete elapsed unemployment duration of the individual since registration at the LEA. Furthermore, let $u$ denote the point of time in the unemployment spell the programme of interest starts and $D_{u}$ the treatment indicator with the discrete time index. $D_{u}=1$ if the individual starts a programme at time $u$ of the unemployment spell, $D_{u}=0$ if the individual remains unemployed at $u$. Programme effects are estimated for time $t$, i.e., the time since the programme started. The hypothetical outcomes for time $t$ given a treatment at time $u$ are then defined as $Y_{t, u}^{1}$ for individuals who received the treatment at $u$ and $Y_{t, u}^{0}$ for individuals who did not receive the treatment at least up to time $u$.

The parameter of interest for each $u$ is then the average effect in $t$ for individuals starting a programme in quarter $u$ of their unemployment spell, of joining the programme at $u$ compared to not joining at $u$. This is (in analogy to eq. 1):

$$
\begin{aligned}
\Delta_{t, u}^{A T T}= & E\left(Y_{t, u}^{1}-Y_{t, u}^{0} \mid D_{u}=1, D_{1}=\cdots D_{u-1}=0\right) \\
= & E\left(Y_{t, u}^{1} \mid D_{u}=1, D_{1}=\cdots D_{u-1}=0\right) \\
& -E\left(Y_{t, u}^{0} \mid D_{u}=1, D_{1}=\cdots D_{u-1}=0\right) .
\end{aligned}
$$

Whereas the first term is identified in the data by the observed outcome of the participants, for the second term to be identified, we have to invoke an adjusted version of the conditional independence assumption. That is, the hypothetical outcome at time $t$ after not participating up to time $u$ is independent of programme participation at time $u$, conditional on a set of observed characteristics $X_{u}$ or the propensity score $p\left(X_{u}\right)$ measured at time $u$. By use of the propensity score, this dynamic version of the conditional independence assumption (Fitzenberger and Speckesser, 2005) is defined as:

$$
Y_{t, u}^{0} \amalg D_{u} \mid p\left(X_{u}\right), D_{1}=\cdots=D_{u-1}=0 .
$$

It states that treated and non-treated individuals are comparable in their non-treatment outcomes at time $t$ conditional on $p\left(X_{u}\right)$, conditional on being unemployed up to time $u-1$, and conditional on not receiving 
treatment before $u$. If this assumption holds, the parameter of interest could be estimated by propensity score matching in the following way:

$$
\begin{aligned}
\Delta_{t, u_{(M A T)}}^{A T T}= & E\left(Y_{t, u}^{1} \mid p\left(X_{u}\right), D_{u}=1, D_{1}=\cdots=D_{u-1}=0\right) \\
& -E_{p\left(X_{u}\right) \mid D_{u}=1, D_{1}=\cdots=D u-1=0}\left\{E_{Y}\left(Y_{t, u}^{0} \mid p\left(X_{u}\right), D_{1}=\cdots=D_{u}=0\right)\right\} .
\end{aligned}
$$

In analogy to the ATT in the static setting, the second term approximates the participants' outcome in $t$ of not joining a programme in $u$ by the outcome of the comparable non-participants in $u$.

For interpretation of the results, one has to bear in mind that the chosen comparison group does not reflect a no-programme state, but rather possibly postponed participation. What should be noted is that individuals are not allowed to anticipate either future treatments or future labour market outcomes. Anticipatory effects of a treatment are present if, for example, those individuals who are informed about a future ALMP programme reduce their search activity in order to wait for the treatment. Anticipatory effects of future employment may occur if the individual knows that the former employer is going to call him or her back. In that case, the person is likely to have no or less incentive to participate in a programme at any given month in unemployment (Sianesi (2004)). However, Abbring and van den Berg (2003) point out that the exclusion of anticipatory effects does not rule out that the individuals know and act on the determinants of assignment to treatment or labour market outcomes, i.e., individuals are allowed to adjust their optimal behaviour to the determinants of the treatment process, but not to realisation of the treatment. This is not a problem for the analysis as long as treated and non-treated individuals anticipate the chances of these events conditional on $p\left(X_{u}\right)$ and the elapsed unemployment duration in $u$ in the same way (Fitzenberger and Speckesser (2005)).

\section{Empirical Analysis}

\subsection{Plausibility of the Conditional Independence Assumption}

A central issue for the evaluation of treatment effects of JCS by matching is the justification of the CIA. As mentioned above, it is necessary to observe all covariates that, conditional on having spent a given unemployment duration $u$, jointly influence the participation decision at that time $\left(D_{u}\right)$ and the outcome variable where such a decision is postponed further $\left(Y_{t, u}^{0}\right)$ (see Sianesi (2004)). If this assumption holds, the observed probability distribution of subsequently finding a job or of later joining a programme for the non-participants in time $u$ of the unemployment spell is the same as the counterfactual distribution for the treated individuals in $u$. However, the choice of the relevant variables is not straightforward. Therefore, we relate our discussion of the plausibility to the (institutional) set-up of the assignment process to JCS and to the rich set of variables available in the data set.

To start with, we will recapitulate the relevant aspects of the assignment process to be considered in the model. Allocation of an unemployed individual to a programme depends to a large extent on the caseworker's 
assessment of the individual's need for assistance. This need for assistance is assessed based on regular interviews with the unemployed individual to evaluate his or her efforts to find a job. In particular groups facing barriers to employment, e.g., long-term unemployed, severely disabled or older unemployed persons, are in need of assistance. In addition, to become eligible for participation in a JCS, people should in general be unemployed for at least six out of the last twelve months before the start of the programme and should fulfil the criteria for receiving UI benefits. The need for assistance as assessed by the caseworker implies that potential participants cannot be integrated into regular employment or into another ALMP programme at that time. Moreover, space in a programme has to be available. If these three preconditions are fulfilled, the caseworker may offer the unemployed individual a specific job in a JCS. For the CIA to be achieved it is crucial to identify enough information that can capture these determinants of allocation.

As mentioned in the description of the data (see Appendix B) we are able to control for a large number of variables characterising the individual's past and current (at the start of the treatment) labour market situation. We expect employment and unemployment experience, gender and geographic region of the unemployed individuals to be the most important determinants of the participation decision. Following Sianesi (2004), the elapsed unemployment duration of the individuals can be used to capture possible unobservable influences for the participation decision. These influences occur, for example, due to changes in motivation, loss of hope, or the perceived or actual human capital depreciation. Moreover, in the presence of duration dependence, the outflow to employment will differ between individuals with unemployment durations less than $u$ for reasons unrelated to the programme. Thus, it is crucial to ensure that comparison individuals have spent at least the amount of time in unemployment that it took the participants to join the programme (Sianesi, 2004). In addition, gender seems to be of particular interest due to the differing labour market attachment and behaviour of men and women. The strong regional differences between East and West German labour market in association with the different amount of ALMP programmes implemented in the two parts are the third main aspect to be considered when evaluating the employment effects of JCS.

For these reasons, we condition on previous unemployment experience by stratifying the samples for East and West Germany and men and women by the discretised unemployment duration $U=1,2, \ldots, U_{\max }$ with $U_{\max }=12$ and quarter as unit. ${ }^{9}$ Hence, we analyse the employment effects of a JCS for groups of individuals that join within the first three years of the current unemployment spell. However, we can only identify the programme effect for persons joining in quarter $k$ and quarter $l$ with $k \neq l$ separately and compare the estimates descriptively ex post. We are not able to analyse the effects for participants in quarter $k$ if they decided to wait longer (or shorter), and started treatment in quarter $l$.

In addition to individual unemployment experience, programme effects may also differ with calendar time. Fitzenberger and Speckesser (2005) note that an ideal approach should consider the different starting dates

\footnotetext{
${ }^{9}$ Using this kind of aggregation is useful for consideration of differences due to the timing of treatments since we expect the probabilities of leaving unemployment for programmes or employment to remain relatively constant within quarters of the unemployment spell.
} 
of unemployment as well as the different starting dates of the programmes. However, the number of observations available for analysis would be too small. Since we use data on programmes that started in a specific year and on persons allocated to programmes at unspecific points in time, we assume the calendar date of unemployment entry to be of minor importance for the evaluation of the programme effects. Therefore, we aggregate the six programme cohorts into one sample and consider the time the individuals spent in unemployment previously. However, to take account of possible seasonal differences, we regard seasonal dummies for the different programme starts in the estimation. ${ }^{10}$

To take account of the employment experience and qualification of the individuals, we use information collected by caseworkers to evaluate the unemployed person's likelihood of employment. These attributes comprise the duration of the last job and a dummy for work experience, schooling and professional training, and the time spent in last occupation. The duration of the last job in combination with work experience are good proxies for the individual's familiarity with employment. We consider employment duration in four different categories, i.e., up to 180 days, between 180 and 365 days, 366 to 730 days, and more than 730 days. This distinction allows us to proxy different levels of specific human capital accumulation during the jobs to some extent. Whereas we could expect persons who have worked for more than two years to have a relevant level of specific human capital, this expectation would not hold for persons who have worked for less than 180 days. Unfortunately, the data do not provide information concerning the nature of the contract, i.e., whether the unemployed individual worked within a permanent or temporary contract before, so the employment duration could be used only as a proxy. Schooling and professional training are regarded as reflecting the general human capital of individuals. Both variables are good indicators for individual qualifications. The time spent in the last job is used to denote the past labour market involvement of the individual. A designation of the individual's qualifications is supplemented by a subjective assessment by the caseworkers. It seems particularly important to consider this valuation in the model as it refers to observed and unobserved differences between characteristics of individuals. It can therefore be viewed as a summary statistic of the level as well as the transferability, effectiveness and obsolescence of previous human capital accumulation. The desired job together with the desired working hours of the individuals provide information on the economic sector of the job the individual seeks and whether he or she prefers a full-time or part-time job. Furthermore, as there is no strong occupational mobility between economic sectors in Germany, this is a proxy for the past occupation of the individuals. In addition, the consideration of the occupation type of the individual and his/her unemployment duration in the estimation is necessary to capture possible anticipatory effects in terms of future employment. For example, seasonal unemployed workers may know in advance that their past employer will call them back. In this case, they would have no incentive to participate in a JCS. By balancing the occupation as well as the time of unemployment start between treated and non-treated individuals, the problem of this type of anticipatory effect should be ruled

\footnotetext{
${ }^{10}$ By doing so, we will implicitly consider the start of the unemployment spell in the estimation as well.
} 
out.

There are also some socio-demographic attributes that are important determinants for the individual labour market prospects, such as citizenship (measured by dummy foreigner), asylum-seeker, the age of the individuals (measured in six categories at the start of the treatment), the number of children, and marriage/cohabitation. For example, the number of children and marriage/cohabitation are indicators for social background, mobility, and responsibility of the individual for other persons. Moreover, the characterisation of the labour market prospects is augmented by a number of further variables. These variables comprise the application for vocational rehabilitation, whether or not the individual has received an ALMP programme at some point in the past, the number of placement offers, the reception of UI and the caseworker's assessment of placement restrictions due to health problems. The number of placement offers indicates the placement restraints of the individual. A higher number of unsuccessful placement offers refers to a higher need for assistance in the placement process, including an adjustment of the unemployed person's human capital to the needs of the labour market. Information on participation in an ALMP programme previously may be used to identify potential 'programme careerists'. In particular in East Germany during the early 1990s, the majority of unemployed persons participated in ALMP programmes. ${ }^{11}$ Prior participation may thus also indicate a general willingness to participate in a future programme.

Obviously, caseworkers play a crucial role in the process of assignment to programmes. Since turning down a job offer in a JCS could be sanctioned by benefit revocation, caseworkers can be assumed to have the final word in the participation decision. If the caseworkers act on unobservable information that is correlated with the individual's potential labour market outcomes, the CIA would be violated. However, as the data used in this analysis are collected by the caseworkers and supplemented by their own subjective assessment of the qualification and placement restrictions of the individuals, we assume that caseworkers act idiosyncratically given the observable characteristics of the unemployed individuals and the subjective assessments. The large degree of freedom of caseworkers has implications for possible anticipatory effects in terms of future participation of unemployed individuals. Unemployed individuals are unlikely to turn down an offered occupation in a JCS in order to wait for a place in another ALMP programme since this would imply a cancellation of unemployment benefits or assistance.

The attributes considered so far concentrate on supply-side aspects of the labour market. However, participation in programmes and labour market outcomes also depend on demand-side aspects, e.g., the local labour market conditions (see Heckman, Ichimura, and Todd (1997)). On the one hand, the situation of the labour market differs between East and West Germany. On the other hand, the enactment of SGB III in 1998 has provided a larger degree of personal responsibility and flexibility to the LEAs, i.e., the individual agencies are responsible for the mixture of ALMP in their districts. For this reason, it is reasonable to assume that different local labour market conditions in the LEAs lead to different mixes of policy interventions.

\footnotetext{
${ }^{11}$ Bielenski, Brinkmann, and Kohler (1997) note that about three-quarters of the East German labour force took part at least once in a labour market programme between November 1989 and November 1994.
} 
Explicit consideration of the 181 labour office districts is not feasible for estimation. Therefore, we use the classification of the FEA (see Appendix B) to characterise the differing local labour market conditions in a parsimonious way.

In summary, the discussion of the CIA in our context has shown that given the detailed and comprehensive data set at hand, we are able to consider most if not all factors that determine participation and labour market outcomes. For this reason, we can argue that the CIA holds and we can use the matching estimator in the dynamic setting to evaluate the employment effects of JCS in Germany.

\subsection{Selected Descriptives}

Based on the extensive set of attributes, we have selected three variables for which we find clear differences between participants and non-participants. Table 1 presents the means of the number of placement offers, of having participated in a programme before unemployment, of placement restrictions assessed by the caseworkers and the programme duration. We distinguish between the four groups under analysis, as well as with respect to the time point in the unemployment spell when the programme started (in quarters from $u=1$ to $u=12) .^{12}$

The results point to two main findings that support our evaluation approach. First, there are clear differences between participants and non-participants in all four groups, as well as between the groups. Second, the participants in the main groups do not differ much within groups, and the same is true for non-participants. To give an example: taking a look at the number of placement offers shows that participants have clearly received a higher number on average. Whereas this difference is about four (non-participants) to ten (participants) for men in West Germany, for women in the region it is about three to nine. In East Germany, this difference is not as pronounced. Here, non-participating men have received on average between four placement offers, the participants about eight. The findings for women are similar (non-participants: about four, participants: about seven). Hence, this variable could be expected as one indicator that determines participation. The variable programme before unemployment highlights the differences of the labour market between East and West Germany. Whereas the share of non-participants in West Germany who have participated is between three to nine percent for men and two to four percent for women, the analogue in East Germany shows a much higher chance of having participated before. Here, the ratios are between 16 to 36 percent for men and 27 to 41 percent for women. Participants in JCS have participated even more often than the non-participants. In West Germany about 27 (20) to 40 (38) percent of the men (women) have joined a programme in the past. The corresponding numbers for East Germany are 48 to 59 percent for men and 61 to 68 percent for women. For this reason, we expect previous programme participation to be an important indicator for a anew promotion. Our third variable are placement restrictions of individuals as assessed by the caseworker. With respect to the law, we expect persons with placement restrictions to be

\footnotetext{
${ }^{12}$ In addition, Appendix C contains descriptive statistics for the variables used in the propensity score model (see below).
} 
Tab. 1: Means of Selected Variables

\begin{tabular}{|c|c|c|c|c|c|c|c|c|c|c|c|c|c|c|c|c|}
\hline \multirow{2}{*}{$\begin{array}{l}\text { Group } \\
\text { West Germany }\end{array}$} & NPart. & Part. & NPart. & Part. & $\begin{array}{l}\text { Part. } \\
\end{array}$ & Part. & NPart. & Part. & NPart. & Part. & NPart. & Part. & NPart. & Part. & NPart. & Part. \\
\hline & \multicolumn{8}{|c|}{ Men } & \multicolumn{8}{|c|}{ Women } \\
\hline & \multicolumn{2}{|c|}{$u=1$} & \multicolumn{2}{|c|}{$u=2$} & \multicolumn{2}{|c|}{$u=3$} & \multicolumn{2}{|c|}{$u=4$} & \multicolumn{2}{|c|}{$u=1$} & \multicolumn{2}{|c|}{$u=2$} & \multicolumn{2}{|c|}{$u=3$} & \multicolumn{2}{|c|}{$u=4$} \\
\hline No. of placement offers & 4.58 & 10.35 & 4.80 & 10.48 & 4.89 & 10.75 & 4.87 & 11.03 & 3.09 & 8.20 & 3.01 & 9.15 & 2.94 & 9.26 & 2.86 & 9.73 \\
\hline Programme bef. unemp. ${ }^{1}$ & 0.03 & 0.35 & 0.05 & 0.40 & 0.06 & 0.36 & 0.08 & 0.38 & 0.02 & 0.31 & 0.02 & 0.30 & 0.03 & 0.33 & 0.04 & 0.37 \\
\hline Placement restrictions & 0.15 & 0.26 & 0.17 & 0.27 & 0.20 & 0.24 & 0.22 & 0.22 & 0.11 & 0.20 & 0.12 & 0.16 & 0.13 & 0.17 & 0.14 & 0.12 \\
\hline \multirow[t]{2}{*}{ Programme duration (in days) } & \multirow{2}{*}{\multicolumn{2}{|c|}{$\begin{aligned} & 290.4 \\
& u=5\end{aligned}$}} & \multicolumn{2}{|c|}{284} & \multicolumn{2}{|c|}{268.6} & & 277.4 & \multicolumn{2}{|c|}{311.1} & \multicolumn{2}{|r|}{305.2} & \multicolumn{2}{|r|}{292.4} & \multicolumn{2}{|r|}{300.4} \\
\hline & & & $u=$ & & $u=$ & & $u=$ & & $u=$ & & $u=$ & & $u=$ & & $u=$ & \\
\hline No. of placement offers & 4.72 & 9.69 & 4.67 & 10.89 & 4.57 & 9.70 & 4.73 & 10.10 & 2.88 & 8.59 & 2.91 & 8.12 & 2.93 & 7.86 & 2.89 & 8.67 \\
\hline Programme bef. unemp. ${ }^{1}$ & 0.07 & 0.37 & 0.08 & 0.33 & 0.08 & 0.34 & 0.08 & 0.33 & 0.04 & 0.38 & 0.04 & 0.28 & 0.04 & 0.28 & 0.04 & 0.27 \\
\hline Placement restrictions & 0.23 & 0.23 & 0.24 & 0.16 & 0.24 & 0.19 & 0.26 & 0.21 & 0.15 & 0.13 & 0.16 & 0.11 & 0.16 & 0.10 & 0.16 & 0.12 \\
\hline \multirow[t]{2}{*}{ Programme duration (in days) } & & 289.8 & \multicolumn{2}{|r|}{267.1} & \multicolumn{2}{|r|}{264.9} & & 281.3 & \multicolumn{2}{|r|}{324.2} & & 301.6 & & 300 & & 303.5 \\
\hline & \multicolumn{2}{|c|}{$u=9$} & $u=$ & 10 & $u=$ & & $u=$ & 12 & $u=$ & & $u=$ & 10 & $u=$ & 11 & $u=$ & 12 \\
\hline No. of placement offers & 3.97 & 9.27 & 3.72 & 10.72 & 3.34 & 9.58 & 3.15 & 12.12 & 2.56 & 8.61 & 2.37 & 10.00 & 2.29 & 8.71 & 2.22 & 9.09 \\
\hline Programme bef. unemp. ${ }^{1}$ & 0.08 & 0.40 & 0.09 & 0.27 & 0.09 & 0.34 & 0.09 & 0.38 & 0.04 & 0.37 & 0.04 & 0.23 & 0.04 & 0.36 & 0.04 & 0.20 \\
\hline Placement restrictions & 0.27 & 0.22 & 0.29 & 0.21 & 0.29 & 0.24 & 0.29 & 0.22 & 0.17 & 0.13 & 0.18 & 0.15 & 0.18 & 0.11 & 0.18 & 0.14 \\
\hline Programme duration (in days) & & 297.7 & & 292.7 & & 272 & & 288.7 & & 335.1 & & 281.3 & & 340.4 & & 299.2 \\
\hline East Germany & & & & & & & & & & & & Nomen & & & & \\
\hline & $u=$ & & $u=$ & & $u=$ & & $u=$ & & $u=$ & & $u=$ & & $u=$ & & $u=$ & \\
\hline No. o & 3.91 & 7.88 & 4.38 & 8.43 & 4.69 & 8.39 & 4.88 & 7.84 & 3.79 & 6.77 & 4.00 & 6.98 & 4.09 & 6.82 & 4.02 & 7.01 \\
\hline Programme bef. unemp. ${ }^{1}$ & 0.16 & 0.59 & 0.23 & 0.56 & 0.27 & 0.52 & 0.32 & 0.56 & 0.27 & 0.63 & 0.34 & 0.63 & 0.37 & 0.61 & 0.41 & 0.64 \\
\hline Placement restrictions & 0.10 & 0.15 & 0.11 & 0.16 & 0.12 & 0.14 & 0.15 & 0.13 & 0.08 & 0.09 & 0.08 & 0.09 & 0.08 & 0.11 & 0.08 & 0.10 \\
\hline Programme duration (in days) & & 256.8 & & 255.8 & & 266.4 & & 268.5 & & 292 & & 298.8 & & 293.8 & & 293.6 \\
\hline & $u=$ & & $u=$ & & $u=$ & & $u=$ & & $u=$ & & $u=$ & & $u=$ & & $u=$ & \\
\hline No. of placement offers & 4.77 & 7.39 & 4.45 & 8.23 & 4.40 & 7.26 & 4.18 & 7.68 & 3.78 & 6.63 & 3.53 & 6.80 & 3.45 & 6.41 & 3.38 & 6.40 \\
\hline Programme bef. unemp. ${ }^{1}$ & 0.32 & 0.52 & 0.30 & 0.48 & 0.32 & 0.51 & 0.30 & 0.50 & 0.40 & 0.67 & 0.38 & 0.63 & 0.38 & 0.63 & 0.37 & 0.62 \\
\hline Placement restrictions & 0.15 & 0.10 & 0.15 & 0.13 & 0.17 & 0.12 & 0.18 & 0.13 & 0.08 & 0.10 & 0.08 & 0.08 & 0.08 & 0.08 & 0.08 & 0.09 \\
\hline Programme duration (in days) & & 270.2 & & 261.4 & & 266.1 & & 274 & & 309.2 & & 301.1 & & 307.3 & & 304.1 \\
\hline & $u=$ & & $u=$ & 10 & $u=$ & & $u=$ & 12 & $u=$ & & $u=$ & 10 & $u=$ & 11 & $u=$ & 12 \\
\hline No. of placement offers & 3.84 & 7.67 & 3.48 & 7.99 & 3.21 & 7.53 & 2.98 & 7.41 & 3.07 & 6.40 & 2.88 & 6.58 & 2.52 & 6.28 & 2.37 & 6.50 \\
\hline Programme bef. unemp. ${ }^{1}$ & 0.30 & 0.56 & 0.27 & 0.54 & 0.27 & 0.53 & 0.28 & 0.48 & 0.31 & 0.68 & 0.29 & 0.63 & 0.29 & 0.61 & 0.31 & 0.62 \\
\hline Placement restrictions & 0.18 & 0.13 & 0.21 & 0.12 & 0.21 & 0.14 & 0.22 & 0.16 & 0.10 & 0.07 & 0.10 & 0.07 & 0.09 & 0.07 & 0.10 & 0.08 \\
\hline Programme duration (in days) & & 280.9 & & 282.2 & & 272.8 & & 269.9 & & 313.7 & & 305.8 & & 307.2 & & 295.5 \\
\hline
\end{tabular}


overrepresented in the participants' groups. However, the empirical results confirm our expectation only in part. For groups with a shorter duration until programme start, it is true, but persons in groups with longer preceding unemployment duration are underrepresented.

These results show that it is necessary to estimate the programme effects separately for the four groups. In addition, explicit consideration of the timing of treatment seems important for reasons discussed above.

\subsection{Estimation}

We have estimated four series of twelve probit models (East and West Germany, men and women), each one modelling the probability of starting a programme in quarter $u$, conditional on $X$, conditional on having reached the unemployment duration of $u \in\{1, \ldots, 12\}$ quarters and conditional on not having received a treatment before $u$ in the unemployment spell. ${ }^{13}$ The variables included in the propensity score model have been chosen in order to justify the CIA (see discussion of the plausibility above) and to achieve an adequate balance of the covariate distributions between participants and non-participants. Estimation of the treatment effects of JCS was done using single nearest neigbour matching on the propensity score without replacement. ${ }^{14}$ To ensure common support, we impose the minima and maxima comparison condition. Since we use propensity score matching to estimate the treatment effects, we have to check the ability of the procedure to balance the relevant covariates. Table 2 provides some quality indicators. The first indicator is the standardised difference in percent as suggested by Rosenbaum and Rubin (1985). It considers the size of the differences in means of a conditioning variable between the treated and matched comparison groups, scaled by the square root of the average variances in the original samples (Smith and Todd, 2005b). To abbreviate the documentation, we present the median of the statistic before and after matching. Moreover, the tables contain the calculated pseudo- $R^{2}$ of the probit models for the full and the matched samples. The idea is to compare the coefficients of determination before and after matching. Successful matching should adjust away all systematic differences with respect to the observable covariates. Therefore, after matching there should be no systematic differences in the distribution of the covariates between the treated and the non-treated group (see Sianesi (2004)). Finally, we have added the number of individuals lost due to the common support condition.

The results show that the matching procedure is able to reduce the differences in the covariate distributions quite well for all points in time except for groups of less than 100 individuals. Hence, we refrain from interpreting the estimates for these groups. Starting with the median of the standardised difference in percent for West Germany shows that the remaining bias after matching is, for men, between $1.83(u=1)$ and $5.12(u=12)$ percent. The corresponding figures for women are slightly worse and amount to a median of

\footnotetext{
${ }^{13}$ The results of the propensity score estimations are given in Appendix D. Since our analysis is based on a stratified random sample, we do not estimate the true, but the conditional propensity score. However, NN matching is not sensitive to this stratification. Hence, estimated treatment effects based on the conditional propensity score are equal to those based on the true propensity score.

${ }^{14}$ All estimations have been done with STATA. For the matching, we have used the programme psmatch 2 by Leuven and Sianesi (2003).
} 
Tab. 2: INDICATORS OF COVARIATE BALANCING BEFORE AND AFTER MATCHING

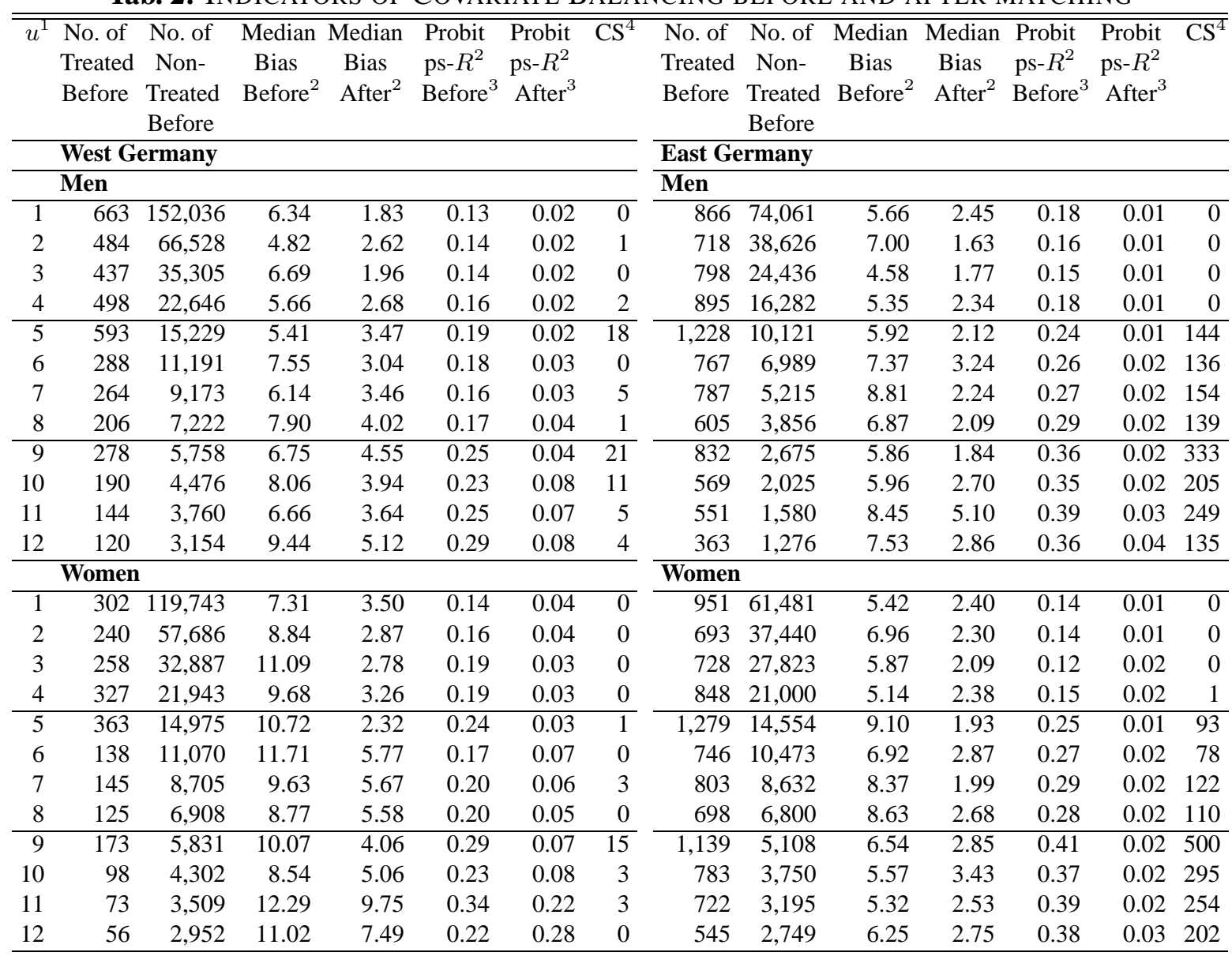

${ }^{1}$ Quarter refers to the quarter the treatment starts in the individual unemployment spell, $u$.

${ }^{2}$ Median bias denotes the median of the standardised difference in percent following Rosenbaum and Rubin (1985) before and after matching.

${ }^{3}$ Probit ps- $R^{2}$ refers to the pseudo $R^{2}$ computed for the full sample (before) and the matched sample (after).

${ }^{4}$ Number of treated individuals lost after imposing the common support condition.

between $2.32(u=5)$ and $5.77(u=6)$ percent. The results of the pseudo- $R^{2}$ 's support these findings. It has to be kept in mind that the median of the standardised difference in percent allows a crude approximation of the bias reduction for the single covariates only. Whereas some of the covariates differ clearly between treated and non-treated groups before matching, others are more similar (see descriptives in Appendix C). In particular for variables that are statistically significant in the propensity score estimations on a high level, e.g., the number of placement offers or having participated in a programme before, the matching procedure reduces the imbalances between treated and non-treated individuals significantly. To give an example, the standardised difference in percent for men (women) in West Germany for $u=1$ is 59.28 (57.78) percent before matching and only 10.31 (19.35) percent after matching for the number of placement offers. The corresponding reduction for programmes before unemployment is even stronger: here, men (women) have a difference of 86.63 (85.36) percent before and of 0.84 (5.81) percent after. The quality indicators for East Germany present a better picture. The median of the standardised difference in percent after matching amounts to between $1.63(u=2)$ and $5.10(u=11)$ percent for men and to between $1.93(u=5)$ and 3.43 
$(u=10)$ percent for women. Again, the differences for some of the variables had to be reduced far more severely than for others. To give the analogous figures to the example for West Germany, men (women) in East Germany for $u=1$ differed in the number of placement offers by 59.23 (56.49) percent before and by 9.11 (7.06) percent after. The difference in programmes before unemployment was 86.92 (73.93) percent before and 1.66 (4.90) percent after.

A final point should be mentioned in regard to the number of potential comparison individuals at each point in time. For persons starting treatment early in the unemployment spell, we have a large number of nonparticipants as potential matches, e.g., for $u=1$, the number of non-participants before matching amounts to $152,036(119,743)$ men (women) in West Germany and 74,061 $(61,481)$ men (women) in East Germany. Thus, it is more likely for the matching procedure to find adequate matches. For persons starting a treatment later in the unemployment spell, the number of potential comparisons decreases because the non-participants have left the unemployment for regular employment or other programmes. For this reason, it is harder for the matching procedure to find adequate comparison individuals to approximate the counterfactual outcome of the participants. This is also one reason for the large number of individuals lost due to the common support condition in East Germany.

\section{Employment Effects of Job Creation Schemes}

We will discuss the results for East and West Germany separately in the following. All treatment effects are estimated from the start of the programmes onwards. As mentioned above, programmes are associated with a locking-in effect, in particular shortly after programmes start. Since the majority of participants leave the programme within one year after the start and we measure the employment effects up to 30 months after treatments start, successful programmes should overcompensate for the expected initial drop in the employment spell.

\subsection{Impacts for West Germany}

The employment effects of JCS with respect to the timing of treatment for men and women in West Germany are presented in Figures 1 and 2. The graphs plot the development of the effects from the first month after treatment start to month 30 . The solid line describes the monthly employment effect, i.e., the difference in the employment rates between treated and matched non-treated individuals. The dotted lines are the lower and upper 95 percent confidence limits. ${ }^{15}$ In addition, to allow a more accurate discussion, Table 3 presents the results for five selected months.

The first thing to note common to all groups independently of the foregoing unemployment duration is a large drop in the effects during the first months after programmes start. For the majority of groups, this

\footnotetext{
${ }^{15}$ Standard errors are calculated following Steiger (2004).
} 
Fig. 1: Employment EfFects for Men in West Germany (TReatment Start between QuarTERS $u=1$ AND $u=12$ )

$u=1$

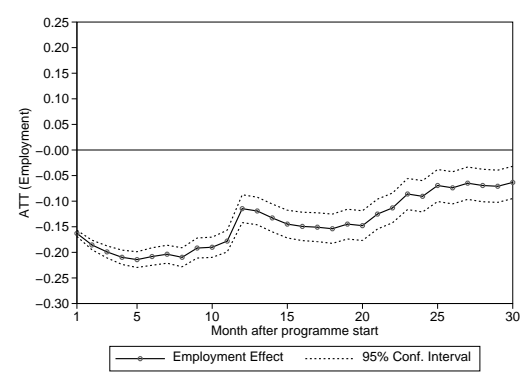

$u=4$

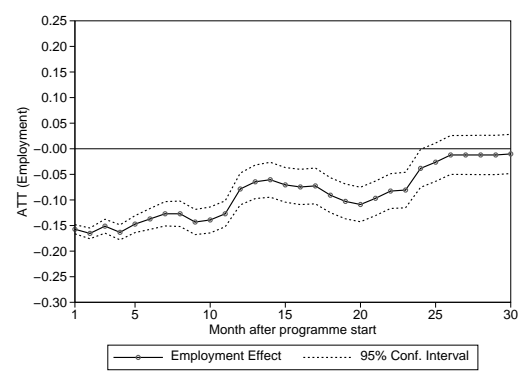

$u=7$

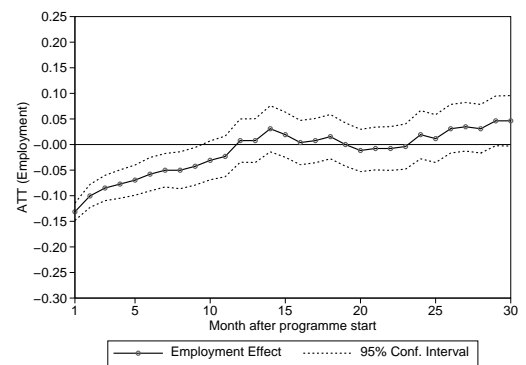

$u=10$

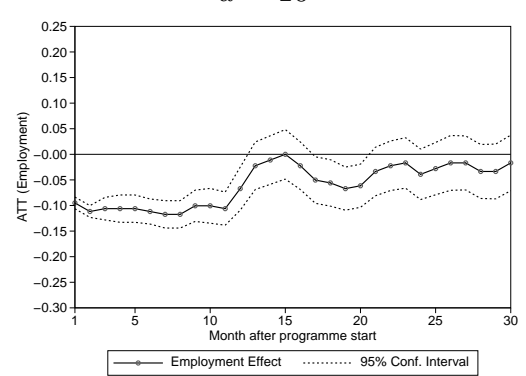

$u=2$

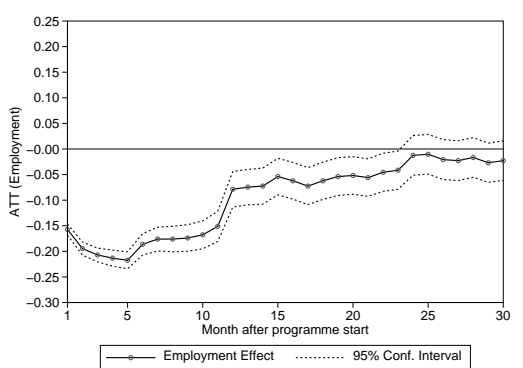

$u=5$

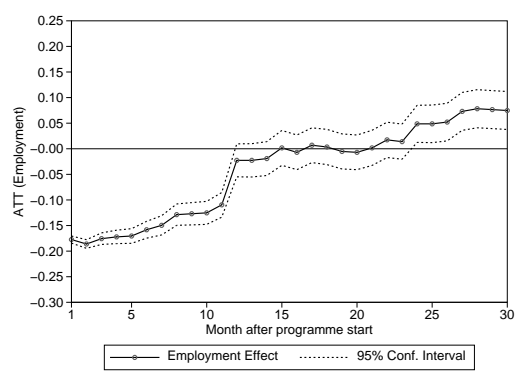

$u=8$

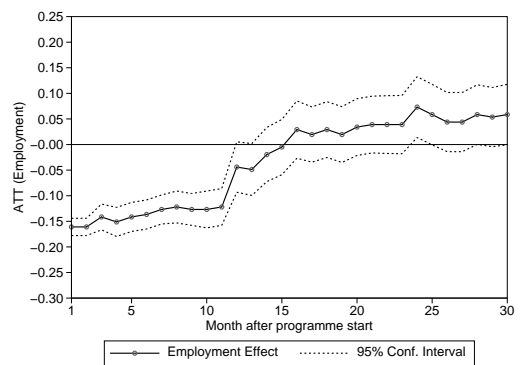

$u=11$

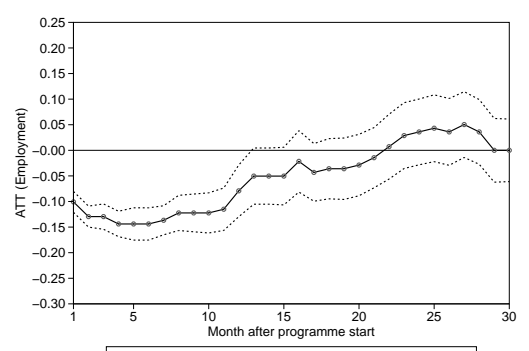

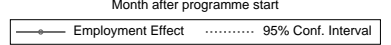

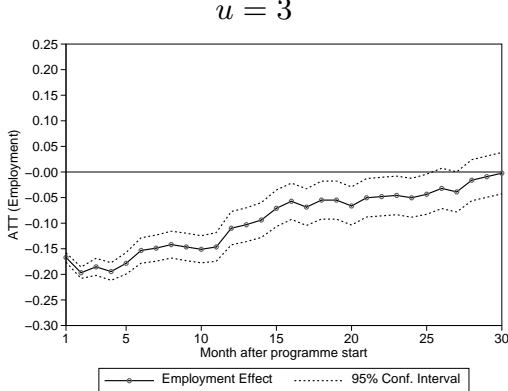

$u=6$

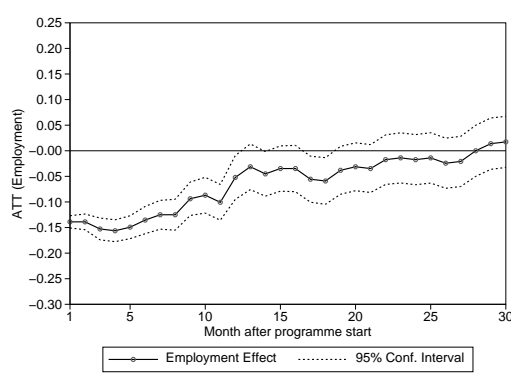

$u=9$

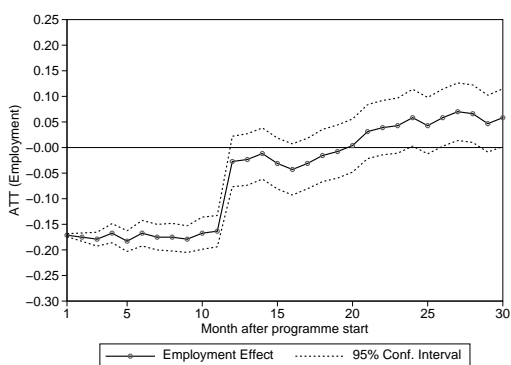

$u=12$

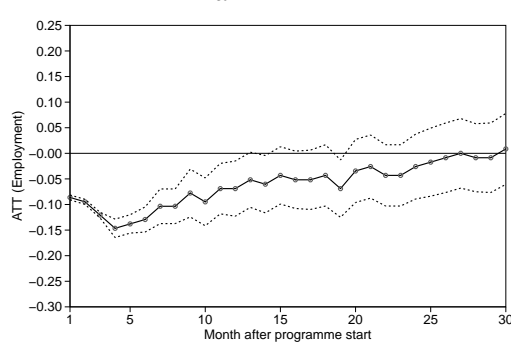

Month after programme start 
Fig. 2: Employment EFfects for Women in West Germany (TREatment start between QUARTERS $u=1$ AND $u=12$ )

$u=1$

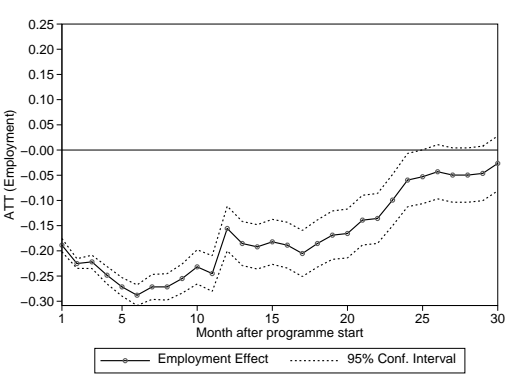

$u=4$

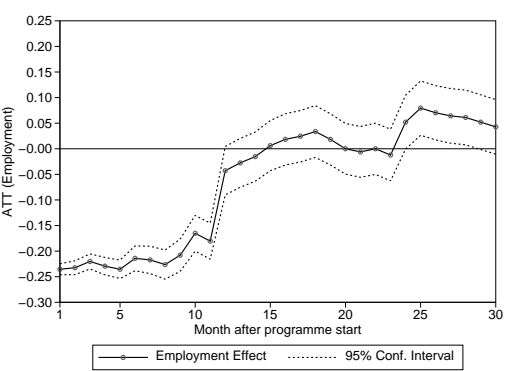

$u=7$

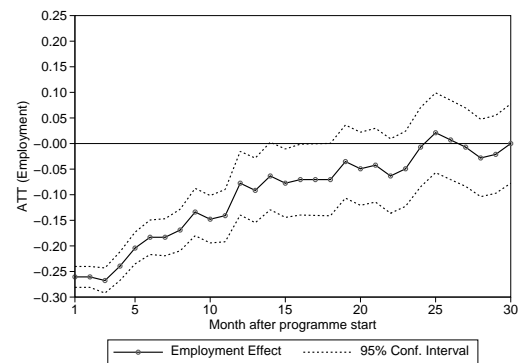

$u=10$

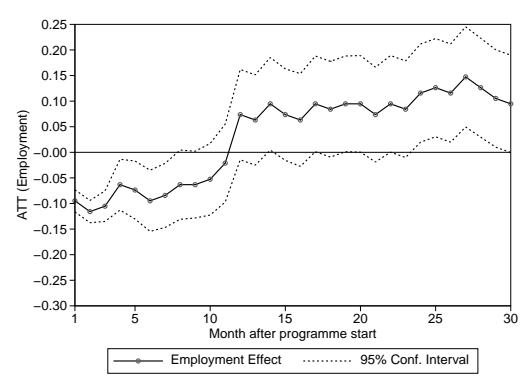

$u=2$

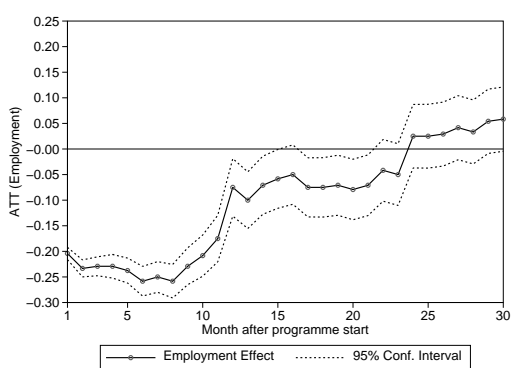

$u=5$

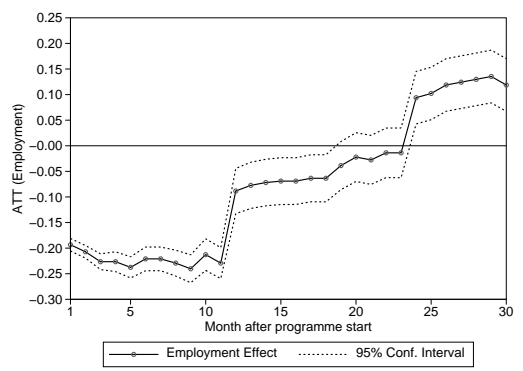

$u=8$

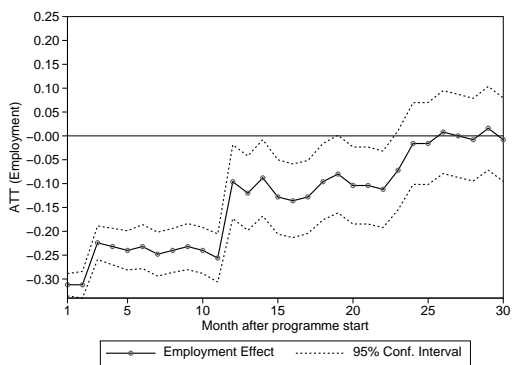

$u=11$

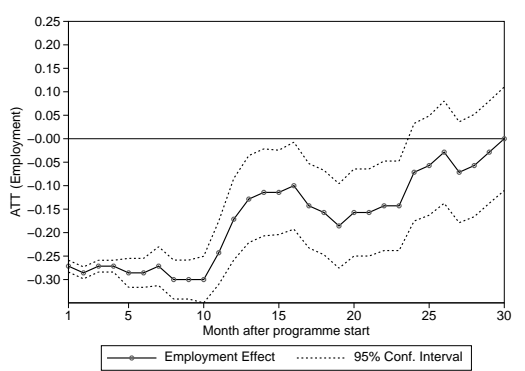

$u=3$

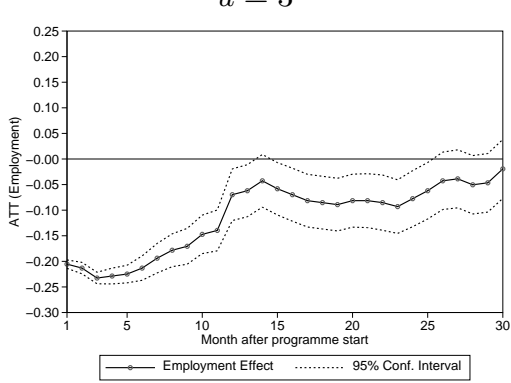

$u=6$

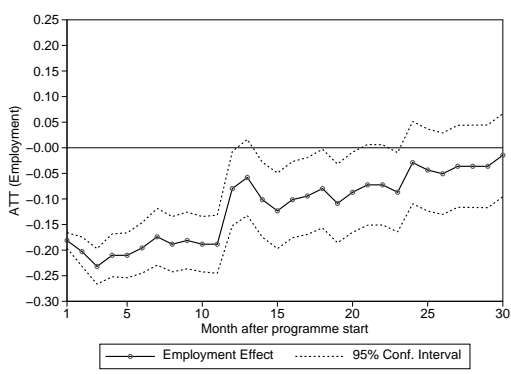

$u=9$

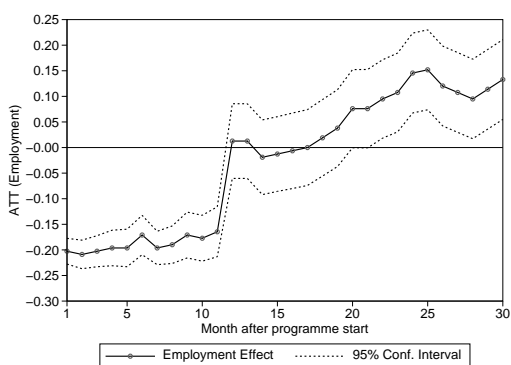

$u=12$

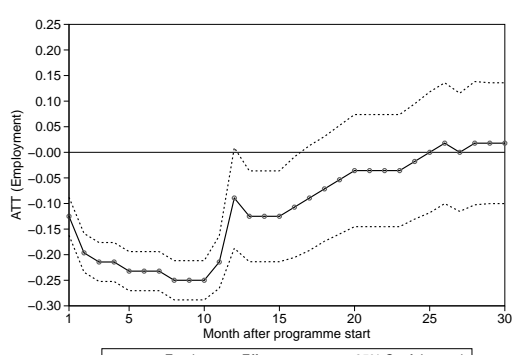

$\Longrightarrow$ Employment Effect 
difference in the employment rates reaches its peak around month six. It is reasonable to interpret the drop in the effects as the expected locking-in effects the participants experience while in the programmes. These locking-in effects are particularly articulated for groups starting a JCS early in the unemployment spell. To give an example, six months after the start of the programmes the employment rate for men starting in $u=1$ $(u=3)$ is $-20.8(-15.3)$ percentage points lower than for the matched non-participants. For groups starting the programmes later in the unemployment spell, the locking-in effects are still observable, but not as strong as for the groups that start earlier. For example, men who have started a programme in quarter $u=7$ of unemployment have an employment rate that is -5.8 percentage points lower. A similar picture can be seen for women. Women in $u=1(u=3)$ experience locking-in effects in the sixth month after programmes start of about -28.8 (-21.3) percentage points. The different magnitude of locking-in effects for different starting points of programmes during the unemployment spell reflects the different labour market situations of the individuals. Persons with only a short duration of unemployment could be expected to have better outside options on the labour market, i.e., finding jobs earlier than individuals with longer unemployment experience ('negative duration dependence'). Therefore, the higher employment probabilities of the comparable nonparticipants to those joining early in the unemployment spell lead to a stronger locking-in effect while in the programme.

As mentioned above, most of the participants left the programmes after twelve months. Therefore, locking-in effects should decrease at that time. The empirical findings confirm this expectation and a leap in the employment effects could be observed between month eleven and thirteen after start of the JCS. Unfortunately, no positive effects could be established for any of the groups at that time. The estimated treatment effects are at best insignificant in month twelve, i.e., the situation of the participants did not improve. In contrast, most of the effects are negative and for the majority of the individuals, the situation is even worse than one year before.

The development of the employment effects in the following months until the end of the observation period (month 30) is mixed. The effects for male participants tend to increase over time, in particular for the groups starting in quarters $u=3,5,6,7,8,9,11$ and 12 of the unemployment spell, and significant positive estimates of the employment effects 30 months after programmes are found for $u=5$ and $u=9$ with 7.5 and 5.8 percentage points. For the other groups, the effects are at best insignificant except for men starting in $u=1$ where we find a negative of -6.3 percentage points. The findings for women are similar. Almost all of the groups have employment rates 30 months after the start of the programmes that do not differ from the non-participants. Only for two groups, i.e., women starting in $u=5$ and $u=9$, did employment rates increase, by 11.9 and 13.3 percentage points. Unfortunately, since the majority of groups do not have an increased employment rate after participation, the results do not indicate the success of JCS.

The matching estimator solves the selection problem on observable variables only and further unobserved influences are assumed to be irrelevant. Although we are able to use a rich set of variables describing the 
Tab. 3: EMPloyment EFFects for Selected Months (WeSt GERMANY, BY QUARTER)

\begin{tabular}{|c|c|c|c|c|c|c|c|}
\hline$u^{1}$ & Obs. $^{2}$ & & $\overline{\Delta_{6, u}}$ & $\Delta_{12, u}$ & $\overline{\Delta_{18, u}}$ & $\Delta_{24, u}$ & $\Delta_{30, u}$ \\
\hline \multicolumn{8}{|c|}{ Men } \\
\hline \multirow[t]{2}{*}{1} & 663 & Effect & -0.208 & -0.115 & -0.154 & -0.090 & -0.063 \\
\hline & & Std. Err. & 0.009 & 0.014 & 0.015 & 0.016 & 0.016 \\
\hline \multirow[t]{2}{*}{2} & 483 & Effect & -0.186 & -0.079 & -0.062 & -0.012 & -0.023 \\
\hline & & Std. Err. & 0.011 & 0.018 & 0.019 & 0.020 & 0.020 \\
\hline \multirow[t]{2}{*}{3} & 437 & Effect & -0.153 & -0.110 & -0.055 & -0.050 & -0.002 \\
\hline & & Std. Err. & 0.013 & 0.017 & 0.019 & 0.019 & 0.021 \\
\hline \multirow[t]{2}{*}{4} & 496 & Effect & -0.137 & -0.079 & -0.091 & -0.038 & -0.010 \\
\hline & & Std. Err. & 0.010 & 0.016 & 0.017 & 0.019 & 0.020 \\
\hline \multirow[t]{2}{*}{5} & 575 & Effect & -0.158 & -0.023 & 0.003 & 0.049 & 0.075 \\
\hline & & Std. Err. & 0.008 & 0.016 & 0.018 & 0.018 & 0.019 \\
\hline \multirow[t]{2}{*}{6} & 288 & Effect & -0.135 & -0.052 & -0.059 & -0.017 & 0.017 \\
\hline & & Std. Err. & 0.014 & 0.022 & 0.023 & 0.025 & 0.025 \\
\hline \multirow[t]{2}{*}{7} & 259 & Effect & -0.058 & 0.008 & 0.015 & 0.019 & 0.046 \\
\hline & & Std. Err. & 0.017 & 0.022 & 0.022 & 0.024 & 0.025 \\
\hline \multirow[t]{2}{*}{8} & 205 & Effect & -0.137 & -0.044 & 0.029 & 0.073 & 0.059 \\
\hline & & Std. Err. & 0.014 & 0.025 & 0.028 & 0.030 & 0.030 \\
\hline \multirow[t]{2}{*}{9} & 257 & Effect & -0.167 & -0.027 & -0.016 & 0.058 & 0.058 \\
\hline & & Std. Err. & 0.013 & 0.025 & 0.026 & 0.028 & 0.029 \\
\hline \multirow[t]{2}{*}{10} & 179 & Effect & -0.112 & -0.067 & -0.056 & -0.039 & -0.017 \\
\hline & & Std. Err. & 0.013 & 0.021 & 0.023 & 0.025 & 0.028 \\
\hline \multirow[t]{2}{*}{11} & 139 & Effect & -0.144 & -0.079 & -0.036 & 0.036 & 0.000 \\
\hline & & Std. Err. & 0.016 & 0.026 & 0.030 & 0.033 & 0.031 \\
\hline \multirow[t]{2}{*}{12} & 116 & Effect & -0.129 & -0.069 & -0.043 & -0.026 & 0.009 \\
\hline & & Std. Err. & 0.013 & 0.028 & 0.031 & 0.032 & 0.035 \\
\hline \multicolumn{8}{|c|}{ Women } \\
\hline \multirow[t]{2}{*}{1} & 302 & Effect & -0.288 & -0.156 & -0.185 & -0.060 & -0.026 \\
\hline & & Std. Err. & 0.010 & 0.023 & 0.024 & 0.027 & 0.028 \\
\hline \multirow[t]{2}{*}{2} & 240 & Effect & -0.258 & -0.075 & -0.075 & 0.025 & 0.058 \\
\hline & & Std. Err. & 0.015 & 0.029 & 0.030 & 0.032 & 0.032 \\
\hline \multirow[t]{2}{*}{3} & 258 & Effect & -0.213 & -0.070 & -0.085 & -0.078 & -0.019 \\
\hline & & Std. Err. & 0.012 & 0.026 & 0.026 & 0.028 & 0.029 \\
\hline \multirow[t]{2}{*}{4} & 327 & Effect & -0.214 & -0.043 & 0.034 & 0.052 & 0.043 \\
\hline & & Std. Err. & 0.012 & 0.024 & 0.026 & 0.027 & 0.027 \\
\hline \multirow[t]{2}{*}{5} & 362 & Effect & -0.221 & -0.088 & -0.064 & 0.094 & 0.119 \\
\hline & & Std. Err. & 0.012 & 0.023 & 0.023 & 0.026 & 0.026 \\
\hline \multirow[t]{2}{*}{6} & 138 & Effect & -0.196 & -0.080 & -0.080 & -0.029 & -0.014 \\
\hline & & Std. Err. & 0.025 & 0.037 & 0.039 & 0.041 & 0.041 \\
\hline 7 & 142 & Effect & -0.183 & -0.077 & -0.070 & -0.007 & 0.000 \\
\hline & & Std. Err. & 0.017 & 0.032 & 0.036 & 0.040 & 0.040 \\
\hline 8 & 125 & Effect & -0.232 & -0.096 & -0.096 & -0.016 & -0.008 \\
\hline & & Std. Err. & 0.024 & 0.039 & 0.041 & 0.044 & 0.045 \\
\hline 9 & 158 & Effect & -0.171 & 0.013 & 0.019 & 0.146 & 0.133 \\
\hline & & Std. Err. & 0.020 & 0.037 & 0.038 & 0.040 & 0.040 \\
\hline 10 & 95 & Effect & -0.095 & 0.074 & 0.084 & 0.116 & 0.095 \\
\hline & & Std. Err. & 0.030 & 0.045 & 0.048 & 0.049 & 0.049 \\
\hline 11 & 70 & Effect & -0.286 & -0.171 & -0.157 & -0.071 & 0.000 \\
\hline & & Std. Err. & 0.016 & 0.044 & 0.046 & 0.053 & 0.056 \\
\hline 12 & 56 & Effect & -0.232 & -0.089 & -0.071 & -0.018 & 0.018 \\
\hline & & Std. Err. & 0.019 & 0.050 & 0.052 & 0.057 & 0.060 \\
\hline
\end{tabular}

Bold letters indicate significance on a $1 \%$ level, italic letters refer to the $5 \%$ level.

$1 u$ denotes the quarters spent in open unemployment.

2 Obs. refers to the number of treated observations when using nearest-neigbour matching with-

out replacement. Common support is imposed by the minimum-maximum comparison.

individual's labour market situation, we test the sensitivity of the results with respect to further unobserved selection. Appendix A provides the outline of this analysis (following Rosenbaum (2002), hidden bias). The 
bounds are calculated to capture possible positive and negative unobserved selection. Positive unobserved selection occurs if participants are also more likely to become employed. In this case, treatment effects would be overestimated. In the opposite case (negative unobserved selection), the effects would be underestimated. It has to be noted that the test does not indicate whether biases are present, but only analyses the sensitivity of the results to a possible hidden bias. The results of the sensitivity analysis (Table A.1) show that the estimates would not be robust against unobserved heterogeneity. This finding is not very surprising. The figures of the development of the employment effects over time show that for significant estimates, the confidence intervals are bounded not far from zero. Hence, further unobserved variables would not require a strong influence to change inferences about the outcomes. However, the discussion of the justification of the CIA in our context has shown that all relevant determinants that drive selection are considered in our model and that further unobserved influences are not very plausible.

To summarise the findings, the results show that independently of the foregoing unemployment duration, participants in JCS experience strong locking-in effects while in the programmes. Moreover, although we considered 12 distinct intervals in the individual unemployment spells when starting a programme, the findings indicate that for most of the groups, the effects do not differ significantly from zero even 30 months after programmes have started. For this reason, JCS do not improve the employment chances of the participants in the short or medium-run. In addition, men who start a programme within the first quarter of the unemployment spell suffer from participation, as the estimated negative employment effects two and a half years after programme start imply. Nevertheless, the programme seems to work in terms of an improved employability of the participants for persons starting in quarters $u=5$ and $u=9$. However, with the exception of these groups, the overall picture of the efficiency of JCS with respect to the goal of improving the employment chances of the participating individuals is rather disappointing for West Germany.

\subsection{Impacts for East Germany}

In analogy to the results for West Germany, the estimates for East Germany are given in Figures 3 for men and 4 for women and Table 4. Similar to the findings already discussed, participants of both genders suffer from locking-in effects during the first months after programmes start. However, in contrast to the West, the magnitude of these effects is smaller. With respect to the tense situation of the East German labour market, this finding is not surprising. Since vacancies are rare, there are not many outside options for the comparable non-participants. Consequently, the number of individuals leaving unemployment for regular jobs is lower than in West Germany, even if they have experienced a short duration of unemployment only. Thus, the employment rates for participating men six months after programmes have started are about $-8.2(u=4)$ to $-15.7(u=10)$ percentage points lower than for the matched non-participants. For women, the figures are similar with employment effects between -9.8 $(u=3)$ and -21.9 $(u=10)$ percentage points.

Similar to West Germany, most of the participants have left the programmes about one year after pro- 
Fig. 3: Employment EfFects for Men in East Germany (TREatment START Between QuaRTERS $u=1$ AND $u=12$ )

$u=1$

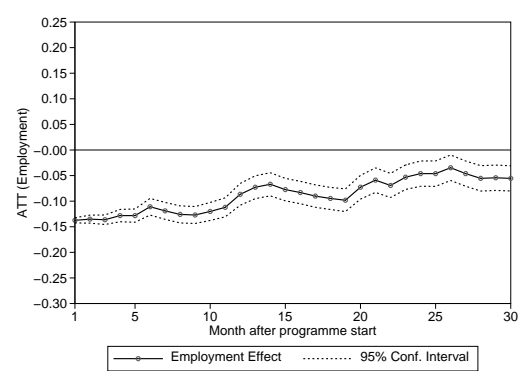

$u=4$

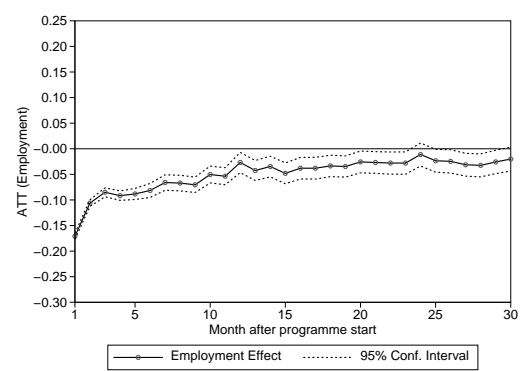

$u=7$

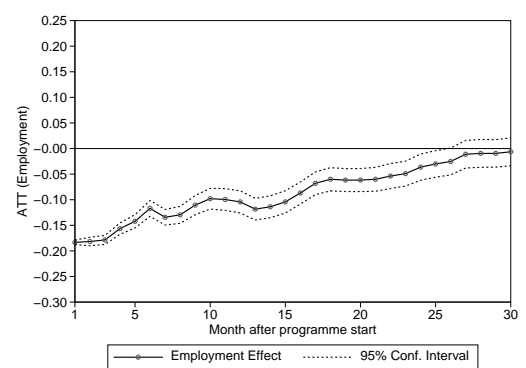

$u=10$

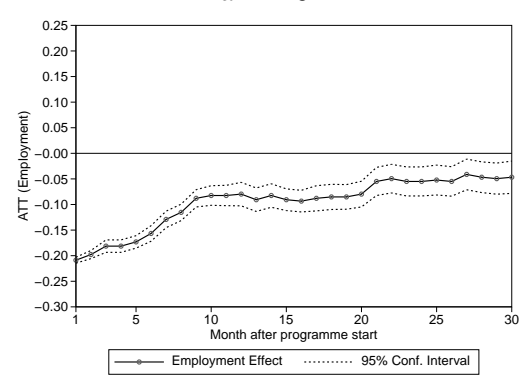

$u=2$

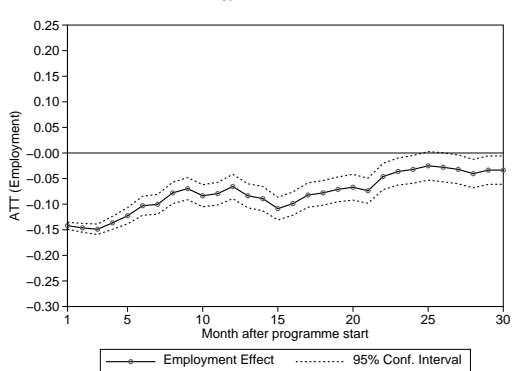

$u=5$

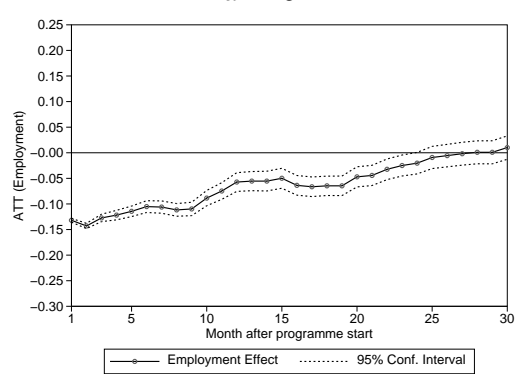

$u=8$

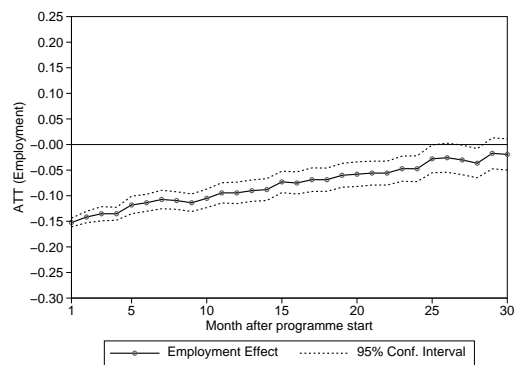

$u=11$

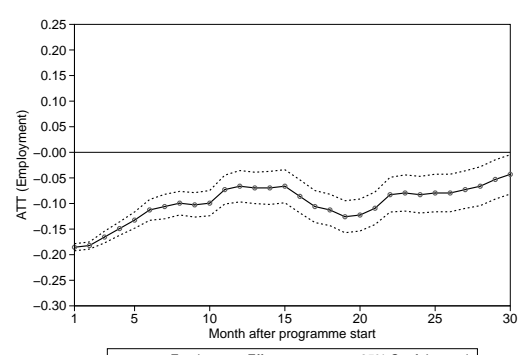

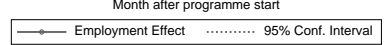

$u=3$

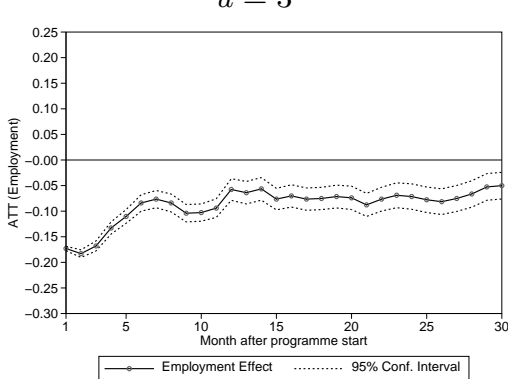

$u=6$

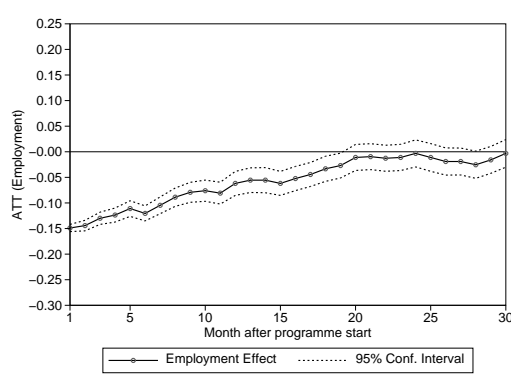

$u=9$

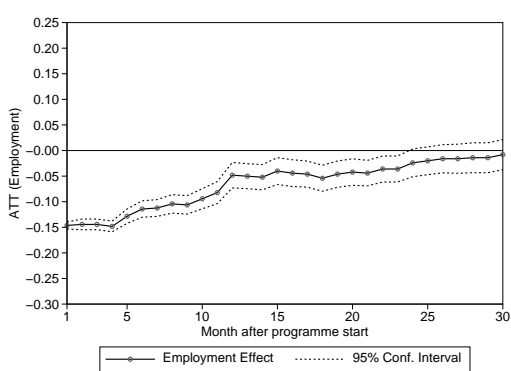

$u=12$

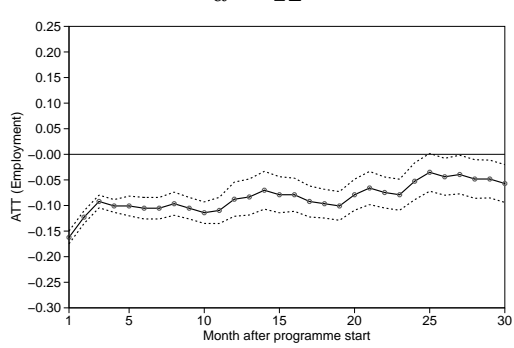

95\% Conf. Interval 
Fig. 4: EMPloyment EFFects for Women in EAst Germany (TREATMEnt Start between QUARTERS $u=1$ AND $u=12$ )

$u=1$

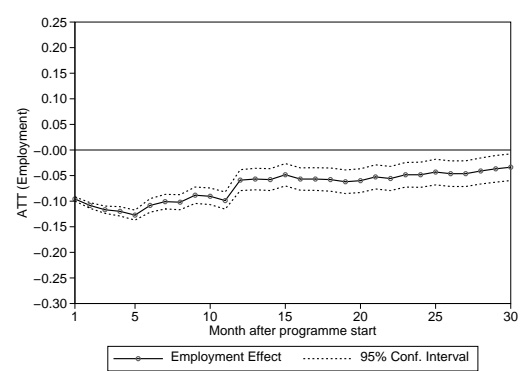

$u=4$

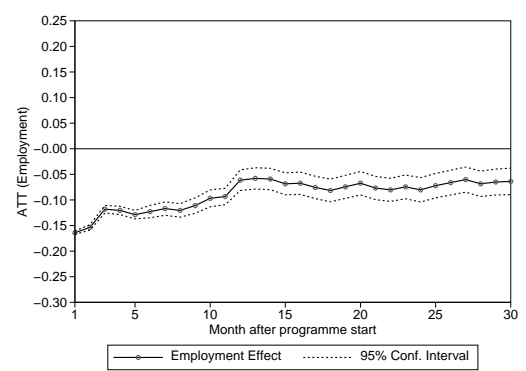

$u=7$

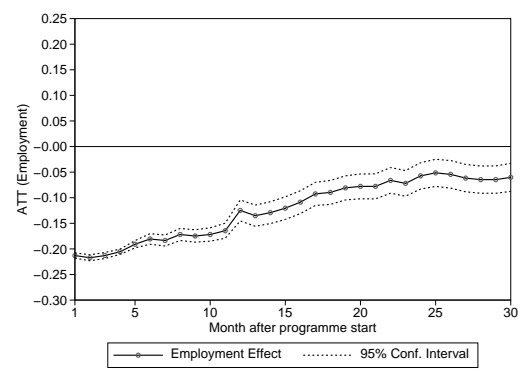

$u=10$

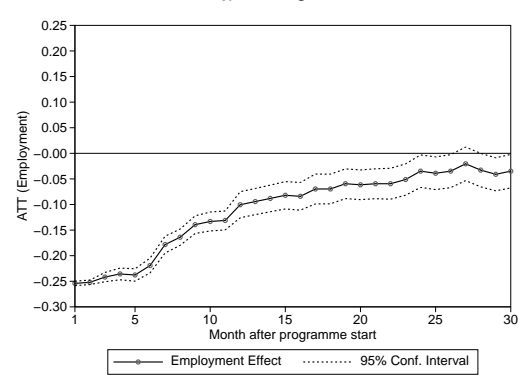

$u=2$

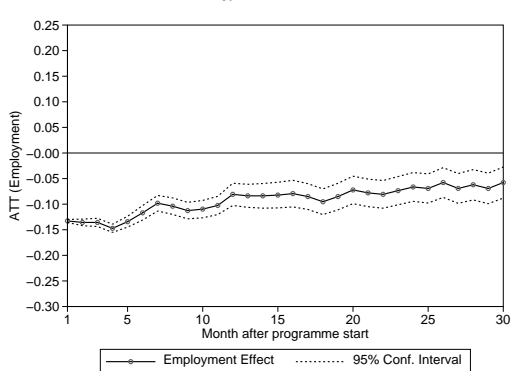

$u=5$

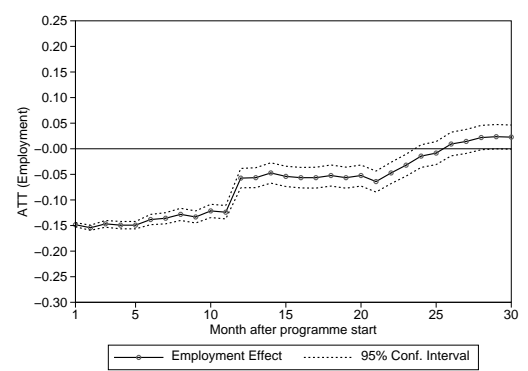

$u=8$

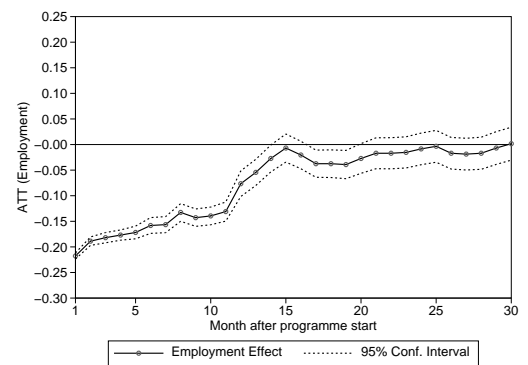

$u=11$

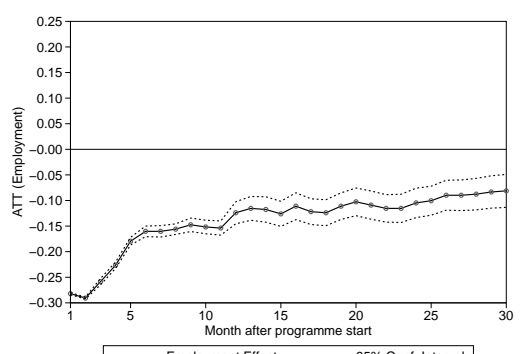

Monith aterer programme start
$-\ldots$ - Employment Effect …....... 95\% Conf. Interval $u=3$

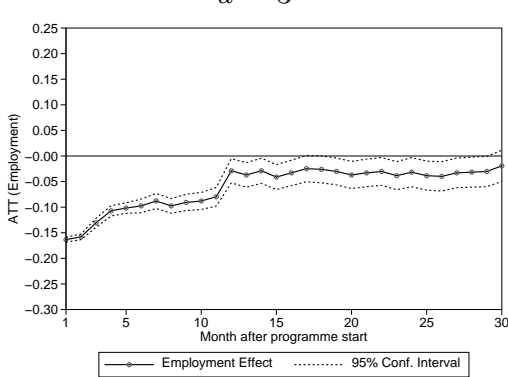

$u=6$

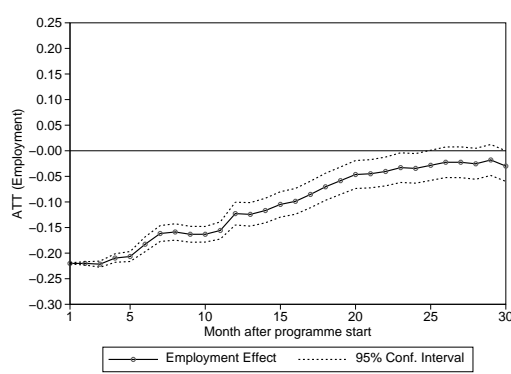

$u=9$

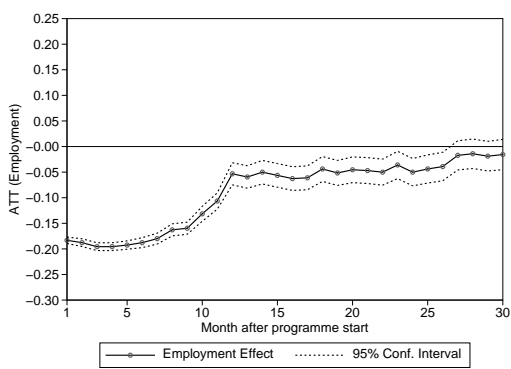

$u=12$

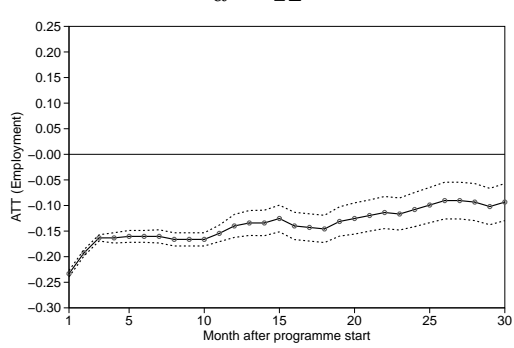

95\% Cont. Interval 
grammes start. But a clear increase in the employment effects could not be established at that time. Although several groups experienced a modest increase, the rising tendency in the development of the results comparable to the West could not be observed for most groups. It should be noted that this improvement is too low to compensate the initial drop in the employment rates, and individuals suffer from JCS even 30 months after programmes start. The graphs for men starting the programmes between quarter $u=5$ to $u=10$ as well as for women in $u=5,6,7$ and 10 show an upward shift during the observation period.

In contrast to West Germany, where most of the estimates do not differ significantly from zero, the results for East Germany provide a clearer picture. Six of the male and eight of the female groups experience negative employment effects until 30 months after the start of the programmes. None of the remaining groups has an increased employment rate at the end of the observation period. The employment rates for men (women) are between -3.3 (-3.0) to -5.7 (-9.3) percentage points lower. The test of robustness against possible unobserved influences (Table A.1) provides similar results to those for West Germany. Again, estimates are sensitive to possible hidden bias, but we have no reason to assume any further influences not considered in the model.

In summary, the findings of the empirical analysis for East Germany indicate that JCS are not able to improve the employment chances for participating individuals within the first 30 months after programmes have started. Although we find some effect heterogeneity with respect to the timing of treatment in the individual unemployment spell, we could not establish any positive treatment effects for the groups under analysis. Participants in JCS suffer from strong locking-in effects during the first months after programmes start. However, in contrast to the results for West Germany, the rising tendency in the development of the employment effects in the time after the majority of the participants have left the programmes could not be established. For this reason, the overall picture of the efficiency of JCS in East Germany in terms of improved employment chances is rather unsatisfying.

\section{Conclusions}

JCS have been an important programme of ALMP in Germany in terms of fiscal spending and the individuals receiving support. Although their importance has recently decreased in recent times, they are still used on a larger scale, particularly in East Germany. Programme effects have been analysed in a number of empirical studies. However, their results are of limited use for several reasons. Earlier studies are based on survey data with a small number of observations and concentrating on the East German labour market (see e.g., Huebler (1997), Kraus, Puhani, and Steiner (2000) and Eichler and Lechner (2002)). In addition, effects are not exactly attributable to specific programmes, since the data suffer from shortcomings with respect to the quality of the programme information and the accuracy of the employment history. Caliendo, Hujer, and Thomsen $(2004 ; 2006)$ have analysed the effects of JCS for Germany. Both studies are based on a 
Tab. 4: EMployment EFFects for Selected Months (EAST GERMANY, BY QUARTER)

\begin{tabular}{|c|c|c|c|c|c|c|c|}
\hline$u^{1}$ & Obs. $^{2}$ & & 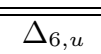 & $\Delta_{12, u}$ & $\overline{\Delta_{18, u}}$ & $\overline{\Delta_{24, u}}$ & $\overline{\Delta_{30, u}}$ \\
\hline \multicolumn{8}{|c|}{ Men } \\
\hline \multirow[t]{2}{*}{1} & 866 & Effect & -0.111 & -0.087 & -0.095 & -0.046 & -0.055 \\
\hline & & Std. Err. & 0.008 & 0.011 & 0.011 & 0.013 & 0.013 \\
\hline \multirow[t]{2}{*}{2} & 718 & Effect & -0.103 & -0.065 & -0.078 & -0.032 & -0.033 \\
\hline & & Std. Err. & 0.010 & 0.012 & 0.012 & 0.014 & 0.014 \\
\hline \multirow[t]{2}{*}{3} & 798 & Effect & -0.084 & -0.058 & -0.075 & -0.071 & -0.050 \\
\hline & & Std. Err. & 0.008 & 0.011 & 0.011 & 0.013 & 0.013 \\
\hline \multirow[t]{2}{*}{4} & 895 & Effect & -0.082 & -0.027 & -0.034 & -0.011 & -0.020 \\
\hline & & Std. Err. & 0.007 & 0.010 & 0.011 & 0.011 & 0.012 \\
\hline \multirow[t]{2}{*}{5} & 1,084 & Effect & -0.105 & -0.057 & -0.065 & -0.020 & 0.010 \\
\hline & & Std. Err. & 0.006 & 0.009 & 0.010 & 0.011 & 0.012 \\
\hline \multirow[t]{2}{*}{6} & 631 & Effect & -0.120 & -0.062 & -0.033 & -0.003 & -0.003 \\
\hline & & Std. Err. & 0.007 & 0.012 & 0.013 & 0.013 & 0.014 \\
\hline \multirow[t]{2}{*}{7} & 633 & Effect & -0.117 & -0.104 & -0.060 & -0.036 & -0.006 \\
\hline & & Std. Err. & 0.008 & 0.011 & 0.012 & 0.013 & 0.014 \\
\hline \multirow[t]{2}{*}{8} & 466 & Effect & -0.114 & -0.094 & -0.069 & -0.047 & -0.019 \\
\hline & & Std. Err. & 0.008 & 0.011 & 0.012 & 0.013 & 0.016 \\
\hline \multirow[t]{2}{*}{9} & 499 & Effect & -0.114 & -0.048 & -0.054 & -0.024 & -0.008 \\
\hline & & Std. Err. & 0.008 & 0.013 & 0.013 & 0.014 & 0.015 \\
\hline \multirow[t]{2}{*}{10} & 364 & Effect & -0.157 & -0.080 & -0.085 & -0.055 & -0.047 \\
\hline & & Std. Err. & 0.008 & 0.012 & 0.013 & 0.014 & 0.016 \\
\hline \multirow[t]{2}{*}{11} & 302 & Effect & -0.113 & -0.066 & -0.113 & -0.083 & -0.043 \\
\hline & & Std. Err. & 0.010 & 0.016 & 0.016 & 0.018 & 0.020 \\
\hline \multirow[t]{2}{*}{12} & 228 & Effect & -0.105 & -0.088 & -0.096 & -0.053 & -0.057 \\
\hline & & Std. Err. & 0.011 & 0.017 & 0.014 & 0.018 & 0.019 \\
\hline \multicolumn{8}{|c|}{ Women } \\
\hline \multirow[t]{2}{*}{1} & 951 & Effect & -0.108 & -0.059 & -0.058 & -0.048 & -0.034 \\
\hline & & Std. Err. & 0.007 & 0.010 & 0.012 & 0.013 & 0.013 \\
\hline \multirow[t]{2}{*}{2} & 693 & Effect & -0.117 & -0.081 & -0.095 & -0.066 & -0.058 \\
\hline & & Std. Err. & 0.007 & 0.011 & 0.013 & 0.014 & 0.015 \\
\hline \multirow[t]{2}{*}{3} & 728 & Effect & -0.098 & -0.029 & -0.026 & -0.032 & -0.019 \\
\hline & & Std. Err. & 0.007 & 0.012 & 0.013 & 0.015 & 0.016 \\
\hline \multirow[t]{2}{*}{4} & 847 & Effect & -0.123 & -0.061 & -0.081 & -0.080 & -0.064 \\
\hline & & Std. Err. & 0.006 & 0.010 & 0.011 & 0.012 & 0.013 \\
\hline \multirow[t]{2}{*}{5} & 1,186 & Effect & -0.138 & -0.057 & -0.052 & -0.014 & 0.023 \\
\hline & & Std. Err. & 0.005 & 0.010 & 0.010 & 0.011 & 0.012 \\
\hline \multirow[t]{2}{*}{6} & 668 & Effect & -0.183 & -0.123 & -0.070 & -0.034 & -0.030 \\
\hline & & Std. Err. & 0.007 & 0.011 & 0.013 & 0.015 & 0.015 \\
\hline 7 & 681 & Effect & -0.181 & -0.125 & -0.090 & -0.057 & -0.060 \\
\hline & & Std. Err. & 0.005 & 0.010 & 0.012 & 0.013 & 0.014 \\
\hline 8 & 588 & Effect & -0.158 & -0.077 & $-\mathbf{0 . 0 3 7}$ & -0.009 & 0.002 \\
\hline & & Std. Err. & 0.008 & 0.013 & 0.014 & 0.016 & 0.016 \\
\hline 9 & 639 & Effect & -0.188 & -0.053 & -0.044 & -0.050 & -0.016 \\
\hline & & Std. Err. & 0.005 & 0.011 & 0.012 & 0.014 & 0.015 \\
\hline 10 & 488 & Effect & -0.219 & -0.100 & -0.070 & -0.035 & -0.035 \\
\hline & & Std. Err. & 0.007 & 0.013 & 0.015 & 0.016 & 0.017 \\
\hline 11 & 468 & Effect & -0.160 & -0.124 & -0.124 & -0.105 & -0.081 \\
\hline & & Std. Err. & 0.005 & 0.011 & 0.013 & 0.015 & 0.016 \\
\hline 12 & 343 & Effect & -0.160 & -0.140 & -0.146 & -0.108 & -0.093 \\
\hline & & Std. Err. & 0.006 & 0.011 & 0.014 & 0.017 & 0.018 \\
\hline
\end{tabular}

Bold letters indicate significance on a $1 \%$ level, italic letters refer to the $5 \%$ level.

$1 u$ denotes the quarters spent in open unemployment.

2 Obs. refers to the number of treated observations when using nearest-neigbour matching without replacement. Common support is imposed by the minimum-maximum comparison.

cross-section of participants of only a single month. Therefore, the studies did not control for changes in the allocation of participants or for changes in the labour market with respect to time. The overall picture of the 
efficiency of JCS presented by previous studies is disappointing.

In this paper, we have evaluated the effects of JCS on the individual re-integration chances into regular (unsubsidised) employment. Seasonal differences are considered by using rich administrative data covering individuals entering programmes for the course of one year. A particular focus of the analysis is the timing of treatment in the individual unemployment spell. Recent empirical literature evaluating social programmes in comprehensive ALMP systems like Sweden, Switzerland and Germany (see e.g., Sianesi (2004), Steiger (2004), and Fitzenberger and Speckesser (2005)) has highlighted the importance of timing to assess the efficiency of programmes. Moreover, it clearly reveals that participation and non-participation have to be defined dynamically, i.e., unemployed persons are non-participants as long as they do not join a programme or leave for regular employment.

We have estimated the treatment effects using propensity score matching. A particular emphasis has been placed on the selection of relevant variables and the quality of the matches. In addition, since matching is not robust with regard to further unobserved influences, we have tested the sensitivity of the estimates for hidden bias according to Rosenbaum (2002). The different labour market conditions and the corresponding differences in the use of ALMP programmes in East and West Germany as well as gender differences were considered in separate analyses for those four groups. The effects of programmes that started within the first three years of the unemployment spell (with a distinction into twelve quarters) have been estimated for up to 30 months following the start of the JCS.

Since JCS generally last for twelve months, the majority of the individuals leave the programmes after that time. By then, participants suffer from strong locking-in effects independently of region and gender. There are differences in the locking-in effects with respect to the timing of treatment which indicate that persons who started a programme early in the unemployment spell suffer more than those who started later. Furthermore, the negative effects for participants attending the programmes are more severe in West than in East Germany. The overall picture at the end of the observation period is unsatisfying and supports the findings from earlier studies. Almost all of the participants experience a decline in their employability due to participation in a JCS. Even 30 months after the programmes started, we find positive effects for only four groups: men and women starting in both quarters five and nine of the unemployment spell. Although this seems to be a light at the end of the tunnel, the results should not be overrated. In particular in West Germany, women have a lower propensity to work than men. Therefore, if no job is available they might tend to leave the labour force after some period of unemployment. As this drop could not be accounted for in the outcome variable without violating the CIA, this 'employment effect' should be interpreted with care. The results for East Germany are even worse. Although the locking-in effects are not as severe as in West Germany, there is a lower increase in employment effects after the majority of participants have left the programmes. Thus, at the end of the observation period none of the groups experiences a positive employment effect.

In summary, the findings of the estimations for West and East Germany indicate that JCS perform poorly in 
improving the employment chances of the participants. In other words, in the 30 months following the start of the programme participants fail to be re-integrated more efficiently into regular (unsubsidised) employment than non-participants.

\section{References}

AAKVIK, A. (2001): "Bounding a Matching Estimator: The Case of a Norwegian Training Program," Oxford Bulletin of Economics and Statistics, 63(1), 115-143.

ABbRING, J. H., AND G. J. VAN DEN BERG (2003): “The Nonparametric Identification of Treatment Effects in Duration Models," Econometrica, 71(5), 1491-1517.

Bielenski, H., C. BRInKMANn, AND B. KohleR (1997): "Beteiligung an Maßnahmen der Arbeitsmarktpolitik," in Der Arbeitsmarkt Ostdeutschlands im Umbruch: Datensätze, Methoden und ausgewählte Ergebnisse des Arbeitsmarkt-Monitors 1989-1994, ed. by H. Bielenski, C. Brinkmann, H. Plicht, and B. von Rosenbladt, vol. 210, pp. 108-119. IAB - Beiträge zur Arbeitsmarkt- und Berufsforschung, Nuremberg.

Blien, U., F. Hirschenauer, M. Arendt, H. J. Braun, D.-M. Gunst, S. Kilcioglu, H. KleinSChmidt, M. Musati, H. Ross, D. Vollkommer, and J. Wein (2004): “Typisierung von Bezirken der Agenturen der Arbeit," Zeitschrift für Arbeitsmarktforschung, 37(2), 146-175.

Blundell, R., And M. Costa Dias (2002): "Alternative Approaches to Evaluation in Empirical Microeconomics," Portuguese Economic Journal, 1, 91-115.

Brodaty, T., B. Crépon, and D. Fougere (2001): "Using Matching Estimators to Evaluate Alternative Youth Employment Programs: Evidence from France, 1986-1988," in Econometric Evaluation of Labour Market Policies, ed. by M. Lechner, and F. Pfeiffer, vol. 13 of ZEW Economic Studies, pp. 85-123. Physica-Verlag, Heidelberg, New York.

Caliendo, M., R. Hujer, and S. L. Thomsen (2004): "Evaluation der Eingliederungseffekte von Arbeitsbeschaffungsmaßnahmen in reguläre Beschäftigung für Teilnehmer in Deutschland," Zeitschrift für Arbeitsmarktforschung - Journal for Labour Market Research, 3, 211-237.

(2005a): "The Employment Effects of Job Creation Schemes in Germany - A Microeconometric Evaluation,” Discussion Paper No. 1512, IZA.

(2005b): "Identifying Effect Heterogeneity to Improve the Efficiency of Job Creation Schemes in Germany," Applied Economics, forthcoming.

(2006): "Sectoral Heterogeneity in the Employment Effects of Job Creation Schemes in Germany," Jahrbücher für Nationalökonomie und Statistik, 226(2), 139-179. 
Eichler, M., And M. Lechner (2002): “An Evaluation of Public Employment Programmes in the East German State of Sachsen-Anhalt," Labour Economics, 9, 143-186.

Fitzenberger, B., And S. SPeckesser (2005): "Employment Effects of the Provision of Specific Professional Skills and Techniques in Germany,” Discussion Paper No. 05-77, ZEW.

Fredriksson, P., AND P. Johansson (2004): "Dynamic Treatment Assignment - The Consequences for Evaluations Using Observational Data," Discussion Paper No. 1062, IZA.

FRÖHLICH, S., S. KAIMER, AND M. STAMM (2004): "Beschreibung und Qualitätsanalyse - Verbleibsnachweis in Beschäftigung," Internal Working Paper, IAB, Nuremberg.

Gerfin, M., And M. Lechner (2002): “A Microeconometric Evaluation of the Active Labour Market Policy in Switzerland," The Economic Journal, 112, 854-893.

Gerfin, M., M. Lechner, And H. Steiger (2005): "Does Subsidised Temporary Employment Get the Unemployed Back to Work? An Econometric Analysis of Two Different Schemes," Labour Economics, forthcoming.

Heckman, J. J., H. Ichimura, J. A. Smith, and P. Todd (1998): “Characterizing Selection Bias Using Experimental Data," Econometrica, 66, 1017-1098.

HeCKMAn, J. J., H. ICHIMURA, And P. TOdD (1997): "Matching as an Econometric Evaluation Estimator: Evidence from Evaluating a Job Training Programme," Review of Economic Studies, 64, 605-654.

Heckman, J. J., R. J. LALonde, And J. A. Smith (1999): “The Economics and Econometrics of Active Labor Market Programs," in Handbook of Labor Economics, ed. by O. Ashenfelter, and D. Card, vol. 3A, chap. 31, pp. 1865-2097. Elsevier, Amsterdam.

Heckman, J. J., And J. A. Smith (1999): "The Pre-Program Earnings Dip and the Determinants of Participation in a Social Program: Implications for Simple Program Evaluation Strategies," Economic Journal, 109(457), 313-348.

Huebler, O. (1997): "Evaluation beschäftigungspolitischer Maßnahmen in Ostdeutschland," Jahrbücher für Nationalökonomie und Statistik, 216, 21-44.

Hujer, R., AND C. ZEISs (2005): "Macroeconomic Impacts of Job Creation Schemes on the Matching Process in West Germany," Applied Economics Quarterly, 51(2), 203-218.

Kraus, F., P. A. Puhani, And V. Steiner (2000): “Do Public Works Programs Work? Some Unpleasant Results from the East German Experience," in Research in Labour Economics, ed. by S. Polachek. JAI Press. 
LeChner, M. (1999): "Earnings and Employment Effects of Continuous Off-the-Job Training in East Germany After Unification,” Journal of Business Economic Statistics, 17, 74-90.

(2001): "Identification and Estimation of Causal Effects of Multiple Treatments under the Conditional Independence Assumption," in Econometric Evaluation of Labour Market Policies, ed. by M. Lechner, and F. Pfeiffer, vol. 13 of ZEW Economic Studies, pp. 43-58. Physica-Verlag, Heidelberg.

Lechner, M., R. Miquel, And C. Wunsch (2005a): "The Curse and Blessing of Training the Unemployed in a Changing Economy - the Case of East Germany After Unification,” Discussion Paper No. $14 / 2005$, IAB.

(2005b): “Long-Run Effects of Public Sector-Sponsored Training in West Germany,” Discussion Paper No. 3/2005, IAB.

Leuven, E., And B. Sianesi (2003): "PSMATCH2: Stata Module to Perform Full Mahalanobis and Propensity Score Matching, Common Support Graphing, and Covariate Imbalance Testing," Statistical Software Components s432001, Boston College Department of Economics, revised 30 April 2004.

Mantel, N., And W. Haenszel (1959): "Statistical Aspects of the Analysis of Data from Retrospective Studies of Disease," Journal of the National Cancer Institute, 22, 719-748.

Neyman, J. S. (1923): "On the Application of Probability Theory to Agricultural Experiments. Essays on Principles. Chapter 9," Statistical Science, 5(4), 463-480, Reprint in English from 1990.

Pagan, A., And A. Ullah (1999): Nonparametric Econometrics. Cambridge University Press, Cambridge.

Rosenbaum, P. R. (2002): Observational Studies. Springer, New York.

Rosenbaum, P. R., And D. B. Rubin (1983): “The Central Role of the Propensity Score in Observational Studies for Causal Effects," Biometrika, 70(1), 41-50.

(1985): “Constructing a Control Group Using Multivariate Matched Sampling Methods that Incorporate the Propensity Score," The American Statistician, 39(1), 33-38.

RoY, A. D. (1951): "Some Thoughts on the Distribution of Earnings," Oxford Economic Papers, 3, 135-145.

Rubin, D. B. (1974): "Estimating Causal Effects to Treatments in Randomised and Nonrandomised Studies," Journal of Educational Psychology, 66, 688-701.

(1986): "Statistics and Causal Inference: Comment. Which Ifs Have Causal Answers," Journal of the American Statistical Association, 81(396), 961-962. 
SiAnesi, B. (2004): "An Evaluation of the Active Labour Market Programmes in Sweden," The Review of Economics and Statistics, 86(1), 133-155.

Smith, J. A. (2000): "A Critical Survey of Empirical Methods for Evaluating Active Labor Market Policies,” Schweizerische Zeitschrift für Volkswirtschaft und Statistik, 136(3), 1-22.

Smith, J. A., And P. TodD (2005a): “Does Matching Overcome LaLonde's Critique of Nonexperimental Estimators?," Journal of Econometrics, 125(1/2), 305-354.

(2005b): "Does Matching Overcome LaLonde's Critique of Nonexperimental Estimators? Rejoinder," Journal of Econometrics, 125(1/2), 365-375.

Speckesser, S. (2004): "Using Social Insurance Data for the Evaluation of Active Labour Market Policy: Employment Effects of Further Training for the Unemployed in Germany,” Working Paper, University of Mannheim.

SPITZNAGEL, E. (1992): "Allgemeine Maßnahmen zur Arbeitsbeschaffung (ABM) in den neuen Bundesländern," Mitteilungen aus der Arbeitsmarkt- und Berufsforschung, 25(3), 277-288.

Spitznagel, E., ANd E. Magvas (1997): "Arbeitsbeschaffungsmaßnahmen (ABM) - berufliche Eingliederung und Einkommenssituation der Teilnehmer," in Der Arbeitsmarkt Ostdeutschlands im Umbruch: Datensätze, Methoden und ausgewählte Ergebnisse des Arbeitsmarkt-Monitors 1989-1994, ed. by H. Bielenski, C. Brinkmann, H. Plicht, and B. von Rosenbladt, vol. 210, pp. 192-208. IAB - Beiträge zur Arbeitsmarkt- und Berufsforschung, Nuremberg.

Steiger, H. (2004): "Is Less More? A Look at Nonparticipation in Swiss Active Labour Market Programmes," Working Paper, University of St.Gallen.

Wilke, R., AND H. Winterhager (2004): "Datenquellen als Voraussetzung für Evaluationsforschung,” in Hartz-Gesetze - Methodische Ansätze zu einer Evaluierung, ed. by T. Hagen, and A. Spermann, vol. 74 of ZEW-Wirtschaftsanalysen, pp. 33-43. Nomos-Verlag. 


\section{A Sensitivity to Hidden Bias}

The estimated treatment effects in this study are identified under the CIA. However, for the CIA to be fulfilled all relevant variables that jointly influence participation and outcomes have to be observed for estimation. Although we have highly informative data at our disposal and have discussed the plausibility of the CIA in detail in Section 5.1, there may be concern about a possible selection on unobserved factors, such as motivational differences between treated and non-treated individuals the so-called hidden bias (Rosenbaum (2002)). Matching estimators are not robust against this hidden bias. Unfortunately, estimation of the magnitude of this bias is impossible, i.e., whether we under- or overestimate the true effects. Rosenbaum (2002) suggests applying a sensitivity analysis to answer the question of whether inference about programme effects may be altered by unobserved factors. The idea is to calculate the lower and upper bounds for different values of unobserved selection bias of a test statistic that tests the null hypothesis of no treatment effect (Aakvik (2001)).

Following Aakvik (2001), let $\pi_{i}=\operatorname{Pr}\left(D_{i}=1 \mid X_{i}\right)=F\left(\beta X_{i}+\gamma v_{i}\right)$ be the probability of participation, where $X_{i}$ are the observed variables, $v_{i}$ the unobserved variable, and $\gamma$ is the effect of $v_{i}$ on the participation probability of individual $i .{ }^{16}$ With $F$ assumed to be distributed logistic, the odds of participation for $i$ is given by $\pi_{i} /\left(1-\pi_{i}\right)=\exp \left(\beta X_{i}+\gamma v_{i}\right)$. Comparison of two persons with common support of $X$ and equal distribution of $X$, i.e., a treated, $i$, and a comparable non-treated individual, $j$, can be accomplished by calculation of the relative odds:

$$
\frac{\left(\frac{\pi_{i}}{1-\pi_{i}}\right)}{\left(\frac{\pi_{j}}{1-\pi_{j}}\right)}=\frac{\exp \left(\beta X_{j}+\gamma v_{j}\right)}{\exp \left(\beta X_{i}+\gamma v_{i}\right)}=\exp \left[\gamma\left(v_{i}-v_{j}\right)\right] \text {, with } i \neq j .
$$

The odds ratio in eq. A.1 is one if there are no differences in unobserved variables or the unobserved variables do not influence the participation decision, i.e., no hidden bias. In this case, controlling for selection based on the observed covariates would produce unbiased treatment effects (Aakvik, 2001). Otherwise, treatment effects may be biased. For simplicity, assume $v \in\{0,1\}$. In this case, eq. A.1 can be rewritten as

$$
\frac{1}{\Gamma} \leq \frac{\pi_{i}\left(1-\pi_{j}\right)}{\pi_{j}\left(1-\pi_{i}\right)} \leq \Gamma
$$

with $\Gamma=\exp (\gamma)$. $\Gamma$ denotes the relative odds of participation of two individuals who appear similar in their $X$. Two individuals $i$ and $j$ have the same participation probability if $\Gamma=1$. They differ if $\Gamma>1$, e.g., if $\Gamma=1.5$ by factor of 1.5 . The estimated treatment effects are said to be sensitive to unobserved selection if $\Gamma$ close to one changes inference about the effects.

We will introduce some additional notation necessary to calculate the nonparametric test-statistics. Let $n_{1}$ denote the number of treated, $n_{0}$ the number of matched non-treated and $n$ the sum of all matched individuals in the sample. $y_{1}\left(y_{0}\right)$ is the number of participants (matched non-participants) who are employed in month

\footnotetext{
${ }^{16}$ For simplicity of notation, we drop the index $u$ for the time until treatment in this description.
} 
30 after programmes have started; $y$ describes the sum of all 'successes' in month 30 . The test-statistic to be used is the Mantel-Haenszel statistic (Mantel and Haenszel, 1959), defined as ${ }^{17}$ :

$$
Q_{\mathrm{MH}}=\frac{\left[y_{1}-E\left(y_{1}\right)\right]^{2}}{\operatorname{Var}\left(y_{1}\right)},
$$

with $E\left(y_{1}\right)=\left(n_{1} y\right) / n$ and $\operatorname{Var}\left(y_{1}\right)=\left[n_{1} n_{0} y(n-y)\right] /\left[n^{2}(n-1)\right]$ (Aakvik, 2001). It provides a nonparametric test of no treatment effect and is $\chi^{2}$ distributed with one degree of freedom. Under the null hypothesis for fixed $\Gamma \geq 1$ and $v \in\{0,1\}$ Rosenbaum (2002) shows that the test-statistics $Q_{\mathrm{MH}}$ can be bounded by:

$$
Q_{\mathrm{MH}}^{+}=\frac{Y_{t, u}^{1}-\widetilde{E}}{\operatorname{Var}(\widetilde{E})} \quad \text { and } \quad Q_{\mathrm{MH}}^{-}=\frac{Y_{t, u}^{1}-\widetilde{E}}{\operatorname{Var}(\widetilde{E})} .
$$

$Q_{\mathrm{MH}}^{+}$is the test statistic given that we have overestimated the true treatment effect, i.e., we have a positive unobserved selection in the sense that persons who are most likely to participate also have higher employment rates. Thus, the $\chi^{2}$ statistics is too high and should be adjusted downwards, $Q_{\mathrm{MH}}^{+} \leq Q_{\mathrm{MH}}$. The opposite case is given by $Q_{\mathrm{MH}}^{-}$, where we have a negative unobserved selection, and underestimate the true treatment effect.

$\widetilde{E}$ and $\operatorname{Var}(\widetilde{E})$ are the large sample approximations to the expectation and variance of the number of successful treated persons. $\widetilde{E}$ is determined by solving the quadratic equation (Rosenbaum (2002)):

$$
\widetilde{E}^{2}(\Gamma-1)-\widetilde{E}\left\{(\Gamma-1) \cdot\left(n_{1}+y\right)+n\right\}+\Gamma \cdot y \cdot n_{1},
$$

with $\max \left(0, y+n_{1}-n\right) \leq \widetilde{E} \leq \min \left(y, n_{1}\right)$. The variance could be calculated by:

$$
\operatorname{Var}(\widetilde{E})=\left(\frac{1}{\widetilde{E}}+\frac{1}{y-\widetilde{E}}+\frac{1}{n_{1}-\widetilde{E}}+\frac{1}{n-y-n_{1}+\widetilde{E}}\right)^{-1} .
$$

The opposite bound on the significance is computed by replacing $\Gamma$ with $1 / \Gamma$.

Table A.1 shows the test statistics $Q_{\mathrm{MH}}$ for $\Gamma=1$ together with the sensitivity of the test statistics. All results refer to month 30 after programmes have started. We have tested the sensitivity for significant employment effects only. The analysis was accomplished by increasing the value of $\Gamma$ in steps of 0.05 . To abbreviate documentation, the table only presents the values of $\Gamma$ where at least one of the bounds of the test statistics become insignificant. Although the results of the sensitivity indicate how biases may alter the inferences and that the estimated treatment effects are sensitive to possible unobserved selection, it has to be kept in mind that the sensitivity analysis could not provide evidence of whether biases are present or what magnitudes are plausible.

\section{B Data Appendix}

The 181 LEAs in Germany collect information within the so-called CoArb system on all registered job seekers. ${ }^{18}$ These are persons who are registered unemployed, persons threatened by unemployment or in

\footnotetext{
${ }^{17}$ The Mantel-Haenszel statistic considers different strata of the population. As this is not necessary in our analysis, we have simplified the notation accordingly.

${ }^{18}$ The term CoArb is an abbreviation for computer-based job placement assistance (computergestützte Arbeitsvermittlung).
} 
Tab. A.1: Sensitivity of the Estimates to Possible Hidden

\begin{tabular}{|c|c|c|c|c|c|c|c|}
\hline \multicolumn{4}{|c|}{ BIAS $^{\mathrm{a}}$} & \multicolumn{4}{|c|}{$\overline{\text { East }}$} \\
\hline$u$ & $\begin{array}{l}Q_{M H} \\
\Gamma=1\end{array}$ & $\begin{array}{l}\text { Value }^{b} \\
\text { of } \Gamma\end{array}$ & $\begin{array}{c}\text { Bounds for } \\
Q_{M H}{ }^{\mathrm{c}}\end{array}$ & $u$ & $\begin{array}{l}Q_{M H} \\
\Gamma=1\end{array}$ & $\begin{array}{l}\text { Value }^{b} \\
\text { of } \Gamma\end{array}$ & $\begin{array}{c}\text { Bounds for } \\
Q_{M H}{ }^{\mathrm{c}}\end{array}$ \\
\hline \multicolumn{4}{|c|}{ Men } & \multicolumn{4}{|c|}{ Men } \\
\hline 1 & 7.08 & 1.10 & $3.65-11.67$ & 1 & 8.62 & 1.15 & $3.23-16.67$ \\
\hline 2 & n.s. & & & 2 & 2.61 & 1.00 & $1.57-3.92$ \\
\hline 3 & n.s. & & & 3 & 6.40 & 1.10 & $3.17-10.80$ \\
\hline 4 & n.s. & & & 4 & n.s. & & \\
\hline 5 & 8.54 & 1.15 & $3.60-15.64$ & 5 & n.s. & & \\
\hline 6 & n.s. & & & 6 & n.s. & & \\
\hline 7 & n.s. & & & 7 & n.s. & & \\
\hline 8 & n.s. & & & 8 & n.s. & & \\
\hline 9 & 2.19 & 1.00 & $1.53-2.99$ & 9 & n.s. & & \\
\hline 10 & n.s. & & & 10 & 3.56 & 1.00 & $2.78-4.44$ \\
\hline 11 & n.s. & & & 11 & 2.14 & 1.00 & $1.56-2.83$ \\
\hline 12 & n.s. & & & 12 & 3.60 & 1.00 & $3.00-4.27$ \\
\hline \multicolumn{4}{|c|}{ Women } & \multicolumn{4}{|c|}{ Women } \\
\hline 1 & n.s. & & & 1 & 3.05 & 1.00 & $1.69-4.81$ \\
\hline 2 & n.s. & & & 2 & 6.36 & 1.10 & $3.13-10.76$ \\
\hline 3 & n.s. & & & 3 & & & \\
\hline 4 & n.s. & & & 4 & 10.36 & 1.20 & $2.88-22.63$ \\
\hline 5 & 10.63 & 1.25 & $3.23-22.47$ & 5 & & & \\
\hline 6 & n.s. & & & 6 & 1.83 & 1.00 & $0.98-2.93$ \\
\hline 7 & n.s. & & & 7 & 8.10 & 1.15 & $3.40-14.89$ \\
\hline 8 & n.s. & & & 8 & & & \\
\hline 9 & 5.93 & 1.15 & $3.38-9.25$ & 9 & & & \\
\hline 10 & n.s. & & & 10 & 2.01 & 1.05 & $1.27-2.93$ \\
\hline 11 & n.s. & & & 11 & 10.09 & 1.25 & $3.44-20.47$ \\
\hline 12 & n.s. & & & 12 & 10.07 & 1.30 & $3.48-20.38$ \\
\hline
\end{tabular}

temporary employment as well as participants in the different ALMP programmes. The purpose of the data collection is to administer the job-seekers and to alleviate the decisions of the local caseworkers regarding the placement of job-seekers in regular employment or ALMP programmes. Furthermore, the data is used to control the UI eligibility of the job-seekers. All data are collected detailed to a daily level, i.e., the day the unemployment spell starts as well as the day it ends are contained. These locally collected data are transmitted to the FEA on a monthly basis. The information for all job-seekers is consolidated in the socalled job-seekers data base ( Winterhager (2004)). The BewA contains a rich set of attributes describing the individual's labour market situation. Three classes of characteristics could be distinguished: The first category, socio-demographic information, incorporates attributes such as age, gender, marital status, citizenship, the number of children, and health restrictions. The second category, the qualification details, consists of such attributes as the individual's graduation, completed professional training, the occupational group of the last job and work experience. The last category, the labour market history, includes the date of registration at the LEA (and 
the duration of unemployment since that date), the duration of the last employment, the number of job offers received by the individual, as well as information on prior programme participation. Although most of the attributes are 'objective' facts, like age or gender, the BewA also contains subjective assessments of the individuals' labour market prospects by the responsible caseworkers. These subjective attributes cover the assessment of the individual's health restrictions with respect to employment chances, but also the assessment of the actual qualifications of the individuals.

The information on the different ALMP programmes is not included in BewA, but is collected separately in the LEAs within the so-called CoSach system ${ }^{19}$ and transmitted to the FEA on a monthly basis as well. As in BewA, data are detailed at a daily level. Information on the individual ALMP programmes are contained in several different data sets. For example, data on vocational training programmes, training measures and German language courses are contained in the so-called ST35, whereas data on subsidised employment programmes in Germany, like JCS and structural adjustment schemes, are consolidated in the so-called ST11. This source contains all information necessary for the administration of the programmes, such as information on the employer who receives the wage subsidy, the economic sector of the activity, times of qualification and/or practical training of the individual during the programme, the beginning and end of the programme (payment of the subsidy) and the ex-ante planned as well as the ex-post realised programme entry and departure dates of the individual. Besides these attributes, a small number of further individual characteristics are included. However, these are redundant to those provided by BewA.

During the years 2000 to 2004, the information of the BewA and the several sources for the different programmes were standardised and merged into one major source: the programme participants' master data set (Maßnahme-Teilnehmer-Grunddatei, MTG). This data set includes information on all programme participation in FEA-sponsored programmes from 2000 to the present. For this reason, the MTG contains on the one hand a large number of attributes to describe the individual's labour market situation. On the other, it provides a reasonable basis for the construction of the comparison group as almost all individual characteristics are available for the participants as well as for the non-participants and originate from the same source. ${ }^{20}$

A further important determinant is the state of the local labour market (Heckman and Smith (1999)). For the description of the regional context, we use the classification of the labour office districts by the FEA (see Blien et al.(2004) for further details). The aim of this classification is to enhance the comparability of the labour office districts for a more efficient allocation of funds. The 181 LEAs are split into twelve types of office districts with similar labour market characteristics. These twelve types of comparable labour office districts can be grouped into five types for strategic purposes. Since almost all labour office districts in East Germany belong to the first of these five strategic types (except the city of Dresden), we use a further

\footnotetext{
${ }^{19}$ The term CoSach is an abbreviation for computer-based case processing (computergestützte Sachbearbeitung).

${ }^{20}$ This same origin of the data is an essential basis for a valid estimation. The results of Heckman, Ichimura, Smith, and Todd (1998), who analyse the sources of potential biases of evaluation estimators, show that having access to a geographicallymatched comparison group who received the same questionnaire as programme participants clearly matters in devising effective non-experimental estimators of programme impacts.
} 
subdivision into three groups. For West Germany, we use the remaining four types. The clusters are ordered according to the labour market conditions, i.e., cluster Ia comprises LEAs with the worst and cluster V LEAs with the most promising labour market situation. ${ }^{21}$ Table B.1 presents the classification used in the analysis with a short description of the clusters and the number of LEAs in each cluster.

Tab. B.1: Classification Of LABOUR OfFiCE Districts in GeRmany

\begin{tabular}{|c|c|c|}
\hline Cluster & Description & No. \\
\hline Ia & East German labour office districts with worst labour market conditions & 5 \\
\hline $\mathrm{Ib}$ & East German labour office districts with bad labour market conditions & 23 \\
\hline Ic & East German labour office districts with high unemployment & 5 \\
\hline II & Labour office districts dominated by large cities & 21 \\
\hline III & $\begin{array}{l}\text { West German labour office districts with rural elements, medium-sized industry } \\
\text { and average unemployment }\end{array}$ & 63 \\
\hline IV & West German centers with good labour market prospects & 10 \\
\hline V & West German labour office districts with the best labour market prospects & 47 \\
\hline
\end{tabular}

No. describes the number of labour offices in cluster.

Source: Blien et al. (2004)

The information available from the FEA for the evaluation of JCS is summarised in Table B.2. We are able to use the five categories of variables as described. For the outcome variable, we use the information from the Employment Statistics Register ( $\underline{B}$ eschäftigtenstatistik, BSt), which includes information on the total population of persons registered in the German social security system since 1975. These include employees and participants in several ALMP programmes, but no self-employed or pensioners. Data on spells of employment subject to social insurance contributions are collected for each employed person in account form based on yearly notification by employers. However, due to delays in reporting by employers, the information available in the BSt has an up to two-year time lag. Therefore, the FEA forecasts the information included. In consequence, assessing contemporary effects of ALMP programmes is possible, but the results may be problematic as they are based purely on forecasted employment information. As a useful evaluation of programme effects should be based on actually reported, rather than forecasted information, our observation period ends in December 2003. However, as the time lag between the corresponding date of information and the extraction from the BSt for our analysis amounted to only eight months, the relation between reported and forecasted data has to be checked and should be considered when interpreting the estimated treatment effects. Based on the results of Fröhlich, Kaimer, and Stamm (2004), the share of forecasted data used in the analyses amounts to between four and ten percent at maximum.

We define only regular employment as success, whereas all other kinds of subsidised employment or participation in ALMP programmes are defined as failure. While this definition may conflict with the in-

\footnotetext{
${ }^{21}$ It should be noted that the regional indicators are based on information from a different point in time than the data on the programmes. However, the clustering provides the most comprehensive and at the same time parsimonious characterisation of the labour market differences. In addition, we assume that the situation of the individual labour office districts did not change much over a few years.
} 
Tab. B.2: Overview on DAtA Sources AND ATtRibutes

\begin{tabular}{|c|c|c|}
\hline \multicolumn{2}{|c|}{ Data Source } & Attributes \\
\hline \multirow[t]{5}{*}{$\mathrm{MTG}^{1}$} & BewA $^{2}$ & $\begin{array}{l}\text { a) Socio-demographic: age, gender, marital status, number of children, citi- } \\
\text { zenship, asylum-seeker, health restrictions }\end{array}$ \\
\hline & & $\begin{array}{l}\text { b) Qualification: graduation (schooling), professional training, occupational } \\
\text { group, work experience, appraisal of qualification by the placement officer, de- } \\
\text { sired occupation, desired work time }\end{array}$ \\
\hline & & $\begin{array}{l}\text { c) Labour Market History: duration of unemployment, duration of last job, } \\
\text { number of job offers, occupational rehabilitation, programme participation be- } \\
\text { fore unemployment }\end{array}$ \\
\hline & $\mathrm{ST} 11^{3}$ & $\begin{array}{l}\text { d) Programme: institution receiving the subsidy, activity sector, time of quali- } \\
\text { fication and/or practical training during programme, beginning and end of pro- } \\
\text { gramme (payment of subsidy), entry to and departure from participation, dura- } \\
\text { tion of programme }\end{array}$ \\
\hline & & e) Regional Information: Types of comparable labour office districts by FEA \\
\hline
\end{tabular}

stitutional setting, it reflects the economic point of view to measure the integration ability of the JCS into non-subsidised employment. To identify spells of regular employment without further promotion, we use the excerpted information of the final version of the MTG on the individual's time spent in ALMP programmes.

For the empirical analysis, we have drawn a random sample of individuals who started a subsidised employment programme, i.e., a JCS or structural adjustment scheme, in the six different months July 2000, September 2000, November 2000, January 2001, March 2001 and May 2001. The comparison group was constructed in a similar way. Based on the information of the BewA-population in the respective months before the participants started their programmes, six random samples were drawn. The proportions of these original samples were 20:1. In other words, for each participant from MTG starting a JCS in July 2000, we draw 20 non-participants from BewA of June 2000 as potential comparisons, and so on. By doing so, we are left with the same set of attributes for participants and potential comparison individuals except the missing programme information. A further advantage of using data on programme entries instead of entries into unemployment is the larger number of participants in the analysis. Hence, we are able to analyse programme effects with respect to several sources of heterogeneity with confidence.

The individual characteristics of the six cross-sections have been supplemented by the employment outcomes of all individuals in our samples. As described above, the relevant information has been taken from the BSt and corrected by times spent in ALMP programmes based on information of an excerpt of the MTG for the same period of time. ${ }^{22}$ However, a complete merge of the cross-section information (MTG/BewA) and the employment outcomes (BSt) was not possible for all observations, since both data sets use different iden-

\footnotetext{
${ }^{22}$ This excerpt contains solely the entry and departure dates of individuals in the different programmes sponsored by the FEA. All remaining attributes are not available for our analysis.
} 
tifiers. Whereas MTG/BewA use FEA-specific customer numbers to identify job-seeking and participating individuals, the BSt refers to the social insurance policy number (Sozialversicherungsnummer). Therefore, only in cases where this information is both available and valid can the data be merged.

Fig. B.1: Available Data for ANALYsis

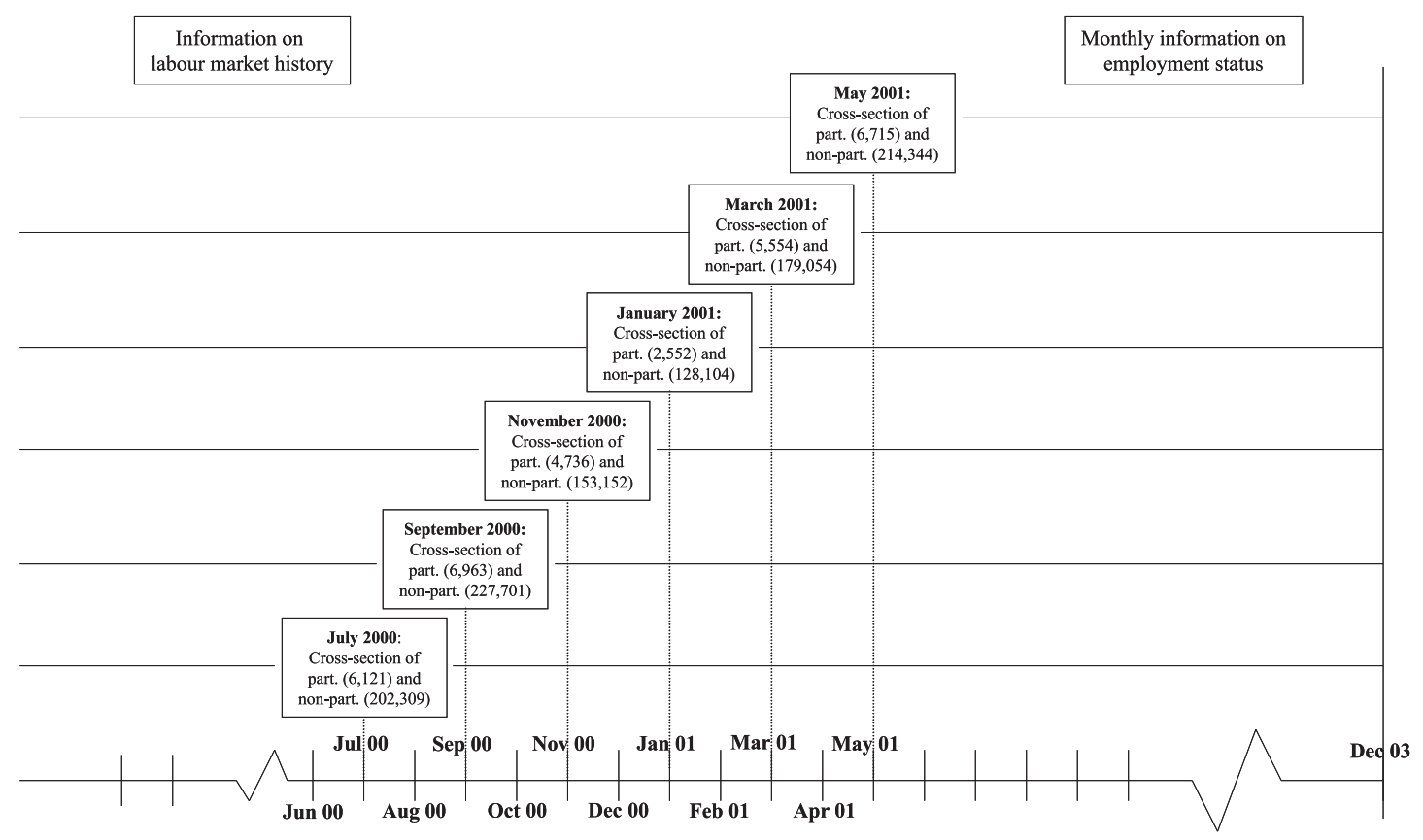

In our empirical analysis, we will evaluate the effects of JCS on regular employment only. The effects of other programmes are not considered. Thus, we have restricted the participants' data to JCS. Furthermore, to avoid issues related to education or basic vocational training we have restricted the data to persons aged 25 years and older. In addition, as early retirement may cause some trouble in the results, persons older than 55 years are excluded as well. Moreover, the labour market of the capital city is not considered in our analysis. The special situation of Berlin would require a separate estimation and interpretation of the effects of JCS for participating individuals into regular employment. Thus, East Germany covers the federal states of Mecklenburg-Western Pomerania, Brandenburg, Saxony, Saxony-Anhalt, and Thuringia for the rest of this study. West Germany refers to all West German federal countries.

Figure B.1 summarises the timeline of the available information and presents the resulting numbers of observations for participants and non-participants, differentiated by month of entry into the programme. The numbers of entries in the months differ. Whereas our data set contains 6,963 participants starting a JCS in September 2000, the corresponding number for January 2001 is only 2,552. Altogether, we are able to use information on 32,641 participants starting a JCS between July 2000 and May 2001 and on 1,104,664 non-participants for the evaluation of the employment effects of JCS. 


\section{Descriptive Statistics}

Tab. C.1: Means of Selected Characteristics (Men in West Germany)

\begin{tabular}{|c|c|c|c|c|c|c|c|c|}
\hline & \multicolumn{2}{|c|}{$u=1$} & \multicolumn{2}{|c|}{$u=2$} & \multicolumn{2}{|c|}{$u=3$} & \multicolumn{2}{|c|}{$u=4$} \\
\hline & Non-Part. & Part. & Non-Part. & Part. & Non-Part. & Part. & Non-Part. & Part. \\
\hline Number of Observations & 152,904 & 663 & 67,166 & 484 & 36,344 & 437 & 23,176 & 498 \\
\hline Programme Duration & & 290.4 & & 284 & & 268.6 & & 277.4 \\
\hline \multicolumn{9}{|l|}{ Age } \\
\hline 25 to 29 years & 0.17 & 0.10 & 0.15 & 0.11 & 0.13 & 0.11 & 0.12 & 0.11 \\
\hline 30 to 34 years & 0.21 & 0.17 & 0.20 & 0.17 & 0.18 & 0.15 & 0.17 & 0.13 \\
\hline 35 to 39 years & 0.20 & 0.22 & 0.20 & 0.18 & 0.20 & 0.23 & 0.19 & 0.16 \\
\hline 40 to 44 years & 0.17 & 0.19 & 0.17 & 0.20 & 0.18 & 0.17 & 0.18 & 0.20 \\
\hline 45 to 49 years & 0.13 & 0.15 & 0.14 & 0.17 & 0.15 & 0.16 & 0.16 & 0.19 \\
\hline 50 to 55 years & 0.12 & 0.17 & 0.14 & 0.17 & 0.17 & 0.18 & 0.18 & 0.20 \\
\hline Foreigner & 0.19 & 0.12 & 0.20 & 0.12 & 0.20 & 0.14 & 0.20 & 0.12 \\
\hline Asylum-seeker & 0.06 & 0.05 & 0.07 & 0.03 & 0.06 & 0.04 & 0.05 & 0.04 \\
\hline No. of placement offers & 4.58 & 10.35 & 4.80 & 10.48 & 4.89 & 10.75 & 4.87 & 11.03 \\
\hline No. of children & 0.58 & 0.52 & 0.57 & 0.56 & 0.58 & 0.67 & 0.57 & 0.55 \\
\hline Placement restrictions & 0.15 & 0.26 & 0.17 & 0.27 & 0.20 & 0.24 & 0.22 & 0.22 \\
\hline Vocational rehabilitation ${ }^{2}$ & 0.05 & 0.08 & 0.06 & 0.08 & 0.07 & 0.07 & 0.07 & 0.07 \\
\hline Health restrictions & 0.23 & 0.36 & 0.27 & 0.38 & 0.30 & 0.36 & 0.33 & 0.31 \\
\hline Marriage/ cohabitation & 0.52 & 0.42 & 0.51 & 0.49 & 0.51 & 0.47 & 0.51 & 0.44 \\
\hline Work experience & 0.93 & 0.92 & 0.93 & 0.93 & 0.93 & 0.92 & 0.93 & 0.91 \\
\hline Programme bef. unemp. ${ }^{3}$ & 0.03 & 0.35 & 0.05 & 0.40 & 0.06 & 0.36 & 0.08 & 0.38 \\
\hline Reception of UI & 0.85 & 0.84 & 0.86 & 0.77 & 0.88 & 0.78 & 0.89 & 0.72 \\
\hline \multicolumn{9}{|l|}{ Duration of Last Job } \\
\hline up to 180 days & 0.28 & 0.31 & 0.28 & 0.43 & 0.27 & 0.48 & 0.26 & 0.50 \\
\hline between 180 and 365 days & 0.18 & 0.15 & 0.15 & 0.11 & 0.12 & 0.09 & 0.11 & 0.08 \\
\hline between 366 and 730 days & 0.16 & 0.16 & 0.17 & 0.14 & 0.16 & 0.11 & 0.16 & 0.13 \\
\hline more than 730 days & 0.38 & 0.38 & 0.41 & 0.32 & 0.44 & 0.32 & 0.47 & 0.30 \\
\hline \multicolumn{9}{|l|}{ Pension } \\
\hline No pension & 1.00 & 1.00 & 1.00 & 1.00 & 0.99 & 1.00 & 0.99 & 1.00 \\
\hline Vocational disability & 0.00 & 0.00 & 0.00 & 0.00 & 0.00 & 0.00 & 0.00 & 0.00 \\
\hline Permanently unable to work & 0.00 & 0.00 & 0.00 & 0.00 & 0.00 & 0.00 & 0.00 & 0.00 \\
\hline Social plan & 0.00 & 0.00 & 0.00 & 0.00 & 0.00 & 0.00 & & \\
\hline \multicolumn{9}{|l|}{ Schooling 4} \\
\hline No school & 0.14 & 0.25 & 0.16 & 0.21 & 0.17 & 0.22 & 0.18 & 0.22 \\
\hline CSE & 0.59 & 0.56 & 0.58 & 0.57 & 0.58 & 0.59 & 0.58 & 0.59 \\
\hline O-levels & 0.14 & 0.09 & 0.13 & 0.09 & 0.12 & 0.06 & 0.12 & 0.07 \\
\hline Adv. technical college entrance ${ }^{5}$ & 0.05 & 0.03 & 0.04 & 0.04 & 0.04 & 0.03 & 0.04 & 0.03 \\
\hline A-levels & 0.09 & 0.07 & 0.08 & 0.09 & 0.09 & 0.09 & 0.08 & 0.10 \\
\hline \multicolumn{9}{|c|}{ Assessment of Individual's Qualification } \\
\hline Other & 0.51 & 0.64 & 0.54 & 0.59 & 0.56 & 0.61 & 0.57 & 0.57 \\
\hline Unskilled employee & 0.00 & 0.00 & 0.00 & 0.00 & 0.00 & 0.00 & 0.00 & 0.00 \\
\hline Skilled employee & 0.40 & 0.27 & 0.37 & 0.31 & 0.35 & 0.27 & 0.34 & 0.32 \\
\hline Ass. to technical school ${ }^{6}$ & 0.03 & 0.02 & 0.03 & 0.04 & 0.03 & 0.04 & 0.03 & 0.03 \\
\hline Ass. to adv. technical college & 0.02 & 0.02 & 0.02 & 0.03 & 0.02 & 0.04 & 0.02 & 0.03 \\
\hline Ass. to university & 0.03 & 0.04 & 0.03 & 0.04 & 0.04 & 0.03 & 0.04 & 0.06 \\
\hline Ass. to top-management & 0.00 & 0.00 & 0.00 & 0.00 & 0.00 & 0.00 & 0.00 & 0.00 \\
\hline \multicolumn{9}{|l|}{ Professional Training } \\
\hline Without compl. prof. training & 0.41 & 0.52 & 0.44 & 0.51 & 0.46 & 0.50 & 0.47 & 0.45 \\
\hline Apprenticeship (on-the-job) & 0.49 & 0.39 & 0.45 & 0.37 & 0.43 & 0.39 & 0.43 & 0.41 \\
\hline Apprenticeship (off-the job) & 0.01 & 0.01 & 0.01 & 0.01 & 0.01 & 0.01 & 0.01 & 0.02 \\
\hline Full-time vocational school & 0.01 & 0.01 & 0.01 & 0.02 & 0.01 & 0.01 & 0.01 & 0.01 \\
\hline Technical school & 0.03 & 0.02 & 0.03 & 0.03 & 0.03 & 0.03 & 0.03 & 0.02 \\
\hline Advanced technical college & 0.02 & 0.01 & 0.02 & 0.02 & 0.02 & 0.02 & 0.01 & 0.02 \\
\hline University & 0.03 & 0.03 & 0.03 & 0.04 & 0.04 & 0.04 & 0.04 & 0.06 \\
\hline \multicolumn{9}{|l|}{ Month of Treatment Start } \\
\hline July 2000 & 0.15 & 0.18 & 0.19 & 0.15 & 0.21 & 0.11 & 0.22 & 0.16 \\
\hline September 2000 & 0.18 & 0.16 & 0.18 & 0.17 & 0.22 & 0.15 & 0.23 & 0.15 \\
\hline November 2000 & 0.13 & 0.17 & 0.12 & 0.14 & 0.13 & 0.19 & 0.15 & 0.12 \\
\hline January 2001 & 0.14 & 0.17 & 0.11 & 0.18 & 0.09 & 0.15 & 0.10 & 0.13 \\
\hline March 2001 & 0.21 & 0.14 & 0.17 & 0.21 & 0.14 & 0.20 & 0.12 & 0.17 \\
\hline May 2001 & 0.19 & 0.18 & 0.24 & 0.16 & 0.21 & 0.20 & 0.17 & 0.26 \\
\hline \multicolumn{9}{|l|}{ Regional Context Variables 7} \\
\hline Cluster II & 0.23 & 0.36 & 0.26 & 0.29 & 0.29 & 0.28 & 0.32 & 0.36 \\
\hline Cluster III & 0.40 & 0.37 & 0.41 & 0.42 & 0.41 & 0.45 & 0.41 & 0.39 \\
\hline Cluster IV & 0.12 & 0.08 & 0.11 & 0.06 & 0.11 & 0.08 & 0.11 & 0.08 \\
\hline Cluster V & 0.25 & 0.18 & 0.21 & 0.23 & 0.18 & 0.20 & 0.16 & 0.17 \\
\hline
\end{tabular}


TABLE C.1: (CONTINUED)
$u=1$
$u=2$
$u=3$
$u=4$

\begin{tabular}{|c|c|c|c|c|c|c|c|c|}
\hline & Non-Part. & Part. & Non-Part. & Part. & Non-Part. & Part. & Non-Part. & Part. \\
\hline Full-time work & 0.99 & 1.00 & 0.99 & 1.00 & 0.99 & 1.00 & 0.99 & 0.99 \\
\hline Part-time work & 0.01 & 0.00 & 0.01 & 0.00 & 0.01 & 0.00 & 0.01 & 0.01 \\
\hline Other (e.g. telework) & 0.00 & 0.00 & 0.00 & 0.00 & & & & \\
\hline \multicolumn{9}{|l|}{ Work Time (Last Job) } \\
\hline Full-time work & 0.59 & 0.50 & 0.52 & 0.54 & 0.49 & 0.56 & 0.45 & 0.53 \\
\hline Part-time work & 0.01 & 0.01 & 0.01 & 0.00 & 0.01 & 0.00 & 0.01 & 0.01 \\
\hline Not applicable & 0.41 & 0.49 & 0.47 & 0.46 & 0.50 & 0.44 & 0.55 & 0.46 \\
\hline \multicolumn{9}{|l|}{ Desired Occupation } \\
\hline Farming $^{8}$ & 0.04 & 0.13 & 0.04 & 0.10 & 0.04 & 0.11 & 0.04 & 0.07 \\
\hline Mining, mineral extraction & 0.00 & 0.00 & 0.00 & 0.00 & 0.01 & 0.00 & 0.00 & 0.00 \\
\hline Manufacturing & 0.49 & 0.48 & 0.47 & 0.50 & 0.46 & 0.52 & 0.45 & 0.49 \\
\hline Technical professions & 0.05 & 0.03 & 0.05 & 0.05 & 0.05 & 0.03 & 0.05 & 0.04 \\
\hline Service Professions & 0.40 & 0.35 & 0.41 & 0.35 & 0.42 & 0.32 & 0.42 & 0.39 \\
\hline Other occupations & 0.02 & 0.01 & 0.03 & 0.01 & 0.03 & 0.01 & 0.03 & 0.01 \\
\hline Other & 0.00 & 0.00 & 0.00 & 0.00 & 0.00 & 0.00 & 0.00 & 0.00 \\
\hline
\end{tabular}

n.a. $=$ not available

${ }^{1}$ Unemployment duration until treatment start.

2 Attendant for vocational rehabilitation.

${ }^{3}$ Similar programme before unemployment, e.g., job creation or structural adjustment scheme.

4 Schooling: CSE $=$ Certificate of Secondary Education.

${ }^{5}$ Advanced technical college entrance qualification (Fachhochschulreife)

${ }^{6}$ Ass. $=$ assimilable

7 Detailed information on regional context variables in Appendix B and Table B.1.

${ }^{8}$ Farming comprises plant cultivation, breeding and fishery.

Tab. C.2: Means of Selected Characteristics (Men in West Germany)

\begin{tabular}{|c|c|c|c|c|c|c|c|c|}
\hline & \multicolumn{2}{|c|}{$u=5$} & \multicolumn{2}{|c|}{$u=6$} & \multicolumn{2}{|c|}{$u=7$} & \multicolumn{2}{|c|}{$u=8$} \\
\hline & Non-Part. & Part. & Non-Part. & Part. & Non-Part. & Part. & Non-Part. & Part. \\
\hline Number of Observations & 15,667 & 593 & 11,692 & 288 & 9,510 & 264 & 7,686 & 206 \\
\hline Programme Duration & & 289.8 & & 267.1 & & 264.9 & & 281.3 \\
\hline \multicolumn{9}{|l|}{ Age } \\
\hline 25 to 29 years & 0.10 & 0.09 & 0.09 & 0.10 & 0.08 & 0.11 & 0.07 & 0.05 \\
\hline 30 to 34 years & 0.16 & 0.15 & 0.15 & 0.19 & 0.14 & 0.10 & 0.13 & 0.14 \\
\hline 35 to 39 years & 0.18 & 0.22 & 0.19 & 0.21 & 0.17 & 0.25 & 0.18 & 0.24 \\
\hline 40 to 44 years & 0.18 & 0.19 & 0.17 & 0.16 & 0.18 & 0.18 & 0.18 & 0.25 \\
\hline 45 to 49 years & 0.17 & 0.18 & 0.18 & 0.16 & 0.18 & 0.19 & 0.19 & 0.16 \\
\hline 50 to 55 years & 0.20 & 0.17 & 0.22 & 0.18 & 0.25 & 0.17 & 0.25 & 0.16 \\
\hline Foreigner & 0.21 & 0.10 & 0.20 & 0.11 & 0.20 & 0.13 & 0.20 & 0.11 \\
\hline Asylum-seeker & 0.05 & 0.04 & 0.05 & 0.06 & 0.05 & 0.04 & 0.05 & 0.08 \\
\hline No. of placement offers & 4.72 & 9.69 & 4.67 & 10.89 & 4.57 & 9.70 & 4.73 & 10.10 \\
\hline No. of children & 0.56 & 0.68 & 0.57 & 0.49 & 0.57 & 0.54 & 0.59 & 0.76 \\
\hline Placement restrictions & 0.23 & 0.23 & 0.24 & 0.16 & 0.24 & 0.19 & 0.26 & 0.21 \\
\hline Vocational rehabilitation $^{2}$ & 0.08 & 0.07 & 0.08 & 0.07 & 0.08 & 0.07 & 0.08 & 0.08 \\
\hline Health restrictions & 0.34 & 0.33 & 0.35 & 0.27 & 0.35 & 0.30 & 0.36 & 0.35 \\
\hline Marriage/ cohabitation & 0.50 & 0.48 & 0.51 & 0.47 & 0.51 & 0.47 & 0.50 & 0.50 \\
\hline Work experience & 0.93 & 0.93 & 0.93 & 0.91 & 0.93 & 0.95 & 0.93 & 0.91 \\
\hline Programme bef. unemp. ${ }^{3}$ & 0.07 & 0.37 & 0.08 & 0.33 & 0.08 & 0.34 & 0.08 & 0.33 \\
\hline Reception of UI & 0.90 & 0.72 & 0.91 & 0.82 & 0.91 & 0.83 & 0.91 & 0.78 \\
\hline \multicolumn{9}{|l|}{ Duration of Last Job } \\
\hline up to 180 days & 0.24 & 0.49 & 0.23 & 0.55 & 0.24 & 0.56 & 0.23 & 0.51 \\
\hline between 180 and 365 days & 0.11 & 0.07 & 0.11 & 0.06 & 0.11 & 0.07 & 0.10 & 0.06 \\
\hline between 366 and 730 days & 0.15 & 0.13 & 0.14 & 0.10 & 0.14 & 0.09 & 0.13 & 0.14 \\
\hline more than 730 days & 0.49 & 0.31 & 0.51 & 0.29 & 0.52 & 0.28 & 0.54 & 0.29 \\
\hline \multicolumn{9}{|l|}{ Pension } \\
\hline No pension & 0.99 & 1.00 & 0.99 & 1.00 & 0.99 & 1.00 & 0.99 & 1.00 \\
\hline Vocational disability & 0.01 & 0.00 & 0.01 & 0.00 & 0.00 & 0.00 & 0.01 & 0.00 \\
\hline Permanently unable to work & 0.00 & 0.00 & 0.00 & 0.00 & 0.00 & 0.00 & 0.00 & 0.00 \\
\hline Social plan & & & 0.00 & 0.00 & & & 0.00 & 0.00 \\
\hline \multicolumn{9}{|l|}{ Schooling $^{4}$} \\
\hline No school & 0.19 & 0.21 & 0.20 & 0.20 & 0.20 & 0.26 & 0.20 & 0.20 \\
\hline $\mathrm{CSE}$ & 0.59 & 0.53 & 0.59 & 0.59 & 0.59 & 0.57 & 0.60 & 0.56 \\
\hline O-levels & 0.11 & 0.09 & 0.11 & 0.07 & 0.10 & 0.06 & 0.10 & 0.06 \\
\hline Adv. technical college entrance ${ }^{5}$ & 0.04 & 0.06 & 0.03 & 0.05 & 0.03 & 0.03 & 0.03 & 0.05 \\
\hline A-levels & 0.08 & 0.12 & 0.07 & 0.08 & 0.07 & 0.08 & 0.07 & 0.13 \\
\hline
\end{tabular}


TABLE C.2: (CONTINUED)

$u=5$

$u=6$

$u=7$

$u=8$

\begin{tabular}{|c|c|c|c|c|c|c|c|c|}
\hline & Non-Part. & Part. & Non-Part. & Part. & Non-Part. & Part. & Non-Part. & Part. \\
\hline \multicolumn{9}{|c|}{ Assessment of Individual's Qualification } \\
\hline Other & 0.59 & 0.56 & 0.60 & 0.63 & 0.61 & 0.64 & 0.62 & 0.58 \\
\hline Unskilled employee & 0.00 & 0.00 & 0.00 & 0.00 & 0.00 & 0.00 & 0.00 & 0.00 \\
\hline Skilled employee & 0.33 & 0.30 & 0.32 & 0.25 & 0.31 & 0.28 & 0.31 & 0.28 \\
\hline Ass. to technical school ${ }^{6}$ & 0.03 & 0.03 & 0.03 & 0.04 & 0.02 & 0.01 & 0.02 & 0.01 \\
\hline Ass. to adv. technical college & 0.02 & 0.06 & 0.02 & 0.03 & 0.02 & 0.04 & 0.02 & 0.08 \\
\hline Ass. to university & 0.03 & 0.06 & 0.03 & 0.05 & 0.03 & 0.03 & 0.03 & 0.05 \\
\hline Ass. to top-management & 0.00 & 0.00 & 0.00 & 0.00 & 0.00 & 0.00 & 0.00 & 0.00 \\
\hline \multicolumn{9}{|l|}{ Professional Training } \\
\hline Without compl. prof. training & 0.48 & 0.43 & 0.49 & 0.57 & 0.50 & 0.48 & 0.49 & 0.47 \\
\hline Apprenticeship (on-the-job) & 0.42 & 0.42 & 0.42 & 0.28 & 0.41 & 0.41 & 0.42 & 0.36 \\
\hline Apprenticeship (off-the job) & 0.01 & 0.02 & 0.01 & 0.02 & 0.01 & 0.02 & 0.01 & 0.01 \\
\hline Full-time vocational school & 0.01 & 0.01 & 0.01 & 0.01 & 0.01 & 0.01 & 0.01 & 0.01 \\
\hline Technical school & 0.03 & 0.03 & 0.02 & 0.05 & 0.02 & 0.02 & 0.02 & 0.02 \\
\hline Advanced technical college & 0.01 & 0.03 & 0.01 & 0.02 & 0.01 & 0.03 & 0.02 & 0.06 \\
\hline University & 0.03 & 0.06 & 0.03 & 0.05 & 0.03 & 0.03 & 0.03 & 0.06 \\
\hline \multicolumn{9}{|l|}{ Month of Treatment Start } \\
\hline July 2000 & 0.22 & 0.19 & 0.21 & 0.14 & 0.22 & 0.22 & 0.22 & 0.23 \\
\hline September 2000 & 0.24 & 0.15 & 0.22 & 0.25 & 0.23 & 0.22 & 0.23 & 0.17 \\
\hline November 2000 & 0.15 & 0.14 & 0.14 & 0.11 & 0.14 & 0.14 & 0.14 & 0.15 \\
\hline January 2001 & 0.11 & 0.10 & 0.10 & 0.12 & 0.10 & 0.11 & 0.11 & 0.08 \\
\hline March 2001 & 0.13 & 0.17 & 0.14 & 0.16 & 0.14 & 0.16 & 0.13 & 0.19 \\
\hline May 2001 & 0.16 & 0.24 & 0.18 & 0.21 & 0.17 & 0.15 & 0.17 & 0.17 \\
\hline \multicolumn{9}{|l|}{ Regional Context Variables $^{7}$} \\
\hline Cluster II & 0.33 & 0.35 & 0.34 & 0.31 & 0.36 & 0.33 & 0.37 & 0.41 \\
\hline Cluster III & 0.41 & 0.42 & 0.40 & 0.44 & 0.40 & 0.46 & 0.39 & 0.42 \\
\hline Cluster IV & 0.11 & 0.06 & 0.11 & 0.08 & 0.10 & 0.08 & 0.10 & 0.03 \\
\hline Cluster V & 0.15 & 0.16 & 0.15 & 0.16 & 0.14 & 0.13 & 0.14 & 0.14 \\
\hline \multicolumn{9}{|l|}{ Desired Work time } \\
\hline Full-time work & 0.99 & 0.99 & 0.99 & 0.99 & 0.99 & 1.00 & 0.99 & 1.00 \\
\hline Part-time work & 0.01 & 0.01 & 0.01 & 0.01 & 0.01 & 0.00 & 0.01 & 0.00 \\
\hline \multicolumn{9}{|l|}{ Other (e.g. telework) } \\
\hline \multicolumn{9}{|l|}{ Work Time (Last Job) } \\
\hline Full-time work & 0.40 & 0.59 & 0.38 & 0.53 & 0.37 & 0.54 & 0.34 & 0.50 \\
\hline Part-time work & 0.01 & 0.01 & 0.00 & 0.01 & 0.01 & 0.01 & 0.00 & 0.01 \\
\hline Not applicable & 0.59 & 0.39 & 0.61 & 0.46 & 0.62 & 0.45 & 0.66 & 0.48 \\
\hline \multicolumn{9}{|l|}{ Desired Occupation } \\
\hline Farming $^{8}$ & 0.04 & 0.10 & 0.04 & 0.14 & 0.04 & 0.14 & 0.05 & 0.13 \\
\hline Mining, mineral extraction & 0.01 & 0.00 & 0.01 & 0.00 & 0.01 & 0.00 & 0.01 & 0.00 \\
\hline Manufacturing & 0.45 & 0.46 & 0.45 & 0.47 & 0.45 & 0.47 & 0.45 & 0.43 \\
\hline Technical professions & 0.04 & 0.04 & 0.04 & 0.04 & 0.04 & 0.02 & 0.04 & 0.02 \\
\hline Service Professions & 0.43 & 0.40 & 0.43 & 0.35 & 0.43 & 0.38 & 0.42 & 0.41 \\
\hline Other occupations & 0.03 & 0.00 & 0.03 & 0.00 & 0.03 & 0.00 & 0.03 & 0.00 \\
\hline Other & 0.00 & 0.00 & 0.00 & 0.00 & 0.00 & 0.00 & 0.00 & 0.00 \\
\hline
\end{tabular}

n.a. = not available

${ }^{1}$ Unemployment duration until treatment start.

2 Attendant for vocational rehabilitation.

${ }^{3}$ Similar programme before unemployment, e.g., job creation or structural adjustment scheme.

${ }^{4}$ Schooling: CSE = Certificate of Secondary Education.

${ }^{5}$ Advanced technical college entrance qualification (Fachhochschulreife)

${ }^{6}$ Ass. $=$ assimilable

7 Detailed information on regional context variables in Appendix B and Table B.1.

${ }^{8}$ Farming comprises plant cultivation, breeding and fishery.

Tab. C.3: Means of Selected Characteristics (Men in West Germany)

\begin{tabular}{|c|c|c|c|c|c|c|c|c|}
\hline & \multicolumn{2}{|c|}{$u=9$} & \multicolumn{2}{|c|}{$u=10$} & \multicolumn{2}{|c|}{$u=11$} & \multicolumn{2}{|c|}{$u=12$} \\
\hline & Non-Part. & Part. & Non-Part. & Part. & Non-Part. & Part. & Non-Part. & Part. \\
\hline Number of Observations & 6,113 & 278 & 4,900 & 190 & 4,127 & 144 & 3,476 & 120 \\
\hline Programme Duration & & 297.7 & & 292.7 & & 272 & & 288.7 \\
\hline Age & & & & & & & & \\
\hline 25 to 29 years & 0.05 & 0.10 & 0.05 & 0.12 & 0.05 & 0.08 & 0.04 & 0.12 \\
\hline 30 to 34 years & 0.12 & 0.15 & 0.11 & 0.16 & 0.11 & 0.17 & 0.11 & 0.17 \\
\hline 35 to 39 years & 0.17 & 0.21 & 0.17 & 0.19 & 0.15 & 0.20 & 0.15 & 0.15 \\
\hline 40 to 44 years & 0.18 & 0.22 & 0.19 & 0.19 & 0.19 & 0.18 & 0.18 & 0.28 \\
\hline
\end{tabular}


TABle C.3: (CONTINUED)
$u=9$
$u=10$
$u=11$
$u=12$

\begin{tabular}{|c|c|c|c|c|c|c|c|c|}
\hline & Non-Part. & Part. & Non-Part. & Part. & Non-Part. & Part. & Non-Part. & Part. \\
\hline 45 to 49 years & 0.20 & 0.16 & 0.19 & 0.16 & 0.21 & 0.15 & 0.21 & 0.17 \\
\hline 50 to 55 years & 0.28 & 0.17 & 0.28 & 0.17 & 0.29 & 0.22 & 0.31 & 0.13 \\
\hline Foreigner & 0.20 & 0.11 & 0.20 & 0.15 & 0.19 & 0.15 & 0.20 & 0.12 \\
\hline Asylum-seeker & 0.05 & 0.05 & 0.04 & 0.07 & 0.05 & 0.06 & 0.04 & 0.05 \\
\hline No. of placement offers & 3.97 & 9.27 & 3.72 & 10.72 & 3.34 & 9.58 & 3.15 & 12.12 \\
\hline No. of children & 0.58 & 0.66 & 0.61 & 0.72 & 0.57 & 0.51 & 0.60 & 0.71 \\
\hline Placement restrictions & 0.27 & 0.22 & 0.29 & 0.21 & 0.29 & 0.24 & 0.29 & 0.22 \\
\hline Vocational rehabilitation $^{2}$ & 0.08 & 0.08 & 0.09 & 0.04 & 0.09 & 0.06 & 0.09 & 0.08 \\
\hline Health restrictions & 0.37 & 0.31 & 0.39 & 0.33 & 0.39 & 0.31 & 0.39 & 0.28 \\
\hline Marriage/ cohabitation & 0.51 & 0.44 & 0.51 & 0.45 & 0.50 & 0.42 & 0.50 & 0.46 \\
\hline Work experience & 0.92 & 0.93 & 0.93 & 0.92 & 0.93 & 0.96 & 0.92 & 0.91 \\
\hline Programme bef. unemp. ${ }^{3}$ & 0.08 & 0.40 & 0.09 & 0.27 & 0.09 & 0.34 & 0.09 & 0.38 \\
\hline Reception of UI & 0.91 & 0.80 & 0.92 & 0.85 & 0.91 & 0.83 & 0.93 & 0.87 \\
\hline \multicolumn{9}{|l|}{ Duration of Last Job } \\
\hline up to 180 days & 0.23 & 0.60 & 0.22 & 0.62 & 0.24 & 0.66 & 0.25 & 0.58 \\
\hline between 180 and 365 days & 0.09 & 0.09 & 0.10 & 0.08 & 0.09 & 0.10 & 0.09 & 0.05 \\
\hline between 366 and 730 days & 0.12 & 0.04 & 0.11 & 0.06 & 0.11 & 0.07 & 0.11 & 0.04 \\
\hline more than 730 days & 0.56 & 0.27 & 0.57 & 0.24 & 0.56 & 0.17 & 0.55 & 0.33 \\
\hline \multicolumn{9}{|l|}{ Pension } \\
\hline No pension & 0.99 & 1.00 & 0.99 & 1.00 & 0.98 & 0.99 & 0.99 & 1.00 \\
\hline Vocational disability & 0.01 & 0.00 & 0.01 & 0.00 & 0.01 & 0.01 & 0.01 & 0.00 \\
\hline Permanently unable to work & 0.00 & 0.00 & 0.00 & 0.00 & 0.01 & 0.00 & 0.01 & 0.00 \\
\hline Social plan & & & 0.00 & 0.00 & & & & \\
\hline \multicolumn{9}{|l|}{ Schooling 4} \\
\hline No school & 0.20 & 0.22 & 0.21 & 0.27 & 0.21 & 0.26 & 0.22 & 0.30 \\
\hline CSE & 0.60 & 0.58 & 0.61 & 0.62 & 0.60 & 0.58 & 0.61 & 0.51 \\
\hline O-levels & 0.10 & 0.07 & 0.09 & 0.05 & 0.09 & 0.07 & 0.08 & 0.09 \\
\hline Adv. technical college entrance ${ }^{5}$ & 0.04 & 0.05 & 0.03 & 0.02 & 0.03 & 0.02 & 0.02 & 0.04 \\
\hline A-levels & 0.07 & 0.09 & 0.07 & 0.04 & 0.06 & 0.07 & 0.07 & 0.06 \\
\hline \multicolumn{9}{|c|}{ Assessment of Individual's Qualification } \\
\hline Other & 0.62 & 0.61 & 0.63 & 0.71 & 0.64 & 0.72 & 0.64 & 0.73 \\
\hline Unskilled employee & 0.00 & 0.00 & 0.00 & 0.00 & 0.00 & 0.00 & 0.00 & 0.00 \\
\hline Skilled employee & 0.30 & 0.26 & 0.30 & 0.25 & 0.29 & 0.20 & 0.29 & 0.19 \\
\hline Ass. to technical school ${ }^{6}$ & 0.02 & 0.04 & 0.02 & 0.01 & 0.02 & 0.02 & 0.02 & 0.03 \\
\hline Ass. to adv. technical college & 0.02 & 0.04 & 0.02 & 0.03 & 0.02 & 0.01 & 0.02 & 0.04 \\
\hline Ass. to university & 0.03 & 0.05 & 0.02 & 0.02 & 0.02 & 0.05 & 0.02 & 0.01 \\
\hline Ass. to top-management & 0.00 & 0.00 & 0.00 & 0.00 & 0.00 & 0.00 & 0.00 & 0.00 \\
\hline \multicolumn{9}{|l|}{ Professional Training } \\
\hline Without compl. prof. training & 0.50 & 0.52 & 0.50 & 0.56 & 0.51 & 0.58 & 0.52 & 0.63 \\
\hline Apprenticeship (on-the-job) & 0.42 & 0.33 & 0.42 & 0.36 & 0.42 & 0.33 & 0.40 & 0.28 \\
\hline Apprenticeship (off-the job) & 0.01 & 0.01 & 0.01 & 0.02 & 0.01 & 0.01 & 0.00 & 0.01 \\
\hline Full-time vocational school & 0.01 & 0.01 & 0.01 & 0.01 & 0.01 & 0.00 & 0.01 & 0.02 \\
\hline Technical school & 0.02 & 0.04 & 0.02 & 0.01 & 0.02 & 0.02 & 0.02 & 0.03 \\
\hline Advanced technical college & 0.01 & 0.02 & 0.01 & 0.02 & 0.01 & 0.01 & 0.01 & 0.03 \\
\hline University & 0.03 & 0.06 & 0.03 & 0.02 & 0.02 & 0.06 & 0.02 & 0.01 \\
\hline \multicolumn{9}{|l|}{ Month of Treatment Start } \\
\hline July 2000 & 0.21 & 0.24 & 0.18 & 0.22 & 0.22 & 0.16 & 0.20 & 0.15 \\
\hline September 2000 & 0.22 & 0.23 & 0.23 & 0.19 & 0.22 & 0.15 & 0.24 & 0.17 \\
\hline November 2000 & 0.15 & 0.13 & 0.15 & 0.15 & 0.14 & 0.15 & 0.15 & 0.18 \\
\hline January 2001 & 0.11 & 0.10 & 0.11 & 0.09 & 0.12 & 0.15 & 0.10 & 0.12 \\
\hline March 2001 & 0.13 & 0.14 & 0.14 & 0.21 & 0.14 & 0.21 & 0.13 & 0.15 \\
\hline May 2001 & 0.17 & 0.15 & 0.19 & 0.13 & 0.17 & 0.19 & 0.19 & 0.24 \\
\hline \multicolumn{9}{|l|}{ Regional Context Variables $^{7}$} \\
\hline Cluster II & 0.37 & 0.38 & 0.38 & 0.40 & 0.36 & 0.42 & 0.38 & 0.51 \\
\hline Cluster III & 0.39 & 0.42 & 0.38 & 0.42 & 0.41 & 0.45 & 0.39 & 0.37 \\
\hline Cluster IV & 0.11 & 0.06 & 0.11 & 0.07 & 0.10 & 0.05 & 0.10 & 0.06 \\
\hline Cluster V & 0.13 & 0.14 & 0.13 & 0.11 & 0.13 & 0.08 & 0.12 & 0.07 \\
\hline \multicolumn{9}{|l|}{ Desired Work Time } \\
\hline Full-time work & 0.99 & 1.00 & 0.99 & 0.99 & 0.99 & 1.00 & 0.99 & 1.00 \\
\hline Part-time work & 0.01 & 0.00 & 0.01 & 0.01 & 0.01 & 0.00 & 0.01 & 0.00 \\
\hline \multicolumn{9}{|l|}{ Other (e.g. telework) } \\
\hline \multicolumn{9}{|l|}{ Work Time (Last Job) } \\
\hline Full-time work & 0.30 & 0.59 & 0.28 & 0.53 & 0.30 & 0.57 & 0.30 & 0.49 \\
\hline Part-time work & 0.00 & 0.01 & 0.00 & 0.01 & 0.00 & 0.01 & 0.00 & 0.01 \\
\hline Not applicable & 0.69 & 0.41 & 0.72 & 0.46 & 0.69 & 0.42 & 0.69 & 0.50 \\
\hline Desired Occupation & & & & & & & & \\
\hline Farming 8 & 0.04 & 0.17 & 0.04 & 0.12 & 0.05 & 0.13 & 0.05 & 0.09 \\
\hline Mining, mineral extraction & 0.01 & 0.00 & 0.01 & 0.00 & 0.01 & 0.00 & 0.01 & 0.00 \\
\hline Manufacturing & 0.45 & 0.42 & 0.44 & 0.52 & 0.46 & 0.53 & 0.45 & 0.53 \\
\hline
\end{tabular}


TABLE C.3: (CONTINUED)

$u=9$

$u=10$

$u=11$

$u=12$

Non-Part. Part. Non-Part. Part. Non-Part. Part. Non-Part. Part.

\begin{tabular}{|c|c|c|c|c|c|c|c|c|}
\hline Technical professions & 0.04 & 0.03 & 0.04 & 0.00 & 0.04 & 0.02 & 0.04 & 0.02 \\
\hline Service Professions & 0.44 & 0.37 & 0.44 & 0.36 & 0.42 & 0.31 & 0.43 & 0.36 \\
\hline Other occupations & 0.02 & 0.00 & 0.03 & 0.01 & 0.03 & 0.00 & 0.03 & 0.00 \\
\hline Other & 0.00 & 0.00 & 0.00 & 0.00 & 0.00 & 0.00 & 0.00 & 0.00 \\
\hline
\end{tabular}

n.a. = not available

${ }^{1}$ Unemployment duration until treatment start.

2 Attendant for vocational rehabilitation.

3 Similar programme before unemployment, e.g., job creation or structural adjustment scheme.

${ }^{4}$ Schooling: $\mathrm{CSE}=$ Certificate of Secondary Education.

${ }^{5}$ Advanced technical college entrance qualification (Fachhochschulreife)

6 Ass. = assimilable

${ }^{7}$ Detailed information on regional context variables in Appendix B and Table B.1.

8 Farming comprises plant cultivation, breeding and fishery.

Tab. C.4: Means of Selected Characteristics (Women in West Germany)

\begin{tabular}{|c|c|c|c|c|c|c|c|c|}
\hline & \multicolumn{2}{|c|}{$u=1$} & \multicolumn{2}{|c|}{$u=2$} & \multicolumn{2}{|c|}{$u=3$} & \multicolumn{2}{|c|}{$u=4$} \\
\hline & Non-Part. & Part. & Non-Part. & Part. & Non-Part. & Part. & Non-Part. & Part. \\
\hline Number of Observations & 120,891 & 302 & 58,204 & 240 & 33,214 & 258 & 22,231 & 327 \\
\hline Programme Duration & & 311.1 & & 305.2 & & 292.4 & & 300.4 \\
\hline \multicolumn{9}{|l|}{ Age } \\
\hline 25 to 29 years & 0.14 & 0.09 & 0.12 & 0.08 & 0.10 & 0.07 & 0.10 & 0.09 \\
\hline 30 to 34 years & 0.20 & 0.18 & 0.19 & 0.19 & 0.19 & 0.19 & 0.19 & 0.13 \\
\hline 35 to 39 years & 0.21 & 0.26 & 0.21 & 0.23 & 0.21 & 0.18 & 0.21 & 0.23 \\
\hline 40 to 44 years & 0.18 & 0.18 & 0.17 & 0.17 & 0.18 & 0.25 & 0.18 & 0.22 \\
\hline 45 to 49 years & 0.14 & 0.15 & 0.15 & 0.17 & 0.15 & 0.17 & 0.16 & 0.18 \\
\hline 50 to 55 years & 0.13 & 0.14 & 0.15 & 0.16 & 0.16 & 0.15 & 0.17 & 0.16 \\
\hline Foreigner & 0.12 & 0.05 & 0.13 & 0.09 & 0.13 & 0.05 & 0.13 & 0.07 \\
\hline Asylum-seeker & 0.06 & 0.06 & 0.07 & 0.02 & 0.06 & 0.04 & 0.06 & 0.04 \\
\hline No. of placement offers & 3.09 & 8.20 & 3.01 & 9.15 & 2.94 & 9.26 & 2.86 & 9.73 \\
\hline No. of children & 0.79 & 0.83 & 0.85 & 0.75 & 0.89 & 0.82 & 0.90 & 0.79 \\
\hline Placement restrictions & 0.11 & 0.20 & 0.12 & 0.16 & 0.13 & 0.17 & 0.14 & 0.12 \\
\hline Vocational rehabilitation $^{2}$ & 0.03 & 0.05 & 0.03 & 0.06 & 0.03 & 0.07 & 0.03 & 0.03 \\
\hline Health restrictions & 0.19 & 0.29 & 0.20 & 0.26 & 0.22 & 0.26 & 0.22 & 0.20 \\
\hline Marriage/ cohabitation & 0.61 & 0.52 & 0.65 & 0.48 & 0.67 & 0.53 & 0.69 & 0.48 \\
\hline Work experience & 0.92 & 0.89 & 0.93 & 0.90 & 0.93 & 0.93 & 0.93 & 0.93 \\
\hline Programme bef. unemp. ${ }^{3}$ & 0.02 & 0.31 & 0.02 & 0.30 & 0.03 & 0.33 & 0.04 & 0.37 \\
\hline Reception of UI & 0.77 & 0.79 & 0.78 & 0.77 & 0.80 & 0.77 & 0.81 & 0.68 \\
\hline \multicolumn{9}{|l|}{ Duration of Last Job } \\
\hline up to 180 days & 0.28 & 0.31 & 0.27 & 0.40 & 0.25 & 0.42 & 0.24 & 0.44 \\
\hline between 180 and 365 days & 0.12 & 0.09 & 0.09 & 0.12 & 0.08 & 0.09 & 0.07 & 0.07 \\
\hline between 366 and 730 days & 0.14 & 0.13 & 0.13 & 0.13 & 0.13 & 0.11 & 0.12 & 0.10 \\
\hline more than 730 days & 0.46 & 0.47 & 0.50 & 0.35 & 0.54 & 0.38 & 0.57 & 0.40 \\
\hline \multicolumn{9}{|l|}{ Pension } \\
\hline No pension & 1.00 & 1.00 & 1.00 & 1.00 & 1.00 & 1.00 & 1.00 & 1.00 \\
\hline Vocational disability & 0.00 & 0.00 & 0.00 & 0.00 & 0.00 & 0.00 & 0.00 & 0.00 \\
\hline Permanently unable to work & 0.00 & 0.00 & 0.00 & 0.00 & 0.00 & 0.00 & 0.00 & 0.00 \\
\hline Social plan & & & & & 0.00 & 0.00 & & \\
\hline \multicolumn{9}{|l|}{ Schooling $^{4}$} \\
\hline No school & 0.08 & 0.08 & 0.09 & 0.07 & 0.10 & 0.08 & 0.10 & 0.08 \\
\hline CSE & 0.48 & 0.41 & 0.49 & 0.39 & 0.49 & 0.41 & 0.50 & 0.41 \\
\hline O-levels & 0.26 & 0.20 & 0.25 & 0.21 & 0.25 & 0.20 & 0.24 & 0.21 \\
\hline Adv. technical college entrance ${ }^{5}$ & 0.05 & 0.11 & 0.05 & 0.12 & 0.05 & 0.09 & 0.05 & 0.09 \\
\hline A-levels & 0.13 & 0.21 & 0.12 & 0.21 & 0.11 & 0.21 & 0.12 & 0.22 \\
\hline \multicolumn{9}{|c|}{ Assessment of Individual's Qualification } \\
\hline Other & 0.44 & 0.39 & 0.46 & 0.33 & 0.47 & 0.39 & 0.47 & 0.37 \\
\hline Unskilled employee & 0.00 & 0.00 & 0.00 & 0.00 & 0.00 & 0.00 & 0.00 & 0.00 \\
\hline Skilled employee & 0.47 & 0.36 & 0.46 & 0.43 & 0.45 & 0.38 & 0.44 & 0.38 \\
\hline Ass. to technical school ${ }^{6}$ & 0.01 & 0.02 & 0.01 & 0.01 & 0.01 & 0.01 & 0.01 & 0.04 \\
\hline Ass. to adv. technical college & 0.02 & 0.09 & 0.03 & 0.13 & 0.03 & 0.13 & 0.03 & 0.10 \\
\hline Ass. to university & 0.05 & 0.14 & 0.04 & 0.11 & 0.04 & 0.09 & 0.04 & 0.11 \\
\hline Ass. to top-management & 0.01 & 0.00 & 0.00 & 0.00 & 0.00 & 0.00 & 0.00 & 0.00 \\
\hline \multicolumn{9}{|l|}{ Professional Training } \\
\hline Without compl. prof. training & 0.35 & 0.33 & 0.37 & 0.29 & 0.38 & 0.30 & 0.38 & 0.31 \\
\hline Apprenticeship (on-the-job) & 0.49 & 0.35 & 0.47 & 0.38 & 0.47 & 0.40 & 0.46 & 0.37 \\
\hline
\end{tabular}


TABLE C.4: (CONTINUED)
$u=1$
$u=2$
$u=3$
$u=4$

\begin{tabular}{|c|c|c|c|c|c|c|c|c|}
\hline & Non-Part. & Part. & Non-Part. & Part. & Non-Part. & Part. & Non-Part. & Part. \\
\hline Apprenticeship (off-the job) & 0.02 & 0.04 & 0.01 & 0.02 & 0.01 & 0.02 & 0.01 & 0.01 \\
\hline Full-time vocational school & 0.03 & 0.02 & 0.03 & 0.02 & 0.03 & 0.05 & 0.03 & 0.03 \\
\hline Technical school & 0.05 & 0.06 & 0.05 & 0.10 & 0.04 & 0.03 & 0.05 & 0.09 \\
\hline Advanced technical college & 0.02 & 0.08 & 0.02 & 0.10 & 0.02 & 0.09 & 0.02 & 0.07 \\
\hline University & 0.05 & 0.13 & 0.05 & 0.08 & 0.04 & 0.10 & 0.05 & 0.11 \\
\hline \multicolumn{9}{|l|}{ Month of Treatment Start } \\
\hline July 2000 & 0.16 & 0.17 & 0.20 & 0.14 & 0.20 & 0.13 & 0.24 & 0.14 \\
\hline September 2000 & 0.20 & 0.20 & 0.20 & 0.21 & 0.23 & 0.17 & 0.24 & 0.22 \\
\hline November 2000 & 0.15 & 0.18 & 0.13 & 0.21 & 0.13 & 0.21 & 0.14 & 0.17 \\
\hline January 2001 & 0.12 & 0.16 & 0.12 & 0.13 & 0.10 & 0.18 & 0.10 & 0.12 \\
\hline March 2001 & 0.17 & 0.12 & 0.16 & 0.19 & 0.14 & 0.16 & 0.12 & 0.17 \\
\hline May 2001 & 0.20 & 0.18 & 0.20 & 0.13 & 0.20 & 0.15 & 0.16 & 0.17 \\
\hline \multicolumn{9}{|l|}{ Regional Context Variables $^{7}$} \\
\hline Cluster II & 0.22 & 0.31 & 0.22 & 0.30 & 0.24 & 0.31 & 0.26 & 0.32 \\
\hline Cluster III & 0.40 & 0.39 & 0.41 & 0.44 & 0.42 & 0.47 & 0.42 & 0.39 \\
\hline Cluster IV & 0.12 & 0.09 & 0.11 & 0.10 & 0.11 & 0.07 & 0.10 & 0.09 \\
\hline Cluster V & 0.26 & 0.20 & 0.25 & 0.17 & 0.23 & 0.14 & 0.22 & 0.20 \\
\hline \multicolumn{9}{|l|}{ Desired Work Time } \\
\hline Full-time work & 0.68 & 0.78 & 0.65 & 0.81 & 0.63 & 0.83 & 0.62 & 0.75 \\
\hline Part-time work & 0.32 & 0.22 & 0.35 & 0.19 & 0.37 & 0.17 & 0.38 & 0.25 \\
\hline Other (e.g. telework) & 0.00 & 0.00 & 0.00 & 0.00 & 0.00 & 0.00 & 0.00 & 0.00 \\
\hline \multicolumn{9}{|l|}{ Work Time (Last Job) } \\
\hline Full-time work & 0.41 & 0.44 & 0.35 & 0.41 & 0.34 & 0.43 & 0.31 & 0.43 \\
\hline Part-time work & 0.11 & 0.08 & 0.10 & 0.10 & 0.11 & 0.08 & 0.09 & 0.07 \\
\hline Not applicable & 0.48 & 0.49 & 0.54 & 0.50 & 0.56 & 0.48 & 0.60 & 0.50 \\
\hline \multicolumn{9}{|l|}{ Desired Occupation } \\
\hline Farming $^{8}$ & 0.02 & 0.04 & 0.02 & 0.05 & 0.01 & 0.04 & 0.01 & 0.03 \\
\hline Mining, mineral extraction & 0.00 & 0.00 & 0.00 & 0.00 & 0.00 & 0.00 & 0.00 & 0.00 \\
\hline Manufacturing & 0.18 & 0.16 & 0.19 & 0.14 & 0.20 & 0.22 & 0.21 & 0.14 \\
\hline Technical professions & 0.02 & 0.02 & 0.03 & 0.02 & 0.03 & 0.01 & 0.03 & 0.01 \\
\hline Service Professions & 0.76 & 0.77 & 0.75 & 0.78 & 0.74 & 0.73 & 0.73 & 0.82 \\
\hline Other occupations & 0.02 & 0.02 & 0.02 & 0.01 & 0.02 & 0.00 & 0.02 & 0.00 \\
\hline Other & 0.00 & 0.00 & 0.00 & 0.00 & 0.00 & 0.00 & 0.00 & 0.00 \\
\hline
\end{tabular}

n.a. = not available

${ }^{1}$ Unemployment duration until treatment start.

2 Attendant for vocational rehabilitation.

3 Similar programme before unemployment, e.g., job creation or structural adjustment scheme.

${ }^{4}$ Schooling: CSE = Certificate of Secondary Education.

${ }^{5}$ Advanced technical college entrance qualification (Fachhochschulreife)

${ }^{6}$ Ass. = assimilable

7 Detailed information on regional context variables in Appendix B and Table B.1.

${ }^{8}$ Farming comprises plant cultivation, breeding and fishery.

Tab. C.5: Means of Selected Characteristics (Women in West Germany)

\begin{tabular}{|c|c|c|c|c|c|c|c|c|}
\hline & \multicolumn{2}{|c|}{$u=5$} & \multicolumn{2}{|c|}{$u=6$} & \multicolumn{2}{|c|}{$u=7$} & \multicolumn{2}{|c|}{$u=8$} \\
\hline & Non-Part. & Part. & Non-Part. & Part. & Non-Part. & Part. & Non-Part. & Part. \\
\hline Number of Observations & 15,194 & 363 & 11,264 & 138 & 9,053 & 145 & 7,108 & 125 \\
\hline Programme Duration & & 324.2 & & 301.6 & & 300 & & 303.5 \\
\hline \multicolumn{9}{|l|}{ Age } \\
\hline 25 to 29 years & 0.09 & 0.06 & 0.07 & 0.04 & 0.07 & 0.09 & 0.07 & 0.06 \\
\hline 30 to 34 years & 0.17 & 0.14 & 0.15 & 0.12 & 0.15 & 0.17 & 0.14 & 0.15 \\
\hline 35 to 39 years & 0.20 & 0.22 & 0.19 & 0.28 & 0.19 & 0.24 & 0.18 & 0.21 \\
\hline 40 to 44 years & 0.17 & 0.25 & 0.17 & 0.28 & 0.17 & 0.23 & 0.17 & 0.24 \\
\hline 45 to 49 years & 0.17 & 0.21 & 0.18 & 0.14 & 0.17 & 0.16 & 0.19 & 0.17 \\
\hline 50 to 55 years & 0.20 & 0.12 & 0.24 & 0.12 & 0.26 & 0.10 & 0.26 & 0.17 \\
\hline Foreigner & 0.14 & 0.05 & 0.15 & 0.07 & 0.15 & 0.05 & 0.15 & 0.05 \\
\hline Asylum-seeker & 0.06 & 0.01 & 0.07 & 0.02 & 0.07 & 0.04 & 0.08 & 0.06 \\
\hline No. of placement offers & 2.88 & 8.59 & 2.91 & 8.12 & 2.93 & 7.86 & 2.89 & 8.67 \\
\hline No. of children & 0.91 & 0.74 & 0.88 & 0.80 & 0.87 & 0.85 & 0.87 & 0.86 \\
\hline Placement restrictions & 0.15 & 0.13 & 0.16 & 0.11 & 0.16 & 0.10 & 0.16 & 0.12 \\
\hline Vocational rehabilitation $^{2}$ & 0.03 & 0.04 & 0.03 & 0.03 & 0.03 & 0.07 & 0.03 & 0.06 \\
\hline Health restrictions & 0.24 & 0.21 & 0.25 & 0.19 & 0.25 & 0.18 & 0.25 & 0.22 \\
\hline Marriage/ cohabitation & 0.70 & 0.54 & 0.71 & 0.59 & 0.71 & 0.61 & 0.70 & 0.62 \\
\hline Work experience & 0.93 & 0.90 & 0.93 & 0.90 & 0.93 & 0.89 & 0.93 & 0.93 \\
\hline
\end{tabular}


TABLE C.5: (CONTINUED)

$\begin{array}{llll}u=5 & u=6 & u=7 & u=8\end{array}$

\begin{tabular}{|c|c|c|c|c|c|c|c|c|}
\hline & Non-Part. & Part. & Non-Part. & Part. & Non-Part. & Part. & Non-Part. & Part. \\
\hline Programme bef. unemp. ${ }^{3}$ & 0.04 & 0.38 & 0.04 & 0.28 & 0.04 & 0.28 & 0.04 & 0.27 \\
\hline Reception of UI & 0.82 & 0.67 & 0.81 & 0.78 & 0.82 & 0.82 & 0.81 & 0.78 \\
\hline \multicolumn{9}{|l|}{ Duration of Last Job } \\
\hline up to 180 days & 0.23 & 0.45 & 0.24 & 0.43 & 0.23 & 0.50 & 0.24 & 0.49 \\
\hline between 180 and 365 days & 0.07 & 0.09 & 0.07 & 0.07 & 0.07 & 0.06 & 0.06 & 0.05 \\
\hline between 366 and 730 days & 0.11 & 0.12 & 0.10 & 0.15 & 0.09 & 0.11 & 0.10 & 0.09 \\
\hline more than 730 days & 0.58 & 0.34 & 0.59 & 0.35 & 0.61 & 0.33 & 0.60 & 0.38 \\
\hline \multicolumn{9}{|l|}{ Pension } \\
\hline No pension & 1.00 & 1.00 & 1.00 & 1.00 & 1.00 & 1.00 & 1.00 & 1.00 \\
\hline Vocational disability & 0.00 & 0.00 & 0.00 & 0.00 & 0.00 & 0.00 & 0.00 & 0.00 \\
\hline Permanently unable to work & 0.00 & 0.00 & 0.00 & 0.00 & 0.00 & 0.00 & 0.00 & 0.00 \\
\hline Social plan & 0.00 & 0.00 & & & & & 0.00 & 0.00 \\
\hline \multicolumn{9}{|l|}{ Schooling ${ }^{4}$} \\
\hline No school & 0.11 & 0.06 & 0.11 & 0.07 & 0.12 & 0.06 & 0.12 & 0.05 \\
\hline CSE & 0.52 & 0.34 & 0.54 & 0.37 & 0.54 & 0.41 & 0.55 & 0.41 \\
\hline O-levels & 0.23 & 0.19 & 0.21 & 0.22 & 0.21 & 0.19 & 0.20 & 0.23 \\
\hline Adv. technical college entrance ${ }^{5}$ & 0.04 & 0.15 & 0.04 & 0.09 & 0.04 & 0.09 & 0.04 & 0.10 \\
\hline A-levels & 0.10 & 0.26 & 0.10 & 0.25 & 0.09 & 0.26 & 0.09 & 0.22 \\
\hline \multicolumn{9}{|c|}{ Assessment of Individual's Qualification } \\
\hline Other & 0.50 & 0.29 & 0.51 & 0.36 & 0.53 & 0.30 & 0.54 & 0.39 \\
\hline Unskilled employee & 0.00 & 0.00 & 0.00 & 0.00 & 0.00 & 0.00 & 0.00 & 0.00 \\
\hline Skilled employee & 0.42 & 0.42 & 0.42 & 0.38 & 0.40 & 0.40 & 0.38 & 0.43 \\
\hline Ass. to technical school ${ }^{6}$ & 0.01 & 0.01 & 0.01 & 0.03 & 0.01 & 0.02 & 0.01 & 0.00 \\
\hline Ass. to adv. technical college & 0.02 & 0.16 & 0.02 & 0.12 & 0.02 & 0.14 & 0.02 & 0.10 \\
\hline Ass. to university & 0.04 & 0.12 & 0.04 & 0.10 & 0.04 & 0.13 & 0.04 & 0.07 \\
\hline Ass. to top-management & 0.00 & 0.00 & 0.00 & 0.00 & 0.00 & 0.00 & 0.00 & 0.00 \\
\hline \multicolumn{9}{|l|}{ Professional Training } \\
\hline Without compl. prof. training & 0.41 & 0.25 & 0.42 & 0.29 & 0.43 & 0.26 & 0.44 & 0.35 \\
\hline Apprenticeship (on-the-job) & 0.45 & 0.34 & 0.45 & 0.39 & 0.44 & 0.41 & 0.43 & 0.38 \\
\hline Apprenticeship (off-the job) & 0.01 & 0.03 & 0.01 & 0.01 & 0.01 & 0.01 & 0.01 & 0.03 \\
\hline Full-time vocational school & 0.03 & 0.05 & 0.03 & 0.01 & 0.03 & 0.03 & 0.03 & 0.02 \\
\hline Technical school & 0.04 & 0.12 & 0.04 & 0.09 & 0.04 & 0.08 & 0.04 & 0.10 \\
\hline Advanced technical college & 0.02 & 0.12 & 0.02 & 0.07 & 0.02 & 0.11 & 0.02 & 0.06 \\
\hline University & 0.04 & 0.09 & 0.04 & 0.14 & 0.04 & 0.11 & 0.04 & 0.06 \\
\hline \multicolumn{9}{|l|}{ Month of Treatment Start } \\
\hline July 2000 & 0.21 & 0.15 & 0.22 & 0.14 & 0.22 & 0.14 & 0.23 & 0.18 \\
\hline September 2000 & 0.25 & 0.21 & 0.24 & 0.30 & 0.24 & 0.25 & 0.23 & 0.24 \\
\hline November 2000 & 0.15 & 0.17 & 0.15 & 0.12 & 0.15 & 0.18 & 0.15 & 0.15 \\
\hline January 2001 & 0.10 & 0.16 & 0.11 & 0.15 & 0.10 & 0.17 & 0.10 & 0.17 \\
\hline March 2001 & 0.13 & 0.13 & 0.13 & 0.15 & 0.13 & 0.12 & 0.13 & 0.18 \\
\hline May 2001 & 0.16 & 0.17 & 0.16 & 0.13 & 0.16 & 0.14 & 0.16 & 0.08 \\
\hline \multicolumn{9}{|l|}{ Regional Context Variables $^{7}$} \\
\hline Cluster II & 0.27 & 0.31 & 0.26 & 0.26 & 0.27 & 0.34 & 0.28 & 0.27 \\
\hline Cluster III & 0.43 & 0.42 & 0.43 & 0.47 & 0.43 & 0.43 & 0.44 & 0.42 \\
\hline Cluster IV & 0.10 & 0.08 & 0.10 & 0.08 & 0.10 & 0.09 & 0.09 & 0.08 \\
\hline Cluster V & 0.21 & 0.19 & 0.20 & 0.19 & 0.20 & 0.14 & 0.19 & 0.23 \\
\hline \multicolumn{9}{|l|}{ Desired Work Time } \\
\hline Full-time work & 0.62 & 0.76 & 0.64 & 0.72 & 0.66 & 0.75 & 0.67 & 0.75 \\
\hline Part-time work & 0.37 & 0.24 & 0.35 & 0.28 & 0.34 & 0.25 & 0.33 & 0.25 \\
\hline Other (e.g. telework) & 0.00 & 0.00 & 0.00 & 0.00 & 0.00 & 0.00 & 0.00 & 0.00 \\
\hline \multicolumn{9}{|l|}{ Work Time (Last Job) } \\
\hline Full-time work & 0.27 & 0.45 & 0.26 & 0.39 & 0.27 & 0.46 & 0.25 & 0.38 \\
\hline Part-time work & 0.10 & 0.11 & 0.09 & 0.12 & 0.09 & 0.12 & 0.08 & 0.12 \\
\hline Not applicable & 0.63 & 0.44 & 0.65 & 0.49 & 0.65 & 0.42 & 0.67 & 0.50 \\
\hline \multicolumn{9}{|l|}{ Desired Occupation } \\
\hline Farming $^{8}$ & 0.01 & 0.02 & 0.02 & 0.01 & 0.02 & 0.03 & 0.02 & 0.06 \\
\hline Mining, mineral extraction & 0.00 & 0.00 & 0.00 & 0.00 & 0.00 & 0.00 & 0.00 & 0.00 \\
\hline Manufacturing & 0.22 & 0.10 & 0.24 & 0.12 & 0.25 & 0.10 & 0.25 & 0.11 \\
\hline Technical professions & 0.03 & 0.02 & 0.03 & 0.01 & 0.02 & 0.03 & 0.03 & 0.05 \\
\hline Service Professions & 0.71 & 0.85 & 0.70 & 0.83 & 0.69 & 0.85 & 0.68 & 0.76 \\
\hline Other occupations & 0.02 & 0.00 & 0.02 & 0.01 & 0.02 & 0.00 & 0.02 & 0.02 \\
\hline Other & 0.00 & 0.00 & & & 0.00 & 0.00 & & \\
\hline
\end{tabular}


TABLE C.5: (CONTINUED)

$u=5$

$u=6$

$u=7$

$u=8$

Non-Part. Part. Non-Part. Part. Non-Part. Part. Non-Part. Part.

n.a. $=$ not available

${ }^{1}$ Unemployment duration until treatment start.

2 Attendant for vocational rehabilitation.

${ }^{3}$ Similar programme before unemployment, e.g., job creation or structural adjustment scheme.

4 Schooling: CSE $=$ Certificate of Secondary Education.

5 Advanced technical college entrance qualification (Fachhochschulreife)

${ }^{6}$ Ass. $=$ assimilable

${ }^{7}$ Detailed information on regional context variables in Appendix B and Table B.1.

${ }^{8}$ Farming comprises plant cultivation, breeding and fishery.

Tab. C.6: Means of Selected Characteristics (Women in West Germany)

\begin{tabular}{|c|c|c|c|c|c|c|c|c|}
\hline & \multicolumn{2}{|c|}{$u=9$} & \multicolumn{2}{|c|}{$u=10$} & \multicolumn{2}{|c|}{$u=11$} & \multicolumn{2}{|c|}{$u=12$} \\
\hline & Non-Part. & Part. & Non-Part. & Part. & Non-Part. & Part. & Non-Part. & Part. \\
\hline Number of Observations & 5,933 & 173 & 4,514 & 98 & 3,655 & 73 & 3,111 & 56 \\
\hline Programme Duration & & 335.1 & & 281.3 & & 340.4 & & 299.2 \\
\hline \multicolumn{9}{|l|}{ Age } \\
\hline 25 to 29 years & 0.05 & 0.08 & 0.05 & 0.06 & 0.04 & 0.11 & 0.04 & 0.05 \\
\hline 30 to 34 years & 0.13 & 0.13 & 0.13 & 0.12 & 0.12 & 0.07 & 0.11 & 0.11 \\
\hline 35 to 39 years & 0.18 & 0.20 & 0.17 & 0.27 & 0.17 & 0.19 & 0.18 & 0.29 \\
\hline 40 to 44 years & 0.16 & 0.27 & 0.17 & 0.11 & 0.18 & 0.22 & 0.18 & 0.18 \\
\hline 45 to 49 years & 0.18 & 0.16 & 0.19 & 0.24 & 0.18 & 0.29 & 0.18 & 0.14 \\
\hline 50 to 55 years & 0.29 & 0.17 & 0.30 & 0.19 & 0.31 & 0.12 & 0.31 & 0.23 \\
\hline Foreigner & 0.15 & 0.06 & 0.16 & 0.13 & 0.16 & 0.12 & 0.15 & 0.04 \\
\hline Asylum-seeker & 0.09 & 0.06 & 0.10 & 0.03 & 0.09 & 0.04 & 0.10 & 0.04 \\
\hline No. of placement offers & 2.56 & 8.61 & 2.37 & 10.00 & 2.29 & 8.71 & 2.22 & 9.09 \\
\hline No. of children & 0.86 & 0.80 & 0.86 & 0.71 & 0.85 & 0.90 & 0.84 & 0.86 \\
\hline Placement restrictions & 0.17 & 0.13 & 0.18 & 0.15 & 0.18 & 0.11 & 0.18 & 0.14 \\
\hline Vocational rehabilitation $^{2}$ & 0.03 & 0.03 & 0.03 & 0.03 & 0.04 & 0.03 & 0.04 & 0.09 \\
\hline Health restrictions & 0.25 & 0.19 & 0.26 & 0.28 & 0.26 & 0.18 & 0.26 & 0.25 \\
\hline Marriage/ cohabitation & 0.72 & 0.52 & 0.73 & 0.55 & 0.72 & 0.60 & 0.72 & 0.50 \\
\hline Work experience & 0.93 & 0.91 & 0.93 & 0.94 & 0.93 & 0.90 & 0.93 & 0.95 \\
\hline Programme bef. unemp. ${ }^{3}$ & 0.04 & 0.37 & 0.04 & 0.23 & 0.04 & 0.36 & 0.04 & 0.20 \\
\hline Reception of UI & 0.80 & 0.82 & 0.78 & 0.80 & 0.79 & 0.84 & 0.81 & 0.89 \\
\hline \multicolumn{9}{|l|}{ Duration of Last Job } \\
\hline up to 180 days & 0.24 & 0.55 & 0.26 & 0.50 & 0.26 & 0.60 & 0.25 & 0.45 \\
\hline between 180 and 365 days & 0.06 & 0.05 & 0.05 & 0.04 & 0.06 & 0.07 & 0.06 & 0.04 \\
\hline between 366 and 730 days & 0.09 & 0.09 & 0.09 & 0.05 & 0.08 & 0.07 & 0.07 & 0.16 \\
\hline more than 730 days & 0.61 & 0.31 & 0.61 & 0.41 & 0.60 & 0.26 & 0.61 & 0.36 \\
\hline \multicolumn{9}{|l|}{ Pension } \\
\hline No pension & 1.00 & 1.00 & 1.00 & 1.00 & 1.00 & 1.00 & 1.00 & 1.00 \\
\hline Vocational disability & 0.00 & 0.00 & 0.00 & 0.00 & 0.00 & 0.00 & 0.00 & 0.00 \\
\hline Permanently unable to work & 0.00 & 0.00 & 0.00 & 0.00 & 0.00 & 0.00 & & \\
\hline \multicolumn{9}{|l|}{ Social plan } \\
\hline \multicolumn{9}{|l|}{ Schooling ${ }^{4}$} \\
\hline No school & 0.13 & 0.08 & 0.13 & 0.04 & 0.13 & 0.04 & 0.14 & 0.14 \\
\hline CSE & 0.56 & 0.35 & 0.57 & 0.53 & 0.57 & 0.41 & 0.57 & 0.48 \\
\hline O-levels & 0.19 & 0.23 & 0.18 & 0.16 & 0.18 & 0.15 & 0.18 & 0.20 \\
\hline Adv. technical college entrance ${ }^{5}$ & 0.04 & 0.12 & 0.03 & 0.07 & 0.03 & 0.12 & 0.03 & 0.07 \\
\hline A-levels & 0.09 & 0.22 & 0.08 & 0.19 & 0.08 & 0.27 & 0.08 & 0.11 \\
\hline \multicolumn{9}{|c|}{ Assessment of Individual's Qualification } \\
\hline Other & 0.57 & 0.34 & 0.58 & 0.43 & 0.59 & 0.33 & 0.58 & 0.48 \\
\hline Unskilled employee & 0.00 & 0.00 & 0.00 & 0.00 & 0.00 & 0.00 & 0.00 & 0.00 \\
\hline Skilled employee & 0.36 & 0.42 & 0.36 & 0.35 & 0.35 & 0.34 & 0.35 & 0.39 \\
\hline Ass. to technical school ${ }^{6}$ & 0.01 & 0.02 & 0.01 & 0.01 & 0.01 & 0.01 & 0.01 & 0.00 \\
\hline Ass. to adv. technical college & 0.02 & 0.13 & 0.02 & 0.10 & 0.02 & 0.18 & 0.02 & 0.04 \\
\hline Ass. to university & 0.04 & 0.09 & 0.03 & 0.11 & 0.03 & 0.14 & 0.03 & 0.09 \\
\hline Ass. to top-management & 0.00 & 0.01 & 0.00 & 0.00 & 0.00 & 0.00 & 0.00 & 0.00 \\
\hline \multicolumn{9}{|l|}{ Professional Training } \\
\hline Without compl. prof. training & 0.47 & 0.27 & 0.48 & 0.32 & 0.47 & 0.30 & 0.47 & 0.39 \\
\hline Apprenticeship (on-the-job) & 0.40 & 0.32 & 0.40 & 0.43 & 0.41 & 0.33 & 0.41 & 0.39 \\
\hline Apprenticeship (off-the job) & 0.01 & 0.01 & 0.01 & 0.03 & 0.01 & 0.00 & 0.01 & 0.04 \\
\hline Full-time vocational school & 0.03 & 0.06 & 0.03 & 0.00 & 0.02 & 0.04 & 0.03 & 0.07 \\
\hline Technical school & 0.04 & 0.12 & 0.04 & 0.03 & 0.03 & 0.07 & 0.03 & 0.04 \\
\hline Advanced technical college & 0.02 & 0.10 & 0.02 & 0.08 & 0.02 & 0.10 & 0.01 & 0.02 \\
\hline
\end{tabular}


TABLE C.6: (CONTINUED)

$u=9$

$u=10$

$u=11$

$u=12$

\begin{tabular}{|c|c|c|c|c|c|c|c|c|}
\hline & Non-Part. & Part. & Non-Part. & Part. & Non-Part. & Part. & Non-Part. & Part. \\
\hline University & 0.04 & 0.12 & 0.04 & 0.11 & 0.04 & 0.16 & 0.04 & 0.05 \\
\hline \multicolumn{9}{|l|}{ Month of Treatment Start } \\
\hline July 2000 & 0.20 & 0.19 & 0.20 & 0.13 & 0.19 & 0.14 & 0.21 & 0.13 \\
\hline September 2000 & 0.24 & 0.32 & 0.22 & 0.23 & 0.22 & 0.22 & 0.23 & 0.25 \\
\hline November 2000 & 0.15 & 0.13 & 0.16 & 0.18 & 0.15 & 0.18 & 0.14 & 0.21 \\
\hline January 2001 & 0.11 & 0.11 & 0.11 & 0.15 & 0.10 & 0.18 & 0.10 & 0.09 \\
\hline March 2001 & 0.14 & 0.10 & 0.14 & 0.16 & 0.15 & 0.18 & 0.14 & 0.21 \\
\hline May 2001 & 0.17 & 0.14 & 0.18 & 0.13 & 0.18 & 0.11 & 0.17 & 0.11 \\
\hline \multicolumn{9}{|l|}{ Regional Context Variables $^{7}$} \\
\hline Cluster II & 0.29 & 0.31 & 0.30 & 0.40 & 0.31 & 0.40 & 0.29 & 0.45 \\
\hline Cluster III & 0.43 & 0.37 & 0.43 & 0.36 & 0.41 & 0.42 & 0.44 & 0.38 \\
\hline Cluster IV & 0.09 & 0.12 & 0.09 & 0.13 & 0.09 & 0.07 & 0.09 & 0.05 \\
\hline Cluster V & 0.19 & 0.20 & 0.18 & 0.11 & 0.18 & 0.11 & 0.18 & 0.13 \\
\hline \multicolumn{9}{|l|}{ Desired Work Time } \\
\hline Full-time work & 0.68 & 0.78 & 0.71 & 0.72 & 0.70 & 0.81 & 0.71 & 0.75 \\
\hline Part-time work & 0.32 & 0.22 & 0.29 & 0.28 & 0.30 & 0.19 & 0.29 & 0.25 \\
\hline Other (e.g. telework) & 0.00 & 0.00 & 0.00 & 0.00 & 0.00 & 0.00 & 0.00 & 0.00 \\
\hline \multicolumn{9}{|l|}{ Work Time (Last Job) } \\
\hline Full-time work & 0.24 & 0.51 & 0.20 & 0.42 & 0.22 & 0.51 & 0.22 & 0.23 \\
\hline Part-time work & 0.08 & 0.14 & 0.06 & 0.12 & 0.07 & 0.10 & 0.07 & 0.11 \\
\hline Not applicable & 0.69 & 0.35 & 0.74 & 0.46 & 0.71 & 0.40 & 0.71 & 0.66 \\
\hline \multicolumn{9}{|l|}{ Desired Occupation } \\
\hline Farming $^{8}$ & 0.02 & 0.01 & 0.02 & 0.02 & 0.02 & 0.01 & 0.01 & 0.02 \\
\hline Mining, mineral extraction & 0.00 & 0.00 & 0.00 & 0.00 & 0.28 & 0.14 & 0.31 & 0.32 \\
\hline Manufacturing & 0.28 & 0.10 & 0.28 & 0.14 & 0.02 & 0.03 & 0.02 & 0.00 \\
\hline Technical professions & 0.02 & 0.01 & 0.02 & 0.02 & 0.66 & 0.82 & 0.64 & 0.64 \\
\hline Service Professions & 0.67 & 0.87 & 0.67 & 0.81 & 0.02 & 0.00 & 0.02 & 0.02 \\
\hline Other occupations & 0.02 & 0.01 & 0.01 & 0.01 & & & 0.00 & 0.00 \\
\hline Other & 0.00 & 0.00 & 0.00 & 0.00 & & & & \\
\hline
\end{tabular}

n.a. = not available

${ }^{1}$ Unemployment duration until treatment start.

2 Attendant for vocational rehabilitation.

${ }^{3}$ Similar programme before unemployment, e.g., job creation or structural adjustment scheme.

${ }^{4}$ Schooling: CSE = Certificate of Secondary Education.

${ }^{5}$ Advanced technical college entrance qualification (Fachhochschulreife)

6 Ass. = assimilable

7 Detailed information on regional context variables in Appendix B and Table B.1.

${ }^{8}$ Farming comprises plant cultivation, breeding and fishery.

Tab. C.7: Means of Selected Characteristics (Men in East Germany)

\begin{tabular}{|c|c|c|c|c|c|c|c|c|}
\hline & \multicolumn{2}{|c|}{$u=1$} & \multicolumn{2}{|c|}{$u=2$} & \multicolumn{2}{|c|}{$u=3$} & \multicolumn{2}{|c|}{$u=4$} \\
\hline & Non-Part. & Part. & Non-Part. & Part. & Non-Part. & Part. & Non-Part. & Part. \\
\hline Number of Observations & 74,160 & 866 & 38,783 & 718 & 24,602 & 798 & 16,503 & 895 \\
\hline Programme Duration & & 256.8 & & 255.8 & & 266.4 & & 268.5 \\
\hline \multicolumn{9}{|l|}{ Age } \\
\hline 25 to 29 years & 0.14 & 0.08 & 0.13 & 0.08 & 0.12 & 0.06 & 0.11 & 0.06 \\
\hline 30 to 34 years & 0.17 & 0.12 & 0.16 & 0.09 & 0.15 & 0.10 & 0.14 & 0.11 \\
\hline 35 to 39 years & 0.19 & 0.15 & 0.19 & 0.19 & 0.18 & 0.16 & 0.18 & 0.16 \\
\hline 40 to 44 years & 0.18 & 0.19 & 0.18 & 0.17 & 0.18 & 0.17 & 0.19 & 0.15 \\
\hline 45 to 49 years & 0.18 & 0.20 & 0.18 & 0.21 & 0.19 & 0.21 & 0.20 & 0.20 \\
\hline 50 to 55 years & 0.14 & 0.27 & 0.15 & 0.25 & 0.17 & 0.29 & 0.18 & 0.33 \\
\hline Foreigner & 0.02 & 0.01 & 0.02 & 0.01 & 0.02 & 0.00 & 0.02 & 0.01 \\
\hline Asylum-seeker & 0.02 & 0.02 & 0.02 & 0.00 & 0.02 & 0.01 & 0.01 & 0.01 \\
\hline No. of placement offers & 3.91 & 7.88 & 4.38 & 8.43 & 4.69 & 8.39 & 4.88 & 7.84 \\
\hline No. of children & 0.57 & 0.54 & 0.56 & 0.58 & 0.55 & 0.58 & 0.54 & 0.54 \\
\hline Placement restrictions & 0.10 & 0.15 & 0.11 & 0.16 & 0.12 & 0.14 & 0.15 & 0.13 \\
\hline Vocational rehabilitation $^{2}$ & 0.04 & 0.08 & 0.05 & 0.09 & 0.05 & 0.08 & 0.07 & 0.06 \\
\hline Health restrictions & 0.16 & 0.26 & 0.18 & 0.28 & 0.20 & 0.25 & 0.23 & 0.21 \\
\hline Marriage/ cohabitation & 0.60 & 0.58 & 0.57 & 0.60 & 0.55 & 0.64 & 0.54 & 0.63 \\
\hline Work experience & 0.93 & 0.92 & 0.93 & 0.92 & 0.92 & 0.93 & 0.92 & 0.92 \\
\hline Programme bef. unemp. ${ }^{3}$ & 0.16 & 0.59 & 0.23 & 0.56 & 0.27 & 0.52 & 0.32 & 0.56 \\
\hline Reception of UI & 0.91 & 0.60 & 0.89 & 0.61 & 0.89 & 0.64 & 0.88 & 0.58 \\
\hline
\end{tabular}

Duration of Last Job 
TABLE C.7: (CONTINUED)

$u=1 \quad u=2 \quad u=3 \quad u=4$

\begin{tabular}{|c|c|c|c|c|c|c|c|c|}
\hline & & & & \\
\hline & Non-Part. & Part. & Non-Part. & Part. & Non-Part. & Part. & Non-Part. & Part. \\
\hline up to 180 days & 0.19 & 0.46 & 0.21 & 0.53 & 0.22 & 0.50 & 0.22 & 0.60 \\
\hline between 180 and 365 days & 0.18 & 0.17 & 0.17 & 0.13 & 0.16 & 0.17 & 0.16 & 0.12 \\
\hline between 366 and 730 days & 0.20 & 0.13 & 0.23 & 0.11 & 0.23 & 0.12 & 0.22 & 0.10 \\
\hline more than 730 days & 0.42 & 0.24 & 0.39 & 0.22 & 0.40 & 0.22 & 0.40 & 0.18 \\
\hline \multicolumn{9}{|l|}{ Pension } \\
\hline No pension & 1.00 & 1.00 & 0.99 & 0.99 & 0.99 & 1.00 & 0.99 & 0.99 \\
\hline Vocational disability & 0.00 & 0.00 & 0.00 & 0.01 & 0.00 & 0.00 & 0.00 & 0.00 \\
\hline Permanently unable to work & 0.00 & 0.00 & 0.00 & 0.01 & 0.00 & 0.00 & 0.00 & 0.00 \\
\hline Social plan & & & 0.00 & 0.00 & & & & \\
\hline \multicolumn{9}{|l|}{ Schooling ${ }^{4}$} \\
\hline No school & 0.06 & 0.11 & 0.08 & 0.11 & 0.09 & 0.09 & 0.10 & 0.10 \\
\hline CSE & 0.29 & 0.39 & 0.31 & 0.40 & 0.33 & 0.38 & 0.34 & 0.41 \\
\hline O-levels & 0.57 & 0.43 & 0.53 & 0.45 & 0.50 & 0.47 & 0.48 & 0.43 \\
\hline Adv. technical college entrance ${ }^{5}$ & 0.01 & 0.01 & 0.01 & 0.01 & 0.01 & 0.01 & 0.01 & 0.02 \\
\hline A-levels & 0.07 & 0.06 & 0.06 & 0.03 & 0.06 & 0.05 & 0.06 & 0.05 \\
\hline \multicolumn{9}{|c|}{ Assessment of Individual's Qualification } \\
\hline Other & 0.31 & 0.38 & 0.34 & 0.41 & 0.37 & 0.32 & 0.39 & 0.38 \\
\hline Unskilled employee & 0.00 & 0.00 & 0.00 & 0.00 & 0.00 & 0.00 & 0.00 & 0.00 \\
\hline Skilled employee & 0.62 & 0.55 & 0.59 & 0.53 & 0.56 & 0.60 & 0.54 & 0.55 \\
\hline Ass. to technical school ${ }^{6}$ & 0.03 & 0.03 & 0.02 & 0.02 & 0.03 & 0.03 & 0.02 & 0.02 \\
\hline Ass. to adv. technical college & 0.02 & 0.02 & 0.02 & 0.02 & 0.02 & 0.02 & 0.02 & 0.02 \\
\hline Ass. to university & 0.03 & 0.03 & 0.03 & 0.02 & 0.03 & 0.03 & 0.03 & 0.02 \\
\hline Ass. to top-management & 0.00 & 0.00 & 0.00 & 0.00 & 0.00 & 0.00 & 0.00 & 0.00 \\
\hline \multicolumn{9}{|l|}{ Professional Training } \\
\hline Without compl. prof. training & 0.12 & 0.16 & 0.15 & 0.19 & 0.17 & 0.14 & 0.19 & 0.16 \\
\hline Apprenticeship (on-the-job) & 0.80 & 0.74 & 0.77 & 0.75 & 0.75 & 0.78 & 0.74 & 0.76 \\
\hline Apprenticeship (off-the job) & 0.01 & 0.01 & 0.01 & 0.01 & 0.01 & 0.01 & 0.01 & 0.01 \\
\hline Full-time vocational school & 0.00 & 0.01 & 0.00 & 0.00 & 0.01 & 0.00 & 0.01 & 0.00 \\
\hline Technical school & 0.03 & 0.03 & 0.03 & 0.02 & 0.03 & 0.03 & 0.03 & 0.03 \\
\hline Advanced technical college & 0.01 & 0.02 & 0.01 & 0.01 & 0.01 & 0.01 & 0.01 & 0.01 \\
\hline University & 0.03 & 0.03 & 0.03 & 0.02 & 0.03 & 0.03 & 0.03 & 0.02 \\
\hline \multicolumn{9}{|l|}{ Month of Treatment Start } \\
\hline July 2000 & 0.14 & 0.21 & 0.19 & 0.17 & 0.21 & 0.19 & 0.18 & 0.17 \\
\hline September 2000 & 0.16 & 0.20 & 0.20 & 0.20 & 0.23 & 0.22 & 0.22 & 0.24 \\
\hline November 2000 & 0.12 & 0.17 & 0.12 & 0.15 & 0.14 & 0.13 & 0.16 & 0.15 \\
\hline January 2001 & 0.15 & 0.07 & 0.10 & 0.05 & 0.10 & 0.04 & 0.12 & 0.04 \\
\hline March 2001 & 0.23 & 0.15 & 0.15 & 0.25 & 0.13 & 0.18 & 0.15 & 0.14 \\
\hline May 2001 & 0.20 & 0.19 & 0.25 & 0.17 & 0.19 & 0.24 & 0.18 & 0.26 \\
\hline \multicolumn{9}{|l|}{ Regional Context Variables $^{7}$} \\
\hline Cluster Ia & 0.15 & 0.17 & 0.15 & 0.14 & 0.16 & 0.14 & 0.18 & 0.15 \\
\hline Cluster Ib & 0.67 & 0.72 & 0.67 & 0.72 & 0.67 & 0.69 & 0.66 & 0.73 \\
\hline Cluster Ic & 0.15 & 0.10 & 0.14 & 0.12 & 0.13 & 0.16 & 0.13 & 0.11 \\
\hline Cluster II & 0.03 & 0.02 & 0.03 & 0.01 & 0.03 & 0.01 & 0.03 & 0.01 \\
\hline \multicolumn{9}{|l|}{ Desired Work Time } \\
\hline Full-time work & 1.00 & 1.00 & 1.00 & 1.00 & 1.00 & 1.00 & 1.00 & 1.00 \\
\hline Part-time work & 0.00 & 0.00 & 0.00 & 0.00 & 0.00 & 0.00 & 0.00 & 0.00 \\
\hline Other (e.g. telework) & 0.00 & 0.00 & & & & & & \\
\hline \multicolumn{9}{|l|}{ Work Time (Last Job) } \\
\hline Full-time work & 0.64 & 0.50 & 0.58 & 0.48 & 0.55 & 0.51 & 0.50 & 0.53 \\
\hline Part-time work & 0.02 & 0.12 & 0.04 & 0.11 & 0.05 & 0.11 & 0.05 & 0.08 \\
\hline Not applicable & 0.33 & 0.38 & 0.38 & 0.41 & 0.41 & 0.38 & 0.45 & 0.39 \\
\hline \multicolumn{9}{|l|}{ Desired Occupation } \\
\hline Farming $^{8}$ & 0.05 & 0.07 & 0.05 & 0.10 & 0.06 & 0.08 & 0.06 & 0.06 \\
\hline Mining, mineral extraction & 0.00 & 0.00 & 0.00 & 0.00 & 0.00 & 0.00 & 0.00 & 0.00 \\
\hline Manufacturing & 0.62 & 0.60 & 0.61 & 0.59 & 0.59 & 0.60 & 0.57 & 0.61 \\
\hline Technical professions & 0.05 & 0.04 & 0.04 & 0.03 & 0.05 & 0.04 & 0.04 & 0.03 \\
\hline Service Professions & 0.26 & 0.27 & 0.26 & 0.27 & 0.28 & 0.27 & 0.29 & 0.28 \\
\hline Other occupations & 0.02 & 0.01 & 0.02 & 0.01 & 0.03 & 0.01 & 0.03 & 0.01 \\
\hline Other & 0.00 & 0.00 & 0.00 & 0.00 & 0.00 & 0.00 & 0.00 & 0.00 \\
\hline
\end{tabular}

n.a. = not available

1 Unemployment duration until treatment start.

2 Attendant for vocational rehabilitation.

${ }^{3}$ Similar programme before unemployment, e.g., job creation or structural adjustment scheme.

${ }^{4}$ Schooling: CSE = Certificate of Secondary Education.

5 Advanced technical college entrance qualification (Fachhochschulreife)

6 Ass. = assimilable

7 Detailed information on regional context variables in Appendix B and Table B.1.

${ }^{8}$ Farming comprises plant cultivation, breeding and fishery. 
Tab. C.8: Means of Selected Characteristics (Men in East Germany)

\begin{tabular}{|c|c|c|c|c|c|c|c|c|}
\hline & \multicolumn{2}{|c|}{$\bar{u}=5$} & \multicolumn{2}{|c|}{$u=6$} & \multicolumn{2}{|c|}{$u=7$} & \multicolumn{2}{|c|}{$u=8$} \\
\hline & Non-Part. & Part. & Non-Part. & Part. & Non-Part. & Part. & Non-Part. & Part. \\
\hline Number of Observations & 10,312 & 1,230 & 7,199 & 767 & 5,381 & 788 & 3,979 & 605 \\
\hline Programme Duration & & 270.2 & & 261.4 & & 266.1 & & 274 \\
\hline \multicolumn{9}{|l|}{ Age } \\
\hline 25 to 29 years & 0.11 & 0.07 & 0.10 & 0.07 & 0.09 & 0.07 & 0.08 & 0.05 \\
\hline 30 to 34 years & 0.13 & 0.09 & 0.13 & 0.10 & 0.13 & 0.09 & 0.14 & 0.10 \\
\hline 35 to 39 years & 0.18 & 0.13 & 0.18 & 0.15 & 0.19 & 0.16 & 0.18 & 0.14 \\
\hline 40 to 44 years & 0.19 & 0.18 & 0.19 & 0.19 & 0.20 & 0.16 & 0.19 & 0.19 \\
\hline 45 to 49 years & 0.21 & 0.22 & 0.21 & 0.20 & 0.21 & 0.19 & 0.22 & 0.20 \\
\hline 50 to 55 years & 0.18 & 0.30 & 0.19 & 0.28 & 0.19 & 0.32 & 0.19 & 0.31 \\
\hline Foreigner & 0.02 & 0.01 & 0.02 & 0.01 & 0.02 & 0.01 & 0.03 & 0.01 \\
\hline Asylum-seeker & 0.01 & 0.01 & 0.01 & 0.01 & 0.01 & 0.00 & 0.01 & 0.01 \\
\hline No. of placement offers & 4.77 & 7.39 & 4.45 & 8.23 & 4.40 & 7.26 & 4.18 & 7.68 \\
\hline No. of children & 0.52 & 0.57 & 0.49 & 0.52 & 0.50 & 0.52 & 0.49 & 0.53 \\
\hline Placement restrictions & 0.15 & 0.10 & 0.15 & 0.13 & 0.17 & 0.12 & 0.18 & 0.13 \\
\hline Vocational rehabilitation $^{2}$ & 0.07 & 0.06 & 0.07 & 0.06 & 0.07 & 0.07 & 0.08 & 0.08 \\
\hline Health restrictions & 0.23 & 0.20 & 0.24 & 0.22 & 0.26 & 0.22 & 0.28 & 0.21 \\
\hline Marriage/ cohabitation & 0.52 & 0.62 & 0.49 & 0.61 & 0.49 & 0.57 & 0.47 & 0.59 \\
\hline Work experience & 0.92 & 0.94 & 0.91 & 0.94 & 0.91 & 0.93 & 0.90 & 0.93 \\
\hline Programme bef. unemp. ${ }^{3}$ & 0.32 & 0.52 & 0.30 & 0.48 & 0.32 & 0.51 & 0.30 & 0.50 \\
\hline Reception of UI & 0.92 & 0.61 & 0.93 & 0.65 & 0.93 & 0.66 & 0.92 & 0.67 \\
\hline \multicolumn{9}{|l|}{ Duration of Last Job } \\
\hline up to 180 days & 0.20 & 0.62 & 0.19 & 0.62 & 0.19 & 0.63 & 0.19 & 0.70 \\
\hline between 180 and 365 days & 0.21 & 0.11 & 0.23 & 0.10 & 0.22 & 0.06 & 0.20 & 0.09 \\
\hline between 366 and 730 days & 0.20 & 0.10 & 0.17 & 0.08 & 0.16 & 0.10 & 0.15 & 0.07 \\
\hline more than 730 days & 0.40 & 0.18 & 0.41 & 0.20 & 0.43 & 0.21 & 0.46 & 0.15 \\
\hline \multicolumn{9}{|l|}{ Pension } \\
\hline No pension & 0.99 & 0.99 & 0.99 & 0.99 & 0.99 & 1.00 & 0.99 & 1.00 \\
\hline Vocational disability & 0.00 & 0.00 & 0.00 & 0.00 & 0.00 & 0.00 & 0.00 & 0.00 \\
\hline Permanently unable to work & 0.00 & 0.00 & 0.00 & 0.00 & 0.01 & 0.00 & 0.01 & 0.00 \\
\hline Social plan & 0.00 & 0.00 & & & & & & \\
\hline \multicolumn{9}{|l|}{ Schooling ${ }^{4}$} \\
\hline No school & 0.12 & 0.09 & 0.13 & 0.12 & 0.13 & 0.11 & 0.14 & 0.13 \\
\hline CSE & 0.35 & 0.40 & 0.36 & 0.42 & 0.37 & 0.42 & 0.37 & 0.41 \\
\hline O-levels & 0.46 & 0.45 & 0.45 & 0.43 & 0.43 & 0.43 & 0.41 & 0.40 \\
\hline Adv. technical college entrance ${ }^{5}$ & 0.01 & 0.01 & 0.01 & 0.01 & 0.01 & 0.01 & 0.01 & 0.01 \\
\hline A-levels & 0.06 & 0.06 & 0.05 & 0.02 & 0.05 & 0.03 & 0.06 & 0.05 \\
\hline \multicolumn{9}{|c|}{ Assessment of Individual's Qualification } \\
\hline Other & 0.40 & 0.33 & 0.42 & 0.40 & 0.44 & 0.39 & 0.45 & 0.42 \\
\hline Unskilled employee & 0.00 & 0.00 & 0.00 & 0.00 & 0.00 & 0.00 & 0.00 & 0.00 \\
\hline Skilled employee & 0.54 & 0.59 & 0.52 & 0.56 & 0.50 & 0.56 & 0.49 & 0.51 \\
\hline Ass. to technical school ${ }^{6}$ & 0.02 & 0.03 & 0.02 & 0.02 & 0.02 & 0.02 & 0.02 & 0.03 \\
\hline Ass. to adv. technical college & 0.02 & 0.02 & 0.02 & 0.01 & 0.01 & 0.01 & 0.01 & 0.02 \\
\hline Ass. to university & 0.02 & 0.03 & 0.02 & 0.01 & 0.02 & 0.02 & 0.02 & 0.02 \\
\hline Ass. to top-management & 0.00 & 0.00 & 0.00 & 0.00 & 0.00 & 0.00 & 0.00 & 0.00 \\
\hline \multicolumn{9}{|l|}{ Professional Training } \\
\hline Without compl. prof. training & 0.20 & 0.14 & 0.22 & 0.20 & 0.22 & 0.17 & 0.22 & 0.20 \\
\hline Apprenticeship (on-the-job) & 0.73 & 0.78 & 0.71 & 0.75 & 0.70 & 0.78 & 0.70 & 0.73 \\
\hline Apprenticeship (off-the job) & 0.01 & 0.00 & 0.01 & 0.01 & 0.00 & 0.01 & 0.01 & 0.00 \\
\hline Full-time vocational school & 0.01 & 0.00 & 0.00 & 0.01 & 0.01 & 0.00 & 0.01 & 0.00 \\
\hline Technical school & 0.02 & 0.04 & 0.03 & 0.02 & 0.03 & 0.02 & 0.03 & 0.03 \\
\hline Advanced technical college & 0.01 & 0.01 & 0.01 & 0.01 & 0.01 & 0.01 & 0.01 & 0.02 \\
\hline University & 0.03 & 0.03 & 0.02 & 0.01 & 0.02 & 0.02 & 0.03 & 0.02 \\
\hline Month of Treatment Start & & & & & & & & \\
\hline July 2000 & 0.18 & 0.27 & 0.18 & 0.22 & 0.19 & 0.23 & 0.16 & 0.25 \\
\hline September 2000 & 0.20 & 0.22 & 0.21 & 0.31 & 0.22 & 0.26 & 0.21 & 0.21 \\
\hline November 2000 & 0.14 & 0.12 & 0.15 & 0.13 & 0.13 & 0.13 & 0.14 & 0.16 \\
\hline January 2001 & 0.12 & 0.04 & 0.10 & 0.02 & 0.12 & 0.04 & 0.11 & 0.05 \\
\hline March 2001 & 0.16 & 0.13 & 0.14 & 0.11 & 0.15 & 0.13 & 0.17 & 0.15 \\
\hline May 2001 & 0.19 & 0.22 & 0.23 & 0.21 & 0.19 & 0.22 & 0.21 & 0.19 \\
\hline Regional Context Variables $^{7}$ & & & & & & & & \\
\hline Cluster Ia & 0.17 & 0.16 & 0.16 & 0.17 & 0.16 & 0.19 & 0.16 & 0.19 \\
\hline Cluster Ib & 0.66 & 0.71 & 0.68 & 0.70 & 0.68 & 0.71 & 0.68 & 0.69 \\
\hline Cluster Ic & 0.13 & 0.11 & 0.13 & 0.12 & 0.12 & 0.09 & 0.12 & 0.09 \\
\hline Cluster II 0.03 & 0.02 & 0.03 & 0.01 & 0.04 & 0.01 & 0.04 & 0.03 & \\
\hline Desired Work Time & & & & & & & & \\
\hline Full-time work & 1.00 & 1.00 & 1.00 & 1.00 & 1.00 & 1.00 & 1.00 & 1.00 \\
\hline Part-time work & 0.00 & 0.00 & 0.00 & 0.00 & 0.00 & 0.00 & 0.00 & 0.00 \\
\hline Other (e.g. telework) & & & & & & & & \\
\hline
\end{tabular}


TABLE C.8: (CONTINUED)

$u=5 \quad u=6 \quad u=7 \quad u=8$

Non-Part. Part. Non-Part. Part. Non-Part. Part. Non-Part. Part.

\begin{tabular}{lcccccccc} 
& Non-Part. & Part. & Non-Part. & Part. & Non-Part. & Part. & Non-Part. Part. \\
\hline Work Time (Last Job) & & & & & & & \\
\hline Full-time work & 0.47 & 0.60 & 0.42 & 0.55 & 0.40 & 0.51 & 0.37 & 0.53 \\
Part-time work & 0.05 & 0.09 & 0.04 & 0.08 & 0.04 & 0.12 & 0.04 & 0.11 \\
Not applicable & 0.48 & 0.31 & 0.53 & 0.37 & 0.56 & 0.37 & 0.59 & 0.37 \\
\hline Desired Occupation & & & & & & & & \\
\hline Farming & & & & & & & & \\
Mining, mineral extraction & 0.07 & 0.08 & 0.06 & 0.08 & 0.07 & 0.09 & 0.07 & 0.09 \\
Manufacturing & 0.00 & 0.00 & 0.00 & 0.00 & 0.00 & 0.00 & 0.00 & 0.00 \\
Technical professions & 0.56 & 0.62 & 0.56 & 0.64 & 0.53 & 0.62 & 0.51 & 0.59 \\
Service Professions & 0.04 & 0.04 & 0.04 & 0.03 & 0.04 & 0.03 & 0.04 & 0.04 \\
Other occupations & 0.30 & 0.25 & 0.31 & 0.25 & 0.33 & 0.25 & 0.35 & 0.27 \\
Other & 0.03 & 0.01 & 0.03 & 0.01 & 0.03 & 0.00 & 0.04 & 0.00 \\
\hline \hline
\end{tabular}

n.a. $=$ not available

${ }^{1}$ Unemployment duration until treatment start.

2 Attendant for vocational rehabilitation.

3 Similar programme before unemployment, e.g., job creation or structural adjustment scheme.

${ }^{4}$ Schooling: CSE = Certificate of Secondary Education.

${ }^{5}$ Advanced technical college entrance qualification (Fachhochschulreife)

6 Ass. = assimilable

${ }^{7}$ Detailed information on regional context variables in Appendix B and Table B.1.

${ }^{8}$ Farming comprises plant cultivation, breeding and fishery.

Tab. C.9: Means of Selected Characteristics (Men in East Germany)

\begin{tabular}{|c|c|c|c|c|c|c|c|c|}
\hline & \multicolumn{2}{|c|}{$u=9$} & \multicolumn{2}{|c|}{$u=10$} & \multicolumn{2}{|c|}{$u=11$} & \multicolumn{2}{|c|}{$u=12$} \\
\hline & Non-Part. & Part. & Non-Part. & Part. & Non-Part. & Part. & Non-Part. & Part. \\
\hline Number of Observations & 2,772 & 832 & 2,130 & 569 & 1,647 & 551 & 1,339 & 364 \\
\hline Programme Duration & & 280.9 & & 282.2 & & 272.8 & & 269.9 \\
\hline \multicolumn{9}{|l|}{ Age } \\
\hline 25 to 29 years & 0.07 & 0.06 & 0.06 & 0.05 & 0.06 & 0.06 & 0.06 & 0.06 \\
\hline 30 to 34 years & 0.12 & 0.08 & 0.13 & 0.12 & 0.11 & 0.07 & 0.12 & 0.09 \\
\hline 35 to 39 years & 0.18 & 0.14 & 0.17 & 0.15 & 0.18 & 0.15 & 0.17 & 0.12 \\
\hline 40 to 44 years & 0.20 & 0.18 & 0.21 & 0.18 & 0.22 & 0.15 & 0.19 & 0.20 \\
\hline 45 to 49 years & 0.22 & 0.23 & 0.23 & 0.22 & 0.22 & 0.23 & 0.24 & 0.27 \\
\hline 50 to 55 years & 0.20 & 0.31 & 0.20 & 0.28 & 0.21 & 0.34 & 0.22 & 0.27 \\
\hline Foreigner & 0.02 & 0.01 & 0.02 & 0.00 & 0.02 & 0.01 & 0.02 & 0.01 \\
\hline Asylum-seeker & 0.01 & 0.01 & 0.01 & 0.00 & 0.01 & 0.00 & 0.01 & 0.01 \\
\hline No. of placement offers & 3.84 & 7.67 & 3.48 & 7.99 & 3.21 & 7.53 & 2.98 & 7.41 \\
\hline No. of children & 0.48 & 0.53 & 0.48 & 0.52 & 0.47 & 0.52 & 0.48 & 0.51 \\
\hline Placement restrictions & 0.18 & 0.13 & 0.21 & 0.12 & 0.21 & 0.14 & 0.22 & 0.16 \\
\hline Vocational rehabilitation $^{2}$ & 0.10 & 0.07 & 0.10 & 0.07 & 0.10 & 0.08 & 0.11 & 0.08 \\
\hline Health restrictions & 0.28 & 0.23 & 0.31 & 0.23 & 0.30 & 0.25 & 0.32 & 0.24 \\
\hline Marriage/ cohabitation & 0.49 & 0.59 & 0.48 & 0.53 & 0.46 & 0.53 & 0.48 & 0.55 \\
\hline Work experience & 0.90 & 0.94 & 0.91 & 0.92 & 0.90 & 0.94 & 0.91 & 0.92 \\
\hline Programme bef. unemp. ${ }^{3}$ & 0.30 & 0.56 & 0.27 & 0.54 & 0.27 & 0.53 & 0.28 & 0.48 \\
\hline Reception of UI & 0.92 & 0.63 & 0.92 & 0.64 & 0.91 & 0.65 & 0.91 & 0.65 \\
\hline \multicolumn{9}{|l|}{ Duration of Last Job } \\
\hline up to 180 days & 0.19 & 0.72 & 0.20 & 0.72 & 0.19 & 0.72 & 0.20 & 0.71 \\
\hline between 180 and 365 days & 0.18 & 0.06 & 0.14 & 0.05 & 0.18 & 0.06 & 0.20 & 0.05 \\
\hline between 366 and 730 days & 0.14 & 0.07 & 0.17 & 0.08 & 0.17 & 0.07 & 0.13 & 0.07 \\
\hline more than 730 days & 0.50 & 0.14 & 0.48 & 0.15 & 0.46 & 0.15 & 0.47 & 0.16 \\
\hline \multicolumn{9}{|l|}{ Pension } \\
\hline No pension & 0.99 & 0.99 & 0.99 & 1.00 & 0.99 & 0.99 & 0.99 & 0.99 \\
\hline Vocational disability & 0.00 & 0.00 & 0.00 & 0.00 & 0.01 & 0.00 & 0.00 & 0.01 \\
\hline Permanently unable to work & 0.01 & 0.00 & 0.01 & 0.00 & 0.01 & 0.00 & 0.01 & 0.01 \\
\hline Social plan & & & & & & & & \\
\hline \multicolumn{9}{|l|}{ Schooling 4} \\
\hline No school & 0.14 & 0.14 & 0.15 & 0.15 & 0.13 & 0.15 & 0.17 & 0.13 \\
\hline CSE & 0.36 & 0.42 & 0.37 & 0.40 & 0.37 & 0.41 & 0.36 & 0.42 \\
\hline O-levels & 0.44 & 0.39 & 0.42 & 0.40 & 0.42 & 0.40 & 0.41 & 0.42 \\
\hline Adv. technical college entrance ${ }^{5}$ & 0.01 & 0.01 & 0.01 & 0.01 & 0.01 & 0.01 & 0.01 & 0.00 \\
\hline A-levels & 0.05 & 0.04 & 0.05 & 0.04 & 0.06 & 0.03 & 0.05 & 0.04 \\
\hline \multicolumn{9}{|c|}{ Assessment of Individual's Qualification } \\
\hline Other & 0.46 & 0.46 & 0.49 & 0.48 & 0.48 & 0.45 & 0.49 & 0.46 \\
\hline Unskilled employee & 0.00 & 0.00 & 0.00 & 0.00 & 0.00 & 0.00 & 0.00 & 0.00 \\
\hline
\end{tabular}


TABLE C.9: (CONTINUED)

$u=9 \quad u=10 \quad u=11 \quad u=12$

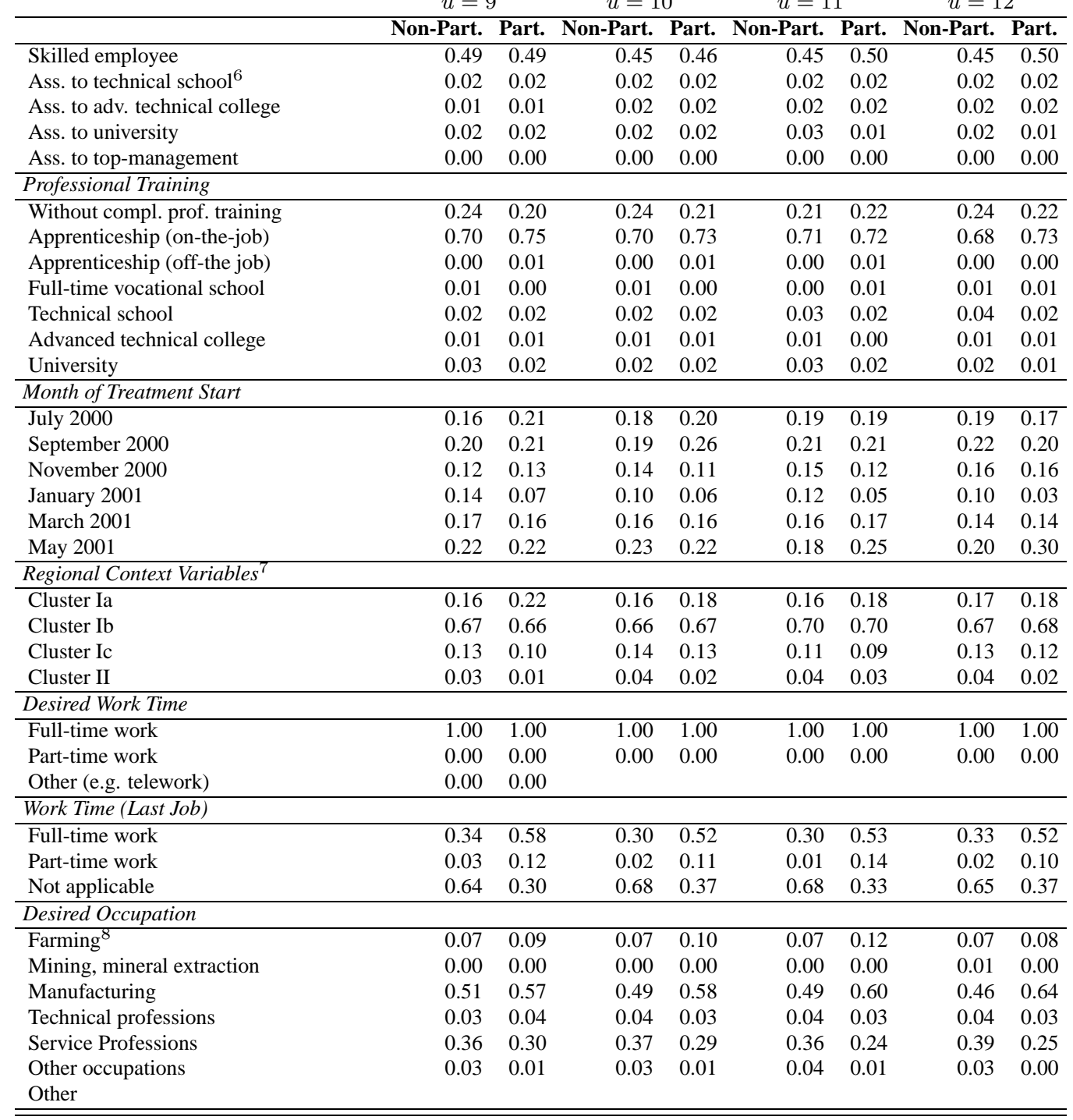

n.a. = not available

${ }^{1}$ Unemployment duration until treatment start.

${ }^{2}$ Attendant for vocational rehabilitation.

${ }^{3}$ Similar programme before unemployment, e.g., job creation or structural adjustment scheme.

${ }^{4}$ Schooling: CSE = Certificate of Secondary Education.

5 Advanced technical college entrance qualification (Fachhochschulreife)

6 Ass. = assimilable

7 Detailed information on regional context variables in Appendix B and Table B.1.

${ }^{8}$ Farming comprises plant cultivation, breeding and fishery.

Tab. C.10: Means of Selected Characteristics (Women in East Germany)

\begin{tabular}{|c|c|c|c|c|c|c|c|c|}
\hline & \multicolumn{2}{|c|}{$u=1$} & \multicolumn{2}{|c|}{$u=2$} & \multicolumn{2}{|c|}{$u=3$} & \multicolumn{2}{|c|}{$u=4$} \\
\hline & Non-Part. & Part. & Non-Part. & Part. & Non-Part. & Part. & Non-Part. & Part. \\
\hline Number of Observations & 61,591 & 952 & 37,483 & 693 & 27,990 & 728 & 21,130 & 848 \\
\hline Programme Duration & & 292 & & 298.8 & & 293.8 & & 293.6 \\
\hline \multicolumn{9}{|l|}{ Age } \\
\hline 25 to 29 years & 0.12 & 0.05 & 0.10 & 0.06 & 0.09 & 0.05 & 0.08 & 0.05 \\
\hline 30 to 34 years & 0.17 & 0.14 & 0.17 & 0.12 & 0.16 & 0.15 & 0.16 & 0.13 \\
\hline 35 to 39 years & 0.20 & 0.20 & 0.20 & 0.18 & 0.20 & 0.19 & 0.20 & 0.19 \\
\hline 40 to 44 years & 0.19 & 0.17 & 0.18 & 0.17 & 0.19 & 0.16 & 0.20 & 0.18 \\
\hline 45 to 49 years & 0.17 & 0.20 & 0.18 & 0.22 & 0.19 & 0.21 & 0.19 & 0.19 \\
\hline 50 to 55 years & 0.15 & 0.24 & 0.16 & 0.26 & 0.17 & 0.24 & 0.17 & 0.26 \\
\hline
\end{tabular}


TABle C.10: (CONTINUED)

$u=1 \quad u=2 \quad u=3 \quad u=4$

\begin{tabular}{|c|c|c|c|c|c|c|c|c|}
\hline & Non-Part. & Part. & Non-Part. & Part. & Non-Part. & Part. & Non-Part. & Part. \\
\hline Foreigner & 0.01 & 0.00 & 0.01 & 0.01 & 0.01 & 0.01 & 0.01 & 0.00 \\
\hline Asylum-seeker & 0.03 & 0.01 & 0.03 & 0.01 & 0.02 & 0.00 & 0.02 & 0.01 \\
\hline No. of placement propositions & 3.79 & 6.77 & 4.00 & 6.98 & 4.09 & 6.82 & 4.02 & 7.01 \\
\hline No. of children & 0.97 & 0.97 & 1.00 & 0.96 & 1.01 & 0.95 & 1.04 & 0.99 \\
\hline Placement restrictions & 0.08 & 0.09 & 0.08 & 0.09 & 0.08 & 0.11 & 0.08 & 0.10 \\
\hline Vocational rehabilitation $^{2}$ & 0.03 & 0.04 & 0.03 & 0.04 & 0.03 & 0.07 & 0.03 & 0.04 \\
\hline Health restrictions & 0.15 & 0.16 & 0.14 & 0.18 & 0.15 & 0.20 & 0.15 & 0.18 \\
\hline Marriage/ cohabitation & 0.71 & 0.74 & 0.72 & 0.71 & 0.72 & 0.73 & 0.73 & 0.70 \\
\hline Work experience & 0.90 & 0.91 & 0.90 & 0.88 & 0.90 & 0.88 & 0.90 & 0.91 \\
\hline Programme bef. unemp. ${ }^{3}$ & 0.27 & 0.63 & 0.34 & 0.63 & 0.37 & 0.61 & 0.41 & 0.64 \\
\hline Reception of UI & 0.88 & 0.60 & 0.86 & 0.59 & 0.85 & 0.59 & 0.83 & 0.52 \\
\hline \multicolumn{9}{|l|}{ Duration of Last Job } \\
\hline up to 180 days & 0.17 & 0.38 & 0.17 & 0.44 & 0.18 & 0.42 & 0.18 & 0.50 \\
\hline between 180 and 365 days & 0.11 & 0.15 & 0.10 & 0.13 & 0.12 & 0.12 & 0.14 & 0.10 \\
\hline between 366 and 730 days & 0.19 & 0.12 & 0.23 & 0.11 & 0.22 & 0.15 & 0.19 & 0.11 \\
\hline more than 730 days & 0.53 & 0.36 & 0.50 & 0.32 & 0.49 & 0.31 & 0.49 & 0.28 \\
\hline \multicolumn{9}{|l|}{ Pension } \\
\hline No pension & 1.00 & 1.00 & 1.00 & 0.99 & 1.00 & 1.00 & 1.00 & 1.00 \\
\hline Vocational disability & 0.00 & 0.00 & 0.00 & 0.00 & 0.00 & 0.00 & 0.00 & 0.00 \\
\hline Permanently unable to work & 0.00 & 0.00 & 0.00 & 0.00 & 0.00 & 0.00 & 0.00 & 0.00 \\
\hline \multicolumn{9}{|l|}{ Social plan } \\
\hline \multicolumn{9}{|l|}{ Schooling $^{4}$} \\
\hline No school & 0.04 & 0.05 & 0.05 & 0.05 & 0.05 & 0.03 & 0.05 & 0.04 \\
\hline CSE & 0.21 & 0.23 & 0.23 & 0.25 & 0.24 & 0.23 & 0.25 & 0.26 \\
\hline O-levels & 0.66 & 0.63 & 0.65 & 0.59 & 0.64 & 0.62 & 0.63 & 0.63 \\
\hline Adv. technical college entrance ${ }^{5}$ & 0.02 & 0.03 & 0.02 & 0.02 & 0.01 & 0.02 & 0.01 & 0.01 \\
\hline A-levels & 0.08 & 0.07 & 0.06 & 0.09 & 0.06 & 0.09 & 0.05 & 0.06 \\
\hline \multicolumn{9}{|c|}{ Assessment of Individual's Qualification } \\
\hline Other & 0.33 & 0.32 & 0.35 & 0.33 & 0.35 & 0.28 & 0.37 & 0.33 \\
\hline Unskilled employee & 0.00 & 0.00 & 0.00 & 0.00 & 0.00 & 0.00 & 0.57 & 0.58 \\
\hline Skilled employee & 0.60 & 0.57 & 0.58 & 0.57 & 0.59 & 0.59 & 0.02 & 0.04 \\
\hline Ass. to technical school ${ }^{6}$ & 0.03 & 0.05 & 0.02 & 0.04 & 0.03 & 0.05 & 0.02 & 0.02 \\
\hline Ass. to adv. technical college & 0.02 & 0.03 & 0.02 & 0.03 & 0.02 & 0.04 & 0.02 & 0.02 \\
\hline Ass. to university & 0.03 & 0.03 & 0.03 & 0.04 & 0.02 & 0.04 & 0.00 & 0.00 \\
\hline Ass. to top-management & 0.00 & 0.00 & 0.00 & 0.00 & 0.00 & 0.00 & & \\
\hline \multicolumn{9}{|l|}{ Professional Training } \\
\hline Without compl. prof. training & 0.12 & 0.11 & 0.14 & 0.14 & 0.15 & 0.09 & 0.15 & 0.13 \\
\hline Apprenticeship (on-the-job) & 0.74 & 0.71 & 0.73 & 0.68 & 0.73 & 0.70 & 0.73 & 0.71 \\
\hline Apprenticeship (off-the job) & 0.01 & 0.01 & 0.01 & 0.01 & 0.01 & 0.01 & 0.01 & 0.01 \\
\hline Full-time vocational school & 0.01 & 0.01 & 0.01 & 0.02 & 0.01 & 0.01 & 0.01 & 0.02 \\
\hline Technical school & 0.07 & 0.11 & 0.06 & 0.11 & 0.06 & 0.12 & 0.06 & 0.09 \\
\hline Advanced technical college & 0.01 & 0.01 & 0.01 & 0.01 & 0.01 & 0.02 & 0.01 & 0.01 \\
\hline University & 0.03 & 0.04 & 0.03 & 0.04 & 0.03 & 0.05 & 0.02 & 0.03 \\
\hline \multicolumn{9}{|l|}{ Month of Treatment Start } \\
\hline July 2000 & 0.18 & 0.19 & 0.20 & 0.19 & 0.19 & 0.17 & 0.20 & 0.15 \\
\hline September 2000 & 0.19 & 0.20 & 0.24 & 0.17 & 0.23 & 0.20 & 0.22 & 0.22 \\
\hline November 2000 & 0.14 & 0.13 & 0.14 & 0.12 & 0.17 & 0.16 & 0.14 & 0.17 \\
\hline January 2001 & 0.12 & 0.09 & 0.11 & 0.07 & 0.11 & 0.07 & 0.11 & 0.06 \\
\hline March 2001 & 0.17 & 0.19 & 0.14 & 0.24 & 0.12 & 0.20 & 0.16 & 0.18 \\
\hline May 2001 & 0.21 & 0.18 & 0.18 & 0.20 & 0.18 & 0.19 & 0.16 & 0.21 \\
\hline \multicolumn{9}{|l|}{ Regional Context Variables $^{7}$} \\
\hline Cluster Ia & 0.15 & 0.17 & 0.16 & 0.16 & 0.17 & 0.16 & 0.18 & 0.11 \\
\hline Cluster Ib & 0.67 & 0.72 & 0.67 & 0.72 & 0.67 & 0.69 & 0.66 & 0.75 \\
\hline Cluster Ic & 0.15 & 0.10 & 0.15 & 0.11 & 0.14 & 0.13 & 0.14 & 0.13 \\
\hline Cluster II & 0.03 & 0.01 & 0.03 & 0.01 & 0.03 & 0.02 & 0.02 & 0.01 \\
\hline \multicolumn{9}{|l|}{ Desired Work Time } \\
\hline Full-time work & 0.95 & 0.98 & 0.96 & 0.99 & 0.96 & 0.99 & 0.95 & 0.98 \\
\hline Part-time work & 0.05 & 0.02 & 0.04 & 0.01 & 0.04 & 0.01 & 0.05 & 0.02 \\
\hline Other (e.g. telework) & 0.00 & 0.00 & & & & & 0.00 & 0.00 \\
\hline \multicolumn{9}{|l|}{ Work Time (Last Job) } \\
\hline Full-time work & 0.45 & 0.39 & 0.42 & 0.39 & 0.41 & 0.34 & 0.39 & 0.35 \\
\hline Part-time work & 0.09 & 0.16 & 0.11 & 0.13 & 0.12 & 0.13 & 0.11 & 0.12 \\
\hline Not applicable & 0.46 & 0.45 & 0.47 & 0.48 & 0.48 & 0.53 & 0.50 & 0.53 \\
\hline Desired Occupation & & & & & & & & \\
\hline Farming $^{8}$ & 0.07 & 0.10 & 0.07 & 0.08 & 0.08 & 0.10 & 0.08 & 0.09 \\
\hline Mining, mineral extraction & 0.00 & 0.00 & 0.00 & 0.00 & 0.00 & 0.00 & 0.00 & 0.00 \\
\hline Manufacturing & 0.17 & 0.18 & 0.19 & 0.17 & 0.19 & 0.17 & 0.20 & 0.18 \\
\hline Technical professions & 0.04 & 0.05 & 0.04 & 0.05 & 0.04 & 0.06 & 0.04 & 0.05 \\
\hline Service Professions & 0.70 & 0.66 & 0.68 & 0.70 & 0.68 & 0.67 & 0.67 & 0.67 \\
\hline
\end{tabular}


TABle C.10: (CONTINUED)
$u=1$
$u=2$
$u=3$
$u=4$

\begin{tabular}{|c|c|c|c|c|c|c|c|c|}
\hline & \multicolumn{2}{|l|}{$a-$} & \multicolumn{2}{|l|}{. } & \multicolumn{2}{|l|}{$a-u$} & \multicolumn{2}{|c|}{ \pm} \\
\hline & Non-Part. & Part. & Non-Part. & Part. & Non-Part. & Part. & Non-Part. & Part. \\
\hline Other occupations & 0.02 & 0.00 & 0.01 & 0.00 & 0.01 & 0.01 & 0.01 & 0.00 \\
\hline Other & 0.00 & 0.00 & & & 0.00 & 0.00 & & \\
\hline
\end{tabular}

n.a. = not available

${ }^{1}$ Unemployment duration until treatment start.

2 Attendant for vocational rehabilitation.

3 Similar programme before unemployment, e.g., job creation or structural adjustment scheme.

${ }^{4}$ Schooling: CSE $=$ Certificate of Secondary Education.

5 Advanced technical college entrance qualification (Fachhochschulreife)

${ }^{6}$ Ass. $=$ assimilable

7 Detailed information on regional context variables in Appendix B and Table B.1.

${ }^{8}$ Farming comprises plant cultivation, breeding and fishery.

Tab. C.11: Means of Selected Characteristics (Women in East Germany)

\begin{tabular}{|c|c|c|c|c|c|c|c|c|}
\hline & \multicolumn{2}{|c|}{$u=5$} & \multicolumn{2}{|c|}{$u=6$} & \multicolumn{2}{|c|}{$u=7$} & \multicolumn{2}{|c|}{$u=8$} \\
\hline & Non-Part. & Part. & Non-Part. & Part. & Non-Part. & Part. & Non-Part. & Part. \\
\hline Number of Observations & 14,669 & 1,279 & 10,563 & 746 & 8,728 & 803 & 6,929 & 698 \\
\hline Programme Duration & & 309.2 & & 301.1 & & 307.3 & & 304.1 \\
\hline \multicolumn{9}{|l|}{ Age } \\
\hline 25 to 29 years & 0.08 & 0.05 & 0.07 & 0.06 & 0.06 & 0.05 & 0.06 & 0.05 \\
\hline 30 to 34 years & 0.15 & 0.11 & 0.16 & 0.12 & 0.14 & 0.11 & 0.14 & 0.11 \\
\hline 35 to 39 years & 0.20 & 0.18 & 0.19 & 0.18 & 0.20 & 0.17 & 0.20 & 0.18 \\
\hline 40 to 44 years & 0.19 & 0.17 & 0.20 & 0.18 & 0.20 & 0.19 & 0.20 & 0.19 \\
\hline 45 to 49 years & 0.20 & 0.20 & 0.20 & 0.21 & 0.20 & 0.21 & 0.21 & 0.20 \\
\hline 50 to 55 years & 0.18 & 0.30 & 0.19 & 0.25 & 0.19 & 0.27 & 0.19 & 0.27 \\
\hline Foreigner & 0.01 & 0.00 & 0.01 & 0.00 & 0.01 & 0.00 & 0.01 & 0.00 \\
\hline Asylum-seeker & 0.02 & 0.01 & 0.01 & 0.00 & 0.02 & 0.00 & 0.02 & 0.00 \\
\hline No. of placement offers & 3.78 & 6.63 & 3.53 & 6.80 & 3.45 & 6.41 & 3.38 & 6.40 \\
\hline No. of children & 1.05 & 0.90 & 1.05 & 0.95 & 1.07 & 0.92 & 1.10 & 0.92 \\
\hline Placement restrictions & 0.08 & 0.10 & 0.08 & 0.08 & 0.08 & 0.08 & 0.08 & 0.09 \\
\hline Vocational rehabilitation $^{2}$ & 0.03 & 0.05 & 0.03 & 0.05 & 0.03 & 0.04 & 0.03 & 0.04 \\
\hline Health restrictions & 0.14 & 0.18 & 0.15 & 0.16 & 0.14 & 0.18 & 0.15 & 0.16 \\
\hline Marriage/ cohabitation & 0.73 & 0.75 & 0.73 & 0.75 & 0.73 & 0.73 & 0.72 & 0.74 \\
\hline Work experience & 0.90 & 0.90 & 0.90 & 0.90 & 0.90 & 0.90 & 0.90 & 0.90 \\
\hline Programme bef. unemp. ${ }^{3}$ & 0.40 & 0.67 & 0.38 & 0.63 & 0.38 & 0.63 & 0.37 & 0.62 \\
\hline Reception of UI & 0.90 & 0.55 & 0.92 & 0.57 & 0.91 & 0.58 & 0.91 & 0.60 \\
\hline \multicolumn{9}{|l|}{ Duration of Last Job } \\
\hline up to 180 days & 0.15 & 0.58 & 0.13 & 0.54 & 0.14 & 0.58 & 0.14 & 0.59 \\
\hline between 180 and 365 days & 0.22 & 0.10 & 0.27 & 0.10 & 0.25 & 0.08 & 0.24 & 0.08 \\
\hline between 366 and 730 days & 0.16 & 0.09 & 0.12 & 0.10 & 0.11 & 0.08 & 0.11 & 0.08 \\
\hline more than 730 days & 0.47 & 0.24 & 0.48 & 0.25 & 0.50 & 0.26 & 0.52 & 0.25 \\
\hline \multicolumn{9}{|l|}{ Pension } \\
\hline No pension & 1.00 & 1.00 & 1.00 & 1.00 & 1.00 & 1.00 & 1.00 & 1.00 \\
\hline Vocational disability & 0.00 & 0.00 & 0.00 & 0.00 & 0.00 & 0.00 & 0.00 & 0.00 \\
\hline Permanently unable to work & 0.00 & 0.00 & 0.00 & 0.00 & 0.00 & 0.00 & 0.00 & 0.00 \\
\hline \multicolumn{9}{|l|}{ Social plan } \\
\hline \multicolumn{9}{|l|}{ Schooling ${ }^{4}$} \\
\hline No school & 0.06 & 0.03 & 0.07 & 0.06 & 0.07 & 0.04 & 0.07 & 0.06 \\
\hline CSE & 0.27 & 0.24 & 0.28 & 0.25 & 0.29 & 0.25 & 0.31 & 0.25 \\
\hline O-levels & 0.62 & 0.63 & 0.61 & 0.61 & 0.59 & 0.64 & 0.57 & 0.63 \\
\hline Adv. technical college entrance ${ }^{5}$ & 0.01 & 0.02 & 0.01 & 0.01 & 0.01 & 0.02 & 0.01 & 0.01 \\
\hline A-levels & 0.04 & 0.08 & 0.04 & 0.06 & 0.04 & 0.06 & 0.04 & 0.05 \\
\hline \multicolumn{9}{|c|}{ Assessment of Individual's Qualification } \\
\hline Other & 0.38 & 0.29 & 0.40 & 0.34 & 0.41 & 0.32 & 0.42 & 0.31 \\
\hline Unskilled employee & 0.56 & 0.61 & 0.55 & 0.57 & 0.55 & 0.59 & 0.53 & 0.60 \\
\hline Skilled employee & 0.02 & 0.05 & 0.02 & 0.05 & 0.02 & 0.04 & 0.02 & 0.04 \\
\hline Ass. to technical school ${ }^{6}$ & 0.01 & 0.03 & 0.01 & 0.02 & 0.01 & 0.02 & 0.01 & 0.02 \\
\hline Ass. to adv. technical college & 0.02 & 0.03 & 0.02 & 0.03 & 0.02 & 0.02 & 0.02 & 0.03 \\
\hline Ass. to university & 0.00 & 0.00 & 0.00 & 0.00 & 0.00 & 0.00 & 0.00 & 0.00 \\
\hline \multicolumn{9}{|l|}{ Ass. to top-management } \\
\hline \multicolumn{9}{|l|}{ Professional Training } \\
\hline Without compl. prof. training & 0.16 & 0.11 & 0.17 & 0.15 & 0.18 & 0.10 & 0.19 & 0.11 \\
\hline Apprenticeship (on-the-job) & 0.73 & 0.70 & 0.74 & 0.69 & 0.73 & 0.75 & 0.72 & 0.72 \\
\hline Apprenticeship (off-the job) & 0.01 & 0.01 & 0.01 & 0.01 & 0.01 & 0.01 & 0.01 & 0.00 \\
\hline Full-time vocational school & 0.01 & 0.02 & 0.01 & 0.02 & 0.01 & 0.01 & 0.01 & 0.02 \\
\hline
\end{tabular}


TABle C.11: (CONTINUED)
$u=5$
$u=6$
$u=7$
$u=8$

\begin{tabular}{|c|c|c|c|c|c|c|c|c|}
\hline & Non-Part. & Part. & Non-Part. & Part. & Non-Part. & Part. & Non-Part. & Part. \\
\hline Technical school & 0.05 & 0.11 & 0.05 & 0.09 & 0.04 & 0.08 & 0.05 & 0.11 \\
\hline Advanced technical college & 0.01 & 0.01 & 0.01 & 0.01 & 0.01 & 0.01 & 0.00 & 0.01 \\
\hline University & 0.02 & 0.04 & 0.02 & 0.03 & 0.02 & 0.03 & 0.02 & 0.02 \\
\hline \multicolumn{9}{|l|}{ Month of Treatment Start } \\
\hline July 2000 & 0.21 & 0.20 & 0.19 & 0.18 & 0.19 & 0.21 & 0.15 & 0.20 \\
\hline September 2000 & 0.24 & 0.19 & 0.26 & 0.27 & 0.24 & 0.22 & 0.20 & 0.24 \\
\hline November 2000 & 0.14 & 0.15 & 0.16 & 0.13 & 0.15 & 0.15 & 0.15 & 0.14 \\
\hline January 2001 & 0.10 & 0.06 & 0.10 & 0.07 & 0.12 & 0.07 & 0.11 & 0.06 \\
\hline March 2001 & 0.13 & 0.19 & 0.13 & 0.19 & 0.14 & 0.18 & 0.17 & 0.20 \\
\hline May 2001 & 0.18 & 0.21 & 0.17 & 0.16 & 0.17 & 0.18 & 0.21 & 0.16 \\
\hline \multicolumn{9}{|l|}{ Regional Context Variables $^{7}$} \\
\hline Cluster Ia & 0.18 & 0.14 & 0.15 & 0.17 & 0.16 & 0.20 & 0.16 & 0.17 \\
\hline Cluster Ib & 0.66 & 0.72 & 0.67 & 0.69 & 0.68 & 0.67 & 0.66 & 0.68 \\
\hline Cluster Ic & 0.14 & 0.12 & 0.15 & 0.13 & 0.14 & 0.12 & 0.15 & 0.14 \\
\hline Cluster II & 0.02 & 0.02 & 0.03 & 0.01 & 0.02 & 0.01 & 0.02 & 0.01 \\
\hline \multicolumn{9}{|l|}{ Desired Work Time } \\
\hline Full-time work & 0.95 & 0.98 & 0.95 & 0.99 & 0.95 & 0.98 & 0.95 & 0.98 \\
\hline Part-time work & 0.05 & 0.02 & 0.05 & 0.01 & 0.05 & 0.02 & 0.05 & 0.02 \\
\hline \multicolumn{9}{|l|}{ Other (e.g. telework) } \\
\hline \multicolumn{9}{|l|}{ Work Time (Last Job) } \\
\hline Full-time work & 0.37 & 0.44 & 0.35 & 0.37 & 0.33 & 0.37 & 0.30 & 0.36 \\
\hline Part-time work & 0.11 & 0.16 & 0.11 & 0.14 & 0.10 & 0.18 & 0.09 & 0.16 \\
\hline Not applicable & 0.52 & 0.40 & 0.54 & 0.49 & 0.57 & 0.45 & 0.61 & 0.48 \\
\hline \multicolumn{9}{|l|}{ Desired Occupation } \\
\hline Farming $^{8}$ & 0.08 & 0.08 & 0.07 & 0.10 & 0.07 & 0.10 & 0.07 & 0.10 \\
\hline Mining, mineral extraction & 0.00 & 0.00 & 0.00 & 0.00 & 0.00 & 0.00 & 0.00 & 0.00 \\
\hline Manufacturing & 0.21 & 0.17 & 0.23 & 0.19 & 0.24 & 0.20 & 0.24 & 0.19 \\
\hline Technical professions & 0.04 & 0.05 & 0.03 & 0.04 & 0.03 & 0.05 & 0.03 & 0.05 \\
\hline Service Professions & 0.66 & 0.70 & 0.66 & 0.67 & 0.65 & 0.64 & 0.65 & 0.65 \\
\hline Other occupations & 0.01 & 0.00 & 0.01 & 0.00 & 0.01 & 0.00 & 0.01 & 0.01 \\
\hline Other & 0.00 & 0.00 & & & & & & \\
\hline
\end{tabular}

n.a. $=$ not available

${ }^{1}$ Unemployment duration until treatment start.

2 Attendant for vocational rehabilitation.

3 Similar programme before unemployment, e.g., job creation or structural adjustment scheme.

${ }^{4}$ Schooling: $\mathrm{CSE}=$ Certificate of Secondary Education.

${ }^{5}$ Advanced technical college entrance qualification (Fachhochschulreife)

${ }^{6}$ Ass. = assimilable

7 Detailed information on regional context variables in Appendix B and Table B.1.

${ }^{8}$ Farming comprises plant cultivation, breeding and fishery.

Tab. C.12: Means of Selected Characteristics (Women in East Germany)

\begin{tabular}{|c|c|c|c|c|c|c|c|c|}
\hline & \multicolumn{2}{|c|}{$u=9$} & \multicolumn{2}{|c|}{$u=10$} & \multicolumn{2}{|c|}{$u=11$} & \multicolumn{2}{|c|}{$u=12$} \\
\hline & Non-Part. & Part. & Non-Part. & Part. & Non-Part. & Part. & Non-Part. & Part. \\
\hline Number of Observations & 5,208 & 1,139 & 3,814 & 783 & 3,238 & 723 & 2,786 & 545 \\
\hline Programme Duration & & 313.7 & & 305.8 & & 307.2 & & 295.5 \\
\hline \multicolumn{9}{|l|}{ Age } \\
\hline 25 to 29 years & 0.05 & 0.04 & 0.05 & 0.05 & 0.05 & 0.05 & 0.04 & 0.03 \\
\hline 30 to 34 years & 0.14 & 0.11 & 0.13 & 0.11 & 0.13 & 0.09 & 0.13 & 0.11 \\
\hline 35 to 39 years & 0.19 & 0.17 & 0.19 & 0.20 & 0.19 & 0.18 & 0.18 & 0.18 \\
\hline 40 to 44 years & 0.19 & 0.20 & 0.20 & 0.17 & 0.21 & 0.19 & 0.21 & 0.17 \\
\hline 45 to 49 years & 0.20 & 0.21 & 0.22 & 0.22 & 0.21 & 0.23 & 0.22 & 0.23 \\
\hline 50 to 55 years & 0.21 & 0.27 & 0.21 & 0.25 & 0.20 & 0.26 & 0.22 & 0.29 \\
\hline Foreigner & 0.01 & 0.00 & 0.01 & 0.01 & 0.01 & 0.00 & 0.01 & 0.00 \\
\hline Asylum-seeker & 0.01 & 0.00 & 0.01 & 0.01 & 0.01 & 0.00 & 0.01 & 0.01 \\
\hline No. of placement offers & 3.07 & 6.40 & 2.88 & 6.58 & 2.52 & 6.28 & 2.37 & 6.50 \\
\hline No. of children & 1.06 & 1.00 & 1.09 & 0.99 & 1.13 & 0.98 & 1.06 & 0.96 \\
\hline Placement restrictions & 0.10 & 0.07 & 0.10 & 0.07 & 0.09 & 0.07 & 0.10 & 0.08 \\
\hline Vocational rehabilitation $^{2}$ & 0.04 & 0.03 & 0.04 & 0.03 & 0.03 & 0.04 & 0.04 & 0.04 \\
\hline Health restrictions & 0.16 & 0.15 & 0.17 & 0.14 & 0.15 & 0.14 & 0.17 & 0.17 \\
\hline Marriage/ cohabitation & 0.74 & 0.78 & 0.74 & 0.73 & 0.75 & 0.76 & 0.76 & 0.73 \\
\hline Work experience & 0.91 & 0.92 & 0.90 & 0.90 & 0.91 & 0.91 & 0.91 & 0.90 \\
\hline Programme bef. unemp. ${ }^{3}$ & 0.31 & 0.68 & 0.29 & 0.63 & 0.29 & 0.61 & 0.31 & 0.62 \\
\hline Reception of UI & 0.90 & 0.59 & 0.89 & 0.58 & 0.88 & 0.58 & 0.89 & 0.62 \\
\hline
\end{tabular}


TABle C.12: (CONTINUED)

$u=9$

$u=10$

$u=11$

$u=12$

Non-Part. Part. Non-Part. Part. Non-Part. Part. Non-Part. Part.

\begin{tabular}{|c|c|c|c|c|c|c|c|c|}
\hline \multicolumn{9}{|l|}{ Duration of Last Job } \\
\hline up to 180 days & 0.14 & 0.70 & 0.16 & 0.68 & 0.16 & 0.66 & 0.16 & 0.65 \\
\hline between 180 and 365 days & 0.19 & 0.06 & 0.16 & 0.05 & 0.17 & 0.04 & 0.22 & 0.05 \\
\hline between 366 and 730 days & 0.12 & 0.05 & 0.11 & 0.06 & 0.10 & 0.07 & 0.10 & 0.09 \\
\hline more than 730 days & 0.56 & 0.19 & 0.57 & 0.21 & 0.56 & 0.24 & 0.53 & 0.21 \\
\hline \multicolumn{9}{|l|}{ Pension } \\
\hline No pension & 0.99 & 1.00 & 0.99 & 1.00 & 1.00 & 1.00 & 1.00 & 1.00 \\
\hline Vocational disability & 0.00 & 0.00 & 0.00 & 0.00 & 0.00 & 0.00 & 0.00 & 0.00 \\
\hline Permanently unable to work & 0.01 & 0.00 & 0.01 & 0.00 & 0.00 & 0.00 & 0.00 & 0.00 \\
\hline Social plan & & & & & 0.00 & 0.00 & & \\
\hline \multicolumn{9}{|l|}{ Schooling ${ }^{4}$} \\
\hline No school & 0.08 & 0.04 & 0.08 & 0.07 & 0.07 & 0.06 & 0.09 & 0.07 \\
\hline CSE & 0.30 & 0.30 & 0.31 & 0.29 & 0.31 & 0.30 & 0.33 & 0.31 \\
\hline O-levels & 0.58 & 0.59 & 0.57 & 0.59 & 0.57 & 0.59 & 0.53 & 0.56 \\
\hline Adv. technical college entrance ${ }^{5}$ & 0.01 & 0.02 & 0.01 & 0.01 & 0.01 & 0.02 & 0.01 & 0.02 \\
\hline A-levels & 0.04 & 0.05 & 0.04 & 0.04 & 0.04 & 0.03 & 0.04 & 0.04 \\
\hline \multicolumn{9}{|c|}{ Assessment of Individual's Qualification } \\
\hline Other & 0.43 & 0.35 & 0.44 & 0.37 & 0.43 & 0.38 & 0.44 & 0.41 \\
\hline Unskilled employee & 0.00 & 0.00 & 0.00 & 0.00 & 0.00 & 0.00 & 0.00 & 0.00 \\
\hline Skilled employee & 0.53 & 0.58 & 0.52 & 0.56 & 0.52 & 0.56 & 0.52 & 0.52 \\
\hline Ass. to technical school ${ }^{6}$ & 0.02 & 0.03 & 0.02 & 0.04 & 0.02 & 0.03 & 0.02 & 0.03 \\
\hline Ass. to adv. technical college & 0.01 & 0.02 & 0.01 & 0.01 & 0.01 & 0.02 & 0.01 & 0.02 \\
\hline Ass. to university & 0.01 & 0.01 & 0.02 & 0.02 & 0.02 & 0.02 & 0.01 & 0.03 \\
\hline Ass. to top-management & 0.00 & 0.00 & 0.00 & 0.00 & 0.00 & 0.00 & 0.00 & 0.00 \\
\hline \multicolumn{9}{|l|}{ Professional Training } \\
\hline Without compl. prof. training & 0.19 & 0.13 & 0.20 & 0.15 & 0.20 & 0.14 & 0.21 & 0.17 \\
\hline Apprenticeship (on-the-job) & 0.73 & 0.74 & 0.72 & 0.72 & 0.71 & 0.77 & 0.71 & 0.73 \\
\hline Apprenticeship (off-the job) & 0.00 & 0.01 & 0.00 & 0.01 & 0.00 & 0.00 & 0.00 & 0.01 \\
\hline Full-time vocational school & 0.01 & 0.01 & 0.02 & 0.01 & 0.02 & 0.01 & 0.01 & 0.01 \\
\hline Technical school & 0.05 & 0.09 & 0.05 & 0.08 & 0.05 & 0.05 & 0.04 & 0.06 \\
\hline Advanced technical college & 0.00 & 0.01 & 0.00 & 0.01 & 0.00 & 0.01 & 0.01 & 0.01 \\
\hline University & 0.02 & 0.02 & 0.02 & 0.02 & 0.02 & 0.01 & 0.02 & 0.02 \\
\hline \multicolumn{9}{|l|}{ Month of Treatment Start } \\
\hline July 2000 & 0.15 & 0.22 & 0.18 & 0.21 & 0.22 & 0.15 & 0.20 & 0.15 \\
\hline September 2000 & 0.18 & 0.21 & 0.19 & 0.23 & 0.22 & 0.28 & 0.24 & 0.23 \\
\hline November 2000 & 0.13 & 0.13 & 0.14 & 0.14 & 0.14 & 0.15 & 0.16 & 0.17 \\
\hline January 2001 & 0.13 & 0.07 & 0.10 & 0.05 & 0.10 & 0.06 & 0.10 & 0.06 \\
\hline March 2001 & 0.18 & 0.15 & 0.15 & 0.18 & 0.14 & 0.17 & 0.13 & 0.17 \\
\hline May 2001 & 0.22 & 0.22 & 0.23 & 0.19 & 0.18 & 0.19 & 0.17 & 0.22 \\
\hline \multicolumn{9}{|l|}{ Regional Context Variables $^{7}$} \\
\hline Cluster Ia & 0.16 & 0.25 & 0.17 & 0.22 & 0.17 & 0.23 & 0.17 & 0.22 \\
\hline Cluster Ib & 0.67 & 0.61 & 0.66 & 0.62 & 0.65 & 0.66 & 0.67 & 0.62 \\
\hline Cluster Ic & 0.14 & 0.12 & 0.15 & 0.14 & 0.15 & 0.10 & 0.13 & 0.14 \\
\hline Cluster II & 0.03 & 0.02 & 0.02 & 0.01 & 0.03 & 0.02 & 0.03 & 0.01 \\
\hline \multicolumn{9}{|l|}{ Desired Work Time } \\
\hline Full-time work & 0.94 & 0.99 & 0.94 & 0.98 & 0.94 & 0.98 & 0.94 & 0.98 \\
\hline Part-time work & 0.06 & 0.01 & 0.06 & 0.02 & 0.06 & 0.02 & 0.06 & 0.02 \\
\hline \multicolumn{9}{|l|}{ Other (e.g. telework) } \\
\hline \multicolumn{9}{|l|}{ Work Time (Last Job) } \\
\hline Full-time work & 0.28 & 0.45 & 0.22 & 0.41 & 0.25 & 0.43 & 0.26 & 0.34 \\
\hline Part-time work & 0.07 & 0.23 & 0.05 & 0.21 & 0.05 & 0.19 & 0.05 & 0.20 \\
\hline Not applicable & 0.65 & 0.32 & 0.72 & 0.38 & 0.70 & 0.38 & 0.68 & 0.46 \\
\hline \multicolumn{9}{|l|}{ Desired Occupation } \\
\hline Farming $^{8}$ & 0.07 & 0.10 & 0.06 & 0.12 & 0.06 & 0.12 & 0.06 & 0.10 \\
\hline Mining, mineral extraction & 0.00 & 0.00 & 0.00 & 0.00 & 0.00 & 0.00 & 0.00 & 0.00 \\
\hline Manufacturing & 0.23 & 0.22 & 0.23 & 0.20 & 0.23 & 0.21 & 0.25 & 0.26 \\
\hline Technical professions & 0.03 & 0.04 & 0.02 & 0.03 & 0.03 & 0.03 & 0.02 & 0.04 \\
\hline Service Professions & 0.66 & 0.64 & 0.67 & 0.65 & 0.66 & 0.64 & 0.66 & 0.60 \\
\hline Other occupations & 0.01 & 0.00 & 0.01 & 0.00 & 0.02 & 0.00 & 0.01 & 0.00 \\
\hline Other & & & & & 0.00 & 0.00 & & \\
\hline
\end{tabular}


TABle C.12: (CONTINUED)

$u=10$

$u=11$

$u=12$

Non-Part. Part. Non-Part. Part. Non-Part. Part. Non-Part. Part.

n.a. $=$ not available

${ }^{1}$ Unemployment duration until treatment start.

2 Attendant for vocational rehabilitation.

${ }^{3}$ Similar programme before unemployment, e.g. job creation or structural adjustment scheme.

${ }^{4}$ Schooling: CSE $=$ Certificate of Secondary Education.

5 Advanced technical college entrance qualification (Fachhochschulreife)

${ }^{6}$ Ass. $=$ assimilable

7 Detailed information on regional context variables in Appendix B and table B.1.

${ }^{8}$ Farming comprises plant cultivation, breeding and fishery.

\section{Propensity Score Estimation}

Tab. D.1: Estimation Results of the Probit-Models for the Propensity SCORES FOR TREATMENT Starting IN QUARTER $u=1$ TO $u=4$ (MEN IN WeST GERMANY)

\begin{tabular}{|c|c|c|c|c|c|c|c|c|}
\hline & \multicolumn{2}{|c|}{$u=1$} & \multicolumn{2}{|c|}{$u=2$} & \multicolumn{2}{|c|}{$u=3$} & \multicolumn{2}{|c|}{$u=4$} \\
\hline & $d F / d x$ & Std. Err. & $d F / d x$ & Std. Err. & $d F / d x$ & Std. Err. & $d F / d x$ & Std. Err. \\
\hline \multicolumn{9}{|l|}{ Age } \\
\hline 25 to 29 years & \multicolumn{2}{|c|}{ Reference } & \multicolumn{2}{|c|}{ Reference } & \multicolumn{2}{|c|}{ Reference } & \multicolumn{2}{|c|}{ Reference } \\
\hline 30 to 34 years & 0.001 & 0.000 & 0.000 & 0.001 & 0.000 & 0.001 & -0.003 & 0.002 \\
\hline 35 to 39 years & 0.002 & 0.001 & 0.000 & 0.001 & 0.001 & 0.002 & -0.004 & 0.002 \\
\hline 40 to 44 years & 0.002 & 0.001 & 0.001 & 0.001 & -0.001 & 0.001 & 0.001 & 0.003 \\
\hline 45 to 49 years & 0.002 & 0.001 & 0.001 & 0.001 & 0.000 & 0.002 & 0.001 & 0.003 \\
\hline 50 to 55 years & 0.003 & 0.001 & 0.002 & 0.001 & 0.001 & 0.002 & 0.002 & 0.003 \\
\hline Foreigner & -0.001 & 0.000 & -0.002 & 0.000 & -0.002 & 0.001 & -0.004 & 0.002 \\
\hline Asylum-seeker & 0.000 & 0.000 & -0.003 & 0.001 & -0.003 & 0.001 & -0.004 & 0.002 \\
\hline No. of placement offers & 0.000 & 0.000 & 0.000 & 0.000 & 0.000 & 0.000 & 0.001 & 0.000 \\
\hline No. of children & 0.000 & 0.000 & 0.000 & 0.000 & 0.001 & 0.000 & 0.001 & 0.001 \\
\hline Placement restrictions & 0.001 & 0.001 & 0.001 & 0.001 & 0.001 & 0.002 & 0.004 & 0.003 \\
\hline Vocational rehabilitation $^{1}$ & 0.000 & 0.000 & 0.000 & 0.001 & 0.000 & 0.002 & 0.003 & 0.003 \\
\hline Health restrictions & 0.000 & 0.000 & 0.001 & 0.001 & 0.002 & 0.001 & -0.003 & 0.002 \\
\hline Marriage/ cohabitation & -0.001 & 0.000 & 0.001 & 0.001 & -0.002 & 0.001 & -0.002 & 0.002 \\
\hline Work experience & 0.000 & 0.000 & 0.000 & 0.001 & 0.000 & 0.002 & 0.000 & 0.002 \\
\hline Programme bef. unemp. ${ }^{2}$ & 0.021 & 0.002 & $\mathbf{0 . 0 3 0}$ & 0.003 & 0.032 & 0.004 & 0.047 & 0.005 \\
\hline Reception of UI & 0.000 & 0.000 & -0.004 & 0.001 & -0.009 & 0.002 & -0.024 & 0.004 \\
\hline \multicolumn{9}{|l|}{ Duration of Last Job } \\
\hline up to 180 days & 0.001 & 0.000 & 0.003 & 0.001 & 0.005 & 0.001 & 0.013 & 0.002 \\
\hline between 180 and 365 days & 0.000 & 0.000 & -0.001 & 0.001 & -0.002 & 0.001 & -0.004 & 0.002 \\
\hline between 366 and 730 days & 0.000 & 0.000 & -0.001 & 0.001 & -0.003 & 0.001 & -0.001 & 0.002 \\
\hline more than 730 days & \multicolumn{2}{|c|}{ Reference } & \multicolumn{2}{|c|}{ Reference } & \multicolumn{2}{|c|}{ Reference } & \multicolumn{2}{|c|}{ Reference } \\
\hline \multicolumn{9}{|l|}{ Pension } \\
\hline No pension & \multicolumn{2}{|c|}{ Reference } & \multicolumn{2}{|c|}{ Reference } & \multicolumn{2}{|c|}{ Reference } & \multicolumn{2}{|c|}{ Reference } \\
\hline Vocational disability & -0.001 & 0.002 & - & - & -0.002 & 0.006 & -0.005 & 0.007 \\
\hline Permanently unable to work & 0.001 & 0.002 & - & - & 0.003 & 0.011 & - & - \\
\hline Social plan & - & - & - & - & - & - & - & - \\
\hline \multicolumn{9}{|l|}{ Schooling ${ }^{3}$} \\
\hline No school & \multicolumn{2}{|c|}{ Reference } & \multicolumn{2}{|c|}{ Reference } & \multicolumn{2}{|c|}{ Reference } & Refer & ence \\
\hline CSE & -0.001 & 0.000 & 0.000 & 0.001 & -0.001 & 0.001 & -0.004 & 0.002 \\
\hline O-levels & -0.001 & 0.000 & 0.000 & 0.001 & -0.003 & 0.001 & -0.008 & 0.002 \\
\hline Adv. technical college entrance ${ }^{4}$ & -0.001 & 0.000 & 0.001 & 0.002 & -0.001 & 0.002 & -0.008 & 0.002 \\
\hline A-levels & -0.001 & 0.000 & 0.001 & 0.001 & 0.001 & 0.002 & -0.006 & 0.002 \\
\hline Professional Training & & & & & & & & \\
\hline Without compl. prof. training & Refer & ence & Refer & ence & Refer & ence & Refer & ence \\
\hline Apprenticeship (on-the-job) & 0.000 & 0.000 & -0.002 & 0.001 & -0.001 & 0.001 & 0.002 & 0.002 \\
\hline Apprenticeship (off-the job) & 0.001 & 0.001 & 0.000 & 0.002 & 0.001 & 0.004 & 0.020 & 0.011 \\
\hline Full-time vocational school & 0.000 & 0.001 & 0.000 & 0.002 & -0.001 & 0.003 & 0.002 & 0.007 \\
\hline Technical school & -0.001 & 0.001 & -0.001 & 0.001 & -0.001 & 0.003 & 0.002 & 0.006 \\
\hline Advanced technical college & -0.001 & 0.001 & -0.002 & 0.001 & -0.002 & 0.003 & 0.015 & 0.013 \\
\hline University & -0.002 & 0.000 & -0.001 & 0.002 & 0.000 & 0.004 & 0.020 & 0.013 \\
\hline
\end{tabular}


TABLE D.1: (CONTINUED)

\begin{tabular}{|c|c|c|c|c|c|c|c|c|}
\hline & \multicolumn{2}{|c|}{$u=1$} & \multicolumn{2}{|c|}{$\bar{u}=2$} & \multicolumn{2}{|c|}{$u=3$} & \multicolumn{2}{|c|}{$u=4$} \\
\hline & $d F / d x$ & Std. Err. & $d F / d x$ & Std. Err. & $d F / d x$ & Std. Err. & $d F / d x$ & Std. Err. \\
\hline Other & \multicolumn{2}{|c|}{ Reference } & \multicolumn{2}{|c|}{ Reference } & \multicolumn{2}{|c|}{ Reference } & \multicolumn{2}{|c|}{ Reference } \\
\hline Unskilled employee & - & - & - & - & - & - & - & - \\
\hline Skilled employee & -0.001 & 0.000 & 0.000 & 0.001 & -0.001 & 0.001 & -0.001 & 0.002 \\
\hline Ass. to technical school ${ }^{5}$ & -0.001 & 0.001 & 0.003 & 0.002 & 0.009 & 0.005 & 0.002 & 0.005 \\
\hline Ass. to adv. technical college & 0.003 & 0.002 & 0.004 & 0.003 & 0.011 & 0.007 & 0.002 & 0.006 \\
\hline Ass. to university & 0.005 & 0.003 & 0.001 & 0.002 & 0.001 & 0.004 & 0.000 & 0.006 \\
\hline Ass. to top-management & - & - & - & - & - & - & - & - \\
\hline \multicolumn{9}{|l|}{ Month of Treatment Start } \\
\hline July 2000 & \multicolumn{2}{|c|}{ Reference } & \multicolumn{2}{|c|}{ Reference } & \multicolumn{2}{|c|}{ Reference } & \multicolumn{2}{|c|}{ Reference } \\
\hline September 2000 & -0.001 & 0.000 & 0.001 & 0.001 & 0.002 & 0.002 & -0.001 & 0.002 \\
\hline November 2000 & 0.000 & 0.000 & 0.002 & 0.001 & 0.010 & 0.003 & 0.000 & 0.002 \\
\hline January 2001 & 0.000 & 0.000 & 0.005 & 0.001 & 0.012 & 0.003 & 0.010 & 0.004 \\
\hline March 2001 & -0.001 & 0.000 & 0.003 & 0.001 & 0.010 & 0.003 & 0.008 & 0.003 \\
\hline May 2001 & 0.000 & 0.000 & 0.000 & 0.001 & 0.005 & 0.002 & 0.013 & 0.003 \\
\hline \multicolumn{9}{|l|}{ Regional Context Variables } \\
\hline Cluster Ia & - & - & - & - & - & - & - & - \\
\hline Cluster Ib & - & - & - & - & - & - & - & - \\
\hline Cluster Ic & - & - & - & - & - & - & - & - \\
\hline Cluster II & \multicolumn{2}{|c|}{ Reference } & \multicolumn{2}{|c|}{ Reference } & \multicolumn{2}{|c|}{ Reference } & \multicolumn{2}{|c|}{ Reference } \\
\hline Cluster III & -0.001 & 0.000 & -0.001 & 0.000 & 0.000 & 0.001 & -0.004 & 0.001 \\
\hline Cluster IV & -0.001 & 0.000 & -0.002 & 0.001 & -0.001 & 0.001 & -0.003 & 0.002 \\
\hline Cluster V & -0.001 & 0.000 & 0.000 & 0.001 & 0.001 & 0.001 & 0.000 & 0.002 \\
\hline \multicolumn{9}{|l|}{ Work Time (Last Job) } \\
\hline Full-time work & \multicolumn{2}{|c|}{ Reference } & \multicolumn{2}{|c|}{ Reference } & \multicolumn{2}{|c|}{ Reference } & \multicolumn{2}{|c|}{ Reference } \\
\hline Part-time work & 0.003 & 0.003 & -0.003 & 0.001 & - & - & 0.008 & 0.011 \\
\hline Not applicable & 0.000 & 0.000 & 0.000 & 0.000 & -0.002 & 0.001 & -0.004 & 0.001 \\
\hline Desired Work Time & & & & & & & & \\
\hline Full-time work & Refer & ence & Refer & ence & Refer & ence & Refer & ence \\
\hline part-time work & -0.002 & 0.000 & -0.002 & 0.002 & - & - & -0.005 & 0.005 \\
\hline Other (e.g. telework) & - & - & - & - & - & - & - & - \\
\hline Desired Occupation & & & & & & & & \\
\hline Farming 6 & Refer & ence & Refer & ence & Refer & ence & Refer & ence \\
\hline Mining, mineral extraction & -0.002 & 0.000 & -0.002 & 0.002 & - & - & - & - \\
\hline Manufacturing & -0.002 & 0.000 & -0.002 & 0.001 & -0.004 & 0.001 & 0.000 & 0.003 \\
\hline Technical professions & -0.002 & 0.000 & -0.003 & 0.001 & -0.006 & 0.001 & -0.003 & 0.003 \\
\hline Service Professions & -0.003 & 0.000 & -0.004 & 0.001 & -0.006 & 0.001 & -0.002 & 0.003 \\
\hline Other occupations & -0.002 & 0.000 & -0.003 & 0.000 & -0.006 & 0.001 & -0.009 & 0.002 \\
\hline Other & - & - & - & - & - & - & - & - \\
\hline$N$ & 152 , & 699 & 67,0 & & 35 & 42 & 23 , & 44 \\
\hline Log-Likelihood & $-3,69$ & 7.96 & $-2,45$ & 6.47 & $-2,03$ & 3.01 & $-2,01$ & 0.49 \\
\hline$R^{2}$ & 0.1 & & 0.1 & & 0.1 & & 0.1 & \\
\hline
\end{tabular}

Bold letters indicate significance at $1 \%$ level, italic letters refer to the $5 \%$ level.

- Variables not included in estimation due to collinearity to other variables, perfect prediction of participation decision or missing.

1 Attendant for vocational rehabilitation.

2 Similar programme before unemployment, e.g., job creation or structural adjustment scheme.

3 Schooling: CSE = Certificate of Secondary Education.

4 Advanced technical college entrance qualification (Fachhochschulreife)

5 Ass. = assimilable

${ }^{6}$ Farming comprises plant cultivation, breeding and fishery.

Tab. D.2: Estimation Results of the Probit-Models for the Propensity SCORES FOR TREATMENT STARTING IN QuARTER $u=5$ TO $u=8$ (MEN IN WeST GERMANY)

\begin{tabular}{|c|c|c|c|c|c|c|c|c|}
\hline & \multicolumn{2}{|c|}{$u=5$} & \multicolumn{2}{|c|}{$u=6$} & \multicolumn{2}{|c|}{$u=7$} & \multicolumn{2}{|c|}{$u=8$} \\
\hline & $d F / d x$ & Std. Err. & $d F / d x$ & Std. Err. & $d F / d x$ & Std. Err. & $d F / d x$ & Std. Err. \\
\hline \multicolumn{9}{|l|}{ Age } \\
\hline 25 to 29 years & \multicolumn{2}{|c|}{ Reference } & \multicolumn{2}{|c|}{ Reference } & \multicolumn{2}{|c|}{ Reference } & \multicolumn{2}{|c|}{ Reference } \\
\hline 30 to 34 years & -0.002 & 0.004 & 0.001 & 0.004 & -0.009 & 0.003 & 0.006 & 0.008 \\
\hline 35 to 39 years & 0.002 & 0.004 & -0.002 & 0.003 & -0.001 & 0.004 & 0.007 & 0.007 \\
\hline 40 to 44 years & -0.003 & 0.004 & -0.006 & 0.003 & -0.008 & 0.003 & 0.008 & 0.008 \\
\hline 45 to 49 years & -0.002 & 0.004 & -0.005 & 0.003 & -0.005 & 0.004 & 0.000 & 0.006 \\
\hline 50 to 55 years & -0.003 & 0.004 & -0.004 & 0.003 & -0.009 & 0.004 & 0.000 & 0.006 \\
\hline Foreigner & -0.014 & 0.002 & -0.009 & 0.002 & -0.008 & 0.003 & -0.009 & 0.003 \\
\hline Asylum-seeker & -0.006 & 0.004 & -0.002 & 0.004 & -0.008 & 0.004 & 0.005 & 0.007 \\
\hline
\end{tabular}


TABLE D.2: (CONTINUED)

\begin{tabular}{|c|c|c|c|c|c|c|c|c|}
\hline & \multicolumn{2}{|c|}{$u=5$} & \multicolumn{2}{|c|}{$u=6$} & \multicolumn{2}{|c|}{$u=7$} & \multicolumn{2}{|c|}{$u=8$} \\
\hline & $d F / d x$ & Std. Err. & $d F / d x$ & Std. Err. & $d F / d x$ & Std. Err. & $d F / d x$ & Std. Err. \\
\hline No. of placement offers & 0.001 & 0.000 & 0.001 & 0.000 & 0.001 & 0.000 & 0.001 & 0.000 \\
\hline No. of children & 0.004 & 0.001 & -0.001 & 0.001 & -0.001 & 0.001 & 0.002 & 0.001 \\
\hline Placement restrictions & 0.003 & 0.004 & -0.004 & 0.003 & -0.006 & 0.004 & -0.007 & 0.003 \\
\hline Vocational rehabilitation $^{1}$ & 0.006 & 0.005 & 0.009 & 0.006 & 0.012 & 0.008 & 0.014 & 0.009 \\
\hline Health restrictions & -0.001 & 0.003 & 0.000 & 0.003 & 0.002 & 0.004 & 0.010 & 0.005 \\
\hline Marriage/ cohabitation & 0.001 & 0.003 & 0.003 & 0.002 & 0.005 & 0.003 & 0.000 & 0.003 \\
\hline Work experience & 0.003 & 0.004 & 0.000 & 0.004 & 0.006 & 0.004 & 0.000 & 0.004 \\
\hline Programme bef. unemp. ${ }^{2}$ & 0.069 & 0.008 & 0.041 & 0.007 & $\mathbf{0 . 0 3 9}$ & 0.008 & 0.034 & 0.008 \\
\hline Reception of UI & -0.052 & 0.007 & -0.013 & 0.005 & $-\mathbf{0 . 0 1 9}$ & 0.006 & -0.023 & 0.007 \\
\hline \multicolumn{9}{|l|}{ Duration of Last Job } \\
\hline up to 180 days & 0.018 & 0.003 & 0.021 & 0.004 & 0.027 & 0.005 & 0.026 & 0.005 \\
\hline between 180 and 365 days & -0.012 & 0.002 & -0.009 & 0.002 & -0.006 & 0.003 & -0.006 & 0.003 \\
\hline between 366 and 730 days & -0.001 & 0.003 & -0.003 & 0.003 & -0.002 & 0.004 & 0.008 & 0.005 \\
\hline more than 730 days & \multicolumn{2}{|c|}{ Reference } & \multicolumn{2}{|c|}{ Reference } & \multicolumn{2}{|c|}{ Reference } & \multicolumn{2}{|c|}{ Reference } \\
\hline Pension & & & & & & & & \\
\hline No pension & Refer & ence & Refer & ence & Refe & ence & Refe & ence \\
\hline Vocational disability & - & - & - & - & - & - & - & - \\
\hline Permanently unable to work & 0.023 & 0.039 & - & - & 0.033 & 0.043 & 0.015 & 0.036 \\
\hline Social plan & - & - & - & - & - & - & - & - \\
\hline Schooling ${ }^{3}$ & & & & & & & & \\
\hline No school & Refer & ence & Refer & ence & Refe & ence & Refe & ence \\
\hline CSE & -0.004 & 0.003 & 0.003 & 0.002 & -0.007 & 0.003 & 0.002 & 0.003 \\
\hline O-levels & -0.003 & 0.004 & 0.000 & 0.004 & -0.007 & 0.004 & -0.003 & 0.005 \\
\hline Adv. technical college entrance ${ }^{4}$ & 0.006 & 0.007 & 0.008 & 0.009 & -0.011 & 0.004 & 0.002 & 0.009 \\
\hline A-levels & 0.004 & 0.007 & -0.003 & 0.005 & -0.002 & 0.006 & 0.011 & 0.011 \\
\hline Professional Training & & & & & & & & \\
\hline Without compl. prof. training & Refer & ence & Refer & ence & Refe & ence & Refe & ence \\
\hline Apprenticeship (on-the-job) & 0.004 & 0.003 & -0.008 & 0.002 & 0.005 & 0.003 & -0.002 & 0.003 \\
\hline Apprenticeship (off-the job) & 0.016 & 0.014 & 0.014 & 0.015 & 0.073 & 0.041 & 0.022 & 0.033 \\
\hline Full-time vocational school & 0.006 & 0.011 & -0.007 & 0.004 & 0.015 & 0.018 & -0.002 & 0.010 \\
\hline Technical school & 0.000 & 0.007 & 0.012 & 0.010 & 0.003 & 0.012 & -0.002 & 0.009 \\
\hline Advanced technical college & -0.005 & 0.008 & 0.003 & 0.012 & 0.030 & 0.030 & 0.005 & 0.015 \\
\hline University & -0.001 & 0.008 & 0.005 & 0.012 & -0.006 & 0.008 & -0.005 & 0.008 \\
\hline Assessment of Individual's Qualt & & & & & & & & \\
\hline Other & Refer & ence & Refer & ence & Refe & ence & Refe & ence \\
\hline Unskilled employee & - & - & - & - & - & - & - & - \\
\hline Skilled employee & -0.004 & 0.003 & -0.001 & 0.003 & -0.003 & 0.003 & 0.001 & 0.004 \\
\hline Ass. to technical school ${ }^{5}$ & 0.009 & 0.009 & 0.009 & 0.009 & -0.013 & 0.004 & 0.004 & 0.013 \\
\hline Ass. to adv. technical college & 0.031 & 0.017 & -0.001 & 0.008 & 0.005 & 0.014 & 0.032 & 0.027 \\
\hline Ass. to university & 0.008 & 0.011 & 0.005 & 0.011 & 0.006 & 0.015 & 0.012 & 0.017 \\
\hline Ass. to top-management & - & - & - & - & - & - & - & - \\
\hline Month of Treatment Start & & & & & & & & \\
\hline July 2000 & Refer & ence & Refer & ence & Refe & ence & Refe & ence \\
\hline September 2000 & -0.008 & 0.003 & 0.008 & 0.004 & -0.001 & 0.003 & -0.006 & 0.003 \\
\hline November 2000 & 0.002 & 0.004 & 0.001 & 0.004 & 0.003 & 0.004 & -0.001 & 0.004 \\
\hline January 2001 & -0.001 & 0.004 & 0.007 & 0.005 & 0.003 & 0.005 & -0.003 & 0.004 \\
\hline March 2001 & 0.011 & 0.005 & 0.003 & 0.004 & 0.001 & 0.004 & 0.006 & 0.005 \\
\hline May 2001 & 0.009 & 0.004 & 0.007 & 0.004 & -0.004 & 0.003 & -0.001 & 0.004 \\
\hline Regional Context Variables & & & & & & & & \\
\hline Cluster Ia & - & - & - & - & - & - & - & - \\
\hline Cluster Ib & - & - & - & - & - & - & - & - \\
\hline Cluster Ic & - & - & - & - & - & - & - & - \\
\hline Cluster II & Refer & ence & Refer & ence & Refe & ence & Refe & ence \\
\hline Cluster III & -0.002 & 0.002 & 0.001 & 0.002 & 0.003 & 0.003 & -0.003 & 0.003 \\
\hline Cluster IV & -0.008 & 0.003 & 0.000 & 0.004 & 0.002 & 0.005 & -0.013 & 0.002 \\
\hline Cluster V & 0.002 & 0.003 & 0.005 & 0.004 & 0.002 & 0.004 & -0.003 & 0.004 \\
\hline Work Time (Last Job) & & & & & & & & \\
\hline Full-time work & Refer & ence & Refer & ence & Refe & ence & Refe & ence \\
\hline Part-time work & 0.003 & 0.013 & 0.015 & 0.020 & 0.007 & 0.019 & 0.012 & 0.021 \\
\hline Not applicable & -0.018 & 0.003 & -0.009 & 0.002 & -0.008 & 0.003 & -0.009 & 0.003 \\
\hline Desired Work Time & & & & & & & & \\
\hline Full-time work & Refer & ence & Refer & ace & Refe & nce & Refe & ence \\
\hline part-time work & -0.010 & 0.008 & 0.004 & 0.012 & -0.006 & 0.011 & -0.009 & 0.008 \\
\hline Other (e.g. telework) & - & - & - & - & - & - & - & - \\
\hline Desired Occupation & & & & & & & & \\
\hline Farming $^{6}$ & Refer & ence & Refer & ence & Refe & nce & Refe & ence \\
\hline Mining, mineral extraction & -0.017 & 0.005 & - & - & - & - & -0.008 & 0.007 \\
\hline Manufacturing & -0.012 & 0.004 & -0.010 & 0.003 & -0.014 & 0.004 & -0.012 & 0.005 \\
\hline Technical professions & -0.018 & 0.002 & -0.010 & 0.002 & -0.014 & 0.002 & -0.014 & 0.002 \\
\hline
\end{tabular}


TABLE D.2: (CONTINUED)

\begin{tabular}{|c|c|c|c|c|c|c|c|c|}
\hline & \multicolumn{2}{|c|}{$u=5$} & \multicolumn{2}{|c|}{$\overline{u=6}$} & \multicolumn{2}{|c|}{$u=7$} & \multicolumn{2}{|c|}{$u=8$} \\
\hline & $d F / d x$ & Std. Err. & $d F / d x$ & Std. Err. & $d F / d x$ & Std. Err. & $d F / d x$ & Std. Err. \\
\hline Service Professions & -0.017 & 0.004 & -0.013 & 0.003 & -0.016 & 0.004 & -0.014 & 0.004 \\
\hline Other occupations & -0.021 & 0.001 & -0.013 & 0.001 & -0.016 & 0.002 & - & - \\
\hline Other & - & - & - & - & - & - & - & - \\
\hline$N$ & \multicolumn{2}{|c|}{15,822} & \multicolumn{2}{|c|}{11,479} & \multicolumn{2}{|c|}{9,437} & \multicolumn{2}{|c|}{7,428} \\
\hline Log-Likelihood & \multicolumn{2}{|c|}{$-2,054.80$} & \multicolumn{2}{|c|}{$-1,108.76$} & \multicolumn{2}{|c|}{$-1,012.22$} & \multicolumn{2}{|c|}{-777.01} \\
\hline$R^{2}$ & \multicolumn{2}{|c|}{0.188} & \multicolumn{2}{|c|}{0.176} & \multicolumn{2}{|c|}{0.160} & \multicolumn{2}{|c|}{0.175} \\
\hline
\end{tabular}

Bold letters indicate significance at $1 \%$ level, italic letters refer to the $5 \%$ level.

- Variables not included in estimation due to collinearity to other variables, perfect prediction of participation decision or missing.

1 Attendant for vocational rehabilitation.

2 Similar programme before unemployment, e.g., job creation or structural adjustment scheme.

3 Schooling: CSE = Certificate of Secondary Education.

4 Advanced technical college entrance qualification (Fachhochschulreife)

${ }^{5}$ Ass. $=$ assimilable

${ }^{6}$ Farming comprises plant cultivation, breeding and fishery.

Tab. D.3: Estimation Results of the Probit-Models for the Propensity Scores For Treatment Starting In Quarter $u=9$ TO $u=12$ (MEN IN West GERMANY)

\begin{tabular}{|c|c|c|c|c|c|c|c|c|}
\hline & \multicolumn{2}{|c|}{$\bar{u} u=9$} & \multicolumn{2}{|c|}{$u=10$} & \multicolumn{2}{|c|}{$u=11$} & \multicolumn{2}{|c|}{$u=12$} \\
\hline & $d F / d x$ & Std. Err. & $d F / d x$ & Std. Err. & $d F / d x$ & Std. Err. & $d F / d x$ & Std. Err. \\
\hline \multicolumn{9}{|l|}{ Age } \\
\hline 25 to 29 years & \multicolumn{2}{|c|}{ Reference } & \multicolumn{2}{|c|}{ Reference } & \multicolumn{2}{|c|}{ Reference } & \multicolumn{2}{|c|}{ Reference } \\
\hline 30 to 34 years & -0.011 & 0.005 & -0.010 & 0.005 & 0.000 & 0.007 & -0.008 & 0.004 \\
\hline 35 to 39 years & -0.013 & 0.005 & -0.013 & 0.004 & -0.005 & 0.006 & -0.013 & 0.003 \\
\hline 40 to 44 years & -0.014 & 0.005 & -0.016 & 0.004 & -0.008 & 0.005 & -0.010 & 0.004 \\
\hline 45 to 49 years & -0.018 & 0.004 & -0.017 & 0.004 & -0.011 & 0.005 & -0.015 & 0.004 \\
\hline 50 to 55 years & -0.019 & 0.005 & -0.018 & 0.005 & -0.011 & 0.006 & -0.024 & 0.005 \\
\hline Foreigner & -0.012 & 0.004 & -0.010 & 0.004 & -0.003 & 0.004 & -0.007 & 0.003 \\
\hline Asylum-seeker & -0.004 & 0.007 & 0.014 & 0.012 & 0.001 & 0.008 & 0.000 & 0.008 \\
\hline No. of placement offers & 0.001 & 0.000 & 0.002 & 0.000 & 0.001 & 0.000 & 0.001 & 0.000 \\
\hline No. of children & 0.004 & 0.002 & 0.003 & 0.002 & 0.000 & 0.002 & 0.002 & 0.002 \\
\hline Placement restrictions & 0.001 & 0.007 & -0.003 & 0.006 & 0.009 & 0.009 & 0.011 & 0.009 \\
\hline Vocational rehabilitation $^{1}$ & 0.010 & 0.010 & -0.006 & 0.006 & 0.004 & 0.009 & 0.012 & 0.011 \\
\hline Health restrictions & -0.001 & 0.006 & 0.009 & 0.006 & -0.004 & 0.006 & -0.006 & 0.006 \\
\hline Marriage/ cohabitation & -0.002 & 0.004 & -0.001 & 0.004 & 0.000 & 0.004 & 0.002 & 0.004 \\
\hline Work experience & 0.006 & 0.005 & -0.001 & 0.007 & 0.006 & 0.005 & 0.001 & 0.005 \\
\hline Programme bef. unemp. ${ }^{2}$ & 0.066 & 0.011 & 0.025 & 0.009 & 0.033 & 0.010 & 0.061 & 0.015 \\
\hline Reception of UI & -0.029 & 0.009 & -0.018 & 0.009 & -0.018 & 0.009 & -0.016 & 0.011 \\
\hline \multicolumn{9}{|l|}{ Duration of Last Job } \\
\hline up to 180 days & 0.040 & 0.007 & 0.047 & 0.008 & 0.048 & 0.009 & 0.013 & 0.005 \\
\hline between 180 and 365 days & -0.004 & 0.005 & -0.005 & 0.005 & 0.006 & 0.008 & -0.011 & 0.003 \\
\hline between 366 and 730 days & -0.013 & 0.004 & -0.004 & 0.006 & 0.001 & 0.007 & -0.011 & 0.003 \\
\hline more than 730 days & \multicolumn{2}{|c|}{ Reference } & \multicolumn{2}{|c|}{ Reference } & \multicolumn{2}{|c|}{ Reference } & \multicolumn{2}{|c|}{ Reference } \\
\hline \multicolumn{9}{|l|}{ Pension } \\
\hline No pension & \multicolumn{2}{|c|}{ Reference } & \multicolumn{2}{|c|}{ Reference } & \multicolumn{2}{|c|}{ Reference } & \multicolumn{2}{|c|}{ Reference } \\
\hline Vocational disability & - & - & - & - & 0.008 & 0.029 & - & - \\
\hline Permanently unable to work & -0.003 & 0.028 & - & - & - & - & - & - \\
\hline Social plan & - & - & - & - & - & - & - & - \\
\hline \multicolumn{9}{|l|}{ Schooling ${ }^{3}$} \\
\hline No school & \multicolumn{2}{|c|}{ Reference } & \multicolumn{2}{|c|}{ Reference } & \multicolumn{2}{|c|}{ Reference } & Refer & ence \\
\hline CSE & 0.006 & 0.004 & 0.002 & 0.004 & 0.003 & 0.004 & -0.001 & 0.004 \\
\hline O-levels & -0.001 & 0.007 & -0.007 & 0.006 & 0.004 & 0.009 & 0.012 & 0.011 \\
\hline Adv. technical college entrance ${ }^{4}$ & 0.022 & 0.020 & -0.017 & 0.004 & -0.009 & 0.008 & 0.019 & 0.025 \\
\hline A-levels & -0.006 & 0.009 & -0.006 & 0.009 & -0.011 & 0.006 & 0.009 & 0.014 \\
\hline Professional Training & & & & & & & & \\
\hline Without compl. prof. training & Refer & ence & Refer & ence & Refer & ence & Refer & ence \\
\hline Apprenticeship (on-the-job) & -0.009 & 0.004 & -0.001 & 0.005 & -0.002 & 0.005 & -0.004 & 0.004 \\
\hline Apprenticeship (off-the job) & 0.021 & 0.032 & 0.060 & 0.055 & 0.029 & 0.041 & 0.030 & 0.071 \\
\hline Full-time vocational school & 0.002 & 0.016 & -0.016 & 0.004 & - & - & -0.003 & 0.011 \\
\hline Technical school & 0.004 & 0.014 & 0.002 & 0.019 & 0.021 & 0.028 & -0.002 & 0.011 \\
\hline Advanced technical college & -0.009 & 0.012 & 0.110 & 0.148 & 0.026 & 0.057 & 0.014 & 0.033 \\
\hline University & 0.050 & 0.044 & 0.000 & 0.027 & 0.037 & 0.056 & -0.003 & 0.019 \\
\hline
\end{tabular}


TABLE D.3: (CONTINUED)

\begin{tabular}{|c|c|c|c|c|c|c|c|c|}
\hline & \multicolumn{2}{|c|}{$u=9$} & \multicolumn{2}{|c|}{$u=10$} & \multicolumn{2}{|c|}{$u=11$} & \multicolumn{2}{|c|}{$u=12$} \\
\hline & $d F / d x$ & Std. Err. & $d F / d x$ & Std. Err. & $d F / d x$ & Std. Err. & $d F / d x$ & Std. Err. \\
\hline Other & \multicolumn{2}{|c|}{ Reference } & \multicolumn{2}{|c|}{ Reference } & \multicolumn{2}{|c|}{ Reference } & \multicolumn{2}{|c|}{ Reference } \\
\hline Unskilled employee & - & - & - & - & - & - & - & - \\
\hline Skilled employee & 0.004 & 0.005 & -0.008 & 0.004 & -0.008 & 0.004 & -0.006 & 0.004 \\
\hline Ass. to technical school ${ }^{5}$ & 0.067 & 0.034 & -0.006 & 0.014 & -0.006 & 0.010 & 0.010 & 0.020 \\
\hline Ass. to adv. technical college & 0.011 & 0.023 & -0.006 & 0.019 & -0.010 & 0.009 & -0.005 & 0.009 \\
\hline Ass. to university & -0.006 & 0.012 & -0.001 & 0.027 & 0.029 & 0.042 & -0.008 & 0.011 \\
\hline Ass. to top-management & - & - & - & - & - & - & - & - \\
\hline \multicolumn{9}{|l|}{ Month of Treatment Start } \\
\hline July 2000 & \multicolumn{2}{|c|}{ Reference } & \multicolumn{2}{|c|}{ Reference } & \multicolumn{2}{|c|}{ Reference } & \multicolumn{2}{|c|}{ Reference } \\
\hline September 2000 & -0.005 & 0.004 & -0.005 & 0.005 & 0.001 & 0.006 & 0.000 & 0.005 \\
\hline November 2000 & -0.011 & 0.004 & -0.003 & 0.005 & 0.016 & 0.010 & 0.013 & 0.009 \\
\hline January 2001 & -0.008 & 0.004 & -0.007 & 0.005 & 0.017 & 0.010 & 0.015 & 0.011 \\
\hline March 2001 & -0.005 & 0.005 & 0.000 & 0.005 & 0.018 & 0.010 & 0.006 & 0.008 \\
\hline May 2001 & -0.009 & 0.004 & -0.014 & 0.004 & 0.006 & 0.007 & 0.012 & 0.008 \\
\hline \multicolumn{9}{|l|}{ Regional Context Variables } \\
\hline Cluster Ia & - & - & - & - & - & - & - & - \\
\hline Cluster Ib & - & - & - & - & - & - & - & - \\
\hline Cluster Ic & - & - & - & - & - & - & - & - \\
\hline Cluster II & \multicolumn{2}{|c|}{ Reference } & \multicolumn{2}{|c|}{ Reference } & \multicolumn{2}{|c|}{ Reference } & \multicolumn{2}{|c|}{ Reference } \\
\hline Cluster III & -0.003 & 0.004 & -0.004 & 0.004 & -0.004 & 0.004 & -0.005 & 0.003 \\
\hline Cluster IV & -0.012 & 0.004 & -0.005 & 0.005 & -0.008 & 0.004 & -0.004 & 0.005 \\
\hline Cluster V & 0.000 & 0.005 & -0.006 & 0.005 & -0.007 & 0.004 & -0.008 & 0.003 \\
\hline \multicolumn{9}{|l|}{ Work Time (Last Job) } \\
\hline Full-time work & \multicolumn{2}{|c|}{ Reference } & \multicolumn{2}{|c|}{ Reference } & \multicolumn{2}{|c|}{ Reference } & \multicolumn{2}{|c|}{ Reference } \\
\hline Part-time work & -0.001 & 0.021 & 0.026 & 0.052 & 0.000 & 0.022 & 0.087 & 0.107 \\
\hline Not applicable & -0.030 & 0.005 & -0.029 & 0.006 & -0.020 & 0.005 & -0.015 & 0.005 \\
\hline Desired Work Time & & & & & & & & \\
\hline Full-time work & Refer & ence & Refer & ence & Refer & ence & Refer & ence \\
\hline part-time work & -0.004 & 0.020 & 0.003 & 0.022 & - & - & - & - \\
\hline Other (e.g. telework) & - & - & - & - & - & - & - & - \\
\hline Desired Occupation & & & & & & & & \\
\hline Farming 6 & Refer & ence & Refer & ence & Refer & ence & Refer & ence \\
\hline Mining, mineral extraction & -0.016 & 0.006 & - & - & - & - & - & - \\
\hline Manufacturing & -0.031 & 0.006 & -0.006 & 0.006 & -0.009 & 0.006 & 0.003 & 0.006 \\
\hline Technical professions & -0.023 & 0.002 & - & - & -0.013 & 0.004 & -0.006 & 0.007 \\
\hline Service Professions & -0.033 & 0.006 & -0.014 & 0.007 & -0.014 & 0.006 & -0.003 & 0.006 \\
\hline Other occupations & - & - & -0.017 & 0.003 & - & - & - & - \\
\hline Other & - & - & - & - & - & - & - & - \\
\hline$N$ & 6,0 & & 4,6 & & 3,9 & & 3,2 & \\
\hline Log-Likelihood & -850 & 01 & $-60 s$ & .05 & -46 & & -362 & 83 \\
\hline$R^{2}$ & 0.2 & & 0.2 & & 0.2 & & 0.2 & \\
\hline
\end{tabular}

Bold letters indicate significance at $1 \%$ level, italic letters refer to the $5 \%$ level.

- Variables not included in estimation due to collinearity to other variables, perfect prediction of participation decision or missing.

1 Attendant for vocational rehabilitation.

2 Similar programme before unemployment, e.g., job creation or structural adjustment scheme.

3 Schooling: CSE = Certificate of Secondary Education.

4 Advanced technical college entrance qualification (Fachhochschulreife)

5 Ass. = assimilable

${ }^{6}$ Farming comprises plant cultivation, breeding and fishery.

Tab. D.4: Estimation Results of the Probit-Models for the Propensity SCORES FOR TREATMENT STARTING IN QUARTER $u=1$ TO $u=4$ (WOMEN IN WEST GERMANY)

\begin{tabular}{|c|c|c|c|c|c|c|c|c|}
\hline & \multicolumn{2}{|c|}{$u=1$} & \multicolumn{2}{|c|}{$u=2$} & \multicolumn{2}{|c|}{$u=3$} & \multicolumn{2}{|c|}{$u=4$} \\
\hline & $d F / d x$ & Std. Err. & $d F / d x$ & Std. Err. & $d F / d x$ & Std. Err. & $d F / d x$ & Std. Err. \\
\hline \multicolumn{9}{|l|}{ Age } \\
\hline 25 to 29 years & \multicolumn{2}{|c|}{ Reference } & \multicolumn{2}{|c|}{ Reference } & \multicolumn{2}{|c|}{ Reference } & \multicolumn{2}{|c|}{ Reference } \\
\hline 30 to 34 years & 0.000 & 0.000 & 0.001 & 0.001 & 0.002 & 0.001 & -0.001 & 0.002 \\
\hline 35 to 39 years & 0.001 & 0.000 & 0.001 & 0.001 & 0.001 & 0.001 & 0.001 & 0.002 \\
\hline 40 to 44 years & 0.000 & 0.000 & 0.000 & 0.001 & 0.003 & 0.002 & 0.000 & 0.002 \\
\hline 45 to 49 years & 0.000 & 0.000 & 0.001 & 0.001 & 0.002 & 0.002 & 0.000 & 0.002 \\
\hline 50 to 55 years & 0.001 & 0.001 & 0.002 & 0.001 & 0.002 & 0.002 & -0.001 & 0.002 \\
\hline Foreigner & -0.001 & 0.000 & 0.000 & 0.001 & -0.002 & 0.001 & -0.002 & 0.001 \\
\hline Asylum-seeker & 0.000 & 0.000 & -0.002 & 0.000 & -0.001 & 0.001 & -0.004 & 0.001 \\
\hline
\end{tabular}


TABLE D.4: (CONTINUED)

\begin{tabular}{|c|c|c|c|c|c|c|c|c|}
\hline & \multicolumn{2}{|c|}{$u=1$} & \multicolumn{2}{|c|}{$u=2$} & \multicolumn{2}{|c|}{$u=3$} & \multicolumn{2}{|c|}{$u=4$} \\
\hline & $d F / d x$ & Std. Err. & $d F / d x$ & Std. Err. & $d F / d x$ & Std. Err. & $d F / d x$ & Std. Err. \\
\hline No. of placement offers & 0.000 & 0.000 & 0.000 & 0.000 & 0.000 & 0.000 & 0.000 & 0.000 \\
\hline No. of children & 0.000 & 0.000 & 0.001 & 0.000 & 0.001 & 0.000 & 0.001 & 0.001 \\
\hline Placement restrictions & 0.001 & 0.001 & 0.000 & 0.001 & 0.000 & 0.001 & 0.000 & 0.002 \\
\hline Vocational rehabilitation $^{1}$ & 0.000 & 0.000 & 0.002 & 0.001 & 0.007 & 0.003 & 0.004 & 0.004 \\
\hline Health restrictions & 0.001 & 0.000 & 0.001 & 0.001 & 0.001 & 0.001 & 0.001 & 0.002 \\
\hline Marriage/ cohabitation & 0.000 & 0.000 & -0.001 & 0.000 & -0.001 & 0.001 & -0.005 & 0.001 \\
\hline Work experience & 0.000 & 0.000 & 0.000 & 0.001 & 0.002 & 0.001 & 0.003 & 0.001 \\
\hline Programme bef. unemp. ${ }^{2}$ & 0.021 & 0.003 & 0.021 & 0.004 & 0.028 & 0.005 & 0.054 & 0.008 \\
\hline Reception of UI & 0.000 & 0.000 & 0.000 & 0.000 & -0.001 & 0.001 & -0.008 & 0.002 \\
\hline \multicolumn{9}{|l|}{ Duration of Last Job } \\
\hline up to 180 days & 0.000 & 0.000 & 0.002 & 0.001 & 0.003 & 0.001 & 0.005 & 0.002 \\
\hline between 180 and 365 days & -0.001 & 0.000 & 0.001 & 0.001 & -0.001 & 0.001 & -0.004 & 0.001 \\
\hline between 366 and 730 days & 0.000 & 0.000 & 0.000 & 0.000 & -0.001 & 0.001 & -0.003 & 0.001 \\
\hline more than 730 days & \multicolumn{2}{|c|}{ Reference } & \multicolumn{2}{|c|}{ Reference } & \multicolumn{2}{|c|}{ Reference } & \multicolumn{2}{|c|}{ Reference } \\
\hline Pension & & & & & & & & \\
\hline No pension & - & - & - & - & - & - & - & - \\
\hline Vocational disability & - & - & - & - & - & - & - & - \\
\hline Permanently unable to work & - & - & - & - & - & - & - & - \\
\hline Social plan & - & - & - & - & - & - & - & - \\
\hline Schooling ${ }^{3}$ & & & & & & & & \\
\hline No school & Refer & ence & Refer & ence & Refer & ence & Refer & ence \\
\hline CSE & 0.000 & 0.000 & 0.000 & 0.001 & -0.001 & 0.001 & 0.000 & 0.002 \\
\hline O-levels & 0.000 & 0.000 & 0.000 & 0.001 & 0.000 & 0.001 & 0.000 & 0.002 \\
\hline Adv. technical college entrance ${ }^{4}$ & 0.001 & 0.001 & 0.001 & 0.001 & 0.001 & 0.002 & 0.000 & 0.003 \\
\hline A-levels & 0.000 & 0.001 & 0.001 & 0.001 & 0.003 & 0.002 & 0.000 & 0.003 \\
\hline Professional Training & & & & & & & & \\
\hline Without compl. prof. training & Refer & ence & Refer & ence & Refer & ence & Refer & ence \\
\hline Apprenticeship (on-the-job) & 0.000 & 0.000 & 0.000 & 0.000 & 0.001 & 0.001 & -0.001 & 0.001 \\
\hline Apprenticeship (off-the job) & 0.002 & 0.001 & 0.000 & 0.001 & 0.004 & 0.004 & -0.003 & 0.003 \\
\hline Full-time vocational school & -0.001 & 0.000 & -0.001 & 0.001 & 0.003 & 0.002 & 0.002 & 0.004 \\
\hline Technical school & 0.000 & 0.000 & 0.002 & 0.001 & -0.001 & 0.001 & 0.004 & 0.003 \\
\hline Advanced technical college & 0.001 & 0.001 & 0.002 & 0.002 & 0.001 & 0.002 & 0.002 & 0.005 \\
\hline University & 0.000 & 0.001 & -0.001 & 0.001 & -0.001 & 0.001 & -0.002 & 0.003 \\
\hline Assessment of Individual's Quali & & & & & & & & \\
\hline Other & Refer & ence & Refer & ence & Refer & ence & Refer & ence \\
\hline Unskilled employee & - & - & - & - & - & - & - & - \\
\hline Skilled employee & 0.000 & 0.000 & 0.001 & 0.000 & 0.000 & 0.001 & 0.000 & 0.001 \\
\hline Ass. to technical school ${ }^{5}$ & 0.002 & 0.002 & 0.000 & 0.002 & -0.001 & 0.002 & 0.030 & 0.013 \\
\hline Ass. to adv. technical college & 0.002 & 0.001 & 0.007 & 0.004 & 0.013 & 0.006 & 0.012 & 0.008 \\
\hline Ass. to university & 0.004 & 0.002 & 0.006 & 0.003 & 0.004 & 0.003 & 0.010 & 0.007 \\
\hline Ass. to top-management & - & - & - & - & - & - & - & - \\
\hline Month of Treatment Start & & & & & & & & \\
\hline July 2000 & Refer & ence & Refer & ence & Refer & ence & Refer & ence \\
\hline September 2000 & 0.000 & 0.000 & 0.001 & 0.001 & 0.001 & 0.001 & 0.004 & 0.002 \\
\hline November 2000 & 0.000 & 0.000 & 0.002 & 0.001 & 0.005 & 0.002 & 0.006 & 0.003 \\
\hline January 2001 & 0.001 & 0.000 & 0.001 & 0.001 & 0.008 & 0.002 & 0.006 & 0.003 \\
\hline March 2001 & 0.000 & 0.000 & 0.001 & 0.001 & 0.003 & 0.002 & 0.010 & 0.003 \\
\hline May 2001 & 0.000 & 0.000 & 0.000 & 0.001 & 0.001 & 0.001 & 0.005 & 0.002 \\
\hline Regional Context Variables & & & & & & & & \\
\hline Cluster Ia & - & - & - & - & - & - & - & - \\
\hline Cluster Ib & - & - & - & - & - & - & - & - \\
\hline Cluster Ic & - & - & - & - & - & - & - & - \\
\hline Cluster II & Refer & ence & Refer & ence & Refer & ence & Refer & ence \\
\hline Cluster III & -0.001 & 0.000 & 0.000 & 0.000 & 0.000 & 0.001 & -0.003 & 0.001 \\
\hline Cluster IV & -0.001 & 0.000 & -0.001 & 0.000 & -0.002 & 0.001 & -0.002 & 0.002 \\
\hline Cluster V & -0.001 & 0.000 & -0.001 & 0.000 & -0.002 & 0.001 & -0.001 & 0.001 \\
\hline Work Time (Last Job) & & & & & & & & \\
\hline Full-time work & Refer & nce & Refer & ence & Refel & ence & Refer & ence \\
\hline Part-time work & 0.000 & 0.000 & 0.001 & 0.001 & 0.001 & 0.001 & -0.001 & 0.002 \\
\hline Not applicable & 0.000 & 0.000 & 0.000 & 0.000 & 0.000 & 0.001 & -0.003 & 0.001 \\
\hline Desired Work Time & & & & & & & & \\
\hline Full-time work & Refer & nce & Refer & ence & Refer & ence & Refer & ence \\
\hline part-time work & 0.000 & 0.000 & -0.001 & 0.000 & -0.003 & 0.001 & -0.002 & 0.001 \\
\hline Other (e.g. telework) & - & - & - & - & - & - & - & - \\
\hline Desired Occupation & & & & & & & & \\
\hline Farming $^{6}$ & Refer & nce & Refer & ence & Refer & ence & Refer & ence \\
\hline Mining, mineral extraction & - & - & - & - & - & - & - & - \\
\hline Manufacturing & -0.001 & 0.000 & -0.001 & 0.001 & -0.001 & 0.001 & -0.005 & 0.002 \\
\hline Technical professions & -0.001 & 0.000 & -0.002 & 0.000 & -0.003 & 0.000 & -0.007 & 0.001 \\
\hline
\end{tabular}


TABLE D.4: (CONTINUED)

\begin{tabular}{|c|c|c|c|c|c|c|c|c|}
\hline & \multicolumn{2}{|c|}{$u=1$} & \multicolumn{2}{|c|}{$\overline{u=2}$} & \multicolumn{2}{|c|}{$u=3$} & \multicolumn{2}{|c|}{$u=4$} \\
\hline & $d F / d x$ & Std. Err. & $d F / d x$ & Std. Err. & $d F / d x$ & Std. Err. & $d F / d x$ & Std. Err. \\
\hline Service Professions & -0.001 & 0.001 & -0.002 & 0.001 & -0.004 & 0.002 & -0.005 & 0.004 \\
\hline Other occupations & -0.001 & 0.000 & -0.002 & 0.000 & -0.003 & 0.000 & -0.007 & 0.001 \\
\hline Other & - & - & - & - & - & - & - & - \\
\hline$N$ & \multicolumn{2}{|c|}{120,045} & \multicolumn{2}{|c|}{57,926} & \multicolumn{2}{|c|}{33,145} & \multicolumn{2}{|c|}{22,270} \\
\hline Log-Likelihood & \multicolumn{2}{|c|}{$-1,811.82$} & \multicolumn{2}{|c|}{$-1,312.59$} & \multicolumn{2}{|c|}{$-1,225.41$} & \multicolumn{2}{|c|}{$-1,372.66$} \\
\hline$R^{2}$ & \multicolumn{2}{|c|}{0.141} & \multicolumn{2}{|c|}{0.157} & \multicolumn{2}{|c|}{0.188} & \multicolumn{2}{|c|}{0.195} \\
\hline
\end{tabular}

Bold letters indicate significance at $1 \%$ level, italic letters refer to the $5 \%$ level.

- Variables not included in estimation due to collinearity to other variables, perfect prediction of participation decision or missing.

1 Attendant for vocational rehabilitation.

2 Similar programme before unemployment, e.g., job creation or structural adjustment scheme.

3 Schooling: CSE = Certificate of Secondary Education.

4 Advanced technical college entrance qualification (Fachhochschulreife)

${ }^{5}$ Ass. $=$ assimilable

${ }^{6}$ Farming comprises plant cultivation, breeding and fishery.

Tab. D.5: Estimation Results of the Probit-Models for the Propensity SCORES FOR TREATMENT STARTING IN QUARTER $u=5$ TO $u=8$ (WOMEN IN WEST GERMANY)

\begin{tabular}{|c|c|c|c|c|c|c|c|c|}
\hline & \multicolumn{2}{|c|}{$u=5$} & \multicolumn{2}{|c|}{$u=6$} & \multicolumn{2}{|c|}{$u=7$} & \multicolumn{2}{|c|}{$u=8$} \\
\hline & $d F / d x$ & Std. Err. & $d F / d x$ & Std. Err. & $d F / d x$ & Std. Err. & $d F / d x$ & Std. Err. \\
\hline \multicolumn{9}{|l|}{ Age } \\
\hline 25 to 29 years & \multicolumn{2}{|c|}{ Reference } & \multicolumn{2}{|c|}{ Reference } & \multicolumn{2}{|c|}{ Reference } & \multicolumn{2}{|c|}{ Reference } \\
\hline 30 to 34 years & 0.001 & 0.003 & 0.002 & 0.004 & -0.002 & 0.003 & 0.001 & 0.004 \\
\hline 35 to 39 years & 0.004 & 0.004 & 0.007 & 0.005 & -0.003 & 0.002 & 0.000 & 0.004 \\
\hline 40 to 44 years & 0.006 & 0.004 & 0.009 & 0.006 & -0.003 & 0.002 & 0.002 & 0.004 \\
\hline 45 to 49 years & 0.005 & 0.004 & 0.002 & 0.004 & -0.004 & 0.002 & -0.001 & 0.004 \\
\hline 50 to 55 years & -0.002 & 0.003 & -0.001 & 0.003 & -0.008 & 0.002 & -0.002 & 0.004 \\
\hline Foreigner & -0.003 & 0.002 & -0.002 & 0.002 & -0.005 & 0.002 & -0.005 & 0.002 \\
\hline Asylum-seeker & -0.010 & 0.001 & -0.006 & 0.001 & -0.003 & 0.002 & -0.005 & 0.002 \\
\hline No. of placement offers & 0.001 & 0.000 & 0.000 & 0.000 & 0.000 & 0.000 & 0.001 & 0.000 \\
\hline No. of children & -0.001 & 0.001 & 0.000 & 0.001 & 0.001 & 0.001 & 0.001 & 0.001 \\
\hline Placement restrictions & 0.003 & 0.004 & -0.002 & 0.002 & -0.001 & 0.003 & -0.005 & 0.002 \\
\hline Vocational rehabilitation $^{1}$ & 0.006 & 0.006 & 0.005 & 0.006 & 0.042 & 0.020 & 0.025 & 0.016 \\
\hline Health restrictions & 0.000 & 0.003 & 0.001 & 0.003 & -0.001 & 0.003 & 0.003 & 0.004 \\
\hline Marriage/ cohabitation & -0.002 & 0.002 & 0.000 & 0.001 & 0.000 & 0.002 & 0.000 & 0.002 \\
\hline Work experience & 0.002 & 0.002 & -0.001 & 0.003 & 0.001 & 0.003 & 0.002 & 0.003 \\
\hline Programme bef. unemp. ${ }^{2}$ & 0.073 & 0.010 & 0.034 & 0.009 & 0.027 & 0.008 & 0.038 & 0.011 \\
\hline Reception of UI & -0.014 & 0.003 & -0.001 & 0.002 & 0.001 & 0.002 & 0.001 & 0.002 \\
\hline \multicolumn{9}{|l|}{ Duration of Last Job } \\
\hline up to 180 days & 0.011 & 0.003 & 0.008 & 0.003 & 0.014 & 0.003 & 0.012 & 0.004 \\
\hline between 180 and 365 days & 0.003 & 0.003 & -0.001 & 0.002 & -0.003 & 0.002 & -0.002 & 0.003 \\
\hline between 366 and 730 days & 0.002 & 0.003 & 0.006 & 0.003 & 0.002 & 0.003 & -0.001 & 0.003 \\
\hline more than 730 days & \multicolumn{2}{|c|}{ Reference } & \multicolumn{2}{|c|}{ Reference } & \multicolumn{2}{|c|}{ Reference } & \multicolumn{2}{|c|}{ Reference } \\
\hline \multicolumn{9}{|l|}{ Pension } \\
\hline No pension & - & - & - & - & - & - & - & - \\
\hline Vocational disability & - & - & - & - & - & - & - & - \\
\hline Permanently unable to work & - & - & - & - & - & - & - & - \\
\hline Social plan & - & - & - & - & - & - & - & - \\
\hline \multicolumn{9}{|l|}{ Schooling ${ }^{3}$} \\
\hline No school & \multicolumn{2}{|c|}{ Reference } & \multicolumn{2}{|c|}{ Reference } & \multicolumn{2}{|c|}{ Reference } & \multicolumn{2}{|c|}{ Reference } \\
\hline CSE & -0.001 & 0.003 & 0.001 & 0.003 & 0.002 & 0.003 & 0.002 & 0.004 \\
\hline O-levels & 0.000 & 0.003 & 0.003 & 0.004 & 0.000 & 0.004 & 0.009 & 0.007 \\
\hline Adv. technical college entrance ${ }^{4}$ & 0.010 & 0.007 & 0.004 & 0.006 & -0.001 & 0.004 & 0.037 & 0.022 \\
\hline A-levels & 0.012 & 0.007 & 0.005 & 0.006 & 0.003 & 0.006 & 0.028 & 0.016 \\
\hline \multicolumn{9}{|l|}{ Professional Training } \\
\hline Without compl. prof. training & \multicolumn{2}{|c|}{ Reference } & \multicolumn{2}{|c|}{ Reference } & Refer & ence & Refer & ence \\
\hline Apprenticeship (on-the-job) & 0.000 & 0.002 & -0.001 & 0.002 & 0.000 & 0.002 & -0.004 & 0.002 \\
\hline Apprenticeship (off-the job) & 0.015 & 0.011 & -0.002 & 0.005 & -0.005 & 0.004 & 0.007 & 0.012 \\
\hline Full-time vocational school & 0.009 & 0.007 & -0.004 & 0.002 & -0.002 & 0.004 & -0.006 & 0.002 \\
\hline Technical school & 0.010 & 0.006 & 0.001 & 0.004 & -0.001 & 0.004 & 0.001 & 0.004 \\
\hline Advanced technical college & 0.002 & 0.006 & -0.003 & 0.003 & -0.003 & 0.003 & -0.006 & 0.002 \\
\hline University & -0.006 & 0.002 & 0.004 & 0.006 & -0.006 & 0.002 & -0.007 & 0.002 \\
\hline
\end{tabular}


TABLE D.5: (CONTINUED)

\begin{tabular}{|c|c|c|c|c|c|c|c|c|}
\hline & \multicolumn{2}{|c|}{$u=5$} & \multicolumn{2}{|c|}{$\bar{u}=6$} & \multicolumn{2}{|c|}{$u=7$} & \multicolumn{2}{|c|}{$u=8$} \\
\hline & $d F / d x$ & Std. Err. & $d F / d x$ & Std. Err. & $d F / d x$ & Std. Err. & $d F / d x$ & Std. Err. \\
\hline Other & \multicolumn{2}{|c|}{ Reference } & \multicolumn{2}{|c|}{ Reference } & \multicolumn{2}{|c|}{ Reference } & \multicolumn{2}{|c|}{ Reference } \\
\hline Unskilled employee & - & - & - & - & - & - & - & - \\
\hline Skilled employee & 0.003 & 0.002 & 0.000 & 0.002 & 0.003 & 0.002 & 0.000 & 0.003 \\
\hline Ass. to technical school ${ }^{5}$ & -0.001 & 0.006 & 0.018 & 0.016 & 0.019 & 0.018 & - & - \\
\hline Ass. to adv. technical college & 0.022 & 0.011 & 0.023 & 0.015 & 0.063 & 0.034 & 0.006 & 0.009 \\
\hline Ass. to university & 0.013 & 0.008 & -0.002 & 0.003 & 0.042 & 0.025 & 0.001 & 0.006 \\
\hline Ass. to top-management & - & - & - & - & - & - & - & - \\
\hline \multicolumn{9}{|l|}{ Month of Treatment Start } \\
\hline July 2000 & \multicolumn{2}{|c|}{ Reference } & \multicolumn{2}{|c|}{ Reference } & \multicolumn{2}{|c|}{ Reference } & \multicolumn{2}{|c|}{ Reference } \\
\hline September 2000 & 0.000 & 0.002 & 0.005 & 0.003 & 0.005 & 0.003 & 0.002 & 0.003 \\
\hline November 2000 & 0.005 & 0.003 & 0.003 & 0.003 & 0.010 & 0.005 & 0.003 & 0.004 \\
\hline January 2001 & 0.012 & 0.004 & 0.007 & 0.004 & 0.014 & 0.006 & 0.011 & 0.006 \\
\hline March 2001 & 0.004 & 0.003 & 0.004 & 0.003 & 0.005 & 0.004 & 0.010 & 0.005 \\
\hline May 2001 & 0.003 & 0.003 & 0.001 & 0.003 & 0.004 & 0.004 & -0.004 & 0.002 \\
\hline \multicolumn{9}{|l|}{ Regional Context Variables } \\
\hline Cluster Ia & - & - & - & - & - & - & - & - \\
\hline Cluster Ib & - & - & - & - & - & - & - & - \\
\hline Cluster Ic & - & - & - & - & - & - & - & - \\
\hline Cluster II & \multicolumn{2}{|c|}{ Reference } & \multicolumn{2}{|c|}{ Reference } & \multicolumn{2}{|c|}{ Reference } & \multicolumn{2}{|c|}{ Reference } \\
\hline Cluster III & -0.001 & 0.002 & 0.001 & 0.002 & -0.001 & 0.002 & 0.000 & 0.002 \\
\hline Cluster IV & -0.004 & 0.002 & -0.001 & 0.002 & -0.002 & 0.002 & 0.000 & 0.003 \\
\hline Cluster V & 0.002 & 0.002 & 0.002 & 0.002 & -0.003 & 0.002 & 0.005 & 0.003 \\
\hline \multicolumn{9}{|l|}{ Work Time (Last Job) } \\
\hline Full-time work & \multicolumn{2}{|c|}{ Reference } & \multicolumn{2}{|c|}{ Reference } & \multicolumn{2}{|c|}{ Reference } & \multicolumn{2}{|c|}{ Reference } \\
\hline Part-time work & -0.001 & 0.002 & 0.002 & 0.003 & 0.000 & 0.003 & 0.006 & 0.005 \\
\hline Not applicable & -0.007 & 0.002 & -0.002 & 0.002 & -0.007 & 0.002 & -0.005 & 0.002 \\
\hline Desired Work Time & & & & & & & & \\
\hline Full-time work & Refer & ence & Refer & ence & Refer & ence & Refer & ence \\
\hline part-time work & -0.003 & 0.002 & -0.002 & 0.002 & -0.003 & 0.002 & -0.003 & 0.002 \\
\hline Other (e.g. telework) & - & - & - & - & - & - & - & - \\
\hline Desired Occupation & & & & & & & & \\
\hline Farming ${ }^{6}$ & Refer & ence & Refer & ence & Refer & ence & Refer & ence \\
\hline Mining, mineral extraction & - & - & - & - & - & - & - & - \\
\hline Manufacturing & -0.005 & 0.004 & 0.004 & 0.008 & -0.003 & 0.005 & -0.011 & 0.003 \\
\hline Technical professions & -0.004 & 0.004 & 0.000 & 0.007 & -0.001 & 0.006 & -0.005 & 0.003 \\
\hline Service Professions & -0.002 & 0.005 & 0.005 & 0.004 & 0.001 & 0.005 & -0.016 & 0.008 \\
\hline Other occupations & -0.009 & 0.002 & 0.010 & 0.017 & - & - & -0.006 & 0.002 \\
\hline Other & - & - & - & - & - & - & - & - \\
\hline$N$ & 15, & 38 & 11, & & 8,8 & & 7,0 & \\
\hline Log-Likelihood & $-1,29$ & 8.76 & -617 & .05 & -59 & .05 & -495 & \\
\hline$R^{2}$ & 0.2 & & 0.1 & & 0.1 & & 0.2 & \\
\hline
\end{tabular}

Bold letters indicate significance at $1 \%$ level, italic letters refer to the $5 \%$ level.

- Variables not included in estimation due to collinearity to other variables, perfect prediction of participation decision or missing.

1 Attendant for vocational rehabilitation.

2 Similar programme before unemployment, e.g., job creation or structural adjustment scheme.

3 Schooling: CSE = Certificate of Secondary Education.

4 Advanced technical college entrance qualification (Fachhochschulreife)

5 Ass. = assimilable

${ }^{6}$ Farming comprises plant cultivation, breeding and fishery.

Tab. D.6: Estimation Results of the Probit-Models for the Propensity SCORES FOR TREATMENT STARTING IN QUARTER $u=9$ TO $u=12$ (WOMEN IN WEST GERMANY)

\begin{tabular}{|c|c|c|c|c|c|c|c|c|}
\hline & \multicolumn{2}{|c|}{$u=9$} & \multicolumn{2}{|c|}{$u=10$} & \multicolumn{2}{|c|}{$u=11$} & \multicolumn{2}{|c|}{$u=12$} \\
\hline & $d F / d x$ & Std. Err. & $d F / d x$ & Std. Err. & $d F / d x$ & Std. Err. & $d F / d x$ & Std. Err. \\
\hline \multicolumn{9}{|l|}{ Age } \\
\hline 25 to 29 years & \multicolumn{2}{|c|}{ Reference } & \multicolumn{2}{|c|}{ Reference } & \multicolumn{2}{|c|}{ Reference } & \multicolumn{2}{|c|}{ Reference } \\
\hline 30 to 34 years & -0.005 & 0.003 & -0.004 & 0.004 & -0.004 & 0.002 & -0.004 & 0.004 \\
\hline 35 to 39 years & -0.006 & 0.003 & -0.002 & 0.005 & -0.004 & 0.002 & 0.001 & 0.007 \\
\hline 40 to 44 years & -0.002 & 0.004 & -0.008 & 0.003 & -0.005 & 0.002 & -0.002 & 0.005 \\
\hline 45 to 49 years & -0.009 & 0.003 & -0.004 & 0.004 & -0.003 & 0.002 & -0.003 & 0.005 \\
\hline 50 to 55 years & -0.009 & 0.003 & -0.009 & 0.004 & -0.008 & 0.003 & -0.001 & 0.006 \\
\hline Foreigner & -0.005 & 0.003 & 0.006 & 0.006 & 0.002 & 0.003 & -0.008 & 0.002 \\
\hline Asylum-seeker & -0.004 & 0.003 & -0.005 & 0.004 & -0.004 & 0.002 & -0.006 & 0.003 \\
\hline
\end{tabular}


TABLE D.6: (CONTINUED)

\begin{tabular}{|c|c|c|c|c|c|c|c|c|}
\hline \multirow{2}{*}{ 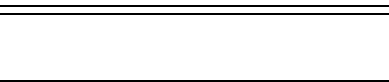 } & \multicolumn{2}{|c|}{$u=9$} & \multicolumn{2}{|c|}{$u=10$} & \multicolumn{2}{|c|}{$u=11$} & \multicolumn{2}{|c|}{$u=12$} \\
\hline & $d F / d x$ & Std. Err. & $d F / d x$ & Std. Err. & $d F / d x$ & Std. Err. & $d F / d x$ & Std. Err. \\
\hline No. of placement offers & 0.001 & 0.000 & 0.001 & 0.000 & 0.000 & 0.000 & 0.001 & 0.000 \\
\hline No. of children & 0.001 & 0.001 & 0.001 & 0.002 & 0.001 & 0.001 & 0.002 & 0.002 \\
\hline Placement restrictions & 0.006 & 0.007 & -0.004 & 0.004 & -0.001 & 0.003 & -0.004 & 0.004 \\
\hline Vocational rehabilitation $^{1}$ & 0.001 & 0.007 & -0.003 & 0.005 & 0.003 & 0.008 & 0.041 & 0.029 \\
\hline Health restrictions & -0.002 & 0.004 & 0.012 & 0.007 & 0.001 & 0.004 & -0.002 & 0.004 \\
\hline Marriage/ cohabitation & -0.007 & 0.003 & -0.004 & 0.003 & -0.001 & 0.002 & -0.006 & 0.004 \\
\hline Work experience & 0.000 & 0.004 & 0.001 & 0.004 & 0.000 & 0.003 & 0.002 & 0.004 \\
\hline Programme bef. unemp. ${ }^{2}$ & 0.068 & 0.016 & 0.035 & 0.014 & 0.036 & 0.015 & 0.015 & 0.011 \\
\hline Reception of UI & 0.002 & 0.003 & 0.000 & 0.003 & 0.002 & 0.002 & 0.004 & 0.003 \\
\hline \multicolumn{9}{|l|}{ Duration of Last Job } \\
\hline up to 180 days & 0.019 & 0.005 & 0.012 & 0.004 & 0.013 & 0.005 & 0.012 & 0.005 \\
\hline between 180 and 365 days & -0.004 & 0.003 & -0.004 & 0.004 & -0.003 & 0.002 & -0.004 & 0.003 \\
\hline between 366 and 730 days & -0.002 & 0.003 & -0.005 & 0.003 & 0.004 & 0.004 & 0.016 & 0.010 \\
\hline more than 730 days & \multicolumn{2}{|c|}{ Reference } & \multicolumn{2}{|c|}{ Reference } & \multicolumn{2}{|c|}{ Reference } & Refe & ence \\
\hline Pension & & & & & & & & \\
\hline No pension & - & - & - & - & - & - & - & - \\
\hline Vocational disability & - & - & - & - & - & - & - & - \\
\hline Permanently unable to work & - & - & - & - & - & - & - & - \\
\hline Social plan & - & - & - & - & - & - & - & - \\
\hline Schooling 3 & & & & & & & & \\
\hline No school & Refer & ence & Refer & ence & Refer & ence & Refe & ence \\
\hline CSE & -0.002 & 0.004 & 0.011 & 0.005 & 0.006 & 0.003 & -0.005 & 0.005 \\
\hline O-levels & 0.001 & 0.005 & 0.015 & 0.012 & 0.009 & 0.009 & -0.003 & 0.004 \\
\hline Adv. technical college entrance ${ }^{4}$ & 0.008 & 0.010 & 0.026 & 0.027 & 0.023 & 0.024 & 0.005 & 0.011 \\
\hline A-levels & 0.004 & 0.007 & 0.017 & 0.018 & 0.013 & 0.014 & -0.003 & 0.006 \\
\hline Professional Training & & & & & & & & \\
\hline Without compl. prof. training & Refer & ence & Refer & ence & Refer & ence & Refe & ence \\
\hline Apprenticeship (on-the-job) & 0.002 & 0.003 & 0.004 & 0.004 & -0.002 & 0.002 & -0.001 & 0.003 \\
\hline Apprenticeship (off-the job) & 0.010 & 0.017 & 0.053 & 0.044 & - & - & 0.029 & 0.041 \\
\hline Full-time vocational school & 0.019 & 0.014 & - & - & 0.000 & 0.004 & 0.013 & 0.015 \\
\hline Technical school & 0.016 & 0.011 & -0.002 & 0.007 & -0.003 & 0.002 & -0.003 & 0.005 \\
\hline Advanced technical college & 0.015 & 0.016 & 0.006 & 0.016 & -0.004 & 0.001 & -0.006 & 0.003 \\
\hline University & 0.023 & 0.020 & -0.001 & 0.008 & -0.002 & 0.004 & -0.006 & 0.003 \\
\hline Assessment of Individual's Qualifi & & & & & & & & \\
\hline Other & Refer & ence & Refer & ence & Refel & ence & Refe & ence \\
\hline Unskilled employee & - & - & - & - & - & - & - & - \\
\hline Skilled employee & 0.000 & 0.003 & -0.003 & 0.003 & 0.003 & 0.003 & 0.003 & 0.004 \\
\hline Ass. to technical school ${ }^{5}$ & 0.004 & 0.011 & 0.003 & 0.017 & 0.024 & 0.033 & - & - \\
\hline Ass. to adv. technical college & 0.018 & 0.016 & 0.010 & 0.018 & 0.106 & 0.070 & 0.015 & 0.031 \\
\hline Ass. to university & -0.007 & 0.003 & 0.020 & 0.022 & 0.019 & 0.025 & 0.020 & 0.032 \\
\hline Ass. to top-management & 0.015 & 0.029 & - & - & - & - & - & - \\
\hline Month of Treatment Start & & & & & & & & \\
\hline July 2000 & Refer & ence & Refer & ence & Refer & ence & Refe & ence \\
\hline September 2000 & 0.002 & 0.003 & 0.004 & 0.005 & 0.005 & 0.004 & 0.005 & 0.005 \\
\hline November 2000 & -0.002 & 0.003 & 0.003 & 0.005 & 0.006 & 0.005 & 0.010 & 0.008 \\
\hline January 2001 & -0.001 & 0.004 & 0.007 & 0.007 & 0.014 & 0.009 & 0.005 & 0.008 \\
\hline March 2001 & -0.005 & 0.003 & 0.000 & 0.005 & 0.003 & 0.004 & 0.007 & 0.007 \\
\hline May 2001 & -0.005 & 0.003 & -0.002 & 0.004 & -0.001 & 0.003 & -0.002 & 0.004 \\
\hline Regional Context Variables & & & & & & & & \\
\hline Cluster Ia & - & - & - & - & - & - & - & - \\
\hline Cluster Ib & - & - & - & - & - & - & - & - \\
\hline Cluster Ic & - & - & - & - & - & - & - & - \\
\hline Cluster II & Refer & ence & Refer & ence & Refer & ence & Refe & ence \\
\hline Cluster III & -0.003 & 0.003 & -0.003 & 0.003 & -0.001 & 0.002 & -0.004 & 0.003 \\
\hline Cluster IV & 0.006 & 0.005 & -0.001 & 0.004 & -0.003 & 0.002 & -0.004 & 0.003 \\
\hline Cluster V & 0.004 & 0.004 & -0.006 & 0.003 & -0.003 & 0.002 & -0.005 & 0.003 \\
\hline Work Time (Last Job) & & & & & & & & \\
\hline Full-time work & Refer & ence & Refer & ence & Refer & ence & Refe & ence \\
\hline Part-time work & 0.005 & 0.005 & 0.000 & 0.005 & 0.002 & 0.004 & 0.014 & 0.012 \\
\hline Not applicable & -0.019 & 0.004 & -0.019 & 0.005 & -0.011 & 0.004 & 0.000 & 0.003 \\
\hline Desired Work Time & & & & & & & & \\
\hline Full-time work & Refer & ence & Refer & ence & Refer & ence & Refe & ence \\
\hline part-time work & -0.005 & 0.003 & 0.002 & 0.003 & -0.002 & 0.002 & -0.002 & 0.003 \\
\hline Other (e.g. telework) & - & - & - & - & - & - & - & - \\
\hline Desired Occupation & & & & & & & & \\
\hline Farming $^{6}$ & Refer & ence & Refer & ence & Refer & ence & Refe & ence \\
\hline Mining, mineral extraction & - & - & - & - & - & - & - & - \\
\hline Manufacturing & 0.007 & 0.015 & -0.008 & 0.007 & -0.001 & 0.005 & 0.009 & 0.019 \\
\hline Technical professions & -0.002 & 0.012 & -0.007 & 0.004 & -0.002 & 0.004 & - & - \\
\hline
\end{tabular}


TABLE D.6: (CONTINUED)

\begin{tabular}{|c|c|c|c|c|c|c|c|c|}
\hline & \multicolumn{2}{|c|}{$u=9$} & \multicolumn{2}{|c|}{$u=10$} & \multicolumn{2}{|c|}{$u=11$} & \multicolumn{2}{|c|}{$u=12$} \\
\hline & $d F / d x$ & Std. Err. & $d F / d x$ & Std. Err. & $d F / d x$ & Std. Err. & $d F / d x$ & Std. Err. \\
\hline Service Professions & 0.010 & 0.008 & -0.005 & 0.010 & 0.001 & 0.005 & 0.002 & 0.011 \\
\hline Other occupations & 0.007 & 0.023 & -0.004 & 0.009 & - & - & 0.009 & 0.033 \\
\hline Other & - & - & - & - & - & - & - & - \\
\hline$N$ & \multicolumn{2}{|c|}{6,004} & \multicolumn{2}{|c|}{4,400} & \multicolumn{2}{|c|}{3,582} & \multicolumn{2}{|c|}{3,008} \\
\hline Log-Likelihood & \multicolumn{2}{|c|}{-553.76} & \multicolumn{2}{|c|}{-359.51} & \multicolumn{2}{|c|}{-236.60} & \multicolumn{2}{|c|}{-216.55} \\
\hline$R^{2}$ & \multicolumn{2}{|c|}{0.294} & \multicolumn{2}{|c|}{0.235} & \multicolumn{2}{|c|}{0.336} & \multicolumn{2}{|c|}{0.223} \\
\hline
\end{tabular}

Bold letters indicate significance at $1 \%$ level, italic letters refer to the $5 \%$ level.

- Variables not included in estimation due to collinearity to other variables, perfect prediction of participation decision or missing.

1 Attendant for vocational rehabilitation.

2 Similar programme before unemployment, e.g., job creation or structural adjustment scheme.

3 Schooling: CSE = Certificate of Secondary Education.

4 Advanced technical college entrance qualification (Fachhochschulreife)

${ }^{5}$ Ass. $=$ assimilable

${ }^{6}$ Farming comprises plant cultivation, breeding and fishery.

Tab. D.7: Estimation Results of the Probit-Models for the Propensity SCORES FOR TREATMENT STARTING IN QUARTER $u=1$ TO $u=4$ (MEN IN EAST GERMANY)

\begin{tabular}{|c|c|c|c|c|c|c|c|c|}
\hline & \multicolumn{2}{|c|}{$\bar{u}=1$} & \multicolumn{2}{|c|}{$\bar{u} u=2$} & \multicolumn{2}{|c|}{$\bar{u} u=3$} & \multicolumn{2}{|c|}{$u=4$} \\
\hline & $d F / d x$ & Std. Err. & $d F / d x$ & Std. Err. & $d F / d x$ & Std. Err. & $d F / d x$ & Std. Err. \\
\hline \multicolumn{9}{|l|}{ Age } \\
\hline 25 to 29 years & \multicolumn{2}{|c|}{ Reference } & \multicolumn{2}{|c|}{ Reference } & \multicolumn{2}{|c|}{ Reference } & \multicolumn{2}{|c|}{ Reference } \\
\hline 30 to 34 years & 0.002 & 0.001 & -0.001 & 0.002 & 0.003 & 0.004 & 0.015 & 0.007 \\
\hline 35 to 39 years & 0.002 & 0.001 & 0.004 & 0.002 & 0.008 & 0.004 & 0.016 & 0.007 \\
\hline 40 to 44 years & 0.004 & 0.001 & 0.003 & 0.002 & 0.009 & 0.004 & 0.012 & 0.007 \\
\hline 45 to 49 years & 0.004 & 0.001 & 0.005 & 0.002 & 0.011 & 0.004 & 0.017 & 0.007 \\
\hline 50 to 55 years & 0.008 & 0.002 & 0.008 & 0.003 & 0.020 & 0.005 & 0.042 & 0.009 \\
\hline Foreigner & -0.003 & 0.001 & -0.007 & 0.001 & -0.016 & 0.002 & -0.021 & 0.005 \\
\hline Asylum-seeker & -0.002 & 0.001 & -0.008 & 0.001 & -0.009 & 0.004 & -0.019 & 0.006 \\
\hline No. of placement offers & 0.000 & 0.000 & 0.000 & 0.000 & 0.001 & 0.000 & 0.001 & 0.000 \\
\hline No. of children & 0.000 & 0.000 & 0.000 & 0.001 & -0.001 & 0.001 & -0.003 & 0.002 \\
\hline Placement restrictions & 0.001 & 0.001 & -0.002 & 0.002 & -0.001 & 0.003 & 0.005 & 0.006 \\
\hline Vocational rehabilitation $^{1}$ & 0.004 & 0.002 & 0.004 & 0.003 & 0.008 & 0.005 & 0.004 & 0.007 \\
\hline Health restrictions & 0.001 & 0.001 & 0.004 & 0.002 & 0.007 & 0.003 & -0.003 & 0.004 \\
\hline Marriage/ cohabitation & 0.000 & 0.001 & 0.001 & 0.001 & 0.006 & 0.002 & 0.011 & 0.003 \\
\hline Work experience & 0.000 & 0.001 & -0.001 & 0.002 & 0.002 & 0.003 & -0.003 & 0.005 \\
\hline Programme bef. unemp. ${ }^{2}$ & 0.014 & 0.001 & 0.011 & 0.001 & 0.012 & 0.002 & 0.012 & 0.003 \\
\hline Reception of UI & -0.017 & 0.002 & -0.022 & 0.002 & -0.041 & 0.004 & -0.062 & 0.006 \\
\hline \multicolumn{9}{|l|}{ Duration of Last Job } \\
\hline up to 180 days & 0.009 & 0.001 & 0.018 & 0.002 & $\mathbf{0 . 0 3 3}$ & 0.004 & 0.066 & 0.006 \\
\hline between 180 and 365 days & 0.003 & 0.001 & 0.002 & 0.002 & 0.014 & 0.004 & 0.012 & 0.005 \\
\hline between 366 and 730 days & -0.002 & 0.001 & -0.004 & 0.001 & -0.005 & 0.002 & -0.004 & 0.004 \\
\hline more than 730 days & \multicolumn{2}{|c|}{ Reference } & \multicolumn{2}{|c|}{ Reference } & \multicolumn{2}{|c|}{ Reference } & \multicolumn{2}{|c|}{ Reference } \\
\hline \multicolumn{9}{|l|}{ Pension } \\
\hline No pension & \multicolumn{2}{|c|}{ Reference } & \multicolumn{2}{|c|}{ Reference } & \multicolumn{2}{|c|}{ Reference } & \multicolumn{2}{|c|}{ Reference } \\
\hline Vocational disability & -0.003 & 0.003 & 0.017 & 0.016 & -0.001 & 0.015 & 0.025 & 0.033 \\
\hline Permanently unable to work & -0.005 & 0.001 & 0.002 & 0.007 & -0.015 & 0.005 & -0.008 & 0.016 \\
\hline Social plan & - & - & - & - & - & - & - & - \\
\hline \multicolumn{9}{|l|}{ Schooling ${ }^{3}$} \\
\hline No school & \multicolumn{2}{|c|}{ Reference } & \multicolumn{2}{|c|}{ Reference } & \multicolumn{2}{|c|}{ Reference } & Refer & ence \\
\hline CSE & 0.000 & 0.001 & 0.000 & 0.002 & 0.002 & 0.003 & 0.004 & 0.005 \\
\hline O-levels & -0.002 & 0.001 & -0.001 & 0.002 & 0.000 & 0.003 & 0.000 & 0.005 \\
\hline Adv. technical college entrance ${ }^{4}$ & -0.002 & 0.001 & -0.004 & 0.003 & 0.000 & 0.009 & 0.012 & 0.016 \\
\hline A-levels & -0.002 & 0.001 & -0.006 & 0.002 & 0.003 & 0.007 & 0.000 & 0.009 \\
\hline Professional Training & & & & & & & & \\
\hline Without compl. prof. training & Refer & ence & Refer & ence & Refer & ence & Refer & ence \\
\hline Apprenticeship (on-the-job) & 0.000 & 0.001 & -0.001 & 0.001 & 0.003 & 0.002 & 0.005 & 0.004 \\
\hline Apprenticeship (off-the job) & 0.006 & 0.004 & 0.005 & 0.007 & 0.008 & 0.012 & 0.045 & 0.028 \\
\hline Full-time vocational school & 0.002 & 0.004 & -0.003 & 0.005 & -0.008 & 0.007 & 0.003 & 0.020 \\
\hline Technical school & 0.006 & 0.003 & 0.001 & 0.004 & 0.008 & 0.008 & 0.011 & 0.013 \\
\hline Advanced technical college & 0.009 & 0.007 & 0.012 & 0.012 & 0.000 & 0.011 & 0.007 & 0.019 \\
\hline University & 0.005 & 0.004 & 0.001 & 0.006 & -0.004 & 0.007 & 0.003 & 0.015 \\
\hline
\end{tabular}


TABLE D.7: (CONTINUED)

\begin{tabular}{|c|c|c|c|c|c|c|c|c|}
\hline & \multicolumn{2}{|c|}{$u=1$} & \multicolumn{2}{|c|}{$u=2$} & \multicolumn{2}{|c|}{$u=3$} & \multicolumn{2}{|c|}{$u=4$} \\
\hline & $d F / d x$ & Std. Err. & $d F / d x$ & Std. Err. & $d F / d x$ & Std. Err. & $d F / d x$ & Std. Err. \\
\hline Other & \multicolumn{2}{|c|}{ Reference } & \multicolumn{2}{|c|}{ Reference } & \multicolumn{2}{|c|}{ Reference } & \multicolumn{2}{|c|}{ Reference } \\
\hline Unskilled employee & - & - & - & - & - & - & - & - \\
\hline Ass. to technical school ${ }^{5}$ & -0.001 & 0.001 & 0.000 & 0.003 & 0.006 & 0.007 & -0.006 & 0.009 \\
\hline Ass. to adv. technical college & -0.001 & 0.002 & 0.003 & 0.005 & 0.005 & 0.010 & 0.023 & 0.020 \\
\hline Ass. to university & -0.001 & 0.002 & 0.005 & 0.006 & 0.013 & 0.012 & 0.002 & 0.014 \\
\hline \multicolumn{9}{|l|}{ Month of Treatment Start } \\
\hline- & - & - & - & - & - & - & - & \\
\hline July 2000 & \multicolumn{2}{|c|}{ Reference } & \multicolumn{2}{|c|}{ Reference } & \multicolumn{2}{|c|}{ Reference } & \multicolumn{2}{|c|}{ Reference } \\
\hline September 2000 & 0.000 & 0.001 & -0.001 & 0.001 & 0.002 & 0.003 & 0.004 & 0.004 \\
\hline November 2000 & 0.001 & 0.001 & 0.003 & 0.002 & 0.000 & 0.003 & 0.001 & 0.004 \\
\hline January 2001 & -0.003 & 0.001 & -0.003 & 0.001 & -0.011 & 0.002 & -0.023 & 0.003 \\
\hline Cluster Ia & \multicolumn{2}{|c|}{ Reference } & \multicolumn{2}{|c|}{ Reference } & \multicolumn{2}{|c|}{ Reference } & \multicolumn{2}{|c|}{ Reference } \\
\hline Cluster Ib & -0.001 & 0.001 & 0.000 & 0.001 & 0.003 & 0.002 & 0.007 & 0.003 \\
\hline Cluster Ic & -0.003 & 0.001 & -0.002 & 0.001 & 0.006 & 0.003 & -0.001 & 0.005 \\
\hline Cluster II & -0.002 & 0.001 & -0.005 & 0.002 & -0.007 & 0.004 & -0.013 & 0.006 \\
\hline Cluster III & - & - & - & - & - & - & - & - \\
\hline Cluster IV & - & - & - & - & - & - & - & - \\
\hline Cluster V & - & - & - & - & - & - & - & - \\
\hline \multicolumn{9}{|l|}{ Work Time (Last Job) } \\
\hline Full-time work & \multicolumn{2}{|c|}{ Reference } & \multicolumn{2}{|c|}{ Reference } & \multicolumn{2}{|c|}{ Reference } & \multicolumn{2}{|c|}{ Reference } \\
\hline Part-time work & 0.004 & 0.001 & 0.005 & 0.002 & 0.009 & 0.004 & 0.003 & 0.005 \\
\hline Not applicable & 0.002 & 0.001 & 0.005 & 0.001 & 0.005 & 0.002 & 0.002 & 0.003 \\
\hline Technical professions & -0.001 & 0.001 & -0.007 & 0.001 & -0.010 & 0.003 & -0.019 & 0.005 \\
\hline Service Professions & -0.002 & 0.001 & -0.005 & 0.001 & -0.008 & 0.003 & -0.006 & 0.005 \\
\hline Other occupations & -0.003 & 0.001 & -0.007 & 0.001 & -0.016 & 0.002 & -0.017 & 0.006 \\
\hline Other & - & - & - & - & - & - & - & - \\
\hline$N$ & 74, & & 39,3 & & 25,2 & & 17, & \\
\hline Log-Likelihood & $-3,86$ & 8.20 & $-3,00$ & 0.10 & $-3,02$ & 7.12 & $-2,89$ & 9.89 \\
\hline$R^{2}$ & 0.1 & & 0.1 & & 0.1 & & & \\
\hline
\end{tabular}

Bold letters indicate significance at $1 \%$ level, italic letters refer to the $5 \%$ level.

- Variables not included in estimation due to collinearity to other variables, perfect prediction of participation decision or missing.

1 Attendant for vocational rehabilitation.

2 Similar programme before unemployment, e.g., job creation or structural adjustment scheme.

${ }^{3}$ Schooling: CSE = Certificate of Secondary Education.

4 Advanced technical college entrance qualification (Fachhochschulreife)

5 Ass. = assimilable

${ }^{6}$ Farming comprises plant cultivation, breeding and fishery.

Tab. D.8: Estimation Results of the Probit-Models For the Propensity SCORES FOR TREATMENT STARTING IN QUARTER $u=5$ TO $u=8$ (MEN IN EAST GERMANY)

\begin{tabular}{|c|c|c|c|c|c|c|c|c|}
\hline & \multicolumn{2}{|c|}{$u=5$} & \multicolumn{2}{|c|}{$u=6$} & \multicolumn{2}{|c|}{$u=7$} & \multicolumn{2}{|c|}{$u=8$} \\
\hline & $d F / d x$ & Std. Err. & $d F / d x$ & Std. Err. & $d F / d x$ & Std. Err. & $d F / d x$ & Std. Err. \\
\hline \multicolumn{9}{|l|}{ Age } \\
\hline 25 to 29 years & \multicolumn{2}{|c|}{ Reference } & \multicolumn{2}{|c|}{ Reference } & \multicolumn{2}{|c|}{ Reference } & \multicolumn{2}{|c|}{ Reference } \\
\hline 30 to 34 years & 0.008 & 0.011 & -0.005 & 0.011 & -0.025 & 0.013 & 0.027 & 0.024 \\
\hline 35 to 39 years & 0.003 & 0.010 & 0.000 & 0.011 & -0.017 & 0.013 & 0.032 & 0.023 \\
\hline 40 to 44 years & 0.021 & 0.011 & 0.018 & 0.012 & -0.021 & 0.013 & 0.047 & 0.024 \\
\hline 45 to 49 years & 0.022 & 0.011 & 0.010 & 0.011 & -0.008 & 0.014 & 0.045 & 0.024 \\
\hline 50 to 55 years & 0.063 & 0.014 & 0.046 & 0.015 & 0.048 & 0.019 & 0.096 & 0.029 \\
\hline
\end{tabular}


TABLE D.8: (CONTINUED)

\begin{tabular}{|c|c|c|c|c|c|c|c|c|}
\hline & \multicolumn{2}{|c|}{$u=5$} & \multicolumn{2}{|c|}{$u=6$} & \multicolumn{2}{|c|}{$u=7$} & \multicolumn{2}{|c|}{$u=8$} \\
\hline & $d F / d x$ & Std. Err. & $d F / d x$ & Std. Err. & $d F / d x$ & Std. Err. & $d F / d x$ & Std. Err. \\
\hline Foreigner & -0.051 & 0.008 & -0.042 & 0.009 & -0.044 & 0.020 & -0.070 & 0.009 \\
\hline Asylum-seeker & -0.022 & 0.017 & -0.038 & 0.011 & -0.062 & 0.014 & -0.057 & 0.016 \\
\hline No. of placement offers & 0.003 & 0.000 & 0.004 & 0.000 & 0.005 & 0.001 & 0.006 & 0.001 \\
\hline No. of children & -0.003 & 0.003 & -0.009 & 0.003 & 0.000 & 0.004 & -0.009 & 0.005 \\
\hline Placement restrictions & -0.028 & 0.008 & -0.007 & 0.010 & -0.034 & 0.012 & -0.008 & 0.018 \\
\hline Vocational rehabilitation $^{1}$ & 0.072 & 0.020 & 0.037 & 0.018 & 0.097 & 0.030 & 0.126 & 0.036 \\
\hline Health restrictions & 0.012 & 0.009 & 0.007 & 0.009 & 0.013 & 0.013 & -0.022 & 0.013 \\
\hline Marriage/ cohabitation & 0.023 & 0.006 & 0.030 & 0.006 & 0.020 & 0.009 & 0.036 & 0.010 \\
\hline Work experience & 0.005 & 0.009 & 0.010 & 0.008 & 0.007 & 0.012 & 0.026 & 0.012 \\
\hline Programme bef. unemp. ${ }^{2}$ & 0.019 & 0.006 & 0.019 & 0.006 & 0.023 & 0.009 & 0.006 & 0.010 \\
\hline Reception of UI & -0.176 & 0.013 & -0.166 & 0.016 & -0.223 & 0.020 & -0.140 & 0.020 \\
\hline \multicolumn{9}{|l|}{ Duration of Last Job } \\
\hline up to 180 days & 0.142 & 0.011 & 0.120 & 0.012 & 0.138 & 0.014 & 0.219 & 0.019 \\
\hline between 180 and 365 days & -0.010 & 0.007 & -0.027 & 0.007 & -0.062 & 0.008 & -0.014 & 0.013 \\
\hline between 366 and 730 days & -0.006 & 0.007 & -0.006 & 0.008 & -0.006 & 0.011 & 0.001 & 0.015 \\
\hline more than 730 days & \multicolumn{2}{|c|}{ Reference } & \multicolumn{2}{|c|}{ Reference } & \multicolumn{2}{|c|}{ Reference } & \multicolumn{2}{|c|}{ Reference } \\
\hline Pension & & & & & & & & \\
\hline No pension & Refer & ence & Refer & ence & Refer & ence & Refer & ence \\
\hline Vocational disability & -0.003 & 0.053 & 0.075 & 0.091 & -0.050 & 0.043 & -0.041 & 0.051 \\
\hline Permanently unable to work & -0.027 & 0.026 & 0.005 & 0.043 & -0.048 & 0.038 & -0.046 & 0.034 \\
\hline Social plan & - & - & - & - & - & - & - & - \\
\hline Schooling ${ }^{3}$ & & & & & & & & \\
\hline No school & Refer & ence & Refer & ence & Refer & ence & Refer & ence \\
\hline CSE & 0.012 & 0.009 & 0.010 & 0.009 & -0.003 & 0.013 & 0.003 & 0.014 \\
\hline O-levels & 0.011 & 0.009 & 0.004 & 0.009 & -0.008 & 0.013 & 0.002 & 0.015 \\
\hline Adv. technical college entrance ${ }^{4}$ & -0.026 & 0.018 & -0.038 & 0.015 & -0.036 & 0.028 & -0.068 & 0.011 \\
\hline A-levels & -0.004 & 0.017 & -0.029 & 0.013 & -0.057 & 0.015 & -0.016 & 0.028 \\
\hline Professional Training & & & & & & & & \\
\hline Without compl. prof. training & Refer & nce & Refer & ence & Refer & ence & Refer & ence \\
\hline Apprenticeship (on-the-job) & 0.014 & 0.007 & 0.006 & 0.007 & 0.025 & 0.010 & 0.006 & 0.012 \\
\hline Apprenticeship (off-the job) & -0.041 & 0.019 & -0.008 & 0.031 & 0.068 & 0.071 & -0.011 & 0.067 \\
\hline Full-time vocational school & -0.036 & 0.023 & 0.074 & 0.060 & -0.055 & 0.023 & 0.004 & 0.058 \\
\hline Technical school & 0.027 & 0.024 & 0.019 & 0.029 & -0.040 & 0.021 & 0.031 & 0.044 \\
\hline Advanced technical college & 0.042 & 0.046 & 0.161 & 0.127 & 0.005 & 0.058 & 0.212 & 0.132 \\
\hline University & 0.038 & 0.037 & 0.044 & 0.057 & 0.001 & 0.051 & -0.026 & 0.038 \\
\hline Assessment of Individual's Quali & & & & & & & & \\
\hline Other & Refer & ence & Refer & ence & Refer & ence & Refer & ence \\
\hline Unskilled employee & - & - & - & - & - & - & - & - \\
\hline Skilled employee & 0.010 & 0.005 & 0.002 & 0.006 & 0.011 & 0.008 & 0.001 & 0.010 \\
\hline Ass. to technical school ${ }^{5}$ & 0.026 & 0.023 & -0.028 & 0.012 & 0.039 & 0.040 & 0.018 & 0.040 \\
\hline Ass. to adv. technical college & 0.076 & 0.041 & -0.032 & 0.016 & 0.143 & 0.091 & 0.033 & 0.056 \\
\hline Ass. to university & 0.026 & 0.031 & -0.050 & 0.007 & 0.175 & 0.091 & 0.090 & 0.079 \\
\hline Ass. to top-management & - & - & - & - & - & - & - & - \\
\hline Month of Treatment Start & & & & & & & & \\
\hline July 2000 & Refer & ence & Refer & ence & Refer & ence & Refer & ence \\
\hline September 2000 & -0.020 & 0.006 & 0.007 & 0.008 & 0.002 & 0.011 & -0.027 & 0.011 \\
\hline November 2000 & -0.038 & 0.005 & -0.016 & 0.007 & -0.010 & 0.012 & -0.034 & 0.010 \\
\hline January 2001 & -0.065 & 0.004 & -0.056 & 0.004 & -0.057 & 0.009 & -0.064 & 0.008 \\
\hline March 2001 & -0.037 & 0.005 & -0.021 & 0.007 & -0.022 & 0.010 & -0.036 & 0.010 \\
\hline May 2001 & -0.023 & 0.006 & -0.021 & 0.006 & -0.004 & 0.011 & -0.035 & 0.010 \\
\hline Regional Context Variables & & & & & & & & \\
\hline Cluster Ia & Refer & nce & Refer & ence & Refer & ence & Refer & ence \\
\hline Cluster Ib & 0.010 & 0.006 & -0.007 & 0.007 & -0.013 & 0.010 & -0.023 & 0.011 \\
\hline Cluster Ic & -0.005 & 0.008 & -0.013 & 0.008 & -0.030 & 0.010 & -0.042 & 0.010 \\
\hline Cluster II & -0.021 & 0.012 & -0.043 & 0.007 & -0.050 & 0.013 & -0.036 & 0.016 \\
\hline Cluster III & - & - & - & - & - & - & - & - \\
\hline Cluster IV & - & - & - & - & - & - & - & - \\
\hline Cluster V & - & - & - & - & - & - & - & - \\
\hline Work Time (Last Job) & & & & & & & & \\
\hline Full-time work & Refer & nce & Refer & ence & Refer & ence & Refer & ence \\
\hline Part-time work & -0.002 & 0.009 & 0.010 & 0.013 & 0.043 & 0.020 & 0.027 & 0.021 \\
\hline Not applicable & -0.028 & 0.005 & -0.017 & 0.006 & -0.027 & 0.008 & -0.031 & 0.009 \\
\hline Desired Work Time & & & & & & & & \\
\hline Full-time work & Refer & ence & Refer & ence & Refer & ence & Refer & ence \\
\hline part-time work & -0.029 & 0.042 & - & - & - & - & -0.029 & 0.063 \\
\hline Other (e.g. telework) & - & - & - & - & - & - & - & - \\
\hline Desired Occupation & & & & & & & & \\
\hline Farming $^{6}$ & Refer & ence & Refer & ence & Refer & ence & Refer & ence \\
\hline Mining, mineral extraction & -0.023 & 0.031 & -0.025 & 0.049 & -0.052 & 0.028 & - & - \\
\hline
\end{tabular}


TABLE D.8: (CONTINUED)

\begin{tabular}{|c|c|c|c|c|c|c|c|c|}
\hline & \multicolumn{2}{|c|}{$u=5$} & \multicolumn{2}{|c|}{$u=6$} & \multicolumn{2}{|c|}{$u=7$} & \multicolumn{2}{|c|}{$u=8$} \\
\hline & $d F / d x$ & Std. Err. & $d F / d x$ & Std. Err. & $d F / d x$ & Std. Err. & $d F / d x$ & Std. Err. \\
\hline Manufacturing & -0.010 & 0.009 & -0.005 & 0.010 & -0.028 & 0.014 & -0.018 & 0.016 \\
\hline Technical professions & -0.045 & 0.008 & -0.004 & 0.020 & -0.048 & 0.014 & -0.046 & 0.017 \\
\hline Service Professions & -0.026 & 0.009 & -0.020 & 0.009 & -0.048 & 0.012 & -0.046 & 0.014 \\
\hline Other occupations & -0.029 & 0.013 & -0.047 & 0.007 & -0.076 & 0.007 & -0.073 & 0.009 \\
\hline Other & - & - & - & - & - & - & - & - \\
\hline$N$ & \multicolumn{2}{|c|}{11,349} & \multicolumn{2}{|c|}{7,756} & \multicolumn{2}{|c|}{6,002} & \multicolumn{2}{|c|}{4,461} \\
\hline Log-Likelihood & \multicolumn{2}{|c|}{$-2,951.48$} & \multicolumn{2}{|c|}{$-1,852.76$} & \multicolumn{2}{|c|}{$-1,712.36$} & \multicolumn{2}{|c|}{$-1,248.73$} \\
\hline$R^{2}$ & \multicolumn{2}{|c|}{0.241} & \multicolumn{2}{|c|}{0.260} & \multicolumn{2}{|c|}{0.266} & \multicolumn{2}{|c|}{0.295} \\
\hline
\end{tabular}

Bold letters indicate significance at $1 \%$ level, italic letters refer to the $5 \%$ level.

- Variables not included in estimation due to collinearity to other variables, perfect prediction of participation decision or missing.

1 Attendant for vocational rehabilitation.

2 Similar programme before unemployment, e.g., job creation or structural adjustment scheme.

3 Schooling: CSE = Certificate of Secondary Education.

4 Advanced technical college entrance qualification (Fachhochschulreife)

5 Ass. = assimilable

${ }^{6}$ Farming comprises plant cultivation, breeding and fishery.

Tab. D.9: Estimation Results of the Probit-Models for the Propensity SCORES FOR TREATMENT STARTING IN QUARTER $u=9$ TO $u=12$ (MEN IN EAST GERMANY)

\begin{tabular}{|c|c|c|c|c|c|c|c|c|}
\hline & \multicolumn{2}{|c|}{$u=9$} & \multicolumn{2}{|c|}{$u=10$} & \multicolumn{2}{|c|}{$u=11$} & \multicolumn{2}{|c|}{$u=12$} \\
\hline & $d F / d x$ & Std. Err. & $d F / d x$ & Std. Err. & $d F / d x$ & Std. Err. & $d F / d x$ & Std. Err. \\
\hline \multicolumn{9}{|l|}{ Age } \\
\hline 25 to 29 years & \multicolumn{2}{|c|}{ Reference } & \multicolumn{2}{|c|}{ Reference } & \multicolumn{2}{|c|}{ Reference } & \multicolumn{2}{|c|}{ Reference } \\
\hline 30 to 34 years & -0.018 & 0.034 & -0.005 & 0.037 & -0.085 & 0.036 & -0.040 & 0.042 \\
\hline 35 to 39 years & 0.014 & 0.034 & -0.011 & 0.036 & -0.050 & 0.040 & -0.038 & 0.041 \\
\hline 40 to 44 years & 0.033 & 0.035 & -0.003 & 0.036 & -0.080 & 0.038 & -0.018 & 0.043 \\
\hline 45 to 49 years & 0.056 & 0.036 & 0.006 & 0.037 & -0.003 & 0.045 & 0.040 & 0.049 \\
\hline 50 to 55 years & 0.110 & 0.039 & 0.059 & 0.042 & 0.069 & 0.050 & 0.053 & 0.051 \\
\hline Foreigner & -0.049 & 0.046 & -0.123 & 0.029 & 0.029 & 0.087 & 0.043 & 0.100 \\
\hline Asylum-seeker & -0.095 & 0.040 & -0.101 & 0.045 & -0.165 & 0.023 & -0.071 & 0.058 \\
\hline No. of placement offers & 0.013 & 0.001 & 0.018 & 0.001 & 0.019 & 0.002 & 0.020 & 0.002 \\
\hline No. of children & -0.011 & 0.009 & -0.012 & 0.010 & 0.000 & 0.012 & 0.000 & 0.012 \\
\hline Placement restrictions & -0.024 & 0.028 & -0.050 & 0.028 & -0.071 & 0.035 & 0.040 & 0.046 \\
\hline Vocational rehabilitation $^{1}$ & 0.086 & 0.041 & 0.058 & 0.046 & 0.104 & 0.057 & 0.054 & 0.051 \\
\hline Health restrictions & 0.000 & 0.024 & 0.017 & 0.028 & 0.069 & 0.037 & -0.013 & 0.035 \\
\hline Marriage/ cohabitation & 0.047 & 0.017 & 0.026 & 0.019 & 0.042 & 0.023 & 0.010 & 0.024 \\
\hline Work experience & 0.057 & 0.022 & -0.014 & 0.031 & 0.060 & 0.030 & -0.021 & 0.039 \\
\hline Programme bef. unemp. ${ }^{2}$ & -0.007 & 0.016 & 0.014 & 0.018 & 0.018 & 0.023 & -0.015 & 0.022 \\
\hline Reception of UI & -0.268 & 0.026 & -0.231 & 0.031 & -0.238 & 0.036 & -0.241 & 0.040 \\
\hline \multicolumn{9}{|l|}{ Duration of Last Job } \\
\hline up to 180 days & $\mathbf{0 . 3 3 2}$ & 0.023 & 0.258 & 0.025 & 0.271 & 0.031 & 0.271 & 0.033 \\
\hline between 180 and 365 days & -0.017 & 0.023 & -0.060 & 0.024 & -0.097 & 0.026 & -0.064 & 0.028 \\
\hline between 366 and 730 days & 0.034 & 0.027 & 0.032 & 0.028 & -0.004 & 0.032 & 0.057 & 0.040 \\
\hline more than 730 days & \multicolumn{2}{|c|}{ Reference } & \multicolumn{2}{|c|}{ Reference } & \multicolumn{2}{|c|}{ Reference } & \multicolumn{2}{|c|}{ Reference } \\
\hline \multicolumn{9}{|l|}{ Pension } \\
\hline No pension & \multicolumn{2}{|c|}{ Reference } & \multicolumn{2}{|c|}{ Reference } & \multicolumn{2}{|c|}{ Reference } & \multicolumn{2}{|c|}{ Reference } \\
\hline Vocational disability & -0.038 & 0.116 & -0.024 & 0.131 & -0.170 & 0.025 & 0.151 & 0.285 \\
\hline Permanently unable to work & -0.002 & 0.113 & - & - & -0.110 & 0.079 & 0.118 & 0.138 \\
\hline Social plan & - & - & - & - & - & - & - & - \\
\hline \multicolumn{9}{|l|}{ Schooling ${ }^{3}$} \\
\hline No school & \multicolumn{2}{|c|}{ Reference } & \multicolumn{2}{|c|}{ Reference } & \multicolumn{2}{|c|}{ Reference } & Refe & ence \\
\hline CSE & 0.006 & 0.024 & -0.006 & 0.026 & 0.019 & 0.034 & 0.027 & 0.034 \\
\hline O-levels & -0.006 & 0.026 & -0.012 & 0.028 & 0.013 & 0.036 & 0.028 & 0.037 \\
\hline Adv. technical college entrance ${ }^{4}$ & -0.056 & 0.070 & 0.013 & 0.100 & -0.052 & 0.092 & -0.092 & 0.087 \\
\hline A-levels & 0.061 & 0.068 & 0.004 & 0.059 & -0.148 & 0.035 & 0.094 & 0.098 \\
\hline Professional Training & & & & & & & & \\
\hline Without compl. prof. training & Refer & ence & Refer & ence & Refer & ence & Refe & ence \\
\hline Apprenticeship (on-the-job) & 0.045 & 0.019 & 0.037 & 0.022 & -0.027 & 0.030 & 0.004 & 0.028 \\
\hline Apprenticeship (off-the job) & 0.114 & 0.127 & 0.246 & 0.175 & -0.104 & 0.083 & -0.013 & 0.167 \\
\hline Full-time vocational school & -0.063 & 0.086 & -0.085 & 0.070 & -0.103 & 0.080 & -0.004 & 0.099 \\
\hline Technical school & -0.063 & 0.049 & 0.024 & 0.077 & -0.031 & 0.074 & -0.108 & 0.037 \\
\hline Advanced technical college & -0.043 & 0.097 & 0.005 & 0.123 & -0.074 & 0.121 & -0.105 & 0.070 \\
\hline University & -0.117 & 0.036 & -0.083 & 0.054 & 0.032 & 0.138 & -0.041 & 0.095 \\
\hline
\end{tabular}


TABLE D.9: (CONTINUED)

\begin{tabular}{|c|c|c|c|c|c|c|c|c|}
\hline & \multicolumn{2}{|c|}{$\bar{u}=9$} & \multicolumn{2}{|c|}{$u=10$} & \multicolumn{2}{|c|}{$u=11$} & \multicolumn{2}{|c|}{$u=12$} \\
\hline & $d F / d x$ & Std. Err. & $d F / d x$ & Std. Err. & $d F / d x$ & Std. Err. & $d F / d x$ & Std. Err. \\
\hline \multicolumn{9}{|c|}{ Assessment of Individual's Qualification } \\
\hline Other & \multicolumn{2}{|c|}{ Reference } & \multicolumn{2}{|c|}{ Reference } & \multicolumn{2}{|c|}{ Reference } & \multicolumn{2}{|c|}{ Reference } \\
\hline Unskilled employee & - & - & - & - & - & - & - & - \\
\hline Skilled employee & -0.023 & 0.016 & -0.024 & 0.018 & 0.011 & 0.023 & -0.021 & 0.023 \\
\hline Ass. to technical school ${ }^{5}$ & -0.037 & 0.058 & 0.037 & 0.070 & -0.025 & 0.071 & -0.040 & 0.071 \\
\hline Ass. to adv. technical college & -0.028 & 0.081 & 0.270 & 0.159 & 0.255 & 0.153 & 0.080 & 0.153 \\
\hline Ass. to university & 0.031 & 0.088 & 0.098 & 0.119 & -0.091 & 0.081 & -0.138 & 0.021 \\
\hline Ass. to top-management & - & - & - & - & - & - & - & - \\
\hline \multicolumn{9}{|l|}{ Month of Treatment Start } \\
\hline July 2000 & \multicolumn{2}{|c|}{ Reference } & \multicolumn{2}{|c|}{ Reference } & \multicolumn{2}{|c|}{ Reference } & \multicolumn{2}{|c|}{ Reference } \\
\hline September 2000 & -0.043 & 0.020 & 0.018 & 0.025 & -0.008 & 0.030 & -0.028 & 0.028 \\
\hline November 2000 & -0.055 & 0.021 & -0.063 & 0.022 & -0.063 & 0.029 & -0.027 & 0.030 \\
\hline January 2001 & -0.139 & 0.014 & -0.087 & 0.021 & -0.096 & 0.029 & -0.091 & 0.028 \\
\hline March 2001 & -0.061 & 0.019 & -0.047 & 0.022 & 0.014 & 0.034 & -0.006 & 0.034 \\
\hline May 2001 & -0.039 & 0.020 & -0.051 & 0.021 & 0.014 & 0.031 & 0.029 & 0.032 \\
\hline \multicolumn{9}{|l|}{ Regional Context Variables } \\
\hline Cluster Ia & \multicolumn{2}{|c|}{ Reference } & \multicolumn{2}{|c|}{ Reference } & \multicolumn{2}{|c|}{ Reference } & \multicolumn{2}{|c|}{ Reference } \\
\hline Cluster Ib & -0.046 & 0.019 & -0.024 & 0.022 & -0.052 & 0.028 & -0.025 & 0.026 \\
\hline Cluster Ic & -0.081 & 0.019 & -0.049 & 0.024 & -0.046 & 0.033 & -0.054 & 0.029 \\
\hline Cluster II & -0.117 & 0.023 & -0.086 & 0.030 & -0.084 & 0.039 & -0.107 & 0.031 \\
\hline Cluster III & - & - & - & - & - & - & - & - \\
\hline Cluster IV & - & - & - & - & - & - & - & - \\
\hline Cluster V & - & - & - & - & - & - & - & - \\
\hline \multicolumn{9}{|l|}{ Work Time (Last Job) } \\
\hline Full-time work & \multicolumn{2}{|c|}{ Reference } & \multicolumn{2}{|c|}{ Reference } & \multicolumn{2}{|c|}{ Reference } & Refer & ence \\
\hline Part-time work & 0.063 & 0.037 & 0.127 & 0.056 & 0.203 & 0.069 & 0.123 & 0.073 \\
\hline Not applicable & -0.117 & 0.016 & -0.135 & 0.019 & -0.158 & 0.023 & -0.105 & 0.023 \\
\hline Desired Work Time & & & & & & & & \\
\hline Full-time work & Refer & ence & Refer & ence & Refer & ence & Refer & ence \\
\hline part-time work & - & - & - & - & -0.033 & 0.266 & - & - \\
\hline Other (e.g. telework) & - & - & - & - & - & - & - & - \\
\hline Desired Occupation & & & & & & & & \\
\hline Farming $^{6}$ & Refer & ence & Refer & ence & Refer & ence & Refer & ence \\
\hline Mining, mineral extraction & - & - & - & - & -0.162 & 0.031 & - & - \\
\hline Manufacturing & -0.006 & 0.028 & -0.033 & 0.029 & -0.063 & 0.035 & 0.031 & 0.038 \\
\hline Technical professions & 0.097 & 0.076 & -0.096 & 0.031 & -0.049 & 0.061 & 0.089 & 0.109 \\
\hline Service Professions & -0.046 & 0.028 & -0.061 & 0.028 & -0.144 & 0.030 & -0.038 & 0.038 \\
\hline Other occupations & -0.141 & 0.024 & -0.111 & 0.029 & -0.148 & 0.029 & -0.132 & 0.025 \\
\hline Other & - & - & - & - & - & - & - & - \\
\hline$N$ & 3,5 & & 2,5 & & 2,1 & & 1,6 & \\
\hline Log-Likelihood & $-1,22$ & 9.39 & -882 & 28 & -738 & 35 & -55 & 21 \\
\hline$R^{2}$ & 0.3 & & 0.3 & & 0.3 & & 0.3 & \\
\hline
\end{tabular}

Bold letters indicate significance at $1 \%$ level, italic letters refer to the $5 \%$ level.

- Variables not included in estimation due to collinearity to other variables, perfect prediction of participation decision or missing.

1 Attendant for vocational rehabilitation.

${ }^{2}$ Similar programme before unemployment, e.g., job creation or structural adjustment scheme.

3 Schooling: CSE = Certificate of Secondary Education.

${ }^{4}$ Advanced technical college entrance qualification (Fachhochschulreife)

5 Ass. = assimilable

${ }^{6}$ Farming comprises plant cultivation, breeding and fishery.

Tab. D.10: Estimation Results of the Probit-Models for the Propensity SCORES FOR TREATMENT STARTING IN QUARTER $u=1$ TO $u=4$ (WOMEN IN EAST GERMANY)

\begin{tabular}{|c|c|c|c|c|c|c|c|c|}
\hline & \multicolumn{2}{|c|}{$u=1$} & \multicolumn{2}{|c|}{$u=2$} & \multicolumn{2}{|c|}{$u=3$} & \multicolumn{2}{|c|}{$u=4$} \\
\hline & $d F / d x$ & Std. Err. & $d F / d x$ & Std. Err. & $d F / d x$ & Std. Err. & $d F / d x$ & Std. Err. \\
\hline \multicolumn{9}{|l|}{ Age } \\
\hline 25 to 29 years & \multicolumn{2}{|c|}{ Reference } & \multicolumn{2}{|c|}{ Reference } & \multicolumn{2}{|c|}{ Reference } & \multicolumn{2}{|c|}{ Reference } \\
\hline 30 to 34 years & 0.004 & 0.002 & 0.001 & 0.002 & 0.010 & 0.004 & 0.002 & 0.005 \\
\hline 35 to 39 years & 0.005 & 0.002 & 0.002 & 0.002 & 0.006 & 0.004 & 0.007 & 0.005 \\
\hline 40 to 44 years & 0.004 & 0.002 & 0.003 & 0.002 & 0.003 & 0.004 & 0.004 & 0.005 \\
\hline 45 to 49 years & 0.008 & 0.002 & 0.007 & 0.003 & 0.009 & 0.004 & 0.009 & 0.005 \\
\hline 50 to 55 years & 0.013 & 0.003 & 0.012 & 0.003 & 0.015 & 0.005 & 0.025 & 0.007 \\
\hline
\end{tabular}


TABLE D.10: (CONTINUED)

\begin{tabular}{|c|c|c|c|c|c|c|c|c|}
\hline & \multicolumn{2}{|c|}{$\overline{u=1}$} & \multicolumn{2}{|c|}{$\overline{u=2}$} & \multicolumn{2}{|c|}{$u=3$} & \multicolumn{2}{|c|}{$u=4$} \\
\hline & $d F / d x$ & Std. Err. & $d F / d x$ & Std. Err. & $d F / d x$ & Std. Err. & $d F / d x$ & Std. Err. \\
\hline Foreigner & -0.005 & 0.002 & -0.003 & 0.003 & -0.006 & 0.005 & -0.014 & 0.007 \\
\hline Asylum-seeker & -0.006 & 0.001 & -0.008 & 0.001 & -0.013 & 0.002 & -0.018 & 0.004 \\
\hline No. of placement offers & 0.001 & 0.000 & 0.001 & 0.000 & 0.001 & 0.000 & 0.002 & 0.000 \\
\hline No. of children & 0.001 & 0.000 & 0.001 & 0.000 & 0.000 & 0.001 & 0.002 & 0.001 \\
\hline Placement restrictions & 0.002 & 0.002 & 0.000 & 0.002 & -0.003 & 0.003 & 0.007 & 0.006 \\
\hline Vocational rehabilitation $^{1}$ & 0.002 & 0.002 & 0.004 & 0.004 & 0.024 & 0.008 & 0.004 & 0.007 \\
\hline Health restrictions & 0.000 & 0.001 & 0.003 & 0.002 & 0.007 & 0.003 & 0.005 & 0.004 \\
\hline Marriage/ cohabitation & 0.000 & 0.001 & -0.001 & 0.001 & 0.000 & 0.002 & -0.007 & 0.002 \\
\hline Work experience & 0.002 & 0.001 & -0.002 & 0.002 & -0.001 & 0.002 & 0.003 & 0.003 \\
\hline Programme bef. unemp. ${ }^{2}$ & 0.014 & 0.001 & 0.010 & 0.001 & 0.010 & 0.002 & 0.009 & 0.002 \\
\hline Reception of UI & -0.019 & 0.002 & -0.016 & 0.002 & -0.023 & 0.003 & -0.037 & 0.004 \\
\hline \multicolumn{9}{|l|}{ Duration of Last Job } \\
\hline up to 180 days & 0.012 & 0.002 & 0.018 & 0.002 & 0.026 & 0.003 & 0.045 & 0.005 \\
\hline between 180 and 365 days & 0.006 & 0.002 & 0.007 & 0.002 & 0.009 & 0.003 & 0.007 & 0.004 \\
\hline between 366 and 730 days & -0.004 & 0.001 & -0.004 & 0.001 & -0.001 & 0.002 & -0.004 & 0.003 \\
\hline more than 730 days & \multicolumn{2}{|c|}{ Reference } & \multicolumn{2}{|c|}{ Reference } & \multicolumn{2}{|c|}{ Reference } & \multicolumn{2}{|c|}{ Reference } \\
\hline Pension & & & & & & & & \\
\hline No pension & Refer & ence & Refe & ence & Refer & ence & Refer & ence \\
\hline Vocational disability & - & - & 0.039 & 0.037 & -0.001 & 0.020 & 0.038 & 0.066 \\
\hline Permanently unable to work & -0.001 & 0.005 & -0.001 & 0.007 & - & - & -0.004 & 0.016 \\
\hline Social plan & - & - & - & - & - & - & - & - \\
\hline Schooling ${ }^{3}$ & & & & & & & & \\
\hline No school & Refer & ence & Refe & ence & Refer & ence & Refer & ence \\
\hline CSE & -0.002 & 0.001 & 0.000 & 0.002 & 0.004 & 0.004 & 0.009 & 0.006 \\
\hline O-levels & -0.002 & 0.002 & 0.000 & 0.002 & 0.005 & 0.004 & 0.010 & 0.005 \\
\hline Adv. technical college entrance ${ }^{4}$ & 0.003 & 0.004 & 0.006 & 0.007 & -0.002 & 0.007 & -0.006 & 0.009 \\
\hline A-levels & -0.003 & 0.002 & 0.007 & 0.005 & 0.008 & 0.007 & 0.007 & 0.010 \\
\hline Professional Training & & & & & & & & \\
\hline Without compl. prof. training & Refer & ence & Refe & ence & Refer & ence & Refe & $\overline{\text { ence }}$ \\
\hline Apprenticeship (on-the-job) & 0.002 & 0.001 & 0.000 & 0.001 & 0.005 & 0.002 & 0.003 & 0.003 \\
\hline Apprenticeship (off-the job) & 0.001 & 0.004 & 0.004 & 0.006 & 0.012 & 0.012 & 0.024 & 0.018 \\
\hline Full-time vocational school & 0.001 & 0.003 & 0.005 & 0.005 & 0.004 & 0.008 & 0.008 & 0.010 \\
\hline Technical school & 0.008 & 0.003 & 0.007 & 0.004 & 0.024 & 0.007 & 0.010 & 0.007 \\
\hline Advanced technical college & -0.001 & 0.003 & -0.003 & 0.004 & 0.023 & 0.018 & 0.029 & 0.025 \\
\hline University & 0.008 & 0.005 & -0.002 & 0.003 & 0.014 & 0.011 & 0.030 & 0.019 \\
\hline Assessment of Individual's Qualif & & & & & & & & \\
\hline Other & Refer & ence & Refer & ence & Refer & ence & Refer & ence \\
\hline Unskilled employee & - & - & - & - & - & - & - & - \\
\hline Skilled employee & 0.000 & 0.001 & 0.001 & 0.001 & 0.002 & 0.002 & 0.000 & 0.002 \\
\hline Ass. to technical school ${ }^{5}$ & 0.001 & 0.002 & 0.003 & 0.003 & 0.004 & 0.005 & 0.006 & 0.007 \\
\hline Ass. to adv. technical college & 0.003 & 0.003 & 0.002 & 0.004 & 0.016 & 0.009 & -0.003 & 0.008 \\
\hline Ass. to university & 0.000 & 0.002 & 0.005 & 0.005 & 0.009 & 0.008 & -0.008 & 0.007 \\
\hline Ass. to top-management & - & - & - & - & - & - & - & - \\
\hline Month of Treatment Start & & & & & & & & \\
\hline July 2000 & Refer & ence & Refer & ence & Refer & ence & Refer & ence \\
\hline September 2000 & 0.001 & 0.001 & -0.003 & 0.001 & 0.000 & 0.002 & 0.003 & 0.003 \\
\hline November 2000 & 0.000 & 0.001 & 0.001 & 0.002 & 0.000 & 0.002 & 0.012 & 0.004 \\
\hline January 2001 & -0.002 & 0.001 & -0.003 & 0.002 & -0.005 & 0.002 & -0.008 & 0.003 \\
\hline March 2001 & 0.001 & 0.001 & 0.011 & 0.002 & 0.015 & 0.004 & 0.009 & 0.004 \\
\hline May 2001 & -0.002 & 0.001 & 0.006 & 0.002 & 0.004 & 0.003 & 0.017 & 0.004 \\
\hline Regional Context Variables & & & & & & & & \\
\hline Cluster Ia & Refer & ence & Refe & ence & Refer & ence & Refer & ence \\
\hline Cluster Ib & -0.001 & 0.001 & -0.001 & 0.001 & -0.001 & 0.002 & 0.010 & 0.003 \\
\hline Cluster Ic & -0.005 & 0.001 & -0.003 & 0.001 & -0.002 & 0.002 & 0.010 & 0.005 \\
\hline Cluster II & -0.004 & 0.002 & -0.007 & 0.002 & -0.007 & 0.003 & 0.000 & 0.008 \\
\hline Cluster III & - & - & - & - & - & - & - & - \\
\hline Cluster IV & - & - & - & - & - & - & - & - \\
\hline Cluster V & - & - & - & - & - & - & - & - \\
\hline Work Time (Last Job) & & & & & & & & \\
\hline Full-time work & Refer & ence & Refe & ence & Refer & ence & Refer & ence \\
\hline Part-time work & 0.004 & 0.001 & 0.000 & 0.001 & 0.003 & 0.003 & 0.000 & 0.003 \\
\hline Not applicable & 0.003 & 0.001 & 0.004 & 0.001 & 0.009 & 0.002 & 0.010 & 0.002 \\
\hline Desired Work Time & & & & & & & & \\
\hline Full-time work & Refer & ence & Refe & ence & Refer & ence & Refer & ence \\
\hline part-time work & -0.004 & 0.001 & -0.007 & 0.001 & -0.011 & 0.002 & -0.009 & 0.004 \\
\hline Other (e.g. telework) & - & - & - & - & - & - & - & - \\
\hline Desired Occupation & & & & & & & & \\
\hline Farming $^{6}$ & Refer & ence & Refer & ence & Refer & ence & Refer & ence \\
\hline Mining, mineral extraction & - & - & - & - & - & - & 0.061 & 0.081 \\
\hline
\end{tabular}


TABLE D.10: (CONTINUED)

\begin{tabular}{|c|c|c|c|c|c|c|c|c|}
\hline & \multicolumn{2}{|c|}{$u=1$} & \multicolumn{2}{|c|}{$u=2$} & \multicolumn{2}{|c|}{$u=3$} & \multicolumn{2}{|c|}{$u=4$} \\
\hline & $d F / d x$ & Std. Err. & $d F / d x$ & Std. Err. & $d F / d x$ & Std. Err. & $d F / d x$ & Std. Err. \\
\hline Manufacturing & -0.003 & 0.001 & -0.002 & 0.002 & -0.005 & 0.002 & -0.008 & 0.003 \\
\hline Technical professions & -0.002 & 0.001 & -0.003 & 0.002 & -0.003 & 0.003 & -0.006 & 0.005 \\
\hline Service Professions & -0.003 & 0.001 & -0.001 & 0.002 & -0.005 & 0.003 & -0.006 & 0.004 \\
\hline Other occupations & -0.008 & 0.001 & -0.008 & 0.001 & -0.008 & 0.004 & -0.019 & 0.004 \\
\hline Other & - & - & - & - & - & - & - & - \\
\hline$N$ & \multicolumn{2}{|c|}{62,432} & \multicolumn{2}{|c|}{38,133} & \multicolumn{2}{|c|}{28,551} & \multicolumn{2}{|c|}{21,848} \\
\hline Log-Likelihood & \multicolumn{2}{|c|}{$-4,216.63$} & \multicolumn{2}{|c|}{$-2,963.94$} & \multicolumn{2}{|c|}{$-2,967.65$} & \multicolumn{2}{|c|}{$-3,040.32$} \\
\hline$R^{2}$ & \multicolumn{2}{|c|}{0.143} & \multicolumn{2}{|c|}{0.144} & \multicolumn{2}{|c|}{0.125} & \multicolumn{2}{|c|}{0.152} \\
\hline
\end{tabular}

Bold letters indicate significance at $1 \%$ level, italic letters refer to the $5 \%$ level.

- Variables not included in estimation due to collinearity to other variables, perfect prediction of participation decision or missing.

1 Attendant for vocational rehabilitation.

2 Similar programme before unemployment, e.g., job creation or structural adjustment scheme.

3 Schooling: CSE = Certificate of Secondary Education.

4 Advanced technical college entrance qualification (Fachhochschulreife)

5 Ass. = assimilable

${ }^{6}$ Farming comprises plant cultivation, breeding and fishery.

Tab. D.11: Estimation Results of THE Probit-Models For the Propensity SCORES FOR TREATMENT STARTING IN QUARTER $u=5$ TO $u=8$ (WOMEN IN EAST GERMANY)

\begin{tabular}{|c|c|c|c|c|c|c|c|c|}
\hline & \multicolumn{2}{|c|}{$u=5$} & \multicolumn{2}{|c|}{$u=6$} & \multicolumn{2}{|c|}{$u=7$} & \multicolumn{2}{|c|}{$u=8$} \\
\hline & $d F / d x$ & Std. Err. & $d F / d x$ & Std. Err. & $d F / d x$ & Std. Err. & $d F / d x$ & Std. Err. \\
\hline \multicolumn{9}{|l|}{ Age } \\
\hline 25 to 29 years & \multicolumn{2}{|c|}{ Reference } & \multicolumn{2}{|c|}{ Reference } & \multicolumn{2}{|c|}{ Reference } & \multicolumn{2}{|c|}{ Reference } \\
\hline 30 to 34 years & 0.001 & 0.008 & 0.001 & 0.008 & 0.001 & 0.010 & -0.009 & 0.011 \\
\hline 35 to 39 years & 0.006 & 0.008 & 0.004 & 0.008 & -0.003 & 0.009 & -0.006 & 0.011 \\
\hline 40 to 44 years & 0.002 & 0.008 & 0.002 & 0.008 & 0.000 & 0.010 & -0.007 & 0.011 \\
\hline 45 to 49 years & 0.004 & 0.008 & 0.012 & 0.009 & 0.004 & 0.010 & -0.001 & 0.012 \\
\hline 50 to 55 years & 0.034 & 0.010 & 0.024 & 0.011 & 0.025 & 0.013 & 0.021 & 0.015 \\
\hline Foreigner & -0.032 & 0.009 & -0.020 & 0.011 & -0.041 & 0.004 & - & - \\
\hline Asylum-seeker & -0.032 & 0.006 & -0.032 & 0.002 & -0.043 & 0.003 & -0.042 & 0.007 \\
\hline No. of placement offers & 0.004 & 0.000 & 0.004 & 0.000 & 0.005 & 0.000 & 0.006 & 0.001 \\
\hline No. of children & -0.001 & 0.002 & 0.001 & 0.002 & -0.002 & 0.002 & -0.003 & 0.003 \\
\hline Placement restrictions & 0.011 & 0.010 & -0.008 & 0.007 & -0.016 & 0.007 & 0.007 & 0.014 \\
\hline Vocational rehabilitation $^{1}$ & 0.042 & 0.016 & 0.056 & 0.021 & 0.033 & 0.021 & 0.060 & 0.028 \\
\hline Health restrictions & 0.009 & 0.007 & 0.011 & 0.007 & 0.031 & 0.010 & 0.012 & 0.011 \\
\hline Marriage/ cohabitation & 0.001 & 0.004 & 0.006 & 0.004 & 0.000 & 0.005 & 0.002 & 0.006 \\
\hline Work experience & 0.005 & 0.005 & 0.002 & 0.005 & -0.003 & 0.007 & 0.003 & 0.008 \\
\hline Programme bef. unemp. ${ }^{2}$ & 0.029 & 0.004 & 0.028 & 0.004 & 0.029 & 0.005 & 0.035 & 0.006 \\
\hline Reception of UI & -0.107 & 0.008 & -0.127 & 0.011 & -0.134 & 0.012 & -0.109 & 0.013 \\
\hline \multicolumn{9}{|l|}{ Duration of Last Job } \\
\hline up to 180 days & 0.111 & 0.009 & 0.094 & 0.010 & $\mathbf{0 . 1 1 5}$ & 0.011 & 0.138 & 0.013 \\
\hline between 180 and 365 days & -0.018 & 0.004 & -0.024 & 0.004 & -0.035 & 0.005 & -0.039 & 0.006 \\
\hline between 366 and 730 days & -0.012 & 0.005 & 0.003 & 0.006 & 0.001 & 0.007 & 0.001 & 0.009 \\
\hline more than 730 days & \multicolumn{2}{|c|}{ Reference } & \multicolumn{2}{|c|}{ Reference } & \multicolumn{2}{|c|}{ Reference } & \multicolumn{2}{|c|}{ Reference } \\
\hline \multicolumn{9}{|l|}{ Pension } \\
\hline No pension & \multicolumn{2}{|c|}{ Reference } & \multicolumn{2}{|c|}{ Reference } & \multicolumn{2}{|c|}{ Reference } & \multicolumn{2}{|c|}{ Reference } \\
\hline Vocational disability & 0.007 & 0.060 & -0.014 & 0.050 & - & - & - & - \\
\hline Permanently unable to work & -0.027 & 0.019 & -0.012 & 0.019 & 0.027 & 0.062 & -0.002 & 0.042 \\
\hline Social plan & - & - & - & - & - & - & - & - \\
\hline \multicolumn{9}{|l|}{ Schooling ${ }^{3}$} \\
\hline No school & \multicolumn{2}{|c|}{ Reference } & \multicolumn{2}{|c|}{ Reference } & \multicolumn{2}{|c|}{ Reference } & Refer & ence \\
\hline CSE & 0.016 & 0.010 & 0.002 & 0.008 & 0.023 & 0.013 & -0.025 & 0.009 \\
\hline O-levels & 0.021 & 0.008 & 0.007 & 0.007 & 0.034 & 0.010 & -0.011 & 0.012 \\
\hline Adv. technical college entrance ${ }^{4}$ & 0.020 & 0.022 & 0.008 & 0.022 & 0.068 & 0.047 & -0.041 & 0.008 \\
\hline A-levels & 0.051 & 0.022 & 0.021 & 0.018 & 0.070 & 0.035 & -0.023 & 0.012 \\
\hline Professional Training & & & & & & & & \\
\hline Without compl. prof. training & Refer & ence & Refer & ence & Refer & ence & Refer & ence \\
\hline Apprenticeship (on-the-job) & 0.004 & 0.005 & 0.002 & 0.005 & 0.013 & 0.006 & 0.019 & 0.007 \\
\hline Apprenticeship (off-the job) & 0.008 & 0.022 & 0.051 & 0.036 & 0.089 & 0.050 & -0.005 & 0.034 \\
\hline Full-time vocational school & 0.029 & 0.018 & 0.018 & 0.019 & -0.005 & 0.017 & 0.040 & 0.032 \\
\hline Technical school & 0.029 & 0.012 & 0.015 & 0.012 & 0.033 & 0.018 & 0.063 & 0.024 \\
\hline Advanced technical college & 0.000 & 0.021 & 0.014 & 0.030 & 0.012 & 0.035 & 0.218 & 0.112 \\
\hline University & 0.007 & 0.018 & 0.002 & 0.018 & 0.002 & 0.023 & 0.078 & 0.058 \\
\hline
\end{tabular}


TABLE D.11: (CONTINUED)

\begin{tabular}{|c|c|c|c|c|c|c|c|c|}
\hline & \multicolumn{2}{|c|}{$u=5$} & \multicolumn{2}{|c|}{$u=6$} & \multicolumn{2}{|c|}{$\overline{u=7}$} & \multicolumn{2}{|c|}{$u=8$} \\
\hline & $d F / d x$ & Std. Err. & $d F / d x$ & Std. Err. & $d F / d x$ & Std. Err. & $d F / d x$ & Std. Err. \\
\hline \multicolumn{9}{|c|}{ Assessment of Individual's Qualification } \\
\hline Other & \multicolumn{2}{|c|}{ Reference } & \multicolumn{2}{|c|}{ Reference } & \multicolumn{2}{|c|}{ Reference } & \multicolumn{2}{|c|}{ Reference } \\
\hline Unskilled employee & - & - & - & - & - & - & - & - \\
\hline Skilled employee & 0.008 & 0.004 & 0.001 & 0.004 & -0.002 & 0.005 & 0.009 & 0.006 \\
\hline Ass. to technical school ${ }^{5}$ & 0.022 & 0.014 & 0.017 & 0.015 & 0.002 & 0.014 & 0.010 & 0.020 \\
\hline Ass. to adv. technical college & 0.025 & 0.019 & 0.002 & 0.016 & 0.035 & 0.029 & -0.029 & 0.012 \\
\hline Ass. to university & 0.004 & 0.016 & -0.005 & 0.014 & -0.016 & 0.014 & 0.028 & 0.032 \\
\hline Ass. to top-management & - & - & - & - & 0.395 & 0.405 & - & - \\
\hline \multicolumn{9}{|l|}{ Month of Treatment Start } \\
\hline July 2000 & \multicolumn{2}{|c|}{ Reference } & \multicolumn{2}{|c|}{ Reference } & \multicolumn{2}{|c|}{ Reference } & \multicolumn{2}{|c|}{ Reference } \\
\hline September 2000 & -0.012 & 0.004 & 0.003 & 0.005 & -0.008 & 0.006 & -0.005 & 0.007 \\
\hline November 2000 & -0.003 & 0.005 & -0.009 & 0.005 & -0.004 & 0.006 & -0.016 & 0.007 \\
\hline January 2001 & -0.020 & 0.005 & -0.013 & 0.005 & -0.021 & 0.005 & -0.033 & 0.006 \\
\hline March 2001 & 0.013 & 0.006 & 0.012 & 0.006 & 0.000 & 0.007 & 0.006 & 0.008 \\
\hline May 2001 & -0.002 & 0.005 & -0.003 & 0.005 & -0.001 & 0.006 & -0.021 & 0.006 \\
\hline \multicolumn{9}{|l|}{ Regional Context Variables } \\
\hline Cluster Ia & \multicolumn{2}{|c|}{ Reference } & \multicolumn{2}{|c|}{ Reference } & \multicolumn{2}{|c|}{ Reference } & \multicolumn{2}{|c|}{ Reference } \\
\hline Cluster Ib & 0.006 & 0.004 & -0.011 & 0.005 & -0.023 & 0.006 & -0.014 & 0.007 \\
\hline Cluster Ic & -0.007 & 0.005 & -0.017 & 0.004 & -0.028 & 0.004 & -0.023 & 0.006 \\
\hline Cluster II & -0.011 & 0.010 & -0.015 & 0.008 & -0.031 & 0.006 & -0.040 & 0.007 \\
\hline Cluster III & - & - & - & - & - & - & - & - \\
\hline Cluster IV & - & - & - & - & - & - & - & - \\
\hline Cluster V & - & - & - & - & - & - & - & - \\
\hline \multicolumn{9}{|l|}{ Work Time (Last Job) } \\
\hline Full-time work & \multicolumn{2}{|c|}{ Reference } & \multicolumn{2}{|c|}{ Reference } & \multicolumn{2}{|c|}{ Reference } & Refer & ence \\
\hline Part-time work & 0.001 & 0.005 & 0.007 & 0.006 & 0.019 & 0.008 & 0.007 & 0.009 \\
\hline Not applicable & -0.009 & 0.004 & 0.002 & 0.004 & -0.005 & 0.005 & -0.007 & 0.006 \\
\hline Desired Work Time & & & & & & & & \\
\hline Full-time work & Refer & ence & Refer & ence & Refer & ence & Refer & ence \\
\hline part-time work & -0.023 & 0.006 & -0.025 & 0.004 & -0.028 & 0.006 & -0.028 & 0.008 \\
\hline Other (e.g. telework) & - & - & - & - & - & - & - & - \\
\hline Desired Occupation & & & & & & & & \\
\hline Farming $^{6}$ & Refer & ence & Refer & ence & Refer & ence & Refer & ence \\
\hline Mining, mineral extraction & - & - & 0.019 & 0.064 & - & - & - & - \\
\hline Manufacturing & -0.008 & 0.006 & -0.017 & 0.005 & -0.019 & 0.006 & -0.026 & 0.008 \\
\hline Technical professions & -0.006 & 0.009 & -0.022 & 0.005 & -0.006 & 0.011 & -0.019 & 0.011 \\
\hline Service Professions & -0.001 & 0.006 & -0.021 & 0.007 & -0.021 & 0.008 & -0.025 & 0.010 \\
\hline Other occupations & -0.043 & 0.004 & -0.030 & 0.004 & -0.039 & 0.005 & -0.041 & 0.008 \\
\hline Other & - & - & - & - & - & - & - & - \\
\hline$N$ & 15,8 & & 11,2 & & 9,4 & & 7,4 & \\
\hline Log-Likelihood & $-3,32$ & 3.24 & $-2,00$ & 0.17 & $-1,95$ & 6.27 & $-1,66$ & 0.66 \\
\hline$R^{2}$ & 0.2 & & 0.2 & & 0.2 & & & \\
\hline
\end{tabular}

Bold letters indicate significance at $1 \%$ level, italic letters refer to the $5 \%$ level.

- Variables not included in estimation due to collinearity to other variables, perfect prediction of participation decision or missing.

1 Attendant for vocational rehabilitation.

${ }^{2}$ Similar programme before unemployment, e.g., job creation or structural adjustment scheme.

3 Schooling: CSE = Certificate of Secondary Education.

${ }^{4}$ Advanced technical college entrance qualification (Fachhochschulreife)

5 Ass. = assimilable

${ }^{6}$ Farming comprises plant cultivation, breeding and fishery.

Tab. D.12: Estimation Results of the Probit-Models for the Propensity SCORES FOR TREATMENT StARTING IN QUARTER $u=9$ TO $u=12$ (WOMEN IN EAST GERMANY)

\begin{tabular}{|c|c|c|c|c|c|c|c|c|}
\hline & \multicolumn{2}{|c|}{$u=9$} & \multicolumn{2}{|c|}{$u=10$} & \multicolumn{2}{|c|}{$u=11$} & \multicolumn{2}{|c|}{$u=12$} \\
\hline & $d F / d x$ & Std. Err. & $d F / d x$ & Std. Err. & $d F / d x$ & Std. Err. & $d F / d x$ & Std. Err. \\
\hline \multicolumn{9}{|l|}{ Age } \\
\hline 25 to 29 years & \multicolumn{2}{|c|}{ Reference } & \multicolumn{2}{|c|}{ Reference } & \multicolumn{2}{|c|}{ Reference } & \multicolumn{2}{|c|}{ Reference } \\
\hline 30 to 34 years & -0.010 & 0.022 & -0.010 & 0.025 & -0.028 & 0.025 & -0.009 & 0.031 \\
\hline 35 to 39 years & -0.019 & 0.021 & -0.001 & 0.025 & -0.012 & 0.026 & 0.001 & 0.032 \\
\hline 40 to 44 years & -0.014 & 0.021 & -0.026 & 0.022 & -0.022 & 0.025 & -0.018 & 0.029 \\
\hline 45 to 49 years & -0.003 & 0.022 & 0.015 & 0.026 & 0.008 & 0.028 & 0.014 & 0.034 \\
\hline 50 to 55 years & 0.039 & 0.026 & 0.047 & 0.030 & 0.025 & 0.030 & 0.041 & 0.037 \\
\hline
\end{tabular}


TABLE D.12: (CONTINUED)

\begin{tabular}{|c|c|c|c|c|c|c|c|c|}
\hline & \multicolumn{2}{|c|}{$u=9$} & \multicolumn{2}{|c|}{$u=10$} & \multicolumn{2}{|c|}{$u=11$} & \multicolumn{2}{|c|}{$u=12$} \\
\hline & $d F / d x$ & Std. Err. & $d F / d x$ & Std. Err. & $d F / d x$ & Std. Err. & $d F / d x$ & Std. Err. \\
\hline Foreigner & -0.024 & 0.048 & -0.022 & 0.043 & 0.046 & 0.110 & -0.013 & 0.074 \\
\hline Asylum-seeker & -0.079 & 0.016 & -0.040 & 0.030 & -0.079 & 0.031 & -0.053 & 0.032 \\
\hline No. of placement offers & 0.015 & 0.001 & 0.016 & 0.001 & 0.024 & 0.001 & 0.023 & 0.002 \\
\hline No. of children & 0.007 & 0.005 & 0.005 & 0.005 & 0.003 & 0.006 & 0.010 & 0.006 \\
\hline Placement restrictions & -0.030 & 0.018 & -0.023 & 0.023 & 0.004 & 0.031 & -0.025 & 0.024 \\
\hline Vocational rehabilitation $^{1}$ & 0.098 & 0.043 & 0.065 & 0.045 & 0.127 & 0.060 & 0.022 & 0.041 \\
\hline Health restrictions & 0.046 & 0.020 & 0.027 & 0.022 & 0.006 & 0.023 & 0.020 & 0.022 \\
\hline Marriage/ cohabitation & 0.017 & 0.010 & -0.022 & 0.012 & -0.014 & 0.013 & -0.009 & 0.014 \\
\hline Work experience & 0.006 & 0.014 & 0.001 & 0.017 & 0.024 & 0.017 & 0.004 & 0.018 \\
\hline Programme bef. unemp. ${ }^{2}$ & 0.088 & 0.011 & 0.065 & 0.013 & 0.051 & 0.014 & $\mathbf{0 . 0 3 7}$ & 0.014 \\
\hline Reception of UI & -0.182 & 0.017 & -0.180 & 0.019 & -0.152 & 0.020 & -0.125 & 0.021 \\
\hline \multicolumn{9}{|l|}{ Duration of Last Job } \\
\hline up to 180 days & $\mathbf{0 . 2 3 3}$ & 0.017 & 0.192 & 0.019 & 0.151 & 0.020 & 0.192 & 0.023 \\
\hline between 180 and 365 days & -0.081 & 0.009 & -0.071 & 0.011 & -0.102 & 0.010 & -0.085 & 0.011 \\
\hline between 366 and 730 days & -0.030 & 0.013 & 0.004 & 0.018 & -0.015 & 0.018 & 0.025 & 0.022 \\
\hline more than 730 days & \multicolumn{2}{|c|}{ Reference } & \multicolumn{2}{|c|}{ Reference } & \multicolumn{2}{|c|}{ Reference } & \multicolumn{2}{|c|}{ Reference } \\
\hline Pension & & & & & & & & \\
\hline No pension & Refer & ence & Refer & ence & Refer & ence & Refer & ence \\
\hline Vocational disability & - & - & -0.016 & 0.133 & - & - & - & - \\
\hline Permanently unable to work & - & - & - & - & -0.016 & 0.096 & 0.013 & 0.123 \\
\hline Social plan & - & - & - & - & - & - & - & - \\
\hline Schooling ${ }^{3}$ & & & & & & & & \\
\hline No school & Refer & ence & Refer & ence & Refer & ence & Refer & ence \\
\hline CSE & 0.044 & 0.024 & -0.003 & 0.022 & -0.023 & 0.023 & -0.009 & 0.022 \\
\hline O-levels & 0.036 & 0.021 & 0.015 & 0.023 & -0.022 & 0.025 & -0.006 & 0.023 \\
\hline Adv. technical college entrance ${ }^{4}$ & 0.132 & 0.082 & -0.045 & 0.042 & 0.083 & 0.090 & 0.012 & 0.072 \\
\hline A-levels & 0.111 & 0.055 & -0.012 & 0.035 & -0.060 & 0.028 & -0.001 & 0.047 \\
\hline Professional Training & & & & & & & & \\
\hline Without compl. prof. training & Refer & ence & Refer & ence & Refer & ence & Refer & ence \\
\hline Apprenticeship (on-the-job) & 0.038 & 0.012 & 0.014 & 0.015 & 0.043 & 0.015 & 0.013 & 0.016 \\
\hline Apprenticeship (off-the job) & 0.279 & 0.137 & 0.294 & 0.124 & - & - & 0.104 & 0.133 \\
\hline Full-time vocational school & 0.068 & 0.052 & -0.037 & 0.031 & -0.066 & 0.026 & -0.059 & 0.023 \\
\hline Technical school & 0.081 & 0.035 & 0.016 & 0.032 & -0.015 & 0.030 & -0.033 & 0.026 \\
\hline Advanced technical college & 0.101 & 0.110 & -0.027 & 0.067 & -0.082 & 0.024 & -0.083 & 0.016 \\
\hline University & -0.021 & 0.044 & -0.045 & 0.036 & -0.037 & 0.048 & -0.056 & 0.034 \\
\hline Assessment of Individual's Qualifi & & & & & & & & \\
\hline Other & Refer & ence & Refer & ence & Refer & ence & Refer & ence \\
\hline Unskilled employee & - & - & - & - & - & - & - & - \\
\hline Skilled employee & 0.001 & 0.010 & 0.008 & 0.011 & -0.026 & 0.013 & -0.021 & 0.013 \\
\hline Ass. to technical school ${ }^{5}$ & -0.006 & 0.029 & 0.035 & 0.045 & 0.039 & 0.050 & 0.092 & 0.068 \\
\hline Ass. to adv. technical college & -0.028 & 0.034 & 0.109 & 0.100 & 0.234 & 0.116 & 0.128 & 0.112 \\
\hline Ass. to university & -0.002 & 0.051 & 0.089 & 0.073 & 0.135 & 0.089 & 0.120 & 0.103 \\
\hline Ass. to top-management & - & - & - & - & - & - & - & - \\
\hline Month of Treatment Start & & & & & & & & \\
\hline July 2000 & Refer & ence & Refer & ence & Refer & ence & Refer & ence \\
\hline September 2000 & -0.037 & 0.011 & -0.007 & 0.015 & 0.051 & 0.020 & 0.012 & 0.018 \\
\hline November 2000 & -0.045 & 0.011 & -0.021 & 0.015 & 0.066 & 0.025 & 0.020 & 0.021 \\
\hline January 2001 & -0.083 & 0.009 & -0.075 & 0.011 & -0.026 & 0.020 & -0.020 & 0.021 \\
\hline March 2001 & -0.042 & 0.011 & -0.014 & 0.015 & 0.043 & 0.022 & 0.026 & 0.022 \\
\hline May 2001 & -0.040 & 0.011 & -0.048 & 0.012 & 0.013 & 0.019 & 0.036 & 0.021 \\
\hline Regional Context Variables & & & & & & & & \\
\hline Cluster Ia & Refer & ence & Refer & ence & Refer & ence & Refer & ence \\
\hline Cluster Ib & -0.060 & 0.012 & -0.060 & 0.014 & -0.048 & 0.015 & -0.065 & 0.016 \\
\hline Cluster Ic & -0.070 & 0.009 & -0.062 & 0.011 & -0.083 & 0.011 & -0.060 & 0.012 \\
\hline Cluster II & -0.039 & 0.021 & -0.072 & 0.018 & -0.058 & 0.022 & -0.079 & 0.014 \\
\hline Cluster III & - & - & - & - & - & - & - & - \\
\hline Cluster IV & - & - & - & - & - & - & - & - \\
\hline Cluster V & - & - & - & - & - & - & - & - \\
\hline Work Time (Last Job) & & & & & & & & \\
\hline Full-time work & Refer & ence & Refer & ence & Refer & ence & Refer & ence \\
\hline Part-time work & 0.035 & 0.016 & 0.062 & 0.023 & 0.078 & 0.027 & 0.083 & 0.029 \\
\hline Not applicable & -0.094 & 0.011 & -0.098 & 0.014 & -0.111 & 0.015 & -0.057 & 0.015 \\
\hline Desired Work Time & & & & & & & & \\
\hline Full-time work & Refer & ence & Refer & ence & Refer & ence & Refer & ence \\
\hline part-time work & -0.072 & 0.012 & -0.058 & 0.017 & -0.073 & 0.015 & -0.055 & 0.017 \\
\hline Other (e.g. telework) & - & - & - & - & - & - & - & - \\
\hline Desired Occupation & & & & & & & & \\
\hline Farming $^{6}$ & Refer & ence & Refer & nce & Refer & ence & Refer & nce \\
\hline Mining, mineral extraction & 0.024 & 0.241 & - & - & - & - & - & - \\
\hline
\end{tabular}


TABLE D.12: (CONTINUED)

\begin{tabular}{|c|c|c|c|c|c|c|c|c|}
\hline & \multicolumn{2}{|c|}{$u=9$} & \multicolumn{2}{|c|}{$u=10$} & \multicolumn{2}{|c|}{$u=11$} & \multicolumn{2}{|c|}{$u=12$} \\
\hline & $d F / d x$ & Std. Err. & $d F / d x$ & Std. Err. & $d F / d x$ & Std. Err. & $d F / d x$ & Std. Err. \\
\hline Manufacturing & -0.025 & 0.015 & -0.046 & 0.016 & -0.056 & 0.017 & -0.029 & 0.019 \\
\hline Technical professions & -0.027 & 0.022 & -0.023 & 0.029 & -0.033 & 0.028 & -0.025 & 0.030 \\
\hline Service Professions & -0.044 & 0.017 & -0.048 & 0.020 & -0.061 & 0.021 & -0.058 & 0.023 \\
\hline Other occupations & -0.090 & 0.012 & -0.065 & 0.035 & -0.083 & 0.023 & -0.080 & 0.021 \\
\hline Other & - & - & - & - & - & - & - & - \\
\hline$N$ & \multicolumn{2}{|c|}{6,247} & \multicolumn{2}{|c|}{4,533} & \multicolumn{2}{|c|}{3,917} & \multicolumn{2}{|c|}{3,294} \\
\hline Log-Likelihood & \multicolumn{2}{|c|}{$-1,748.25$} & \multicolumn{2}{|c|}{$-1,310.90$} & \multicolumn{2}{|c|}{$-1,139.47$} & \multicolumn{2}{|c|}{-913.97} \\
\hline$R^{2}$ & \multicolumn{2}{|c|}{0.411} & \multicolumn{2}{|c|}{0.372} & \multicolumn{2}{|c|}{0.391} & \multicolumn{2}{|c|}{0.381} \\
\hline
\end{tabular}

Bold letters indicate significance at $1 \%$ level, italic letters refer to the $5 \%$ level.

- Variables not included in estimation due to collinearity to other variables, perfect prediction of participation decision or missing.

1 Attendant for vocational rehabilitation.

2 Similar programme before unemployment, e.g., job creation or structural adjustment scheme.

${ }^{3}$ Schooling: CSE $=$ Certificate of Secondary Education.

4 Advanced technical college entrance qualification (Fachhochschulreife)

5 Ass. = assimilable

${ }^{6}$ Farming comprises plant cultivation, breeding and fishery. 